
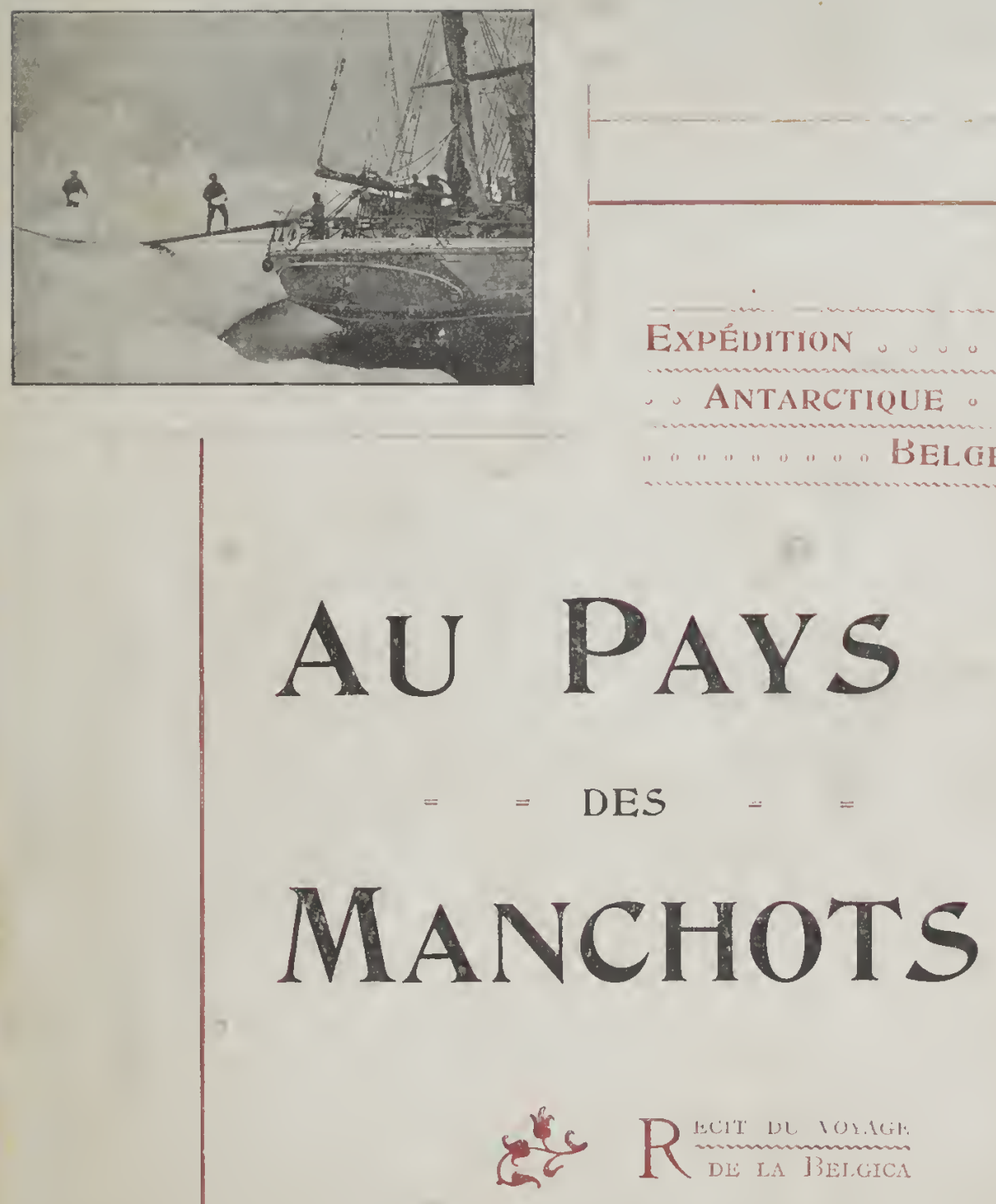

ExpÉdITION

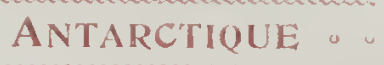

BELGE

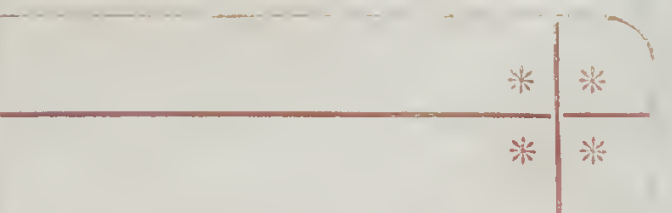





Au Pays

des

Manchots 




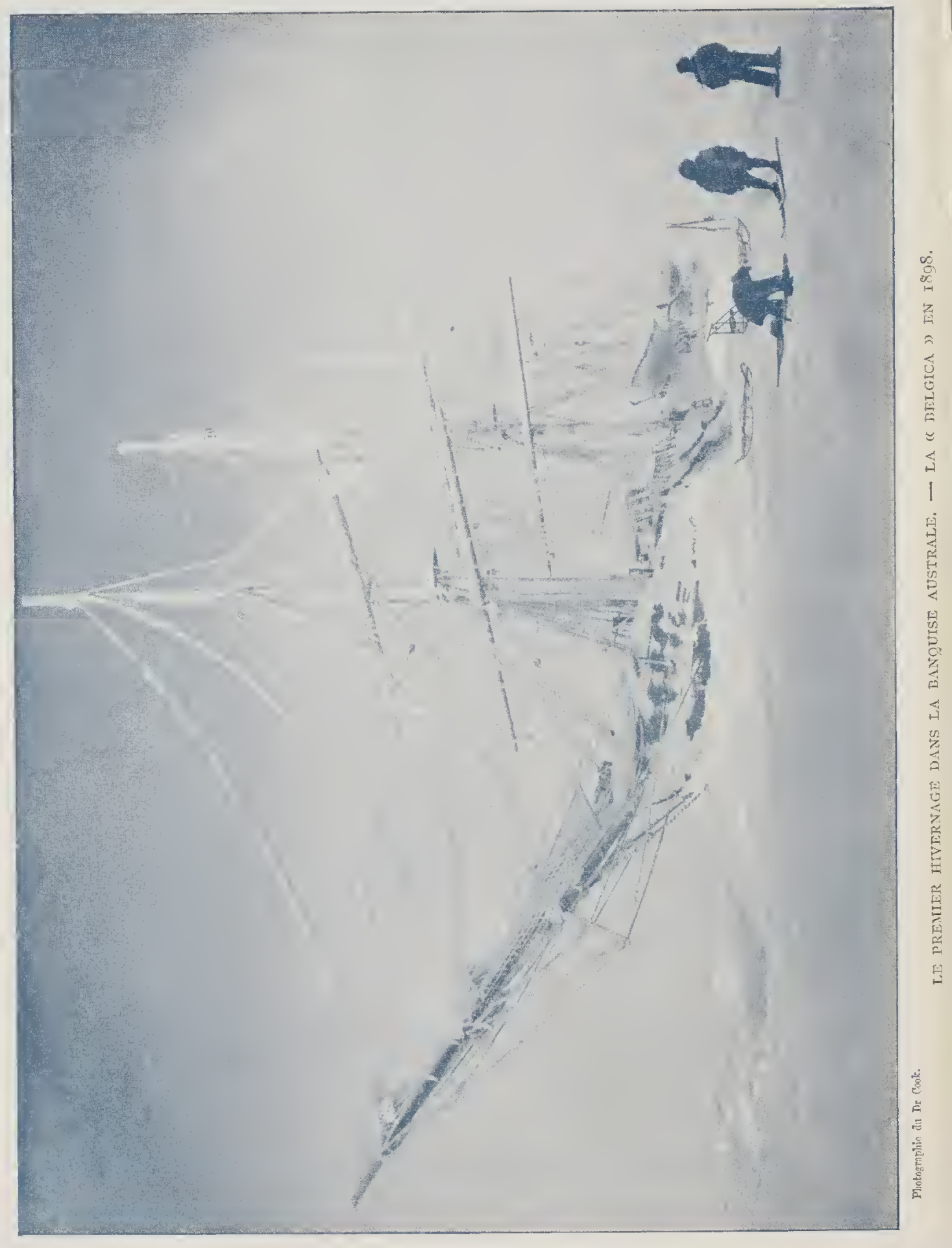


BEI_GE

\title{
Au Pays
}

des

\section{Manchots}

RÉCIT

\author{
DU \\ VOYAGE DE LA "BELGICA ,, \\ $P A R$
}

\section{GeORgES LECOINTE}

Directeur scientiflque a l'Obserratoire Royal he Belgique Commandant en second de l'Expédition

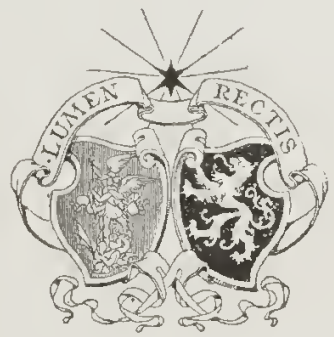

BRUXEILES

SOCIÉTÉ BELGE DE LIBRATRIE

Oscar Schepens \& Cie, Éditeurs

I6, The Treurenlyerg, 16 





\title{
INTRODUCTION HISTORIQUE
}

\author{
TRÈS SUCCINCTE
}

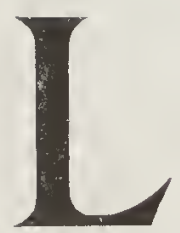

A zone antarctique est la portion de la calotte sphérique limitée par le cercle polaire austral, mais la région appelée Antarctique est plus vaste et moins bien définie. Quelques géographes la circonscrivent à la limite des glaces flottantes; d'autres la déterminent plus vaste encore et lui font même englober une partie importante de la Patagonie.

La région antarctique, au delà du cercle polaire austral, nous est bien plus inconnue que la partie correspondante de la terre dans l'hémisphère Nord. Et il est tout naturel qu'il en soit ainsi.

En effet, la banquise australe s'avançant vers l'Équateur bien plus que la banquise boréale, les glaces éternelles y sont plus étendues et, par suite, leur étude est plus longue que dans le Nord. En outre, peu d'expéditions ont été organisées vers le Sud, tandis que les explorateurs ont concentré leurs efforts vers le pôle boréal. Ce pôle devait tenter davantage les voyageurs, pour de multiples raisons. 
D'abord, parce que l'hémisphère boréal présente, par une latitude déjà élevée, d'excellents ports de refuge pouvant servir de base d'opération; ensuite, parce que dans le Nord des voyageurs en détresse peuvent ètre secourus par les Esquimaux ou recueillis par des pêcheurs qui fréquentent régulièrement ces régions; puis, parce que la. faune (l'ours blanc, le renne, le morse, etc.) fournit un gibier assez abondant, parce que la banquise touche à des terres qu'on peut espérer rejoindre en cas de sinistre, enfin parce que le climat du Nord est moins malsain que celui de l'Antarctique.

Sur la banquise australe, au contraire, des marins désemparés n'ont guère de ressources : pas de navire croisant dans ces parages, aucun habitant dans ces terres inhospitalières où le gibier est rare et d'un goùt douteux.

Notons, enfin, que l'Amérique du Sud et l'Australie sont les seuls pays dans lesquels peut s'établir la base d'opération des expéditions antarctiques. Encore, ils exigent, avant d'être atteints, une longue traversée peu facile pour les navires qui seraient aménagés spécialement en vue de la navigation dans les glaces.

Les premières découvertes au Sud du Cap Horn furent dues à des marchands européens cherchant dans ces parages une voie de navigation. Les tempètes, qui sévissent au Sud de l'Amérique, furent leurs meilleurs alliés; même, elles les conduisirent successivement, bien malgré eux parfois, aux découvertes géographiques de l'Ile des États, de la Géorgie du Sud, etc. 
Pendant ses voyages de I772 à I775, l'explorateur anglais Cook dressa d'importants levers de la Géorgie du Sud et des Iles Sandwich. Il traversa le premier le cercle polaire austral, en janvier 1773 .

Quarante-quatre années s'écoulèrent ensuite sans que la région de l'Antarctique fût visitée.

En I8Ig, Smith découvrit les Shetland du Sud; et Bransfield, en I820, cingla, pour la première fois, clans le Détroit qui porte son nom.

Cette même année, Palmer, commandant d'un petit navire destiné à la pêche aux phoques à fourrure, reconnut la terre aux environs du parallèle 63030' et s'approcha de la Terre de la Trinité.

I’endant les années I8Ig-I82I, une expédition russe, commandée par Bellingshausen, découvrit l'Ile Pierre Ier et la Terre Alexandre I .

De I820 à I 824, la chasse aux phoques attira de nouveau, vers le Sud, un grand nombre de petits bâtiments, dont deux commandants se distinguèrent particulièrement: Pauwell, qui découvrit les Orcades du Sud, et Weddell, qui atteignit 74. I5' environ de latitude. Arrivé à ce point austral, il rehroussa chemin, parce que la saison était trop avancée et qu'il ne voulait pas courir les risques d'un hivernage pour lequel il n'était nullement préparé. Pauwell et Weddell ont laissé, tous deux, des documents précicux, prouvant qu'ils n'étaient pas seulement de bons marins, mais encore de sérieux observateurs.

En I829, s'organisa l'expédition de Foster. Ce jeune savant effectua des mesures pendulaires importantes. 
Malheureusement, il mourut accidentellement en cours de route.

En I83I-r832, Biscoë entra en campagne; il reconnut la Terre Enderby, l'Ile Adélaïde, la Terre de Graham et les Tles Biscoë. Il débarqua ensuite dans une vaste baie correspondant sensiblement à celle que l'expédition antarctique belge dénomma plus tard Baie de Biscoë (au Sud de l'ile Anvers).

En I833-I834, Kemp poussa une pointe vers le Sud et découvrit la Terre qui porte son nom.

En r838. Dumont d'Urville rapporta des documents scientifiques importants. Il visita le groupe Ouest des Shetland et les Orcades du Sud; puis, le z2 janvier I838, il continua à faire route vers le Sud, mais ne dépassa pas cependant le $64^{\mathrm{e}}$ parallèle. Il reconnut la Terre de Joinville et la Terre Louis-Philippe. En I 840 , il découvrit encore la Terre de Clarie et la Terre d'Adélie, comprises l'une et l'autre entre l'ile Balleny et la 'Terre Sabrina, que Balleny avait reconnues l'année précédente ( I83g).

Entre I 838 et I 842 , une expédition américaine(Wilkes, Hudson, Ringgold et Knox) fait de très sérieuses découvertes et, de I840 à I 843 , l'expédition de l'Errebus et du Terror (Ross et Croziei), osant, la première, s'aventurer au loin dans la banquise, découvrit la mer de Ross et

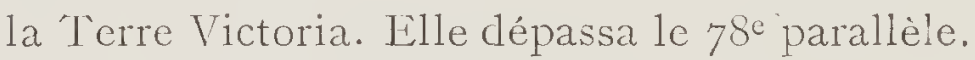

En I873, Dallmann, tout en chassant le phoque, recueillit de nombreuses notes de voyage. Il signala notamment la présence du Détroit de Bismarck, de la 
baie de Dallmann et du chenal de Dallmann (au sud de la Terre de la Trinité).

En I874, la remarquable expédition du Challonger poussa une pointe jusqu'au cercle polaire. Elle rapporta des documents scientifiques très nombreux et très importants (1873-I876).

En I882, les Mllemands établirent une station dans la Géorgie du Sud.

Enfin, en ISg2-I8g3, les voyages de l'Active et de la Balacna rapportèrent quelques renseignements utiles.

En I892-I894, Larsen visite la région antarctique voisine du cap Horn et fournit des données géographiques intéressantes. Toutefois, Larsen produit des affirmations inexactes en plusieurs circonstances, de sorte que beaucoup de ses renseignements sont acceptés avec réserve.

C'est à peine s'il y a lieu. enfin, de parler de l'expédition de l'Antarctic (I894-r895), à laquelle prend part Borchgrevink.

A partir de r897, une ère nouvelle s'inaugure pour les explorations antarctiques.

En I 897-I 899 a Iieu l'expédition antarctique belge, sous le commandement d'Adrien de Gerlache. Les pages qui suivent sont le récit de voyage de cette expédition scientifique.

En I898-I899, l'expédition allemande de la Valdivia rapporte d'importants résultats scientifiques.

En I8́g9-Igoo, le Norvégien Borchgrevink (déjà men- 
tionné ci-contre) débarque à la Terre Victoria et cherche à faire des records.

En Igor, trois expéditions scientifiques fort bien organisées font route vers le Sud : l'expédition antarctique allemande, sous les ordres de von Drygalski; l'expédition antarctique suédoise commandée par Nordenskjold; enfin l'cxpédition antarctique anglaise sous les ordres de Scott.

La première de ces expéditions (Drygalski) a établi sa base d'opération aux îles Kerguelen, où elle a laissć une importante station scientifique; puis elle a fait route vers le Sud-Est et a bientôt été emprisonnée dans les glaces, à proximité d'une terre nouvelle appelée Kaiscr Wilhelm II Kiiste. Cette expédition n'a pas atteint une forte latitude - elle n'a pas dépassé le cercle polaire - mais ce fait n'a aucune importance; elle a fait mieux qu'un record : elle a rapporté des résultats scientifiques qui lui donnent droit aux plus vives félicitations du monde savant.

L'expédition de Nordenskjold avait pour but de ses recherches la partie Est de la Terre de Graham. Elle eut d'importants résultats scientifiques, recueillis dans le détroit de Bransfield, la Terre Louis-Philippe et l'ile Seymour. Le navire "de Nordenskjold a été écrasé par les glaces et les membres de l'expédition ont été recueillis par la canonnière Unuguay, que le Gouvernement argentin avait envoyé à leur recherche.

Quant à l'expédition antarctique anglaise, elle séjourne encore dans la mer de Ross, où le navire ne parvient pas à être dégagé. Avec une ténacité remarquable, les membres 
de cette expédition n'ont pas cessé de travailler et il est dès à présent certain qu'ils rapporteront une ample moisson de découvertes.

Pour le moment, une expédition écossaise, dirigée par Bruce, travaille dans le Nord de la Terre de Graham et deux nouvelles expéditions font route vers l'Antarctique. J'une de ces expéditions est placée sous les ordres du Suédois Gylden et l'autre est commandée par le docteur Charcot.

Nous souhaitons à ces hommes vaillants de réussir pleinement et nous ne doutons pas un instant que ces savants ne rendent les plus grands services à la science. 



\section{AU \\ Pays des Manchots \\ $\cdot \equiv:$ \\ CHAPITRE PREMIER.

\author{
Organisation générale
} \\ de l'Expédition Antarctique Belge.}

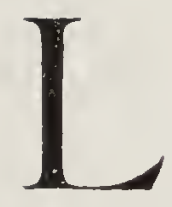

'Expénitrox antarctique belgc fut organiséc sur l'initiative do son chef, le commandant Adien de (icrlache de Gomery.

Au commencement de l'année 1804 , M. de Gerlache, lieutcnant de la marinc de l'État bclge, fit part à M. Du Fief, sccrétaire générál de la Société royale beloge de Géographie, du projet qu'il avait formé d'organiser une expédition belge rers les régions polaires australes. La Société royale belge de Géographie prodigua ses encouragements au jeune officier, et, peu de temps apris, S. A. R. le Prince Albert de Belgique roulut bien accorder à l'cxpédition son haut patronage.

Le succès de l'entreprise semblait dès lors assuré, mais il importait de résoudre tout d'abord la question pécuniaire. Comment recucillir, en Bclgique, les fonds néccssaires à l'exécution d'un si rastc projet?

M. de Gerlache déploya unc activité inoüe; il fit precuve d'une persévérance, d'une paticnce dont on ne saurait assez le louer.

La Société rosale belge de Ciéograplie, de soll côté, ouvrit une liste de souscription, sur laquelle de généreur donateurs 
s'inserivirent spontanément et, par son appui moral puissant, elle mit le projet en pleine lumière.

Si, dans les débuts, de Gerlaehe dut surmonter de grands obstacles, il reneontra, par contre, de nombreux proteeteurs, qui lui aplanirent vien des diffieultés. Citons tout d'abord M. Du Fief, le dévoué et sarant secrétaire de la Société royale belge de Géographie, ct le lieutenant-général Brialmont, l'illustre ingénicur, dont la Belgique cntic̀re honore aujourd'hui la mémoire; MLA. Charles Lagrange, Lancaster, van Beneden, Renard, Spring, Léo Lirera, Dupont et Crépin, ces nembres savants de notre Aeadémie royale; nommons Mmes de Rongé et Osterrieth, ces femmes intelligentes, dont la bourse devient inépuisable, lorsqu'il s'agit de eréer une bonne auvre ou de favoriser des recherches seientifiques; rappelons les noms de MIme M. Errera, du Comte Hipp. d'Ursel, de MM. Houzeau de Lehaie, Solvay, Campers, Ed. Cattier, Delaite, de la Vallée Poussin, l’aul Errera, Eugène Lagrange, Lequarré, Pelseneer le baron Lambert, le ]jr Taquin, de nombreux offieiers de l'armée belge, parmi lesquels le eommandant C. Lemaire, le vaillant explorateur du Katanga, qui ne s'épargna aucune peine pour aider et encourager de Gerlache.

La somme reeueillie par la souseription publique n'étant pas suffisante, M. Schollaert, alors ministre de l'Intérieur et de l'Instruction publique, sollieita des Chambres et obtint, à l'unanimité de nos Représentants et de nos Sénateurs, un premier crédit de 100,000 francs, qui permit d'activer les aehats.

En I 895, de Gerlache, accompagné du licutenant Daneo, se rendit en Norvige, où il prit une option pour le baleinier norvégien Patria et où il s'oceupa des approrisionnements de son tutur navire. İn I896, les nouveaux aménagements du baleinier étaient aehevés.

Dès I895, de Gerlaehe in'arait prié d'accepter les fonetions de commandant en seeond de l'expédition; mais, pour diverses raisons spéeiales, javais décliné l'lonneur qui m'était fait. 
Au mois de juin I897, de Gerlache m'ayant adressé une nouvelle demande dans le même but, je soumis la question à la déeision de M. Vandenpeereboom, qui était alors ministre de la Guerre.

Le Président du Conseil des Ministres me fit rappeler d'urgence de France, où, après un séjour de trois ans dans la marine de guerre, j'étais attaché à l'Observatoire du Bureau des Longitudes de Montsouris.

I la fin du mois de juin 1897 , j'étais cn Belgique et, à la même époque, le navire de l'expédition quittait la Norvège et faisait voile vers la Belgique, ou il devait terminer son armement.

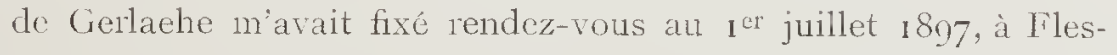
singue.

Le 2 juillet, vers i 3 heures, la Belgica arrive devant Flessingue et je me rends à bord. J'y trouve de Gerlaehe, Amundsen et Daneo, deux mécaniciens et quatre hommes d'équipage, tous éreintés par une lraversée de quatre jours, qui ne s'est pas passée sans eneombre et pendant laquelle ils n'ont pu fermer l'xil. Leurs provisions sont épuisćes, car ils ne s'attendaient pas à devoir rester si longtemps cn route. Malgré cela, chacun semble dans les meilleures dispositions d'esprit. Le navire me fait bonne impression; sa solidité est manifeste, et je suis charmé de son élégance. L'armement est cepencłant loin d'être complet, la mâture mè̀ne doit subir certaines modifications. 11 nous sera difficile d'ètre prêts dans un mois, surtout que nous allons perdre un temps considérable à " battre la grossc eaisse " pour recueillir un peu d'argent.

Apres un eourt entretien arec de Gerlache, je suivis mon vieux canarade de promotion, le lieutenant d'artillerie Danco, qui ne se tenait pas de joie à l'idée de me faire visiter le navire. Etait-il assez enthousiaste, ce brave anni! Tout lui semblait admirable! Il parlait avec une volubilité extraordinaire : rien n'était plus beau, plus pratique que nos logements! Je ne tardais pas à en juger.

11 me conduisit à une eabine minuseule, prinitivement destinće 
aux lieutenants Amundsen et Mélaerts, mais transforméc et amé nagée plus tard en chambre pour le commandant; puis, s'arêtant derant une porte, il s'éeria : "Tout cela est trés bien, mais tu vas voir. le clou et tu seras enchanté. n

Il ourrit, et je me trouvai à l'entrée d'un réduit sans rentilation, où le jour pénétrait à peine par une lucarne donnant sur le couloir. Là, apris quelques instants, je pus distinguer une armoire, sur laquelle s'étalait une sorte de lit et, dans un coin, une caisse de bois blane grossièrement peinte en chêne. P'récisément sous ce local, se trourait la chambre des machines, d'où montait une fade odeur d'huile bouillante.

Apris un moment dexamen : " (Ju est-ce cela? fis-je, intrigué ; la lampisterie! » Danco bondit : « La lampisterie! Comment, tu ne rois pas? tu n'es pas enchanté? mais c'est ta chambre! »

Je restai stupéfait, pendant que lui continuait : "Crois-moi, ce sera superbe et, à peu de frais, tu t’arrangeras à merveille. L'expédition est dans la dêche, nous tirons tous le diable par la queue. »

Il ouvit une autre boite dans laquelle régnait une chaleur atroce : "Vois, tu ne te plaindras plus: Amundsen et Mélacrts logeront là. )

Il me fit eneore traverser le carré, et me désignant une sorte de couloir : "Racovitza, Arctowsli, le clneteur et moi, nous serons installés ici (I). )

Je fis le tour complet du navire, puis remontai sur le pont, ou je remplaçai cle Gerlache, qui alla se reposer.

Et tout en faisant route vers Anvers, je me répétai à plusieurs reprises: Dans quelle galìe suis-je tombé!

I.a Belgica était un aneien baleinier norrégien (Patria), long de 30 mitres, large de $6 \mathrm{~m} 50$ et jaugeant 244 tonneaux. Il fut remis en état et spécialement aménagé pour le vosage qu'il allait entreprendre.

(I) I.es logements furent considérablement améliorés pendant notre séjour dans le port d'Anvers. 


La coque du navire, en bois de Norvigge d'une cxtrême dureté, arait encore été renforcéc par un soufflage en greenheart sétendant sur toute sa longucur et à peu près jusqu'à la lisse de plat bord. Ce soufflage était destinć à protégor la coque proprement dite contre la friction des glaces.

A l'avant, un certain nombre de bandages te fer consoliclaicnt l'étrave et, vers l'étambot, denx puits mettaient en communication le pont et la mer. L'un de ces puits, la jaumic̀e, servant au passage de la partic supérieure de la mèche du gourernail, permettail, en cas d'avaric, de remplacer ce lernier plus facilement. Le sccond était utilisé pour relever l'hélice, afin de la protéçer contre les gylaces ou encore afin de mareher plus facilement ì la voile.

I.a Belgica possérlait une hélice en acier de Suède; cette hélice, à deux branches et de faibie largeur, (tait cachéc en majeure partie pár l'étambot, lorsqu'clle était placéc verticalement pour la marche à la voile. En outre, le navire avait une hélice de rechange cu bronze du mème modèle.

La machine, ì couble expansion, avait une force de 35 chevaux nominaux. A toute rapeur ( I 5 tours), le navire filait sept milles à l'heure; à l'allure moyenne, il parconrait quatre milles; enfin, a l'allure trés économicue $(1,8$ tonne de charbon par jour), il franchissait trois milles.

La machine ne possédait qu'un seul condenseur arec bagues cu bois: qui, souvent, nous donna de sérieuses préoccupations, et une sculc pompe de circulation ne pouvant fonctionner que quand la machine était en marche (1). Par contre, nous pouvions, éventucllement, lintiliser pour vider la calc. Ajoutons que notre unique pompe à air et à eau avait une soupape de refoulement à la mer, défectueusc, et que la pompe d'ulimentation et la pompe de cale étaicnt parfois enrayées toutes les deux.

(1) Lorsque nous étions stoppés et que nous faisions usage de la bobine denroulement, du treuil ou de la machine à sonder, la circulation dans le conclenseur clevait ètre faite par le petit cheval dont le délbit itait insufisant. 
Le petit cheral de la maehine était un rioux rossignol, muni d’un tuyautage mal distribué. Enfin, nous arions une pompe d'alimentation à la main, qui ne serrit qu'en Norrège pour les essais à froid.

La chautlic̀re de la Belgica était neure, mais si malleureusement construite qu'on ne pourait la visiter que très imparfaitement dans certaines parties et aueunement dans quelyues autres. I.orsqu'il s'agissait de la nettoyer, nous devions chereher, dans les ports de relache, un enfant excessirement mince, qui, moyennant une forte rétribution, eonsentît à deseendie dans les endroits resserrés et à les nettoyer, en s'y recroquerillant dans les positions les plus extranndinaires. Ce travail devait être peu récréatif, ear, malgré la bonne aubaine, le gamin ainsi enròlé désertait à bref đélai.

Comme machines auxiliaires, la Belgica possédait un distillateur très pratique, destiné à faire de l'eau douee en mer et qui nous fut des plus utile dans la banquise; puis, un treuil puissant pour relerer les ehaluts et aider, éventuellement, aux mancurres de force; puis eneore une machine pour la bobine d'enroulement du eable de dragage, véritable bijou sorti de l'arsenal de guerre de Copenhague; cnfin, une machine à sonder de Le Blanc.

Je viens, en toute franehise, de critiquer notre machine au point de rue teehnicute; il est juste aussi que je reeonnaisse, et aree une enticre satisfaction, que cette machine, si naïrement construite, nous a laissés rarement dans l'embarras. C'est peut-ètre mème à sa grossière simplicité que nous derons la foree avec laquelle elle triompha de tous les obstacles.

La Belgica était gréée en trois màts barque. Sa màture présentait la particularité des huniers à rouleaux. Ce genre de huniers, qui n’est pas recommandable pour les navires de fort tonnage, était, au contraire, très arantageux pour un navire comme le nôtre: $1^{\circ}$ il exige fort peu l'hommes pour la manouvre; $2^{\circ}$ il permet dr prendre tres rapidement un ou plusieurs ris; 30 il ne réclame aucun homme clans la màture pendant le maurais temps; $4^{\circ}$ enfin, son fonctionnement est 
parfait, lorsque, pour hisser ou pour anener les hunicrs, on a soin de prendre, au préalable, le rent arrière.

Tous ees arantages sont d'un prix inestimable quand il s'agit d'explorer des régions ou le temps varie tries brusquement.

Ce systène, qui nous rendit des services précieux, a cependant des ineonrénients : Io la toile s'use rapidement pris des racages; zo les racages doivent être fort cxactement ajustés : s’ils sont trop petits, la toile se dichire; s'ils sont trop grands, le rouleau les foree ct sort luimème de leurs guides, par vent violent; 30 guand le rouleau est sorti des racages et qu’il n’a pas été possible de le remettre en place immédiatement, il fléchit et prend une déformation telle, qu'il derient diffieile, par la suite, de l'y faire rentrer.

Le gouvernail se composait d'une série d’importantes pièces de bois. Il était actionné soit par une roue placée à l'arric̀re et à l'aicle de laquelle on gouvernait sous voiles, soit par une roue plaeće sur la passerclle d'avant et avec laquelle on gourcrnait sous rapeur. Or. lorsqu'il s'agissait de ehanger de roue pour gouverner, nous perdions un temps eonsidérable à l'ajustage des chaînes.

Pour obvier à cet ineonvénient, le système fut changé en cours de route, et l'on fit usage d'une drosse sans fin, s'enroulant, cn mème temps, sur les arbres des deux appareils de gouverne.

Les ancres étaient au nombre de quatre : deux aneres de bossoir ayant chaeune 20 mètres de chaine onviron, une ancre de miséricorde de petite dimension et une anere d'embarcation. On les mano'urrait arec le traditionnel et misérable guindeau des baleiniers, les fonds de l'expédition n'ayant pas permis l'acquisition d'un cabestan à rapeur.

Les embarcations, au nombre de quatre, comprenaicut deux baleinières tris lourdes, qui ne furent presque jamais employées, un bon canot et un youyou. Ces deux demiers ctaient d'un gente gracieux, bien que le youyou fùt peu stable. Tos embareations n'arairnt pas de gréement à la voile; pourtant, tout à la fun de notre hivernage, nous en fimes construire un pour le cas oú, notre navire étant écrasé par les glaces; il ne nous resterait que ce moyen de salut. 
Les locaux habités comprenaient:

Sous la dunette, les chambrcs occupées par l'état-major; sous la passerclle centralc, le laboratoire; enfin, à l'avant, dans l'cntrepont, le poste de l'équipagc.

Le vaigrage et les cloisons, à l'arric̀re, ćtant doubles, on avait placé, dans l'intervalle, une épaisse couche de feutre, afin de conser. ver plus facilcment la chaleur dans cette partic du navire.

La description des logements de l'état-major trouverait peutêtre place ici, mais nous aurons occasion d'y revenir dans la banquise.

Le poste de l'équipage était grand, très bien aéré et prenait jour par un vaste lantcrneau. Il était garni de scizc couchettes, placées en abord sur deux étages et munies de bons matelas et de chaudes couvertures de laine. Au centrc même du poste, deux grandes tables se trouraient montées en pcrmanence, tandis quc, près du màt de misaine, s’élevait un lavabo-bébé, surmonté d'une glacc minuscule. Dans un coin, une bibliothèque peu garnic, ct, à còté, suspendue au cloisonnement, une cartc sur laquelle nous tracions la route suivic par le navire.

Lc laboratoire, installé sur le pont, ćtait éclairé par deux grandes fenêtres et six larges hublots. Il était divisć longitudinalcment en deux compartiments : le compartiment de tribord, occupé par Racovitza, et le compartiment de babord, réservé à Arctowski.

I) u côté Racovitya, unc grande bibliothèque de cent volumes, contcnant des mémoires sur la flore et la faune antarctiques,ainsi que des livres de détermination pour tous les groupes; une armoire oi s'étagcaient des tubes de toutes tailles pour les échantillons à recueillir; enfin, sur la table, les appareils de précision, tandis que, dans le fond du réduit, s'entassaient des filets, des lignes, des cngins de pêche de toutes sortes.

Du côté Arctowslí, l'encombrement de thermomètrcs marins, d'anémomètres, de baromètres, d'hygromètres, de bouteilles à eau, de cornues à formes bizarres était tel, qu'on se demandait comment 


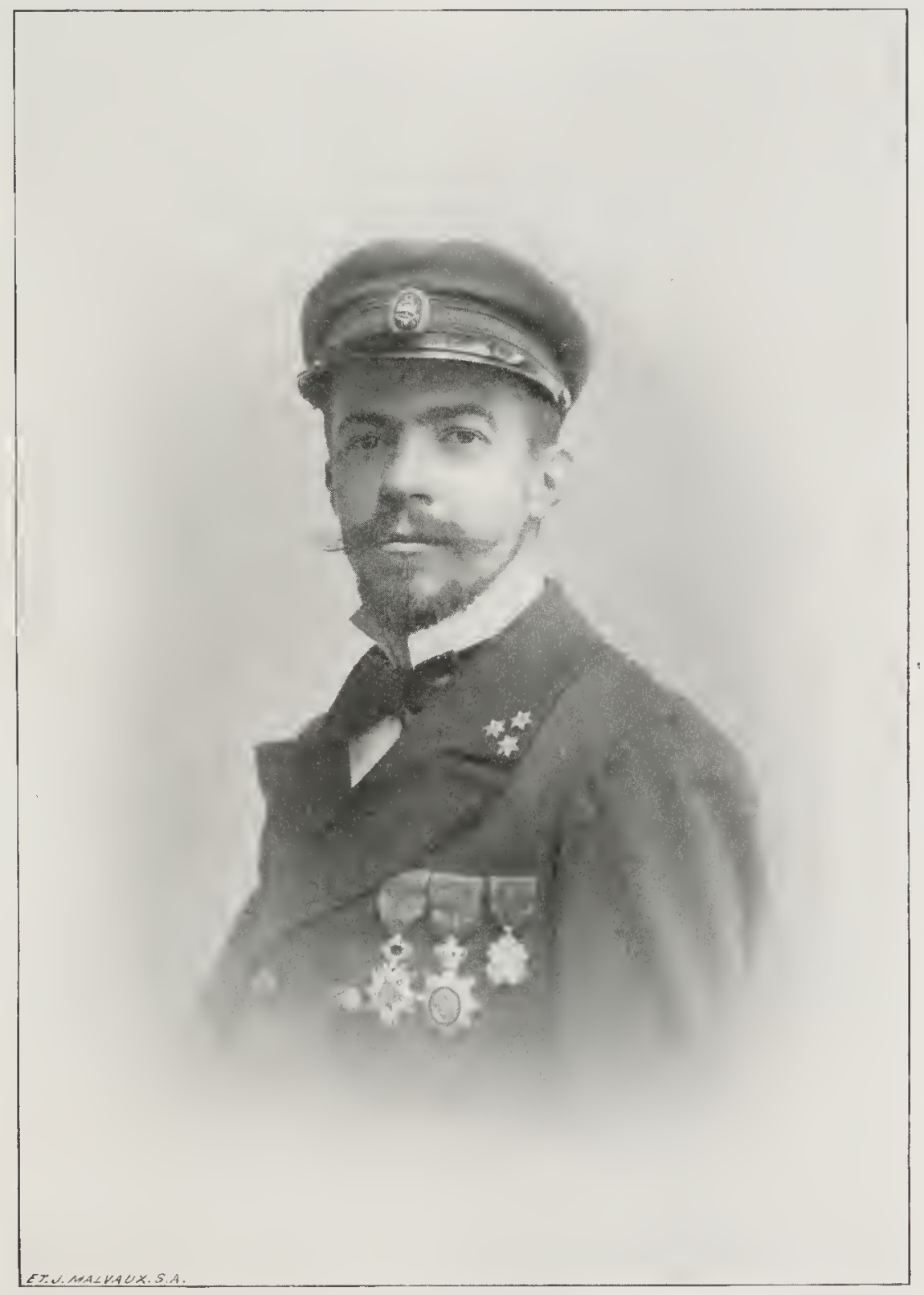

IIG. 2.

GEORGISS LECOINTE

COMMANDANT EN SECOND DE L'TXPTEDITION 

tout eela pouvait tenir dans un espace aussi restreint et n'être pas brisé par le roulis et le tangage.

L'état-major de l'expédition antaretique belge était composé comme suit :

M.M. Adrien de (ierlaehe, commandant de l'expédition;

Georges Leeointe, eommandant en seeond, officier de navigation et hydrographe, qui se ehargea de la physique du globe après la mort du licutenant Daneo;

Henryli Aretowski, géologue, oeéanographe et météorologiste; Firédériek Cooli, médecin et photographe; s'occupa, en outre, de l'anthropologie;

Émile Danco, ehargé de la phýsique du stobe, mourut le 5 juin 1898 ;

Antoine Dobrowolshi, attaelié à lá météorologice;

Emile-Cieorges Racovitza, naturaliste;

Roald Amundsen, premicr lieutenant;

Jules Mélaerts, sceond lieutenant;

I lenri Somers, chef mécanicien;

Max Van Rirsselberghe, sceond méeanicicn.

Totie programme scientificue embrassait des puestions multiples. Il nous imposait notamment : de dresser la carte des régions parcourues; de prendre de nombreuses observations astronomiques, magnétiques el pendulaires; d'étudier la dérive du navire, dans le eas oi il serait emprisonné dans les glaces; de fáre des observations métécrologiques suivies; d'étudier les aurores polaires et les gláciers; de rapporter des ćelantillons géologiques des terres où nous débarquerions; de prendre la température de l'eau de mer, d'en mesurer les densités et d'en prélever des éehantillons à différentes profondeurs; de pêeher au filet pélagique à toutes les profondeurs, d'y draguer et d'en. rapporter des spécincens de la faune et de la flore; de déterminer, par des ascensions, la hauteur de eertaines montagnes; enfin, d'établir a terre une station d'hirernage ou d'hiverner arce le navire. 
Ce programme trop vaste, vu notre peu nombreux pcrsonnel, s’imposait cependant, puisque nous nous rendions dans une région absolument inexplorée.

Pour mener à bien des travaux de cette importance et de cette diversité, il aurait fallu de vastes laboratoires bien installés et un matéricl scientifique très complet.

Or, notre baleinier ne pouvait nous donner qu'un laboratoire assez exigu et l'état de nos finances ne nous avait pas permis l'achat de nombreux instruments. Toutefois, il convient de dire qu'un grand navire aurait été désarantageux au point de vue de la manœuvre dans les glaces et que sa machine aurait consommé une quantité trop considérable de combustible. De même, la nomenclature qui va suivre établit que nous disposions d'un matériel scientifiquc assez étendu et que si, dans nos rapports, nous insistons spécialement sur l'absence de certains instruments qui nous auraient été utiles, nous avons surtout cn vue d'éclairer ceux qui se rendront après nous dans l'Antarctique : nous voulons que notre expérience leur profite.

Le matériel scientifique dont l'expédition disposait peut se grouper comme suit :

Navigation et hydrograplice: Trois grands chronomètres et une montre de torpilleur, un sextant de Hurlimann, avec prisme biréfringent et lunettc de nuit de Fleuriais, un horizon gyroscopique dans le vide de l'amiral Fleuriais, un horizon artifieiel liquide, un horizon artificiel à glace, un compas rapporteur et des règles métalliques, un théodolite de campagne, un compas étalon de Thomson, un compas liquide, une série de compas d'embarcation.

Physique du globe : Un théodolite magnétique et une boussole d'inclinaison de Brunner, un magnétomètre de Neumayer et un pendule de von Sternecli.

Météorologie : Un baromètre marin, un grand anéroïdc, un petit anéroïde, un abri météorologique installé sur la passerelle, six thermometres frondes, deux paires de thermomètres psychromètres 
avec montures, six thermometres à alcool arec graduation centimétrique, un thermomètre à toluene pour basses températures, deux paires d'aetinometres Arago, un "sunshine recorder ", un anémomètre de Mohn, un anémomètre de Dines pour estimer la force du vent, trois thermometres terrestres, un atlas de nuages, un hygrometre d'Alluard, plusieurs enregistreurs hebdomadaires du systime Richard: un baromètre, un hygronetre, un thermometre, un psychromctre; un thermometre enregistreur journalier du même constructeur; enfin, différents ouvragres et tables météorologiques.

Océanographie: Une machine à sonder de Le Blanc, un sondeur de Belloc (petite machine à utiliser en curlot), fil d'acier et cordelette pour sonder, trois sondes (systène du prince de Monaco), une sonde à cuvette construite pal Chabaud d'après les instructions de M. Arctowsli, trois sondes (systime de Sygsbee modifié), une sonde "nouvelle " construite dans l'Antarctique d'après les instructions de M. Aretowsti, trois bouteilles de Sygsbee, une bouteille de Buchanan, deux densimetres de Buchanan, un réfractometre de Abbe, deux disques de Secchi, un flotteur pour étudier les courants le long des còtes, des flacons à large goulot pour la eonservation des échantillons de sédiments, des flacons pour la conservation dans le laboratoire des cichantillons d'cau de nier réeoltés au cours des sondages, deux seaux pour puiser l'eau de sulface, des montures de thermomètres et deux thermonctres gradués au I/Io de degré, pour la détermination de la température des eaux de surface, des montures de thermomètres, des thernometres de Negretti et Zambra et de Chabaud, pour la détermination de la température en profondeur, des curseurs de Rung, dos échelles de Fiorel et de Ule, deux thermometres normaux (pour les comparaisonsi, une éprouvette montée à la Cardan pour les déterminations de la densité des eaux, le nécessaire pour distiller de petites quantités d'eau et un grand flacon pour conserver de l'eau distillée dans le labordtoire.

Géologie: Une sonde portative (système Van den Broecli), un microscope, un chalumedu et les réactifs pour chalumeau fournis par le 
laboratoire de minéralogie de l'Université de Gand, des réactifs et tout le nécessaire pour effectucr des analyses chimiques qualitatires, deux marteaux géologiques, deux piolets, une pioche, deux harresacs pour les échantillons, une quantité suffisante de saes en toile pour la conservation de sables, ctc, une boussole géologique, un appareil photographique, un barometre anćrö̈de altimétrique, un hypsomètre, un barometre liortin (petit modile).

Zoologie et botanique: I)ragage : quatre chaluts à étrier du sýstème Sygsbee, cle 5 et 7 pieds d'ourerture, un petit chalut fabriqué à bord de la Belgica pendant l'hivernage et qui servit à la pêche à travers un trou foré dans la banquisc. Deux dragues arec cadre en fer, une barre porte-faubert.

Pèche : un trémail, des palangres, des lignes et hameçons variés, des nasses en fer et en osicr.

Pêche pélagique : trois filets en étamine de soie à seau filtreur, deux filcts pour pècher cn grande vitessc système Buchet, deux filets fermants, bathỹpélagiques, système Giesbrecht.

I) $\mathrm{cs}$ hareneaur, des troubleaux des foënes, des harpons à main, des crochets, etc. I) eux canons porte-harpon pour la pêchc aux hyperoodons, des fusils et des carabines de chassc.

Ln treuil à rapeur pour les dragages, arec une poupée à rapeul portant 6,000 mètres de câble d'acier, un mât de charge avec dyna. momitre.

Ln laboratoirc complet arec microscopes, loupes de dissection, instruments de dissection, réactifs rariés, r, 500 litres d'alcool, bocaux, tubcs en rerrc, caisscs en zinc, ctc.

Une presse botanique ct du papier burard pour sécher les plantes.

Bibliotheque : Elle contenait la plupart des ourrages de quelque importance écrits sur l'Antarctique, les instructions nautiques françaises et anglaises, les lirres de phares français et les cartes de l'amirauté anglaise.

Les approvisionrements de toutes sortes dont une telle expédition 
doit se charger sont innombrables. Le combustible est d'une importanee capitale. La Belgica avait emporté d'Anvers r 20 tonnes de charbon aggloméré et $4^{\circ}$ tonnes de charbon anthraciteux, destiné aux poêles, à borl et dans les baraques d'hivernage. En outre, Ioo tonnes de eharbon aggloméré avaient été envoyées à Punta Arenas, que nous prenions comme base d'opération.

Par économie, de Gerlache avait limité au strict minimum l'approvisionnement en huile de graissage, en bourrages, en objets de matelotage, en toile à voile de rćserve, en outils et en bois de eharpentage.

Les approvisionnements en vêtements avaient été faits avec la même économie.

Pour bien comprendre les principes qui avaient guidé de (ierlache dans ees acquisitions, il faut se rappeler le plan primitif de l'expédition.

La Belgica eomptait arriver dans le secteur antarctique sud-américain au commencement de l'été austral 1897; puis, longeant la banquise vers l'Est ou vers l'Ouest, elle devait tâcher de clébarquer, pour un hivernage, à la Terre Victoria, près du cap Adare, quatre membres de l'expédition : de Gerlache, Amundsen, Danco et Arctowski. Pendant ce temps, le navire aurait fait une eampagne dans le Pacifique, sc serait approvisionné à Melbourne et, l'année suivante, serait retourné au cap Adare rechercher les explorateurs.

11 suffisait done, si tout se passait comme on l'avait prévu, d'avoir un outillage et des vêtements spéciaux pour les quatre personnes destinées à l'hivernage.

Acheter un matériel complet d'hivernage pour ehaque homme eût été par trop coûteux. Il fallut donc se bercer de l'illusion (illusion que les ćvénements eurent bientôt dissipée!) que, si la Belgica était prise dans la banquise, ce ne serait pas bien loin de la mer libre, qu'elle jouirait là d un climat maritime et n'y devrait pas affronter de grands froids.

Une éventualité aurait encore dû engager à l'aequisition d'un équipement spécial pour ehaque homme : celle où le navire, après avoir débarqué unc partie du personnel au cap Adare, aurait été écrasé dans 
les glaces! Ces hypothèses n'avaient certes pas ćchappé à de Gerlache, mais le manque de ressources l'avait obligé à n'cn pas tenir compte.

Le matériel et l'équipement destinés aux quatre personnes de la station d'hivernage comprenait : un vêtement de fourrure par personne; des rêtements spéciaux en laine, achetés par ceux mêmes qui devaient hiverner; deux baraques en bois, deux traineaux, une tente, des skis, des raquettes à neige, des finshoes, des koemaker's, des bottes en feutre et cleux petits réchauds, dont un du modèlc employé par Jáclison.

Quant aux autres rêtements destinés, éventucllement, aux membres du personnel, si tous devaient hiverner, ils formaient une assez paure garde-robe!

La question des rivres, on ra le comprendre, est aussi importante quc celle du combustible et des rêtements.

Nul n'ignore que l'extrêne froid comme l'extrême chaleur constitue un climat auquel on ne s'cxpose pas sans danger. Les fievres ne rignent pas dans lus régions australes, mais d'autres maladies s'y développent arec une rapidité foudroyante: le scorbut, les troubles cardiaques, les accès de phobie, etc. Le lieutenant Danco fut cmporté, en lunit jours, par une maladie de coeur. L_a longue nuit polaire dćprime rapidement lindividu le plus sain, le plus résistant, et occasionne une anémic, aggravée encorc par les travaux excessifs qui incombent naturellement à tout équipage peu nombreux. La privation de riande fraîche, l'abus des conserves amènent peu à peu le dégoût de tonte nourriture, alors que la xigueur du climat exigerait, an contraire, une alimentation plus variée, plus copicuse que l'alimentation habituelle.

Toutes ces considérations prouvent surabondamment que le choix des vivres ne peut être laissé au hasard, puisque de ce choir dépendent la santé, la rigueur physique et intellectuelle cle l'explorateur. Je próconise done les mesures suivantes:

Io La nourriture scra aussi variée que possible;

$2^{\circ}$ En quittant le dernier port de relàche, on emportera non 
seulement de la viancle abattue, mais de la viante su pied : buxuls, poulets, oies, canarts, cochons, guí, ces fleniers surtont, vivent i ancrveille ì bord;

$3^{\circ}$ ()n se chargera de viandes consevées de toutes especes, non seulement de viátndes bouillies ot hachées, mais surtout de viandes fraîches, salées, fumées, rôties; de nombrenses esperes également de légumles et cle fruits;

$4^{\circ}$ ()n réservera spécialement pour l'hivenage les sompes extratordinaties, les lógumes comprimés et les farines de tous genes, afin que l'épuipage n’en soit pás fátigué, an noment oil l'appétit lui deviendra plus nécessaire;

50 On tiendia compte des gonts, des habitudes de la population cmbarequé, et on ne se basera pas sur le cloix fait, précélemment, far des marins d'autres pays : les linangais, los belges ne mangeront pas ave le mene plaisir la cuisine des Norvégiens ou des Chinois, ot vice reisa;

6" Les fatigues, les dèngers élant les mêmes pout lons, la nou1riture doit être la même, à quel pues rlétails près, pour les marins of pour l'etal-major. Ce principe d'égalité cetant arhnis, il faut non pas róluire l'état-major át régime alimentatire d'un wavire de commeree ordinaire, mais élever lo régine de l’épuipazge an régine d'un étatmajor qui doit etre bien traité, afin de conserver sa vigueur physique et intellectuelte;

$7^{0}$ linfun, il faut que, penclant toute la périofle préparatoire à l'expédition et lá longue traverséc de l’Nulantiejue, on fasse, dans cháque escale, des approvisionnements en vivres frats (viande sur pied), sans être obligé de regarder à lá dépense.

Nais l'alimentation telle que je la préconise cotite cher, tris cher nême. Comment coneilier cela avee une strictécónomír?

beux arguments étaient en présence :

N'oubliez pas, nous criait le premicr, que l'argent de l'expédition n’est pas loural! N'oublícz pas qu'il a été souscrit el que cerlains 
petits souscripteurs, peu versés dans les nécessités d'une grande cntreprise, trouveraient juste de se plaindre de ce que les membres de l'expédition désirassent se gaver de bonnes choses à leurs frais! N'oubliez pas les haro qui furent poussés lorsqu'on fit courir le bruit que vous aviez embarqué du foie gras, alors que vous aviez embarqué du foic de cochon, dont le prix de revient est infime! N'oubliez pas que, si vous avez des amis et des juges éclairés, vous avez aussi des juges ignorants et, surtout, des jaloux de votre persévérance, des jaloux de la gloire que vous cherchez à recueillir pour votre pays! N'oubliez pas la presse, faites en sorte qu'elle n'ait pas de jugement à prononcer. Craignez la presse! craignez la presse!!!...

L'autre argument répondait avec énergic:

Ne vous occupez pas des racontars qui se feront au retour sur les repas pantagruéliques qu'on rous attribuera. Surtout ne craignez pas la presse : certes, elle vous analysera en détail, mais elle vous jugera par ce que rous aurez accompli plutôt que par ce que vous aurez mangé. La presse, dans son ensemble, n’est jamais injuste; la presse intelligente reconnaîtra toujours que la santé seule permet d'exécuter de grandes explorations et clle sera la première à harceler les petites feuilles ignorantes qui vous critiqueraicnt niaisement.

Certes, il faut avoir de la délicatesse envers les sonscripteurs, mais n'est-ce pas outrcpasser la mesure que de s'imaginer que les souscripteurs, eux, auront l'indélicatesse de vous exploiter?

Comment! l'équipage touche une solde dérisoire, il doit mêmo payer une bonne partie de son équipement; l'expédition coûte un temps précieux et plusieurs milliers de franes à la plupart des membres de l'état-major, et vous leur reprochez d'exiger le nécessairc?... Ces mêmes membres de l'état-major, qui se sont acheté des instruments et des vêtements onéreux, pourraient aussi se payer, chaque jour, un petit supplément de 20 à 30 sous, sur la ration quotidienne; mais, comme ils sont partisans du principe de l'égalité dans l'alimentation là où il y a égalité dans le danger, ils subissent doeilement le sort général!... 
Que de fois ces différents arguments ont dû hanter le sommeil dc notre commandant!

Il résolut le problème en admettant que la dćpense par homme matelots ou état-major) serait de moins de 2 francs par jour, y compris la boisson.

La Belgica emportait 500 kilogrammes de tonite (I), destinće à faire sautcr les blocs de glace dont l'approche devicndrait dangcreuse ou pour écarter ceux qui barreraicnt, éventuellcment, l'entrée d'une clairière d'cau libre.

La mise de feu devait se faire à l'aide do mèches bickford et de capsules de fulminate de mercure, dont nous avions un assez grand approvisionnement.

Enfin, nous possédions six grandes scics à glace, qui nous rcndirent des services inappréciables : ouvrant les trous pour les sondages et les pêches et nous permettant finalement même de nous légager des glaces en 1899 .

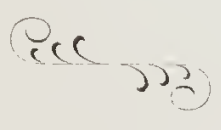

(1) Explosif dunt les effets devaient etre sensiblement los mèmes qur ceux de la dynamite. 


\section{CHAPITRE II.}

Dans le port d'Anvers.

Au moment où la Belgica arrivait à Anvers, le laboratoire ne contenait encore absolument rien. Il fallait changer une partic des logements, mettre la machine en état, embarquer les approvisionnements ct les vivres, enrôler un complément d’équipage. Il fallait... oh! tourment! rccueillir encore 80, ooo francs, somme absolument nécessaire à l'exécution de l'entreprise!

Pour bien comprendic mon état d'âme, il faut se rappeler que mon départ pour l’Antarctique avait été décidé brusqucment, par télé graple, que j'étais frais émoulu de la marine de guerre française et que, prêt à remplir le rôle d'officier de navigation, à faire de l'hydrographie et des observations astronomiques ou magnétiques, je ne mo reconnaissais cependant aucunc aptitude spéciale pour une croisière dans les régions australes. Les ptemiers jours, je me sentis complitement désorienté. Rien ne me semblait plus extraordinaire que co bâtiment qui allait cntrer cn campagne et dont l'équipage, encore incomplet, comptait déjà quclques matelots indisciplinés et mêmo dangereux.

Comme de Gerlache n'avait pas de rôle d'équipage, nous n'avions aucune action répressive sur les hommes, si cc n'est le renroi. Et encore, il fallait songer aux conséquences qu'aurait produites, autour de nous, l'application quelconque d'une peine disciplinaire. L'opinion publique, encore hésitante, nous eût blàmés et abandonnés!...

Au bout de quelques jours, notre horizon s'éclaircit heureusement : certains hommcs se retirc̀ent d'eux-mêmcs, d'autres s'amendèrent provisoirement.

Restait la question d'argent! de Gerlache dccida que, pour attirer l'attention du public, nous organiserions, sur le quai, une exposition du matériel de la Belgica. 
Pendant cinq jours, régna une fièrre intense de travail; l'état-major sacharnait comme les simples matelots. Racovitza persuada même ì un ami intine, qui venait lui faire ses alieux, cu'il devait nous aider dans notre labeur. Et, muni d'un marteau et de clous, le brave gatçon travailla d'arrache-pied aux baraques d'hivernage!

Enfin, les campements furent montés, les harpons, les filets, les anoralis, les chaussures, les skis, les traineaux, sortis kle leurs cases ct étalés d'une façon pittoresque, afin de séluire les curieux.

P’uis vint une période plus extraordinaire eneore.Pendant huit jours, on nous accabla de visites! 11 fallut sourire à chacun, témoigner des égarls spéciaux aux membres de la presse et, du matin au soir, faire un petit boniment analogue à celui du forain, cui, du seuil de sá roulotte, s’écric : Entrez, Messieurs, Mesłlames, venez voir la merreille qu'on annonce à la porte! "

Xous manquions un peu l'habitude ct de voix pour ce métier-là, mais, au fond, c'était cela. Sevant une galerie sans cesse renourelée, nous lonnions des explications sur la pèche, sur les sonlages, sur les dragages, sur... la banquise mème, que nous n'avions jamais vue!...

Parfois, les (questions nous léconcertaient légèrement.

Une jolie femme, en toilette noire des plus seyantes, nous prie de lui montrer la route suivie par Xansen au pôle Sud! Plein d'égarls pour ce naïf géographe, nous glissons une carte de l'Aretique sur celle de l'Antaretique, et nous donnons l'explication demantée, sans que la belle visitcuse ait à rougir de sa question.

Un homme politique influent nous demande, d'un air malin, pourquoi nous nous imposons la fatigue le prenile ales échantillons d'eà à différentes profondeurs, alors qu'il est si facile d'en puiscr, arec un scau, à la surface?

Une autre dame nous plaint, à haute voix, des chaleurs atoocis que nous derrons supporter près du pôle Sud.

Un monsieur nous dit confidentiellement qu'une des questions géographiques les plus importantes serait de déterminer la distanee 
exaete qui sépare les deux pôles et que, à ce point de vue, il y aurait peut-être avantage à passer par le pôle Nord pour atteindre le pôle Sud.

Nous en sommes eneore à mûrir ectte idée!...

Et voilà le métier que nous faisons pendant des jours et des jours. Le soir, parfois, lorsque nous nous retrouvons avee Arctowski et Raeovitza, nous déplorons ce temps préeieux que nous perdons, alors que nous n'aurions pas assez de tous nos instants pour régłer nos instruments, pour revoir certaines questions.

Et le temps passe, et l'argent ne vient pas.

Enfin, un matin, M. Schollaert, ministre de l'lntérieur et de l'Instruetion publique, fait annoncer sa visite pour it heures. Aussitôt renaît en notre âme une lueur d'espoir.

A l'heure dite, le ministre, aeeompagné de son chef de cabinct, M. Van Overbergh, et du représentant I-Ielleputte, visite le navire et se fait longuement expliquer nos plans, notre projet d'itinéraire. A 6 heures, lorsqu'il nous quitte, il ne promet rien eneore, mais dans son regard satisfait, nous lisons un sineère eneouragement. Le lendemain, le Gouvernement demandait à la législature un erédit supplémentaire de 60,00o francs, et cette proposition était votée a l'unanimité.

Enfin!

Enfin! surtout pour de Gerlache, qui, depuis trois ans, mendiait pour son expédition et subissait avec une parfaite sérćnité, il est r rai, toutes les humiliations..., pourru qu'elles fussent payées.

Quelle vie!

Nais notre brave commandant derait encore éprourer un ennui sérieux avant le départ.

Lorsque la Belgica avait quitté la Norvège, le bàtiment était lège. Pour le lester, de Gerlache avait fait remplir d'eau douze grands réservoirs plaeés à fond de eale et qui, primitivement, serraient à reeueillir l'huile pendant les pêehes, dans le Nord. 




Photog raplihe Fabronins.

FIG. 3.

II. HRINS SCHOLLAERT

ANCIEY NINISTRE DI L'INTÉRIEUR IT DE L'INSTRUCTION I'LBLIOUE PRLSIDEAT DI: LA CHAMHRE DES REPRLSTXTANTS. 

Pour alléger le service de notre équipage restreint, le commandant des pompiers soffrit à vider nos calles. Il n'en fallut pals davantage pour que le butit se répanclit, avee persistance, gue le navire liasait call.

Pour comble de malheur, une soupape de wefoulement it lat mes

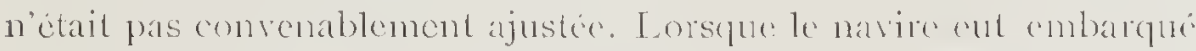
son combustible et qu'il fut change, cotte souprape so trouval sous

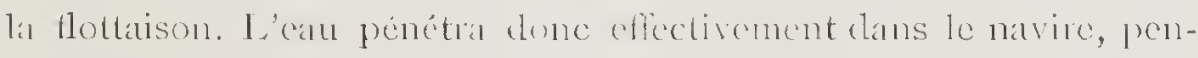
dant quelepues instants. I)ès lors, l'incuicule se manilesta sériensement. P'eu s'en fallut que, pour rassurer l'opiniom publipue, de cierlache ne füt astreint à entrer en cale siche!

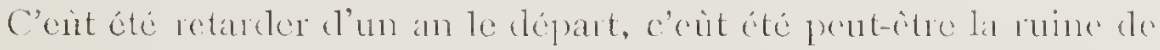
l'expéclition! de cierlache se démena tant et si bien, (pu'il finit pan dissiper les craintes.

Le: 15 andit 1897 , la belgiar sortit des bassins, de grand matin,

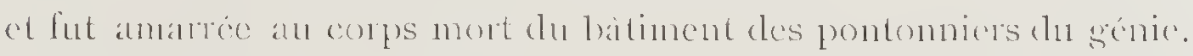
A micli, une réception grandiose nous fut oflente par lo " V'acht

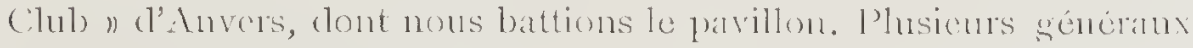
assistatient à cette fète.

Vers ig heures, mous nous sépanions, an milien de leffusion géné vale.

Libre de mon temps, je me rends an chatealu de Niel, ou se

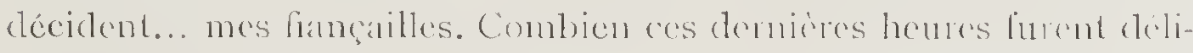
cicusement imues! Sue de conscils, que de recommantations! fe

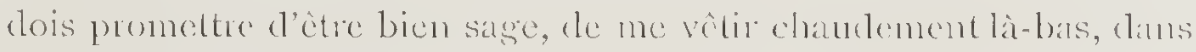
les glaces, de ne fate aucune impundence!... Je promis tont. 


\section{$-44-$}

\section{CHAPITRE III.}

Faux départ.

Le I6 aoùt 1897 , dès l'aube, tout le monde, à bord, était sur pied. On embarquait los derniers approvisionnements, tandis que, sur la passerelle, nous fixions le compas-étalon de Thomson, qui venait enfin de nous parrenir.

A 8 heures, la rade était cn fète, les nombreux navires du port arboraient leur: grand parois, tandis que nous envoyions les eouleurs avec une eertaine émotion.

Bientôt la Belgica est envahie par une foule de parents et d'amis (1). Que de discours! Que de phrases bizarres!

Depuis un mois, on ne parlait de nous qu'avec les ćpithètes : hardis, couragcux, vaillants, valeureux, hommes d'elite, savants, ete.!... C'est inouï comme on se fait rite à cct honneur, surtout quand on n'a rien fait pour le mériter.

Le 16 août, ce fut bien autre chose. On nous donnait tous ees qualificatifs à la fois! On nous embrassait, 1nème les personnes qui nous eonnaissaient à peine! On suppliait : "Rapportez-moi un petit souvenir des régions polaires, n'importe quoi, mais quelque chose de là-bas! " Et nous répondions sans eessc : "Oui, oui, c’cst entendu. " Je promis une ringtaine de fois... la peau du premier ours blanc que je tuerais pendant la eampagne. Je ne m'engageais pas à grand' ehose!

A Io heurcs préeises, l'ancre est levée. I.es visiteurs nous ont quittés; il ne reste plus à bord que les mombres de la famille de Gerlache ct deux de leurs amis intimes.

(I) Ln ce qui me concerne, $\mathrm{j}$ 'avais prié ma famille, dont les nembres sont fort nombreux, de ne pas venir me faire d'adieux, le jour du départ. Je ne voulais pas l'attendrissement à bord, ni de scènes d'émotion. Mon désir fut respecté. Seul, mon frère aîné vint me serrer la main, ail dernier moment, et se retira. 
I a Belgica vire de bord, défilant le long des quais où se trouve massée une foule enthousiaste.

Sur le grand ponton, la musique militaire joue l'air national, répété au loin par le carillon de la eathédrale, dont la flèehe porte un gigantesque pavillon et une flamme belges.

A bord de la Belgica, le pavilion est amené, puis hissé à bloe lentement. L'équipage crie : "Vive la Belgique! " tandis que les membres de l'état-major se déeouvrent (I).

Nous naviguons de eonserve avee un grand nombre de petits navires gracieusement pavoisés.

Toici le Brabo de M. R. Osterrieth, la Mariana du baron t' Serelaes, l'Express de M. Cogels; voilà le Nixe de M. Karcher, le Lovelei de M. Reiss, la Fauvette de M. Hanssens; plus loin, le Mimosa de M. Nyssens, le Colibri de M. Walseharts et l'Oscar et Virginie le M. Lissnyder; plus loin encore, la Vague, Telegraaf III, Telegraaf IV, ete.; sans oublier la gracieuse Mouette, que gouverne son propriétaire, M. Albert Grisart, seerétaire adjoint du lacht Club, excellent marin, et l'un de nos meilleurs amis.

Le temps est superbe, le ciel est d'azur et le soleil brille de tous ses feux.

De la rade, le bruit monte, le canon tonne au Yaeht Club, les sirènes des navires jettent leurs appels stridents, auxquels répond le sifflet de la Belgica, et, dans les moments d'aecalmie, les sons de la Brabançome arrivent jusqu'à nous.

Loin clerrière nous, un vapeur s'efforee de nous rejoindre. C'est l'Émeraude, le bâtiment officiel, à bord duquel se trouvent le ministre de l'Intérieur et de l'Instruetion publique, les présidents des Soeićtés de Géographie de Bruxelles et d'Anrers, des sénateurs, des députés, des membres de l'Académie et la foule de nos amis.

Nous passons à eontre-bord du San-Francisco de lá marine de guerre

(I) MM. Arctowski, Danco et Racovitza avaient pris passage à bord de l'Émeraude ct ne'devaient monter à notre bord qu'à la frontière hollandaise. 
des États-Unis; nous ćchangeons un salut, ct tandis que nous hissons le pavillon de la République amie, la musique du navire de guerre répond par notre hymne national.

Au Docl, tandis que la Belgica cmbarque la tonite, l'Éméraude nous accoste ct les autorités ciriles et militaires passent à notre bork.

M. 1e ministre Schollacrt nous adresse alors l'allocution du départ : quelques mots simples, mais presque affectueux et très cncourageants.

Les passagers de l'Émeraude nous quittent au bout de quelques instants, et, notre chargcment effectué, nous poursuivons notre route.

Tout à coup, vcrs notre avant, apparait un cuirassé. C'est le Kortenaar, que S. M. la Reine des Pays-Bas envoie à notre rencontre.

Le navire hollandais hisse notre pavillon et salue la Belgique de vingt et un coups de canon, tandis que son équipage tout entier passe à la bande.

La Belgica et plusicurs yachts de l'escorte répondent en hissant au grand mât lcs couleurs de la Hollande; puis, dans un vif élan de reconnaissance pour cette marque de courtoisic de la Reine Wilhelmine, les Bolges cntonnent l'air national nécrlandais. Qu'elles sont loin les querelles d'autrefois! Aujourd'hui, les deux peuples sont sincirement amis.

Mais à mesure que nous nous ćloignons de la fronticre belge, notte escorte diminue

Bientòt l'Émeraude vire de bord et il ne reste plus que quelques. yachts voguant avec nous, à tribord de l'immense Kortenaar.

Vers 3 heures, le Brabo nous accoste, les parents du commandant de Gerlache et Mme Osterrieth viennent nous faire leurs adieux. Une profondc émotion étreint tous les cœurs, cn voyant ce pćrc, cette mère, cmbrasser leur enfant, peut-être pour la dernière fois! Je me sens pris d'attendrissement; je pense à mes ehers parents, à la dou* leur qui les aurait déchirćs s'ils avaient vécu jusqu'à ce jour!... 
de Gerlache est près de moi, son épaule touche légèrement la mienne; je lis dans ses yeux et ceux de sa mère une douleur profonde, et, voulant, à la fois, rassurer et la mère et le fils, je m'avance vers Nme de Gerlache, je lui dis de ne rien craindre pour l'arenir, que mes compagnons et moi, nous lui ramenerons son fils et nous nous dérouerons sans réserve au succès de l'expédition.

Les adieux terminés, on largue les amarres et chacun retourne à son poste. Le Brabo s'éloigne; de Gerlache, dans le nid de corbeau, le suit longtemps des yeux.

Un tout petit rapeur ne nous a pas quittés : c'est l'Express. I son bord, se trouvent M1. Henri Cogels, son propriétaire, ainsi que MMI. Joostens et Mols.

l'cudant une heure, le yacht nous accompagne encore; puis, au moment de la séparation, ces messicurs, voulant nous donner une marque de joyeuse sympathie, nous rendent les honneurs à l'instar des navires de guerre. L'un d'eux amène le pavillon; l'autie, armé d'un fusil à répétition, tire une salve qui n'en finit plus; le troisiome souffle une stridente brabançonne dans... un cor de cliasse, tandis qu'un matelot, suspendu à la corde de la sirène, fait hurler le sifflet et qu'un timonier nous envoie les derniers adicux par un des signaux du code!

'loute cette parolie, plaisante au possible, se passe à courte distanee du Liortenaar, dont elle doit amuser l'état-major.

l'eu à peu, les coups de feu s'éloignent, on les devine cncore au jet de flamnie qui, par intervalle, scintille; la Braban onne n'est plus qu'un souffle; la patrie est loin déjà, mais la roix de la sirine nous rappelle encore nos bons et joyeux amis...

Maintenant, tout est calme à bord et semble triste. La brise s'est levée, de gros nuages noirs se montrent au suloit, l'Isscaut s'agite et la marée, qui vient de changer, est contre nous. Nous n'arançons gue lenterment. 
Pour sauver la situation ris-à-vis des Hollandais, de Gerlaelıe fait amener un canot et se rend en visite de remereiments à bord du Kortenaar. Là, il boit lentement, à petites gorgées, le verre de porto qui lui est offert; il veut nous laisser le temps de nous débrouiller.

Tain espoir : la manouve se fait avee une sage lenteur. Alors de Gerlaehe explique, au commandant du Kortenaar, nos diffieultés et le prie, étant données les critiques réeentes eoneernant le navire, de ne point parler de eet incident. Au bout de trois quarts d'heure, de Cicrlaehe revient à bord; le noend, formé dans la chaîne, venait enfin d’être défait. La machine étant aussi réparée, nous nous remettons en marehe.

Par suite de la résistanee qu'offrait l'ancre non relevée, nous gouvernions eneore avee de telles difficultés, que le Kortenaar, s'imaginant que nous prenons un mauvais ehemin, nous devanee comme pour jous indiquer la vraie route!

Oh! quel sentiment de profonde humiliation je ressentis à ce moment! Tontes les prúoccupations des derniers jours me revinrent à l'esprit. Arec éeveurement, je détournai mes regards du eompasétalon, non eompensé, non réglé, auquel le eonstrueteur avait même oublié de joindre l'aliłałle pour l'observation des relèvements.

Enfin, l'ancre fut remise à son poste, le navire reprit sa route (1).

I midi, nous établissons une partie de la voilure, mais vers I6 heures, nous n'avançons presque plus, nous avons le vent et la mer clebout. De plus, la marée a changé et le courant est contre nous. T.e Kortenaar voit notre situation; il nous offre la remorque, que nous

(I) Dans la chambre des machines, régnait lepuis toujours une certaine anarchic. A Anvers déjà, MI. Van Rysse'berghe s'était retirc, tandis que le commandant avait clù, par suite de circonstances spéciales, se priver des services de M. Somers. Deux autres mécaniciens, 1)... et P'... s’étant engagés, .I. Somers avait proposé de les mettre au courant de la machine pendant le trajet d'dnvers à Flessingue. Là, il proposa au commandant de faire cncore route avec l'expédition jusqu'à MIontevideo. 
Il est déeidé que nous passerons la nuit en rade de Flessingue, pour remettre un peu d'ordre dans notre navire.

Après un échange de signaux avec le Kortenaar, il est arrèté quc nous ne reprendrons la mer que le lendemain matin, à 8 heures, et nous mouillons devant Flessingue, tandis que le Kortenaar va se mettre à l'abri dans le port.

Pendant que l'équipage vaque à différents travaux, l'état-major tout entier, réuni au carré, reeopie un grand nombre de fois une espèce de proelamation que de Gerlaehe adresse à la Belgique.

Ce travail nous amuse énormément; ehacun de nous s'interrompant, tour à tour, pour faire quelques remarques humoristiques de cireonstanec, que de Gerlache éeoute, d'ailleurs, avee une entière bonne grâce.

Le travail terminé, le pilote emporte notre eourrier et nous allons nous reposer jusqu'au lendemain matin.

Le I 7 août, à 8 heures, le Kortenaar nous rejoint et nous levons l'anere.

A peine l'hélice est-elle en marehe, que le méeanieien nous prévient qu'il faut immédiatement stopper, attendu que le condenseur ehauffe d'une façon extraordinaire (I).

Aussitôt de Gerlaehe eommande de mouiller l'anere de tribord. Lorsque eelle-ei est à 20 mètres du bord, la ehaîne se eoinee sur le guindeau!

Le navire tangue; il reçoit même des seeousses assez violentes, ear l'anere ne touche pas le fond; il est aussi impossible de la relever que de filer plus de ehaîne. Nous tournons dans tous les sens et le navire ne gouverne presque plus (2).

(I) Pour vider l'cau de la cale, on avait fait usage de la pompe de circulation; par suite de cette manouvre, des escarbilles provenant de la cale s'ćtaient intro duites dans la pompe et l'empêchaient de fonctionner.

(2) Il ne pouvait ètre question de mouiller une seconde ancre. Les deux chaìnes se fussent probablement tournées l'une autour de l'autre, et, comme la mer se formait, notre situation eùt pu devenir critique. 
acccptons jusclu'au jusant. A I 7 h. 40, nous sommes devant le bateauphare, le Trandelaar, oi lc Kortenaar doit nous quitter.

La rcmorque est largućc, le cuirassé défile à contre-bord de la Belgica, que l'équipage hollandais acclamc pendant que l'équipage belge crie : "Vive la Hollande! »

Les deux navircs amènent leurs pavillons. La Belgica envoic lo signal "remerciments ", le Kortenarr répond "souhaits ). La Belgica dit encorc : "Mcrci ct adieu! " Puis, lcs navires s'ćloignent l'un de l'autre et, bicntôt, ne se distinguent plus.

Sur le pont de la Belgica règne un grand désordic : des caisses et des objets de toutes espèces sont là, pêle-mêle, n’ayant pas trouvé place dans la calc. de Gerlache et moi, nous sommes sur la passerelle et, chose extraordinaire, jc n'ai pas le mal de mer (1).

Racovitza cst clans son laboratoire; Danco se promène en fumant sa pipe comme un vieux loup de mer; Arctorrsli, affalé sur la dunette, est visiblement indisposé.

Je m'approche pour lui dire qu'une de scs malles encombre le pont et ne peut trouver place dans la cale, déjà pleine. Aussitôt, il

(1) J'ai beaucoup navigué : sur des cuirassés, des croiseurs, des torpilleurs, des paquebots, des frégates à voiles, et partout et sans cesse j'ai eu le mal de mer. Je l'avais même au mouillage, clans es racles mal abritées. J'ai toujours réagi autant que possible et je ne me suis jamais abstenu de faire mon service au complet. Au reste, malgré ce rude tribut payé à Neptune, je ne m'en portais pas plus mal. Chose singulière : par les très mauvais temps, le mal cessait, pour revenir plus impitoyable dès qu'une accalmie se jroduisait! Cerlains faits permettraient de supposer que ce mal provient parfois d'une suggestion. J'étais dans l'escadre active de la Méditerranée, à bord du Magenta, et je venais d'avoir le mal de mer, pendant plusieurs semaines. Je débarque, un jour, au golfe Juan, et je vais à Xice, ò̀ je prends enfin un repas... qui me reste fidèle! Le soir, en rentrant au golfe Juan, je demande une chambre dans un hôtel de la plage, j'ouvre ma fenêtre et je regarcle au loin, le Magrenta qui tangue sous une petite levée. IIes yeux, avec plaisir, suivent le cuirassé, quand tout à coup, je vois mon balcon se soulever et s'abaisser... J'étais ressaisi par le mal de mer !... J'ai constaté souvent des cas analogues chez des officiers de marine. 
m’engage à la faire jeter par-\{lessus borl. Il se soulève mème, un instant, pour voir exécuter cet arrèt, puis... retombe dans sa pénible méditation $! . .$.

Tout à eoup, le mécanicien nous annonee que le tuyau de refou-

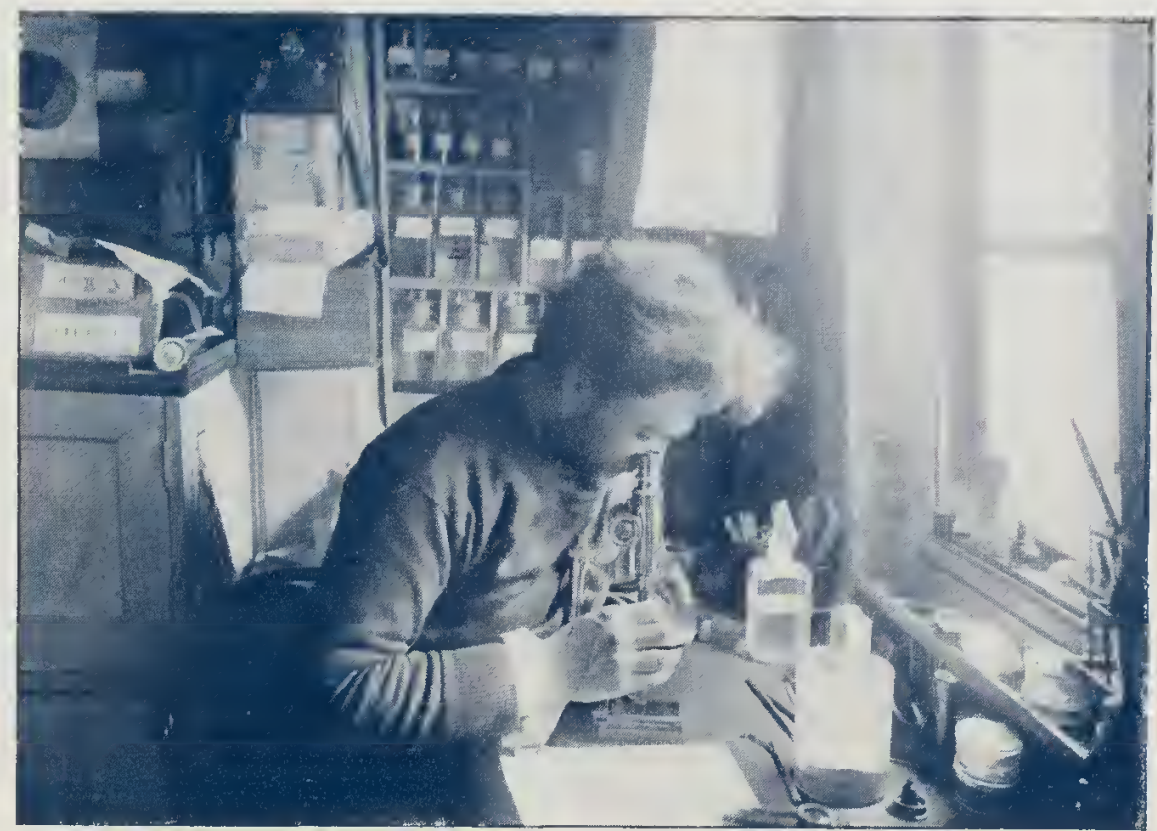

P'otograghie du 175 Cook.

I'IG. 4 .

RACOVITZA LT SON LABORATOIRE A BORג DE LA (( BELGICA )

lement de la pompe d'alimentation s'est crevé et que, malgré là réparation provisoire, il n'est pas possible de s'éloigner de Belgique dans ces eonditions.

Une seule solution se présente: faire route vers Ostende, ou la machine scra revuc complètement dans les chanticrs de l'fitat.

Cctte ligne de conduite étant adoptée, à 2 heurcs du matin, par une nuit très noire, la Belgica est mouilléc ct anarrée à Ostende, à quelques mìtres du yacht du Roi, la Clémentine.

İ̀s 4 heures du matin, mon frère, ingénieur en chef de la marine, 
est à bord avec des mécaniciens. Après une inspection minutieusc, on s'aperçoit quc la machine réclame quelques réparations urgentes, qui temanderont plusieurs jours de travail...

Lit voilà comment la Belgica se retrouve en Belgique, alors que, depuis un mois au moins, elle devrait voguer vers le Sud!

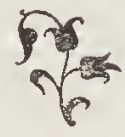




\section{CHAPITRE IV.}

A Ostende.

Oh! la bonne idée qu'a eue notre machine de se détraquer! Nous pourrons réparer maintenant, du moins en partie, les laeunes de nos premiers préparatifs.

Pendant que les méeanieiens du bord et eeux de l'Etat travaillent, que les matelots font l'arrimage du matériel et des vivres embarqués, que Raeovitza et Aretowski aménagent leur laboratoire, je m'empresse de régler le compas-étalon et fe faire łles observations astronomiques pour le calcul de la marehe des chronomctres.

La foule eherehe encore, mais en vain, à envahir le navire. Peu de personnes sont admises à bord et on les laisse visiter seules le bâtiment, aucun de nous n'ayant le loisir de leur servir de guide.

Le is aoùt, à 9 heures 1 u matin, le yacht royal est en émoi : le Roi arrive dans une heure et se rendra à bord de la Clémentine. Iussitôt la Belgica fait un brin de toilette pour se présenter avec plus d'avantages.

A ro heures précises, le Roi eireule sur rade, dans son canot à vapeur, qui ne porte aucune marque distinclive.

Nous plaçons tous nos hommes sur le pont et, au moment oì le canot passe à notre arant, l'officier de quart pousse trois fois le cri de "Vive le Roi! " répété avec élan par tout l’équipage. İn même temps, le pavillon belge deseend lentement pour saluer Ie Souverain.

Sa Majesté monte à bord de la Clémontine, puis, se plaçant au bastingage : “Où est le chef le ee bateau? » de Gerlaehe s'avance et se présente. Le Roi fait un signe et, quelques instants après, monte à notre bord.

Alors, nouveau passage à la bande de l'équipage, nouveau salut des 
couleurs, tandis qu'un immense parillon est hissé en tête du grand mât (1).

Le Roi à bord de la Belgica! IEnfin, nous allions connaître le mot de l'énigme...

Pendant toute la période préparatoire à l'expédition, Sa Majesté avait observé à notre égard la plus striete réserve, et cette ligne de conduite était, pour chacun de nous, un mystère.

Comment le Souverain qui a créé l'œurre gigantesque du Congo se désintéressait-il d'une expérition scientifique belge, soutenue par de nombreux membres de l'Académie, appuyée moralement par le Gouvernement, pour laquelle son peuple avait ouvert une souscription publique et la Chambre et le Sénat avaient roté un important crédit? Comment le Roi ne prenait-il aucun souci d'une expédition qui pouvait donner une impulsion nouvelle au projet de création d'une marine nationale?

Pourtant, la Belgica était commandée par un homme qui, depuis des années, avait donné des preures d'une énergie, d'une persérérance extraordinaires. Dans son état-major, se trouvaient également deux officiers de l'armée belge, Daneo et moi-mème, de cette ar'mée qui a été l'instrument de la grande cuvre africaine et qui, en maintes cireonstanees, a prouré qu'elle sait mourir pour faire son devoir.

J'étais, je l'aroue, profondément humilié. Comment nous expliquer cette abstention de notre Roi, alors que les souverains d'Allemagne, d'Angleterre, de Suède et Norrège, de Danemark encouragent de tout leur pouroir les expéditions scientifiques dirigées vers les régions polaires?

Mais revenons à la visite royale à bord de la Belgica.

Sa Majesté se fit montrer minutieusement nos aménagements, le laboratoire et les instruments qui se trouvaient à portée. Elle félicita

(I) Cela se passe ainsi dans les marines de guerre, quand le chef de l'Etat est à bord. 
rivement Daneo d'aroir insisté pour obtenir du ministre de lit Guerre l'autorisation de partir. Elle eut, pour ehaeun de nous, quelques mots bienveillants, saupoudrćs parfois d'une fine et spirituelle raillerie.

Au moment de nous quitter, Elle nous dit, en substanee, ees quelques mots: "Je me suis vivement intéressé à tont ee qui enneerne rotre royage scientifique, mais il est bon que le Chef de l'Etat et le Gouvernement laissent le plus de latitude possible à l'initiative privée. Le sentiment populaire est d'autant plus puissant, que l'œuvre est plus belle et que le peuple sent que e'est lui seul, tout à fait librement, qui la soutient et l'eneourage. L'abstention du Chef de l'État n'est, en réalité, qu'apparente. Le Roi s’intéressera toujours à ee qui touehe à l'avenir scientifique et à l'avenir maritime du pays. "

Ces quelques paroles nous causèrent une grande joie, un véritable soulagement! Iit dire que, sans l'aceident survenu à notre brave maehine, nous serions partis avee un doute pénible.

Rentré à son bord, le Roi fait mander de Gerlaehe, qu'il interroge sur le plan général du voyage. Quand, une demi-heure plus tard, Sa \Lajesté repasse dans son eanot à vapeur, l'ćtat-major et l'équipage de la Belgica poussent des vivats frénétiques. Longtemps eneore, nous le suivons des yeux, en songeant: ee Roi constitutionnel d'un tout petit payss s'est joué des diffieultés que lui ont eréées parfois des puissanees formidables; par sa volonté de fer, il sait vainere tous les obstaeles. Qu'il te serve d'exemple, petite Belgica! Comme lui, ne fléehis jamais, sois forte pour affronter la région glaeée et ses périls!...

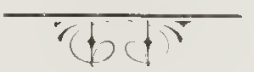




\section{CHAPITRE I.}

\section{Ennuis domestiques.}

Le 19 août, le mécanicien P... sc porte malade et repart pour Anvers. Lc maître de l'équipagc J... donne sa démission : il sc plaint de ce que, certains matclots s'absentant constamment d'unc façon illégale, tout lc travail rctombe sur les mêmes hommes, ct lc charpentier G... inyoque les mêmes motifs pour se retirer.

Le 20, deux de nos matelots se rendent à terrc, sans permission, et nc reviennont à bord que le lcndemain. L'un d'eux est pris de boisson, incapablc de tout travail.

La nuit, la brise du Sud-Ouest souffle arcc forcc; la Belgica, chassant sur son ancre, court sur le yacht royal. Un violent cffort est nécessairc pour raidir les amarres; on appclie tout le monde sur le pont. Un matelot déclare arec sérénité qu'il restc couché, attendu que, si les navires s'abordent, la Belgica étant la plus solide, c'est la Clémentine qui coulcra!

Voilà les misérables qui nous accompagnent! V'oilà l'équipage d'élite!

Ajoutons à cela que plusicurs de ces hommes ne connaissent presque rien du métier de marin.

J'avais proposé à de Gcrlache, pendant le séjour à Anvers, de faire quelques cxercices d'cnsemblc de manouvrc et de nage, dans les embarcations. Le commandant me pria aussitòt de renoncer à ce projet, attendu que les hommes, n'étant astreints, sur les bateaux de commercc, à aucune manœuvre cn dehors de lcur service, manifcsteraicnt une mauvaise volonté évidente, si nous adoptions la mesure que je préconisais pour la sécurité de tous (I).

1) Ces marins insubordonnés et dangerenx, dont je 1uarrerai plus loin quelques prouesses, furent délarqués à Punta-Arenas; mais ce qu'il y a de révoltant, cest que, jusqu'ì ce jour, ils sont demcurés impunis. 
En fin do compte, de Gerlache ramena d'Anvers deux bons matelots; M. Somers fut engagé de nouveau, ainsi que M. Van Rysselbcrghe.

Dis le I 8 aoutt, second jour de notre escalc, un nouvcau personnage fit tout à coup son apparition parmi nous. Un jeune Polonais, M. Dobrowolski, s'était présenté à bord de la Belgica avec un vêtement de rechange, un peu de linge, beaucoup d'intelligence, d'activité et de modestie! de Gierlache apprécia à sa juste valeur ce jeune garȩon, possédant une base scientifique sérieuse, qui lui permit d'être enrôlé comme météorologiste adjoint. Il refusa toute indemnité pour s'équiper, n'ayant qu'un regret, disait-il, celui de ne posséder aucune fortune qui lui permit d’aider l'expédition. Brave cour, dévoué jusqu'au sacrifice, nous aurons sourent occasion de reparler de lui.

Cependant, le temps passait : il fallait absolument partir, malgré la mauraisc brise qui soufflait avec riolence.

Le 23 aoùt 1897 , à 8 heures du soir, nous appareillons. Le temps est couvert, la nuit obscure, le rent Sud-Ouest continue à souffler. Le grand remorqueur de l'État doit nous entrainer jusqu'à l'ile de Wight.

Lorsque nous sortons du port, l'équipage royal nous salue de ses derniers " hourras », auxquels nous répondons; puis, nous longcons la jetée.

Dans la nuit, dans l'embrun, dans la houle, on ne distingue rien. Pourtant quelques roix s'élevent de la grande estacade, et même, au moment où nous la franchissons, un sanglot, un suprême adicu déchire l'air et arrive jusqu'à nous!...

Mais la mer mugit avec force, étouffant tous les bruits de la terre. Adieu! adieu à tous ceux que nous aimons! Puissions-nous les revoir tous dans deux ans! Puissions-nous aussi être tous présents à l'appel de nos familles!

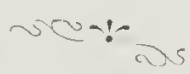




\section{CHAPITRE VI.}

\section{Dans I'Atlantique.}

Le grand remorqueur nous entraînait avec énergie, faisant bondir sur les lames notre petit baleinier. La remorque se raidissait pour nous arraeher à la vague, puis se détendait pour nous rendre notre libcrté : nous marehions ainsi de seeousse en seeousse!

Nous navions pas quitté Ostende depuis dix minutes, que je me sentais... tout anéanti! Mélaerts, qui faisait le quart avee moi, me regardait du coin de l'oeil ct paraissait me plaindre sinec̀rement.

A minuit, au moment où j'allais mo coucher, le méeanieien D... m'aborde : "Capitaine (I), nous sommes tous "impressionnés " dans la maehine, par cette mauvaisc mer! Je vois que vous souffiez égale. ment. Me permettez-rous de rous offrir ee flaeon de Néréide, qu’on dit souverain pour ee genre d'affeetion? 》 - Je le remereiai de son aimable attention et, tout en m'étendant sur mon étroite eouehette, je pensais : "Une statue à l'inventeur de la N'éréide, si le remède est efficace!..."

Lorsque, ì 4 heures du matin, je repris mon poste, j'eus soin de me munir du flacon, et́, bereé par de douces illusions et lc roulis du narire, j'attendis. ()h! pas bien longtemps! i 4 h. ro, j'ingurgitai déjà, d'après l'indieation, une gorgée do la méeieuse liqueur. Ce n'était pas désagréable: un goùt de rihum très aromatisé.

Par politesse, j'en offris à MIélaerts; mais lui, aussi à l'aise sur notre montagne russe que dans un bon fauteuil, ne roulut pas m'en priver!

A 4 h. 25, nouvelle gorgée; à 5 h. 3o, idem; et ainsi de suite

(1) Le capitaine du navire était de Gerlache, nais je portais le titre de capitaine, ayant gardé les insignes et les prérogatires de mes fonctions clans la marine de guerre française, ou les attributuns de lieutenant de vaisscau correspondent au grale de capitaine-commandant dans l’armée belge. 
jusqu'à la cinquième. Il était alors 8 heures, mon quart finissait, heu. reusement! Titubant eomme un homme irre, je me hâtai de regagner ma chambre.

Jamais, non, jamais, dans le passé, ni plus tard, je ne fus aussi malade que ce jour-1à !...

Ivec fureur et désappointement, jc lançai dans la mer eette funeste "Néréide ", qui, pareille à ses sœurs de la Fable, ne m'avait un instant assoupi que pour me mieux tourmenter. Quant à D..., il avait éprouvé les mêmes effets que moi et paraissait littéralement abruti.

Dans la Manche et le golfe de (jascogne, le voyage fut des plus pénible. Parfois, nous nous retrouvions plus au Nord que la veille, alors que nous cherchions le Sud. Cortains jours, la mer fut si mauraise, que nous dûmes filer de l'huile (I).

Enfin, le 3 septembre, bien que la brise fut eneore très forte, le temps se mit au beau. Ce fut unc joie générale à bord, où je n'étais pas le seul que Neptune perséeutât. Les plus résistants contre le mal de mer, de Gerlache, Danco et Amundsen, eommonçaient à être las de cetic gymnastique insensée et continuelle! Mélaerts seul eonservait son calme flegmatique.

Bientôt le rent tomba, la mer devint gentille, une délicieuse petite hrise se mit ì souffler du Nord-Est.

La vie se ranime à bord. Chacun raque aree plaisir à ses oeeupations, prend des notes ou même élabore un programmo d'observations polaires. Aux moments de loisir, on se recueille pour écrire aux absents...

(I) Le filage d'huile consiste à suspendre au hossoir de tribord ou hâbord (suirant que la mer vient d'un de ces côtés) des sacs renfermant de l'étoupe fortement imprégnée d'huile lourde. Cette huile sort lentement du sac, goutte à goutte, et s'étend sur la mer, qui cesse alors de briser contre le navire. Il existe des sacs spéciaux ne contenant pas d'étoupe, mais dont le fond est muni d'une lame de cuirre percée de petit trous qui donnent passage à l'huile. 
Le I s septembre, l'île Madire est en vue. Il est indispensable d'y faire escale pour remettre un peu d'ordre à bord et surtout régler ccrtains instruments, tels que les chronomètres.

A 9 heures du soir, nous mouillons en rade de Funchal, précisément à l'endroit où, trois ans auparavant, et pourr la première fois, la Melponène m'avait amené dans l'ile.

Ce n'est pas sans émotion que je foulai à nouveau le sol de l'île Madère, où, deux fois déjà, j'avais fait unc assez longue escale avec les bâtiments de la flotte française.

Une grosse déception m'y attendait : notre compatriote, le baron van Beneden, chez qui j'avais toujours trouvé un accueil des plus sympathique, était absent. Je ne fus pas plus heureux dans mes autres visites à Funchal : tout le monde était hors ville, excepté le consul de France, l'exccllent docteur Mrurao Pitta, dont je fus tout heureux de serrer la main.

J'offris à de Gerlache et aux membres de l'état-major de les présenter à nos "Petites-Sours de Saint-Tincent "!

Lit comme on souriait de ma proposition, je les entrainai vers le couvent ct leur expliquai le rôle des "Petites-Sœurs " dans la flotte française.

Lorsque des bâtiments mouillent en rade de Madère, ce sont elles qui lavent et entretiennent le linge des officiers de marine et des off-ciers mariniers; elles encore qui soignent les malades, lorsqu'on est obligé d'en débarquer. Dans l'ile, elles donnent aux enfants une instruction tout à fait satisfaisante.

Et puis, ces religieuses de Saint-Tincent sont des femmes du monde; leur conversation est d'une gaité charmante. La supćrieure, grande dame dans toute l'acception du mot, ne manque jamais l'offrir à ses visiteurs un verre de Madère, de vrai Madère!

Ce détail acheva de convaincre l'état-major et c'est arec une véritable hâte que nous franchimes la grille du parc. Accueil charmant, promenade dans la propriété, mais, hélas! le verre de Madère ne rint pas!... L'heure ne s'y prêtait point, quelle guigne! 
Mes camarades me narguaient du coin de l'œeil. Au moment du départ, la supérieure nous remit à chacun une petite médaille, qui, disait-elle, nous porterait bonheur; de Gerlache reçut, en supplément, une brochure portant les noms des bienfaiteurs de la maison.

I1 frémit d'épouvante, mais il n'y avait pas à tergiverser : il fallait s'exécuter. La Belgica faisant l'aumône ! Quelle chose extraordinaire! de Gerlache, n'écoutant que son couragre, plongea dans sa poche presque toujours à sec - et en retira deux livres sterlıng. Du coup, l'Expédition antarctique belge fut inscrite dans les fastes du couvent, car la somme donnée se traduisait, en monnaie du pays, par le chiffre fabuleux de onze mille... reis !

Notre séjour à Madire se prolongea pendant deux jours. Je troure noté, dans mon journal, pour ce laps de temps : un charmant déjeûner qui nous fut offert par MI. Carlo de Bianchi, fils du consul de Belgique à Funchal; une excursion au Grand-Curral à laquelle prirent part MIM. de Gerlache, Amundsen, Mélaerts, Danco, Arctowski, Racnvitza et Dobrowolski; une promenade à Del Monte, avec la traditionnelle descente en toboganing; enfin, un échange de visites entre la Belgica et le commandant d'une division anglaise constituée par le cuirassé Blenheim, le Madway et deux canonnières torpilleurs.

L'île Madère, qui appartient au Portugal, offre, sur l'Atlantique, un point stratégique de la plus haute importance. L'Angleterre y acquiert chaque année plus d’influence, au détriment de la F'rance. Lîle est défendue par le fort Loo; mais on la prendrait avec... un bâtiment de la flotte belge ! C'est tout dire !... Pourvu, bien entendu, que les Anglais ne syy soient pas déjà installés!

Le I4 septembre I 897 , nous appareillons et faisons route vers Riode-janeiro. Les chronomètres sont réglés; leur marche diurne moyenne a été reconnue convenable.

Une noble émulation a saisi les mécaniciens : chacun prétend con- 
duire la chauffe et la machine mieux que ses deux camarades Pour encourager leur zcle, nous organisons des essais de chauffe méthodique. Il est convenu et arrêté : que le mécanicien qui prend le quart devra nettoyer les feux; qu'il devra chauffer pendant douze heures consécutives; que les briquettes seront pesées avant d'être livrécs; que la pression sera de 70 et le nombre de tours de 65 à la minute.

A peine le concours est-il commencé, que la brise régulic̀re s'établit. A la grande joie des mécaniciens, l'hélice est remontée, la machine arrêtée, les voiles dépliées dans toute leur envergure. La Belgica avance avec une sage lenteur.

La chaleur commence à devenir un peu plus vive. L'équipage recouvre de bandelettes de toile les cuivres de la passcrelle. de Gerlache et Amundsen préparent les objets et virres qui devront être probablement débarqués à la Terre Victoria, puis ils arriment de nouveau les boîtes de conscrves.

Pendant cet aménagement, bien des denrées disparaissent comıne par enchantement. Certain matelot fait souvent la navette entre la cambuse et le poste de l'équipage, où il va ensevelir, sous son matelas, les boites qu'il a maraudées et qui seront partagées la nuit. Un matin même, le chef-mécanicien trouve toute une boule de fromage de Hollande cachée dans le charbon!

A partir du I $_{4}$ septembre, le quart se fit à courir entre les licute. nants Amundsen et Mrélaerts; je jouissais dono de quelques heures de liberté. J'en profitais pour faire des observations astronomiques. le matin, à midi et vers 4 heures ou dans la soiréc. Je déterminais le point et les éléments relatifs au compas, et, les calculs terminés, je les portais à de Gerlache, en lui proposant la route à suivre.

J'avais aussi organisé un petit cours de navigation pratique, auquel assistaient régulièrement plusicurs hommes de l'équipage.

Pendant cette longue traversée, les caractères se dessinaient, nous apprenions à nous connaître; à la sympathie suecédait l'amitié : le camarade de la veille devenait l'ami dévoué du lendemain. 
C'est Danco qui ful chargé d'abord de la direction du ménage. I la suite de je ne sais quelle circonstance, il me céda ces importantes fonctions. Mon rigne fut court : l'ćconome de Gerlache se hâta, au bout de quelques jours, de m'enlever délicatement cette besogne ingrate.

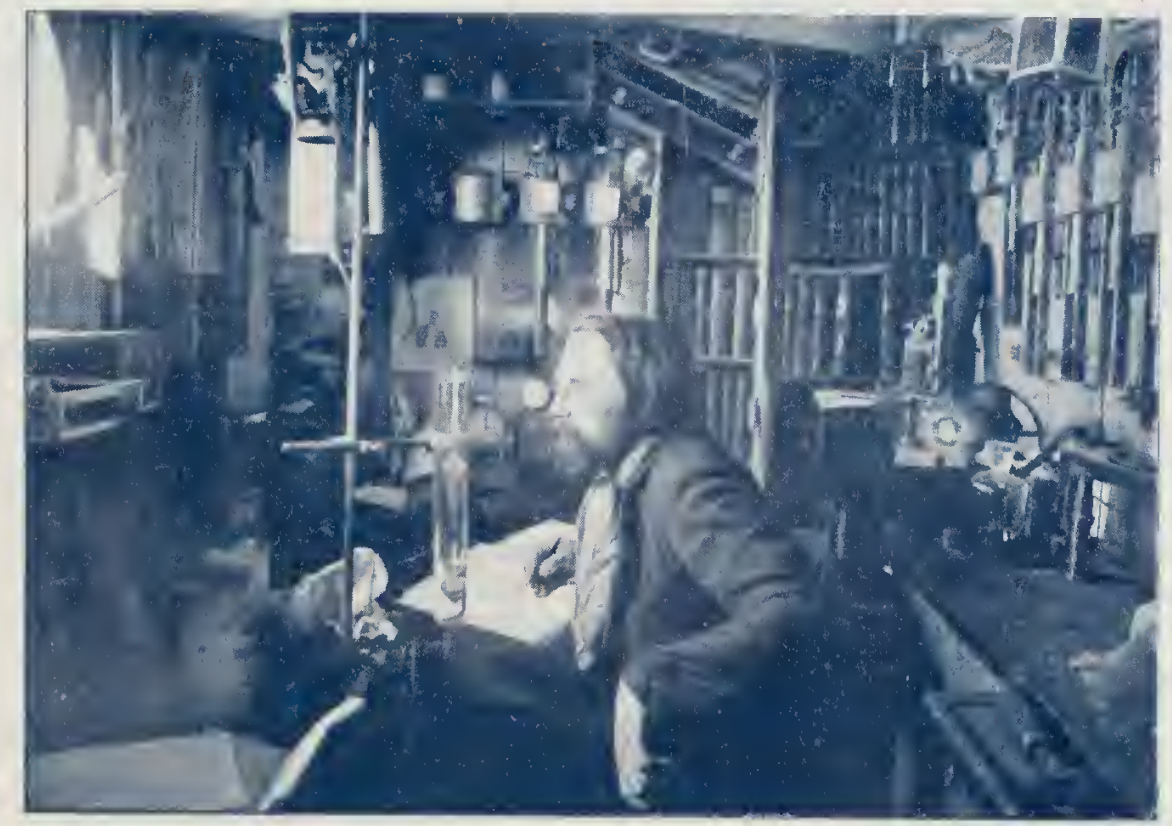

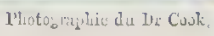

lifi. 5.

ARCTOWSKI IET SON TADORATOLRE A BORI) IIE LA ( BELGICA ).

Combien joycux paffois ces repas en commun! Arctorvski sontenait des paradoxes extraordinaires, qui faisaient bondir d'indignation notre ami Danco.

Et la préparation du cafe! Combien délicate, danģereuse mêne! Danco avait acheté, à cet effet, un appareil tellement perfectionné, qu'il faisait réguliècunent cxplosion a la fin de chaque repas. Le café Ćtait projeté en ondes bouillantes dans toutes les directions, et le sauve-qui-peut général, les rires, le désarroi avaient du moins l'heu1eux résultat de faire oublier à quelques-uns d'entre nous, qui n'ai- 
maient pas les conserves norrégiennes, que leur estomac criait famine!

Le 6 octobre, nous franchissons l'Équateur. L'équipage obtient le service du dimanche et organise un "baptême " en régle pour tous ccus qui n'ont pas encorc "passé la ligne ».

T) c temps à autre, nous rencontrons un navire. C'est d'abord le quatre-mâts français Antoinette, avec qui nous échangeons des marques de vive sympathic; puis, un grand voilier espagnol, à peu près lège, qui semble avoir perdu ses chronomctres! Il croit être à $27^{\circ}$ longitucle ouest de Greenwich, alors que nous sommes en réalité à $33^{\circ}$.

Le I 3 octobre, j'eus une forte déception: nous franchissions 1'Équateur magnétique, toutes mes dispositions avaient été prises pour compenser définitivement le compas-étalon et l'état de la mer ne me permit pas d'effectuer ce travail.

Le 20 octobre, à 6 heures du matin, nous apercerons la terre; lc 22, nous entrons dans la rade de Rio-de-Janeiro. C'est là que Cook doit nous rejoindre.

Un petit vapeur battant pavillon belge vient à notre rencontre, puis navigue de conserve avec nous. Du bord, on nous fait force signe d'amitié, et nous en augurons que Cook doit ĉtre dans ce groupe d'amis.

Immédiatement, nous examinons tous les passagers, afin de deviner lequcl est Cook. - C'est ce petit gros, à l'air enthousiaste! — I u tout, e'est ce long maigre! - Ne serait-ce pas cet homme à barbe grise ct inculte? - Ou plutôt ce jeune homme plein d'attentions pour la vicille dame qui se tient à ses côtés, sa mère sans doute?...

Et tandis que nous devisions ainsi, Coolr se trouvait à Pétropolis, où, depuis plusicurs jours déjà, il était l'hôte de notre ministre, le comte van den Steen de Jehay.

Dès que les formalités de la douane ct celles du scrvice de santé sont aceomplies, le petit vapeur nous accoste.

Voici M. Laureys, consul de Belgique, accompagné de M. Dart, 
notre compatriote, représentant de la maison Pécher d'Anvers, et de M. Cruls, autrefois officier l'artillerie dans l'arméc belge, actuellement directeur de l'Observatoire de Rio-de-Janeiro. Ils nous souhaitent, tous les trois, la bienvenue au nom du ministre de lielgique, le eomte van den Steen de Jehay, qui viendra lui-même nous rendro visite le lendemain.

Tos huit jours d'escale à Rio-de-Janeiro s'écoulìrent d'une façon chamante, gràce aux fètes slonnés en notre honneur par la colonie belge.

Impossible d'ailleurs de conecroir une hospitalité plus aimable, plus généreuse que celle qui uous fut offerte au Brésil. Les autorités civiles et militaires rivaliscrent, pour nous, de clélicates attentions: la douane nous permit, sans difficultés, de lébarejuer les instruments que nous devions comparer ou étudier à l'observatoire de Rio; l'amiral directeur de l'arsenal de suere fit exécuter plusicurs petites réparations à notre matériel; lá presse tout entière publia d’éloşieux articles à notre sujet; enfin, le président de la répulsliçue et le ministre des Affities étrangères nous reçurent eli audience spéciale.

L’écuipage de la Biclgica fut également bien accucilli par les lirésiliens; aucun de nos marins n'auráit eu à se pláindre si, une nuit, en rentrant à bord, Tollefsen n’avait été complètement dévalisé par... la police alc Rio!

Le 25 octobre, la colonie lolge nous offit un superbe banquet. Il était présiclé par le ministre de Belgique; les représentants de tous les journaux de Rio y assistaient.

Le ministre fit le discours officiel, puis les toasts se succédient sans interruption. Pas un scul convive qui n'y allat d'un petit discours au moins, on français, en italien ou en portugais, discours exubérants, où les grestes énergicpues soulignaient les paroles. A la fin d'un joyeux festin, un mot sonore suffit pour enthousiasmer.

" L'Anćrique, sécriait José de P’atrocinio, a engrendié les lítats- 
Unis; l'Europe a enfanté la Belgique! " Et dos bravos frénétiques éclataient.

Il était intćressant, pcndant toute cette fêtc, de suivre l'attitude du docteur Cook, qui, ne parlant que l'anglais, ne comprenait pas un traître mot à toutes ccs allocutions. S'il entendait le nom "Léopold II ", il criait: "Vive le Roi! " et si le nom "Moréas " frappait son oreille, il s'cxclamait de plus belle : "Tive la République! "

Lc 28 octobre, l'Institut historique ct géographique du Brésil nous reçut cn séance solennelle. Pour la circonstance, la plus haute assemblée scientifique du pays avait confié à son "orateur officiel " le soin de nous souhaiter la bienvenuc.

Jo ne puis résistcr au désir de reproduirc ici ce discours, in extenso. Ccpendant, pour bicn jugcr de l'effet qu'ont produit ces paroles, ainsi que de la couleur, de l'animation de toutc cette scène, il faut se représenter le milieu où ellcs furent prononcécs :

\section{" Messieurs,}

") Voilà que vient de jetcr l'ancre dans les caux du Guanabara la Belgica, qui porte à son bord des marins hardis qui ront śavcnturer sur dos mers inconnues. Les voilà, derant vous, ces fils de l'Océan, qui s'arrêtcnt ici un moment à pcine, pour partir vers le pôle antarctique! Un si grand événemcnt ne pourait pas nous être indifférent, et il nous était impossible de laisser passer devant nous. sans la solennelle consécration de notre hommagc, ceux qui s'en vont ainsi par le chemin qui mènc à la gloire.

"Salut, Argonautes témćraircs, vous qui allez à la conquêtc d'un nouveau monde! Que les mers vous soicnt propiccs; qu'clles ouvrent devant la prouc de votre vaisscau la route sans traces, naguère cncorc vicrge de l'assaut des quilles tranchantes!

1) Que les souffles de l'océan viennent baiser les voilcs qui bravent les tempêtes; que les brises chantent, dans les cordages des 
mâts, les strophes des hymmes que la civilisation anvoic rers les confins du monde; que le drapeau qui, plein de regret s'éloigne de la patric, tremble toujours sur des ners tranquilles, en offrant un calme éternel à eeux qui s'en vont du monde s'égarer dans l'immensité sans bornes de l’inconnu!

) Allez, nouveaux Colombs, allez trainer vos ancres sur les salles des mers antaretiques; allez, par la careasse de votre machine flottante, terrifier les monstrueux corps des cétacés de ees plages; allez faire s'envoler de peur les essaims d'oiseaux, qui réveilleront les ćchos de ces mortes contrées, en voyant se lever à l'horizon toujours virle l'envergure des ailes immenses de ce monstre ailé qui vous améne d'un monde quils ne rêvaicnt pas.

"Allez, intrépides marins, allez faire voir au pòle le roi te la création!

" Plongé dans les ténchbes, cnveloppe dans les glaces éternelles, cn recevant à peine de temps en tcmps un fugitif baiser des oblicpues rajons clu soleil mourant, le pôte n'a pas cneore contemple l'homune, n'en a pas eneore senti le poids, n'en a pas encore subi le pouvoir dominateur; if éprouve seulement dans les trépidations de l’axe, qui y tomme, élemellement, l'agitation de la vie qui panllule bouillonnante à l'Équateur de la spllère. Rampent sur sa surface glacéc, coupent son atmosphère brumeuse, nagrent lans ses eaux froides, les tristes représentants suprêmes des époques, il y a déjà longtemps disparues clans les abîmes du passé. Monde des phoques et des ours blaues, pâfurage đles rennes, lantérè à peine des oiscaux de la mer et des géantes bakeines, les contrérs des pôles ne connaissent pas encore le type supérieur de l'animalité, ee demi-dieu conquérant et invineible que l'évolution de la vie a fait cnfin sortiu de la chrysalicle animale, couvéc par les sićcles!

"Allez, et retounez vainqueums. (c ne sont plus les chants des sirènes qui vous séduiront; ce n'est plus la trompette des lritons qui vous sommera de ne pas aller plus loin; ee n'ost plus le trident de Neptune qui fera noyer vos vaisscaux; ce n'est plus le géant 
Adamastor qui vous barrera le chemin par une rebutante menace d'anéantissement. Non, les mers se sont dépeuplées de ces monstres rêvés par l'imagination de l'homme, effrayéc devant l'immensité; mais voilà que restent, comme des barrières infranehissables, pour veiller sur la blanche virginité du pôle, la rigueur invincible de l'hiver, la lame tranchante du froid glacial, les déserts et les -montagnes de glace, les banquises, les avalanches et les tempêtes de ncige, bien plus affreuses que le brûlant simoun des sablières du Sahara, soufflant impétueux au-dessus d'un monde sépulcral!

"Allez et revenez vainqueurs de ees mille obstacles, en rapportant au monde l'esquuisse du paysage de ces mortes contrées, pour offrir l'image de ce qu'il deviendra plus tard, lorsque le cours des siècles aura glacé toute la planète.

1) Maintenant vous voilà arrivés à la balise méridionale qui marque chaque année les bornes du parcours des radiations du soleil vers le Sud.

1) Ici, c'est le solstice de l'astre-roi ; ici finit la zone torride, cette chaudière immense où vient se ehauffer la veine fluide du gulfstrean qui va lécher de sa chaude lymphe les rebords des plages polaires. Ci-gît endormi, eomme un gardien invincible, le géant de pierre dont le profil tranchant, fixant le ciel étoilé, pointe au soleil qui s'avance le cancer du zodiaque qui le fera revenir sur ses pas.

"Nais ne craignez point ; si le soleil est contraint de s'arrêter ici, vous autres, vous pouvez passer. Vaincu par l'homme, qui franchit les frontières qu'il devait garder, le géant reçut le châtiment de sa faute, et au dire du poète, la foudre en passant l'a foudroyé : l'aurore qui se lìve ne le réveillera point!

") Le gardien des frontières méridionales de l'Afrique a été métamorphosé en dur roeher, noire falaise en laquelle s'est changé le monstre Adanastor de la légende. Le géant qui avait sous sa garde 1e pays brésilicn, lui aussi, a été changé en bloc de granit; et dans le sommeil éternel de la mort, veillé par la croix du Sud, il a laissé Cabral franchir le seuil qu'il guettait et venir élever ici, dans la 
contrée qu'il gardait, un entrepot de la civilisation envahissante.

" Mais, Messieurs, pourquoi l'homme veut-il encore aller au delà rle ces bornes lointaines qu'il réussit à conquérir? Qu'est-ce qu'il cherehe dans ces explorations polaires? Pourquoi s'égare-t-il dans ees contrées inhospitalicres, d'ok la vie elle-mème semble fuir et sur lesquelles le silence regne seul?

"C'est l'avidité de savoir ; c’est la déenuverte de la terre, il y a tant de siccles commencéc, qu'il cherche; c'est l'émiettement qu'il lui faut faire de toutes les pices rle ce vaisseau fantastique sur lequel neus sommes tous emportés, à lavers l'espace, dans le tourbillon des mondes, rers l'infini, par des routes sans bornes, par des sicleles sans fin!

"Si le pôle Norl a été l'objectif de nombreuses entreprises de conquète, au entraire son antiporle a élé bien moins exploré. Par cela mème, il offre plus cle mystères, il cnferme plus de sćductions et il attire plus fort la curiosité de l'homme, toujours insatiable et investigateur. Les noms de La Roche, Bouvet, Kerguelen, Marion ct Crozet se trouvaient déjà inserits parmi ceux des aventuriers de ces mers, lorsque, vers la fin du siccle dernier, lo célébre capitaine Cooli s'arança liardiment vers le pôle; mais ce voyage, loin d'ètre plein d'esponir en l'avenir, au enntraire plongea tous les marins dans le découragement, car les daugers que l'on eourait - dit-il clans sa relation - en voulant explorer ces mers terribles sont tels, que personne, je pense, n'osera s'aventurer plus loin et que les terres situées

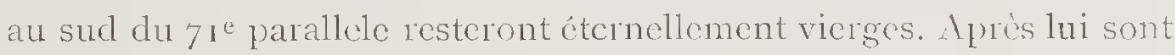
venues les vaines enquêtes de liellingausen et les hardies explorations de Weddel et Brisbane, conduisant le fane et le Beaufort vers le $74^{\mathrm{e}}$ parallele où personne n'était encore arrivé, cn ouvrant le ehemin par lequel bientôt Dumont d'Urville cinglait, portant l'Astrolabe et la Zélée jusqu'au bout franchissable de l'Océan polaire. ('e voyage remarquable, une des plus belles pages de l'histoire maritime, outre les terres nouvelles dont cette expédition enriehit la géographie, recueillit une abondante moisson d'observations seicntifiques et 
fut l'arant-courrier des trois célébres expéditions de James Ross, qui deseendit jusqu'au $78^{e}$ degré de latitude, réalisant ainsi encore plus largement ce que le capitaine Cook tenait pour impossible.

" Mais au delà? Quels secrets garde encore cet éternel suaire de glaces éternelles? Y a-t-il, vraiment, au pôle antarctique, un continent, comme on a supposé ? Dumont d'Urville ne le croit pas et James Ross non plus; mais voici les nouveaux éclaireurs qui vont poursuivre leurs traces, et plût à Dieu que, plus heureux que leurs prédécesseurs, ils puissent descendre encore plus loin, pour lever le drapeau de leur patrie au delà du pavillon français et de celui de l'Angleterre, en donnant aux contrées antarctiques, ou peut-être à ce continent inconnu, leurs noms glorifićs!

1) Mais, dira-t-on, à quoi bon tant de peine? Quel avantage portera à l'humanité le terrible combat contre tant d'obstacles ? S'il n'y a pas d'avantages matériels, les sciences en profiteront beaucoup; et, d'ailleurs, tout s'évanouit derant la volonté dominatrice dc l'homme, qui rencontre des raisons suffisantes, pour ces luttes, dans l'indomptable impulsion de marcher résolu vers tout ce qu'il ignore. Ces voyages sont des écoles d'héroïsme. Dans les paroles de Charies Martin, ces héros de la paix ćlèvent le niveau intellectuel et moral d'une nation. Nul sentiment de regret ou de tristesse ne doit troubler les élans d'admiration et de respect qu'ils inspirent. Leur gloire est pure du sang et des douleurs de leurs semblables, et le génie de l'humanité n'a pas à génir sur des triomphes dont la science ct la morale recueilleront tous les fruits. Ce qui attire l'homme vers les hautes régions, dit encore Tschudi, c'est le sentiment de la puissance immense qui brille en lui et qui maintient son énergie devant les obstacles parfois terribles que la nature lui suscite; c'est la satisfaction de triompher, par l'effort persévérant d'une volonté intelligente, de l'àpre opposition de la matière; c'est l'ardent amour de l'éternelle scienee, le saint désir de découvrir les lois mystérieuses qui président à la vie universelle. C'est peut-être aussi la noble ambition du seigneur de la terre qui, par un aete libre et hardi, veut grarer en sa 
conscience, sur la dernière cime conquise et devant l'immensité du monde qu'il contemple, le sceau de sá parenté avec l'infini !

") Allez, voyageurs! Dans ses rêves fantastiques, l'maginatif Jules Verne a posé sur le pôle Nord le fameux Hatteras; et dans le Vautilus sous-marin, il a fait arriver jusqu'au $90^{\circ}$ degré de latitude: méridionale le capitaine Nemo, pour planter sur le pôle antarctique son pavillon or et noir. Eh bien! Messieurs, les progrès de la science ont déjà réalisé le fantastique Nautilus et aujourdhui les vaisseaux sous-marins ne sont plus des visions chimériques de l'imagination fantaisiste. Complétez maintenant la réalisation de la prophétie: allez arracher du pôle Sud ce pavillon noir d'une patrie qui n'existe pas et faites rester à sa place le drapeau d'un peuple qui vit à la lumière méridienne; effacez dans ce poste de conquête le nom du capitaine Nemo, qui signifie Persome, et faites-y graver à sa place celui d'Adrien de Gerlache!

\section{"I) Alffredo Nascimento."}

Cette éloquence imagée semblerait emphatique, peut-être même ridicule, dans nos contrées du Nord. Là-bas, sous ce soleil ardent qui électrise les cœurs, elle n'est que l'expression réelle de sentiments intenses. Pour moi, dis les premiers mots, mon Télémaque me revint en mémoire. Je m'imaginai entendre Mentor, dans le langage fleuri cher à l'ancicnne Grèce, exhorter le jeune Télémaque à traverser tous les dangers, à braver tous les périls dans l'espoir de retrouver enfin son père Ulysse.

Ce discours du I) Nascimento m'avait profondément ému par son éloquence! Cependant, lorsque l'orateur s'était écrié : "Monde des phoques et des ours blancs, pâturage des remnes, etc., " j'étais devenu inquiet, me rappelant ma promesse " des vingt peaux du premier ours que je tuerais dans l'Antarctique ».

Mais bientôt j'avais relevé la tête avec courage, convaincu du succès, car l'orateur officiel, faisant allusion à notre passage du tropique diu Capricorne, venait de révéler toute notre puissance : "Mais 
ne craignez point; si le soleil est contraint de s'arrêter ici, vous autres, vous pouvez passer. "

Plusieurs discours, en portugais, tous aussi riches en expressions et en documents scientifiques, suivirent. Enfin de Gerlache prit la parolc et termina son allocution en ces termes: "Eh bicn! Messicurs, je désire consacrer le souvenir de notre séjour ici et, plus spécialement, celui de cette séance, en hissant le 28 octobre prochain, en même temps que le pavillon belgc, celui de votre belle patrie. Ce jour-là, plus que les autres encore, nous songerons à vous tous et nous formerons des voux ardents pour la prospérité de votre Institut, pour la grandeur et la gloire des Ŕtats-Unis du Brésil. "

Lc lendemain, 29 octobre, l'ère des fètes étant passéc, on se remet au travail. On procède à l'embarquement du matéricl du doctcur: Cest tout un magasin! In homme pratique, Cook emporte tout ce qui peut lui être utile et... même davantage. Il a deux traineaux, des slis, des raquettes, des fourrures, sans compter une importante, une sérieusc pharmacic, composéc spécialcment pour les régions polaires. Nous voyons arriver successivement quinze coffres, et des boites, et des paquets à n'cn pas finir.

Pendant toutc la durée de notre séjour à Rio, Danco passa de longues heures à l'Observatoire, où $\mathrm{M}$. Cruls lui fit un excellent accueil. Le savant astronome m’aida également pour mes observations concernant lc réglage des chronomitres et le calcul de la forcc directrice de notre compas-étalon.

Au début, l'équipage s'était comporté relativement bien. Ira coquc extéricure du navire avait été repeinte, le postc aménagé, et l'on avait embarqué les approvisionnements que nous avait gracieusement offerts la colonic belge de Rio.

Bientòt cependant des faits regrettables se produisirent. Le cuisinier L... entra en lutte ouverte arec tout l'équipage, qu'il insultait constamment. 
Lc 27 octobre, au moment où je rentre à bord, après la visite officiclle au ministre des Affaires étrangères, le licutenant Amundsen me prévient que le mécanicien D... est pris de boisson, qu'il a été peu respectueux, à plusieurs reprises, en s'adressant à un vice-amiral brésilien, cn visite officielle à bord de la Belgica.

Je fais appeler D... pour lui reprocher sa conduite, mais il se fàche, élève la voix et refuse de sortir, lorsque je le renvoic au poste. 11 insulte le lieutenant Amundsen, lui reprochant grossicrement sa nationalité norvégienne. 11 cherche mème à s'emparer des deux revolvers accrochés au râtelier d'armes. Cette scène se passe publiquement, devant de nombreux étrangers.

En attendant le rctour du commandant, j'interdis tout travail à D ...

Deux jours après, lorsque de Gerlache rentre de Pétropolis, D... est désespérć : il pleure, il supplic le commandant de le conserver à bord. L'équipagc et Amundsen lui-même intercìdent pour le coupable. En présence de ce ropentir et de la démarche du personnel, de Gerlache consent à oublicr ce qui s’est passé.

Le 30 octobre, dès l'aube, nous nous apprêtons à quitter Riode-Janciro. Tous nos instruments sont ramenés à bord, ainsi qu'une certaine quantité de vivres frais.

A midi, commence le défilć des visites.

Le ministre et lc consul de Belgique, don Rego Barros iI), MM. Courty, Mertens, Monet, Ponthas, Pécher, Dard; M. Pieard, IIme Picard, fille de l'éminent directeur de l'Observatoire de Paris, M. et M[le Cruls, sont à bord de la Belgica.

Successivement, le président de la République, le ministre des Affaires étrangères et le ministre de la Narine nous envoient leurs souliaits, par des missions spéciales.

(I) Don Rego Barros ent l'aimable attention, lors de nutre départ, de me faire présent d'un coffret contenant la collection complète de tous les remèdes insentés at Brésil... contre le mal de mer! 
A 2 heures préeises, l'ancre cst levée et nous passons lcntement au milieu des navircs de guerre, qui tous, indistinetcment, anglais, allemands, américains, abaissent les premiers leur pavillon devant la petite Belgica. C'est la force s'inclinant sans honte devant la faiblesse qui cherche à accomplir une aetion d'éclat !

Nous stoppons au fort de Santa Cruz, où un petit vapeur doit reprendre nos passagers. Le ministre de Belgique nous fait ses adieux. Puisse-t-il avoir compris combien nous avons été touchés de sa bonté, de sa délicatesse, de son amabilité de tous les instants! I.a Belgique a le droit d'êtrc fière de son représentant à Rio-de-Janeiro. Nous arons d'ailleurs pu constater, par nous-mêmes, la respcetueuse sympathie dont il est, là-bas, entouré, ainsi que la confiance que nos compatriotes lui témoignent.

Comme je pensais à toutes ces choses, le petit vapeur emportait nos amis. Et je vis, au loin, le ministre de Belgique, monté sur le gaillard d'arric̀re, où flottaient nos coulcur's nationales. J'une main, it s'appuyait à la hampe du drapcau belge, qui, par moments, l'enveloppait de ses plis; de l'autre, il nous faisait eneore des signes d'adieu $! . .$.

Et la Belgica prit la pleine mer, roulant et tanguant sous la houle du Sud.

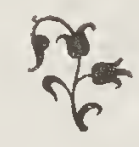




\section{CHAPTKL VII. \\ Dans l'Atlantique (suiti).}

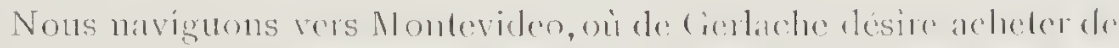

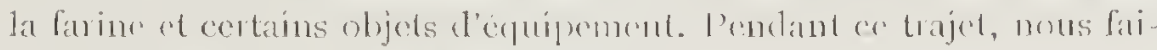
soms plus ample commatissanee arver cook.

Le doetenr est joune, frente ans all plus; la physionomie est

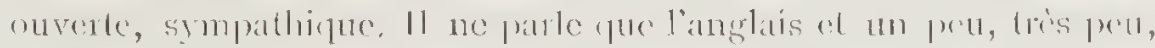

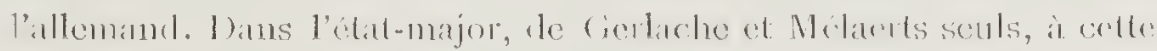
ipopue, pataiont eomamment l'anglais. Nos comversalinns aver

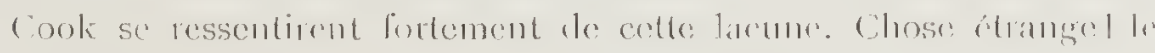

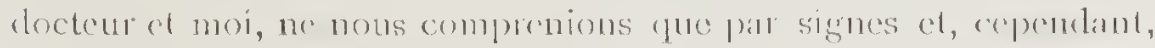

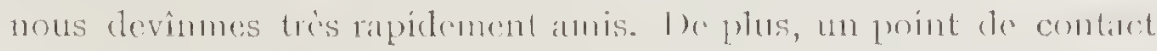
nous rapptocha cucore: Cook souffatid atussi du mal de mer! Nous

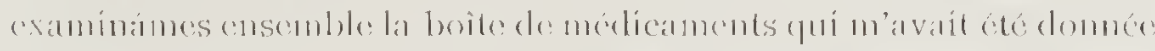

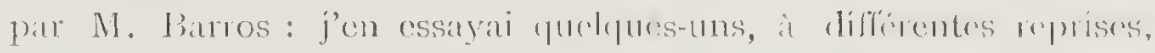

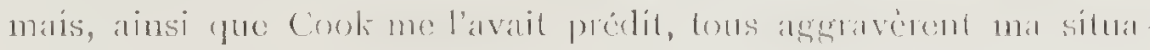
tion,

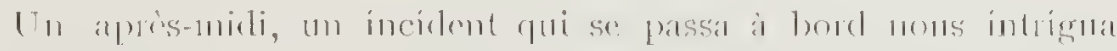
bxatco()11]).

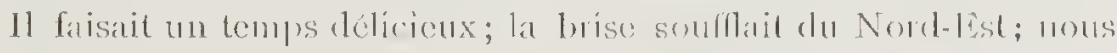

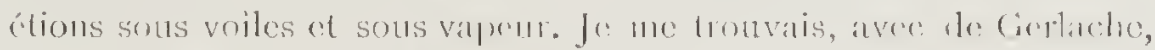
sur la passerelle, lenspue M. Somers vint nous anmoneer quôl serait

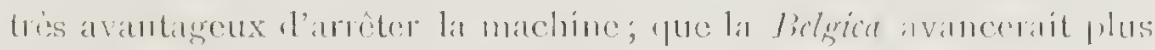
rapjodement sous l'impulsion senle des voiles, altendu que l’helice, qui

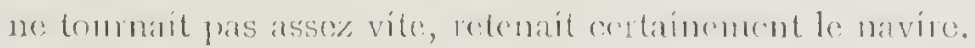

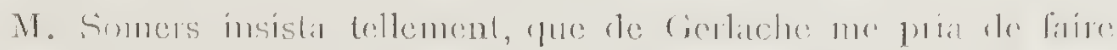

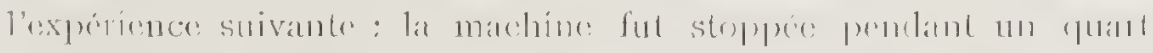

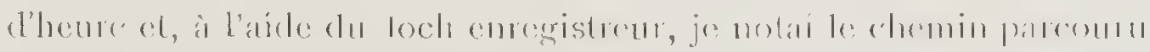

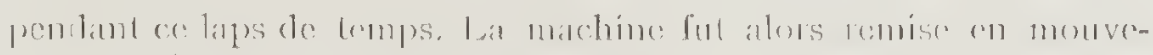
ment el, a mon complet shatissement, je comstatai, an effer, mo 
vitesse bien inférieure dans la marche du navire! de Gerlache ayant reconnu que la preuve était concluante, la machine fut arrètée, tandis que M. Somers put gouter, cemme les autres, des doucenrs du farniente. Je dois avoucr que cette expérience me laissa tout rêvenr!... Comme M. Somers est et a toujours été un travailleur acharné, je ne pense pas lui faire tort en arouant que j'éprouvaj, malgré moi, la conviction intime qu'il avait, ce jour-là, fait marcher la machine en arrière!... En effet, jamais, dans la suite, mème dans des circonstances analogues, nous ne retrouvâmes un résultat semblable. Je veux bien admettre cependant, pour résoudic cette énigme, que ce soit moi qui ai mal lu le loch!

Jusqu'au 8 norembre, la brise fut bonne, mais à minuit le rent se leva du Sud et augmenta sans cesse.

Le 9 , à 8 heures du matin, nous sommes à la hauteur de la IBaic de Castillo, que nous ne parrenons pas à clnubler, malgré roiles et vapeur. de Gerlache décide alors de mouiller dans la baie, à l'abri de la mer. A I heure, nous laissons tomber l'ancre de tribord. I.e soir, vers 7 heures, le pampero derient tris violent: nous filons plus de chaîne et restons sous pression.

Le lendemain, profitant d'une accalmie, l'état-major se rencl au phare, dont les gardiens se montrent le plus accucillants.

Le ro norembre, à 5 heures du matin, nous reprenons le mer. Le lendemain, à 6 heures du soir, nous mouillons deux ancres dans la rade de Montevideo.

A 7 h. I'2, nouveau pampero. Au Sud-Ouest, le ciel est d'un rouge intense, donnant l'illusion d'un raste incendic. Au-dessus, au zénith, des nuages gris le plomb apparaissent menaçants. Tout à coup, le rent force et une grêle à grains énormes s'abat sur la mer. Elle dure quelques minutes seulement et est suivie d'une pluie torrentielle; le vent persiste avec violence jusqu'à minuit, puis tout rentre dans le calme.

Le lendemain, je descends à terre, ou je tois retrourer de Gerlache. 


$$
\Delta
$$





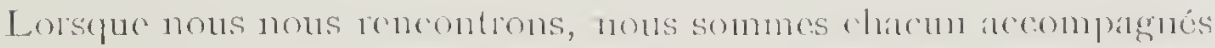

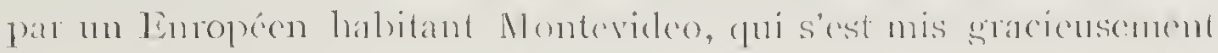
à 110 tre disposition.

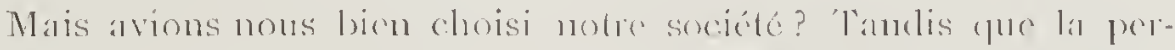

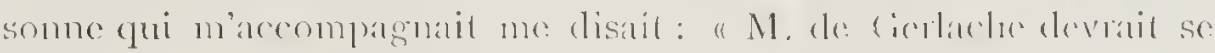

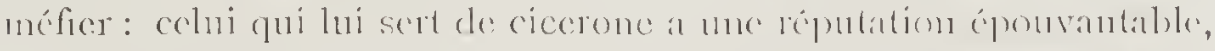

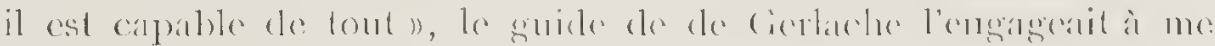

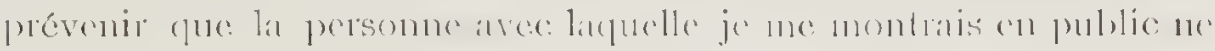
jouissatit d'aucune consideration.

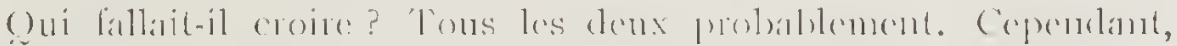

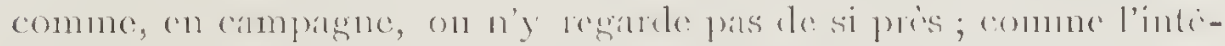

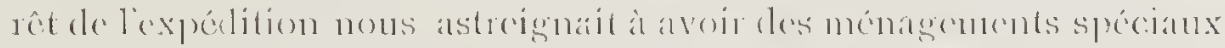

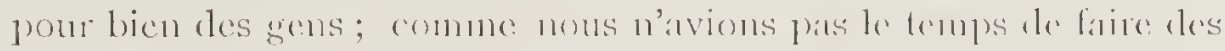

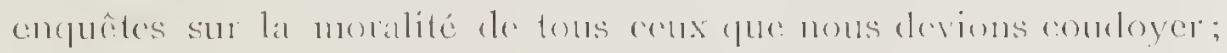

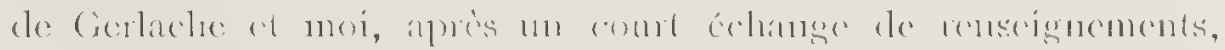

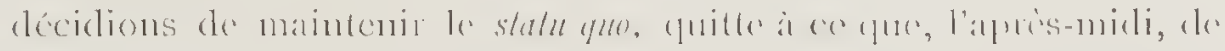

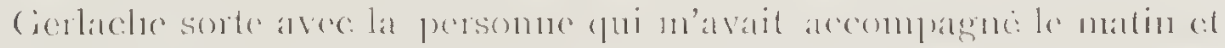

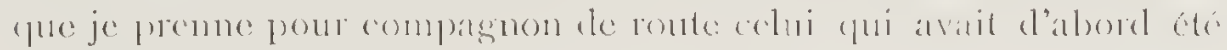

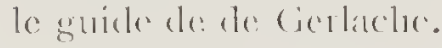

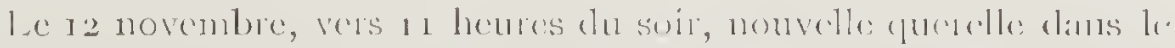

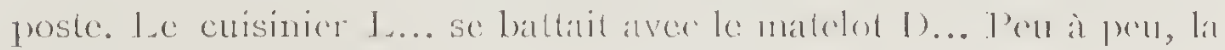
dispute devint générale.

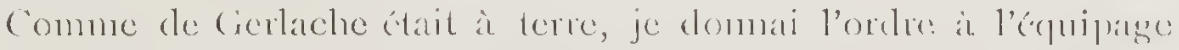
d'oloserver le silence le plus absolu et j’ajoulati qua le: lemelemain matiu, j’ouvriratis unr onquêtr.

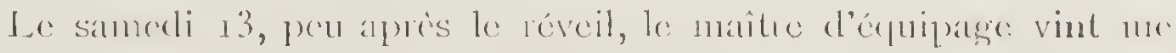

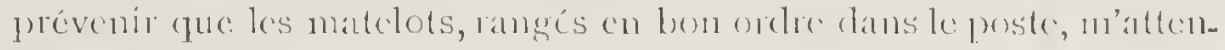
daicint.

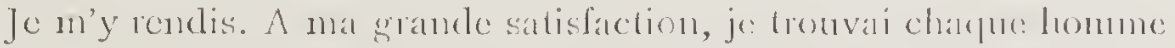

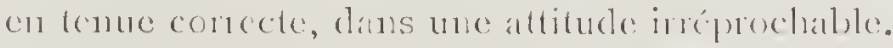

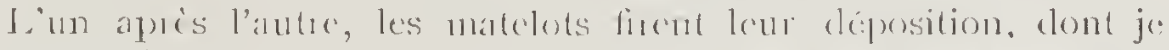
dérluisis les falits suivants : I la bataille avatit été amence par les 
provoeations du euisinier L...; $2^{\circ}$ ee dernier insultait et injuriait journellement le personnel du poste; 30 il eritiquait, en termes grossiers, les aetes du commandant et de l'état-major; $4^{\circ}$ il avait déelaré que, tôt ou tard, il se vengerait de l'expédition, dont le chef l'arait empêehé, prétendait-il, de devenir cuisinier du Roi!...

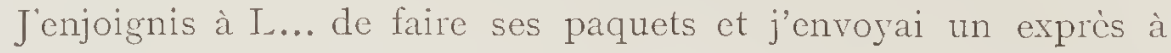
de Gerlaehe pour demander son renvoi.

Le commandant se mit aussitôt en eampagne. Nais où trouver, dans cette région torride, un euisinier qui eonsentìt à s'embarquer immédiatement pour une région glacié? de Gerlache ne put que s'adresser à un "marchand d'hommes " (I).

Il embarqua ainsi le Suédois Rose... en qualité de euisinier; puis, il aeeorda le passage, jusqu'a Punta-Arenas, à un autre Suédois, Rosb..., qui s'engageait, en éehange, à travailler à bord.

Notre séjour à Montevideo fut eourt. A noter, eependant, un superbe festin qui nous fut offert par notre aimable eompatriote, M. Huysman, ainsi que notre visite aux immenses installations de $\mathrm{MI} \ldots$

M... nous avoua qu'il avait éprouvé, à cause de nous, une eertaine désillusion: on lui avait signalé notre arrivée intempestive dans la baie de Castillo, et, aussitôt, eroyant à la bonne aubaine d'un navire

(1) Pour compléter un équipage, dans certains pays, on s'adresse à un « marchand d'hommes ». Le marchand d'hommes est un rôdeur de quais, qui encourage les matelots à déserter en leur faisant entrevoir des embarquements plus avantageux. Il leur avance de l'argent, les entraîne clans de mauvais lieux, puis les héberge... en leur faisant signer des reçus. Au bout de quelque temps, le marin endetté signe un engagement pour se libérer. Le marin ainsi engagé reçoit "comme arances » un chèque payable après le dépurt du navire. Le marchand d'hommes rachète de suite, à vil prix, ce chèque, dont personne d'autre ne veut, lans la crainte que 1 homme ne s'embarque pas Le marchand d'hommes prélève, en outre, une retenue égale à ses débours et fournit ì sa victime un équipement déplorable pour un prix énorme. Le jour du départ, le marchand d'hommes enivre le marin et le conduit lui-mème à bord. I'uis le navire prend le large, entrainant le malheureux à l'autre bout du monde. 
désemparć, il avait tait chauffer un de ses remorqueurs. M... a, en effet, la spécialité de renflouer les bâtiments échoués et a même gagné une fortune très considérable à ce métier, fortune qu'il ne demandait pas mieux que d'accroître encore, fût-ce même de l'épave de la Belgica!

Le dimanche, I4 novembre, à peine avons-nous repris la mer, que le nouveau cuisinier tombe séricusement malade. Un des novices, Van Mirlo, se présente pour remplir ses fonctions; il est agréć par de Gerlache. Cependant, la bonne volonté ne suffit pas : deux jours plus tard, Van Mirlo fut remplacé par V... D..., qui, jusqu'alors, avait été... voilier!

Du I 5 au 26, la vie s'ćcoule calme; l'équipage prépare la mâture pour les mauvais jours.

Le 26 , la brise fraichit, augmente, devient tempêtc, puis ouragan.

Le navire, mis à la cape, sc comporte admirablement par unc mer démontée. Nous sommes tous fiers de notre Belgica! Nous avons confiance dans l'avenir : nous comprcnons que sa solidité est à l'abri de toute épreuve.

Le 27, nous reprenons la route du détroit de Magellan, dont la tempête nous avait écartés.

Le 28, un tube de la chaudière crève. On le répare d'une façon provisoire; mais, ce moyen ćtant inefficace, les feux sont étcints. Afin de perdre le moins de temps possible, M. Somers, dont le réel dévouement mérite à cette occasion nos sincères éloges, s'introduit dans les foyers encorc brûlants et, au risque de s'asphyxier, cffectue la réparation.

Le 29 novembre, nous doublons le cap des Vicrges ct nous cntrons dans le détroit de Magellan.

En dépit de ce qu'impriment les instructions nautiques, la traversée du détroit de Magellan ne présente aucune difficulté. Actuellement, les vapeurs allemands et anglais y naviguent même en pleine nuit. 
Toutefois, il est évident que les navires qui ont de petites machines comme la nôtre doivent user de certaines précautions, afin de ne pas se laisser entraîner, sur les bancs de roche et de sable, par lc courant, tris violent en certains endroits.

Le 29, vers 4 heures du soir, le mécanicien I)... quitte la machine où M. Somers doit aller prendre le quart. D... passe à côté du commandant et lui assure que la pression se maintient.

Dès que M. Somers est descendu, il constate qu'il n'y a plus d'eau dans le tube du niveau. Il prévient aussitôt de Gerlache, qui me dépêche dans la machine. J'observe que les foyers sont en pleine activité et que la quantité d'eau est si faible, qu'on ne la voit plus dans le nivcau. La machine cst imınédiatement stoppée. IIeureusement quc les tubes de la chaudièrc ne sont pas surchauffés: M. Somers peut lalimenter avec le petit cheval.

Pendant ce temps, Van Nirlo, aide-chauffeur depuis la veille, me déclare avoir prévenu, à diverses reprises, le mécanicien D... de ce qui se passait. Ce dernier, affolú, lui ordonnait de se taire, de pousser les feux et de graisser la machine!... Un tel incident se passe de commentaires!

de Gerlache, convaincu par cette nouvelle expérience, décida que le mécanicien D... serait clébarqué et rapatrié dès notre arrivée à Punta-Arenas.

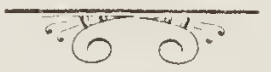




\section{CHAPITRE IIII.}

\section{Un fameux coup de balai.}

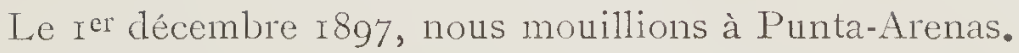

Racovitza nous avait quittés à Rio-de-Janeiro, gagnant PuntaArenas par un vapeur anglais, l'Oravia. Arrivé là un mois avant nous, il avait mis ce temps à profit pour faire d'intéressantes études sur la faune et la flore du Sud de la Patagonie. Au cours d'une de ees exeursions, il fut le eompagnon de voyage du Dr Moreno, direeteur du Musée de la Plata et arbitre argentin pour régler la question de frontière entre le Chili et la République Argentine.

Le I)r Moreno, mis au courant de notre expédition, signala notre passage au gouvernement de la République Argentine, qui nous invita, immédiatement, à prendre, dans son dépòt de charbon d'Ushuwaïa, tout le combustible dont nous pouvions avoir besoin.

Cette gracieuse attention ehangea notre route; de Gerlache adopta le programme suivant : embarquer à Punta-Arenas les roo tonnes de charbon que nous avions fait venir de Belgique; y eompléter nos approvisionnements en eau, vivres, vêtements; faire route sur Ushuwaïa, d'où nous emporterions le plus de eharbon possible.

Mais à Punta-Arenas survinrent de nouveaux embarras domestiques (1).

Samedi + décembre. - S... et W... sont fortement pris de boisson; ils font du seandale à bord, en s'injuriant et en se provoquant. J'interviens, on se tait; puis, deux minutes après, la querelle reprend de plus belle.

Dimanche 5. - S... s'est oublié au point de frapper un noviee. A minuit, 'T... rentre à bord, pris de boisson; M... et D... déeouehent.

Lundi 6. - Le eommandant fait prier WW..., qui se trouvait à terre avee un eanot, de transporter à bord deux caisses de vêtements

(I) Les incidents qui suivent sont copiés, tels quels, dans mon journal de bord. 
destinés à l'équipage. W... refuse de faire le transport; il fait répondre qu'il n'est pas un débardeur.

Mardi 7. - Le eommandant et le lieutenant Amundsen rapportent eux-mêmes, à bord, un rouleau de toile destinée aux vêtements de l'équipage. IV... marehe allègrement à eôté d'eux sans les aider !

feudi g. - V... D... demande de l'argent au commandant et se prépare à se rendre à terre sans autorisation.

Étant donné que des avances eonsidérables ont déjà été faites à l'équipage et que ees avances n'ont pas été prévues dans les fonds emportés de Montevideo, de Gerlache refuse. V... D..., furieux, apporte son livret, demande son eompte et aecuse catégoriquement le commandant de partialité envers les Norvégiens. de Gerlache cède et donne l'argent devant eette menace de départ.

Le même jour, W..., J... et X... "tirent bordéc ".

Le même jour eneore, W... et J..., qui avaient été envoyés à terre pour me reprendre, ainsi que des instruments d'observation, abandonnent le canot avec son armement et courent les estaminets.

J'attends, pendant une heure, le retour des marins; puis, je prie Arctowski ct Cook de se mettre aux avirons pour rentrer à bord.

Le canot est aussitôt renvoyé à terre pour y conduire les permissionnaircs et pour reprendre W... et J... Aueun de ees deux derniers ne revicnt. Le canot, à 9 h. 1/2, est encore renvoyé à terre : aucun des permissionnaires ne rentre.

Le soir, à 1 I h. 1/2, le commandant rencontre X..., W... et D... et leur donne l'ordre de rentrer à bord; il leur promet même de payer le canot qui les transportera. Aucun d'eux n'obéit.

Vendredi ro. - La Belgica est amarrée à la Martha, sur laquelle se trouve le eombustible à embarquer. La mer est forte, les ehaînes menacent de se rompre, les amarres se brisent plusieurs fois, et... la moitié à pcine du personnel est à bord.

A 6 h. 30 du matin, j'envoie un canot à terre pour ehercher les retardataires. V... D... répond qu'il ne veut pas encore rentrer.

A 8 heures, envoi d'un nouveau canot. V... D... déclare qu'il nc 
rentrera qu'à 9 heures. W... et J ... refusent de revenir. Le canot ne ramène que $\mathrm{S} . .$. et $\mathrm{X}$...

A 10 h. 3o, D... rentre à bord, gagne le poste et se couche! Je me rends auprès de lui; il me déclare quill n'est pas malade, mais fatigué de la nuit.

Sur ces entrefaites, de Gerlaehe était rentré, et en prévision des désordres qui pourraient se produire, il s'était aussitôt rendu à bord de la canonnière chilienne Magallanes. Ià il convient avee le commanclant en seeond de ee navire de guerre qu'un détachement de six hommes sera envoyé à bord de la Belgica " comme moyen d'intimidation " dans le cas où nous hisserions le pavillon $\mathrm{B}$ (pavillon rouge) du Code international.

Pendant que de Gerlaehe est à bord de la Magallanes, D... s'est levé et demande à débarquer. Je le fais aussitôt conduirc à terre.

lìn quittant la Magallanes, de Gerlache se rend à terre... à la recherche de son équipage.

Pendant ee temps, D... et V... D... rentrent à bord, dans un canot qu'ils ont loué et, eomme ils n'ont plus d'argent, c'est l'expédition qui paye. Ne doutant pas qu'ils vont être renvoyés. ils font leur sac, y mettent des vêtements qui appartiennent à l'expédition et veulent partir. Je m'y oppose formellement.

A 7 h. 30 du soir, de Gerlache et Amundsen rentrent à bord. Le commandant congédie V... D..., qui se montre très insolent à son égard et veut emporter son sac avee les vêtements qui ne lui appartiennent pas.

de Gerlache me fait un signe : je hisse la flamme rouge au grand mât. Mais l'obseurité empêche le timonier de service sur la Magallanes de distinguer notre signal.

de Gerlache se rend à bord de la Magallanes et demande l'envoi d'une garde à bord de la Belgica. Le commandant en second du navire chilien répond que cette garde ne peut être fournie que sur un réquisitoire adressé, par le gouverneur, au capitaine du port.

de Gerlache et le médeein de la Magallanes se rendent à terre à la reeherche du capitaine du port et du gouverneur. 
Sur ces entrefaites, 11 ... rentre à bord. Il est encore pris de boisson. Pour empêcher que sa conduite n'influe d'une façon néfaste sur le moral des rares hommes qui font leur devoir, je lui défends l'accis du poste et je monte la garde près de lui, sur la dunette. J'avais mis un revolver dans ma poche et j'étais bien décidé à brùler la cervelle au premier homme qui broncherait.

Le lieutenant Amundsen, craignant que je ne sois acculé à cette cxtrémité, s'installe sur la passerelle, prêt à me prêter main-forte.

De 9 I/2 heures à minuit, la situation reste aussi pénible. C'est épourantable de se dire que, d'un moment à l'autre, une circonstance fortuite, un rien peut rous obliger à devenir meurtrier! J'étais cependant très calme : ma conscience me représentait nettement que jarais le droit de frapper, pour éviter un malheur plus grand... Tous ceux qui sont au courant des choses de la mer me comprendront et m'approuveront.

A minuit, de Gerlache rentre à bord dans un canot appartenant à la direetion des mouvements du port. Il est accompagné du second officier de police de I’unta-Arenas, du médecin de la Magallanes et d'un détachement de six hommes armés de fusils, que le gouverneur. enroie à bord.

L'officier de police monte, sabre au clair. Il estime qu'il convient de ne pas attendre le lendemain pour débarquer $T$... D... et $I T$... En conséquence, V...D... reçoit l'ordre de se lever. 11 s'habille rapidement, met d'une façon ostensible un revolver dans sa poche et se rend chez de Gerlache. Je le suis, en surveillant tous ses mourements. T... D... renourelle ses insultes grossicres envers le chef de l'expédition, puis il rentre au poste, rend les effets qui appartiennent à la Belgica ef fait son sac. Il cxhibe au commandant un registre qu'il a l'intention de faire publier et dans lequel il déclare avoir inscrit, jour par jour, ce qui s'est passé à bord.

Les deux matelots font leurs adicux à leurs anciens camarades. TT..., pris dun mourement de repentir, quitte le poste en disant: "Faites honneur à la patrie. mes amis, ne faites pas comme moi! " 
V... D... et WV... passent devant de Gerlache, qui, en signo de pardon, leur donne la main et... une livre sterling.

A I $1 / 4$ heure du matin, le calme est rétabli.

Le lendemain, samedi I I décembre, le grand coup de balai est donné.

Le mécanicien I)..., qui nous eausait des inquićtudes depuis l'ineident de la chaudière, est devenu inutile, sinon dangereux. Toutefois, il convient de dire qu'il n’a pas pris part aux ineidents du jour préećdent, ni à ceux de la nuit. I)... est done débarqué, mais dans des conditions absolument avantageuses pour lui.

Le Suédois Rose... est débarqué égalcment pour cause de maladie.

Le matelot suédois Rosl)... nous quitte, eomme il avait été conrenu à Montevideo. Les matelots belges $I V \ldots, V \ldots$ D... et I)... sont lieeneiés. Les matelots norvégiens 'T ... et J... reçoivent une semonec paternelle. Enfin, î est recommandé à S... et à X... de ne plus manquer le eanot!

Nous voilà de nouveau sans euisinier à bord! Miehotte accepte les insignes du cordon bleu. Le brave garçon se dévoue pour le salut publie et s'en tire avee honneur, eomme nous aurons oceasion de lo voir par la suite.

Mais que de vides à bord! (Ouel fameux coup de balai !

Peut-ètre était-il dangereux de s'aventurer dans l'Antaretique avee si peu de bras. Inutile pourtant de ehereher, à Punta-Arenas, un complément d'équipage. D'ailleurs, mieux vaut un petit nombre d'hommes surs, qu'un nombreux personnel composé d'individus louches, dont l'insubordination nous met dans un péril eontinuel.

L'équipage ainsi réduit eomprend :

Johan Koren (Norvégien), I 8 ans à peine, noviec;

Auguste Vienele (Norvégien), 20 ans, novice;

Van Mirlo (Belge), 20 ans, noviee, attaché à la machine ;

I) ufour (Tielge), 2 r ans, novice ;

Knnudsen (Norvégien), 2 I ans, matelot;

Johansen (Norvégien), 25 ans, matelot; 
Michotte (Belge), 3 I ans, maître d'hôtel ;

Tollefsen (Norvégien), 33 ans, maître d'équipage.

En résumé, un maître d'équipage, deux matelots et quatre novices (1)! Qu'importe? Audaces fortuna juvat!

... Il n'y a d'ailleur s pas moyen de choisir une autre devise !

(I) Nous ne comprenons éridemment pas le maître d'hôtel dans le persunnel marin.

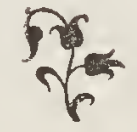




\section{$80-$}

\section{CHAPITRE IX.}

\section{Vers Ushuwaïa.}

L.e r 3 décembre, vers la soirée, comme nous embarquions des quarticrs de viande fraiche que nous avait gracicusement efforts la mission catholique de Punta-Arenas, un Français établi dans la localité, II. Alexis Panté, nous apporta en grande pompe une petite cage dans laquelle se trouvaient deux pigeons voyageurs de premier choix.

Un manuscrit traitant de la colombophilie accompagnait l'envoi, ainsi que cette note, dont je respecte le style et l'orthographe:

"Les deux champions, qui ont fournie le plus long parcour dans le détroit de Magellan, sont offert en essais aux explorateurs du Bataux Belgica,

\section{Par Alexis Panté}

forgeron francé à Punta-Arenas lequelle est bien reconnaissant si ces mesieurs veulent bien avoir la bonté de lui faire savoir le résultat de leur périllieuse exploration."

Ceux qui connaissent l'attachement passionné de tout colombophile pour ses pigeons peuvent seuls apprécier la valeur de ce présent, dont nous fûmes très touchés. Malleureusement, nous avions "d'autres chats à fouetter ») et les pauvres pigeons furent souvent médiocrement soignćs. Nous ne nous doutions guc̀re, alors, que, gràce à eux, nos familles seraient, un jour, plus ou moins rassurées sur notre sort (I).

Le If décembre 1897 , ̀̀ I heure du matin, nous quittons Punta-

(I) Nous ne savons ce qu'il advint de nos pigeons; mais, plus tard, des individus fircnt croire qu'ils étaient rentrés au colombier. La presse américaine s'empara de la nouvelle et répandit dans le mondo entier le bruit que tout allait bien pour nous. 
Arenas et nariguons quelque temps de conserve aree la canonnicre ehilienne le Toro.

Lorsque nous nous séparons, le Toro embouque dans le Foráard Reach, tandis que nous pénétrons dans le Magdalen Somn.

Bientôt une brume épaisse vient entraver notre marehe et nous eherehons refuge dans le IIave IIope, ravissante petite baie de l'Ile Clarence. Cette baie est emmurée comme un fjord par des montagnes esearpées faisant partie d'une chaìne importante, que domine le mont Vernal. Des rafales riolentes, mais cle courte durée, deseendent constamment de ees hauteurs.

La brume se dissipa vers 3 heures, mais nous ne reprimes pas la mer ce jour-là, étant donné que nous n'aurions pu atteindre, arant la nuit, le dépôt de charbon argentin. Or* par suite des diffieultés de la navigation dans les canaux du Sud, il est de néeessité, pour un navire comme le nôtre, de mouiller dans une baie pendant les heures les plus obseures de la nuit.

Pour eoncilier notre clésir d'exploration dans les canaux de la Terre de Feu, qui sont peu eonnus, avee le eourt laps de temps dont nous pouvions disposer, il fut déeidé que nous ne ferions qu'un petit nombre d'escales, mais que nous les prolongerions de manicre à y prendre quelques observations, ainsi que des éehantillons de la faune et de la flore.

Notre arrêt dans le Hazre Hope fut fixé à quarante-huit heures, à la demande du géologue et du naturaliste de l'expédition.

Le 16 décembre, nous appareillons dè l'aube, par un temps gris et maussade. Les cimes des láutes montagnes étant encore eaehćes dans la brume, nous ne pouvons distinguer que le pied du Sarmiento.

A midi, comme nous nous engageons dans le Cockbum Channel, la houle se forme, monte rapidement et, lorsque nous approehons des roches Tussac ( $\mathrm{I}$ ), la brise souffle avec violenee.

(I) 11 nous a scmblé que ces roches derraient être placées à deux ou trois milles au sucl cle la position indiquée sur la carte de 1'Amirauté. Nous avons eu cncore la 


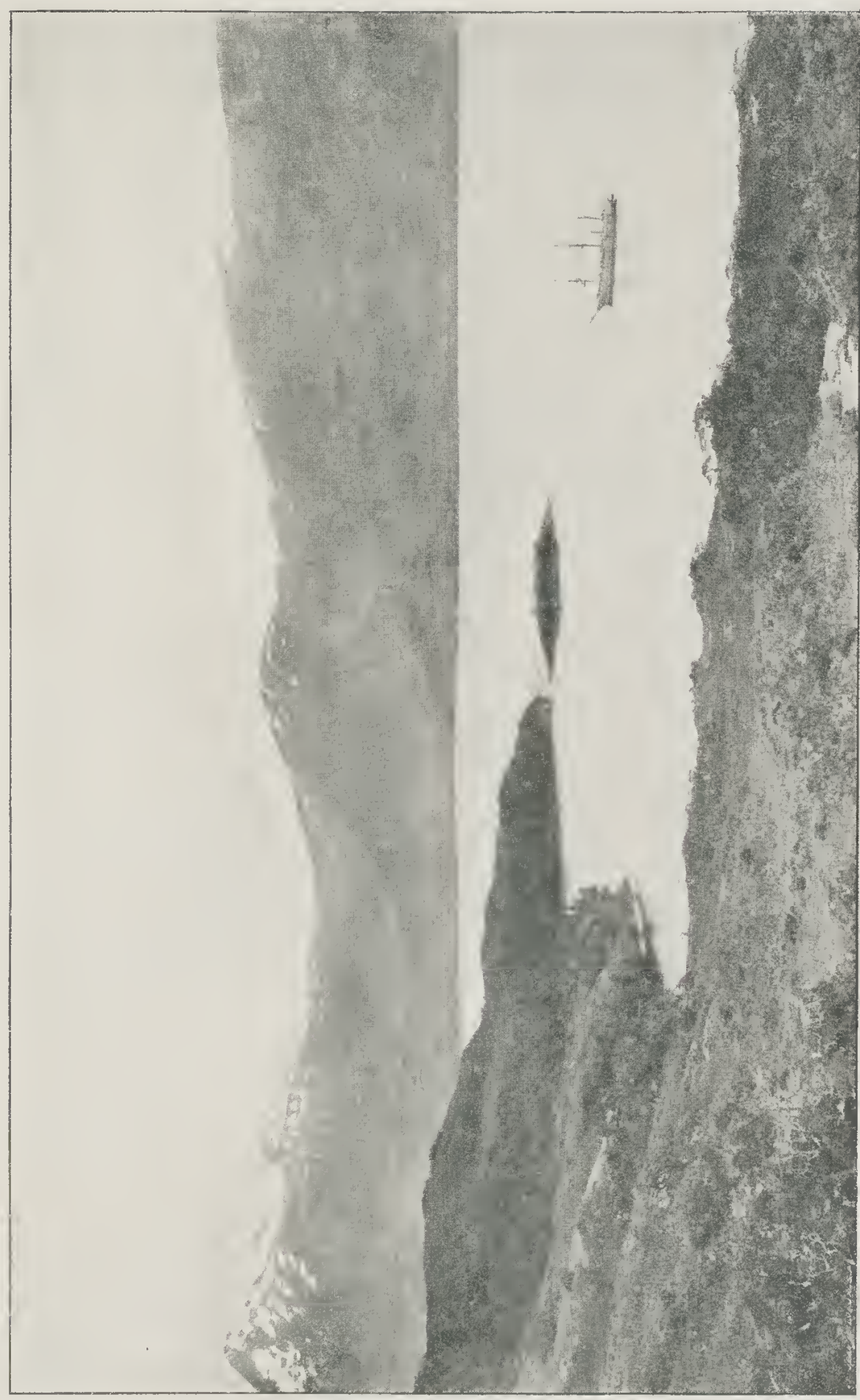

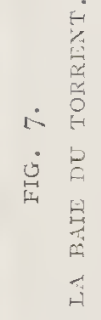



A peinc sommes-nous engagés dans le Brecknock passage, quc la brise devient rafale. Au Tord, nous arons la péninsule de Brecknock, à l'Est, l'île Georgiana, au Sud, l'íle London. Ces différentes terres présentent des contours et des aspects correspondant fort peu à ccux que donnent les cartes ou les courtes descriptions de ces régions.

Nous nous décidons à chercher un abri dans une petitc baie de l'île London; de Gerlache me chargc d'aller en canot reconnaître la baie. Le temps est épouvantable, la mer brise, il pleut à torrents. J'endosse le suroît de notre long Danco et j'attends un moment do calme. Le vent rcdouble, l'cmbarcation ne peut être mise à la mer; la Belgica fait route directement, mais le plus lentement possible, vers la petite baic. Comme nous n’en sommes plus trés éloignés, de Gerlache aperçoit soudain des brisants qui en barrent l'accès. Aussitôt il cherche à virer de bord, mais le vent et la mer nous entrainent vcrs la côtc, et c'est avec grand'peine que la manœuvre s'exécutc.

Nous espérons être plus heureux vers le Nord, en demandant abri a l'île Georgiana : notre machine se trouve incapable de lutter contre un tel vent.

Nous reprenons donc la route du Sud-Est. Nous défilons près de l'ile Sydney' et d'une série d'autres îles non marquées sur la carte.

A vue d'ocil, par une mer de plus en plus méchante, nous nous dirigeons vers l'íle Basket, que nous reconnaissons à peine lorsque nous l'atteignons. Enfin, aveuglés, harassés, trempés jusqu'aux os, nous mouillons, par 20 metres de profondeur, sur un fond de roche, où l'ancre menace à tout moment de déraper. Tout autour de nous,

mème impression en I899, lorsque, passant par les îles Furies, nous sommes entrés dans le Cockburn. Si cette appréciation est exacte, elle a une importance ríclle, attendu que les roches Tussac sont précisément donnécs comme repère, par les instructions nautiques, pour entrer, par le Sud, dans le détroit de Magellan.

Malheureusement, les deux fois où nous avons passé près de ces roches, les circonstances nous ont empêchés d'en fixcr exactement la position. Nous faisons donc cette romarque sous toutes réserves. 
des récifs. L'équipage peut aller se coucher, mais notre mouillage offre si peu de sécurité, que les offieiers continuent à faire le quart.

Le lendemain, I7 décembre, à 3 heures du matin, la Belgica reprend le large.

A midi, nouveau mouillage dans une baic de l'ile Londonderry, que nous baptisons Baie du Torrent (I) à cause du cours d'eau rapide qui descend bruyamment de la montagne.

L'après-midi, le personnel scientifique explore une petite partie de l'ile et les hauteurs, où nous découvrons un lac aux pentes très abruptes et couvertes de nombreux petits arbres tout rabougris.

Racovitza et Arctorslis expriment le désir de séjourner pendant quarante-huit heures dans la baic.

Des hauteurs qui bordent la baie du Torrent, nous avions aperçu un gigantesque glaeier de l'autre côté du Canal de Darain, dans la Terre de Feu. Il nous parut utile d'aller l'examiner de près. Aussi, le 18 décembre, nous rendions-nous dans la baie où il débouche (2).

Le I9, un dimanche, de trís bon matin, je partis en canot avec MI. MIélaerts, Van Rysselberghe et quelques hommes d'ćquipage.

Après avoir doublé une moraine remarquable, nous apercevons le pied du glacier, à une distance de plusicurs milles. A. mesure que nous en approchons, nous découvrons une quantité plus grande d'oiscaux aquatiques.

Du gibier! Et dire que nous n'avons pas de fusil!

Mes compagnons me proposent une "chasse à courre »!

En un clin d'œil, ils se mettent aux avirons, tandis que je tiens le

(1) Nous l'avions nommée d'abord "Baic de l'As de pique » ¿̀ cause de sa forme particulière. Nais une semblable cénomination eùt permis de supposer que nous nous occupions de jeux à bord. Ii s'agissait de ne pas donner prise à la critique! Il ne fallait pas oublier qu'une partie de nos fonds arait été recueillie par une souscription publicue!

(2) Nous avons appelé cette baie « Baie du grand Glacier ». 


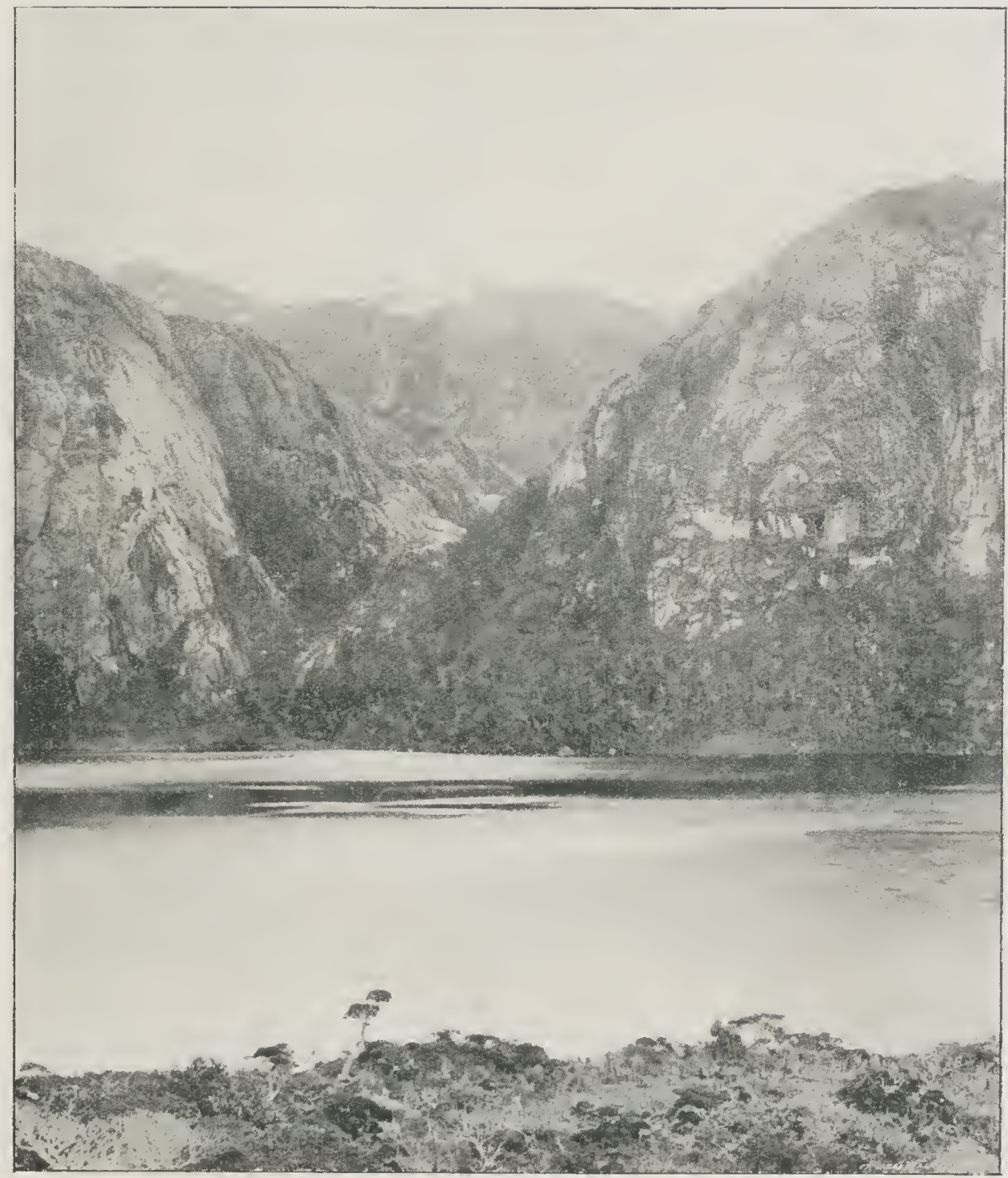

PLotogriaphise de Y. G. T. cointe.

IIG. 8.

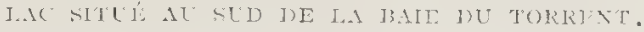



gouvernail, et nous poursuivons ainsi une espece de canard qui nage très bien, mais ne vole que très difficilement.

Quelle course! Quclle lutte! L'oiseau volait sur une longucur de Ioo à I 50 inctres, puis, brusquement, se remettait ì nager avec affolement. Bientôt, nous le rattrapions, pour le voir s'envoler de nouveau quand nous nous apprêtions à lc saisir.

Au bout de dix minutes, le pauvre volatile, exténué, fut assommé d'un coup d'aviron au moment oì il sortait de l'cau.

Nous supputions déjà le nombre de bons morceaux que nous donnerait notre capture, quand, à Ioo mètres de nous, surgit un magnifique cygne à tête noire. Il avait, sans loute, perdu de vuc sa mère et ses frères, car il ćtait jeune et ne volait que difficilement. L'aspect de cette nouvelle proic ranime nos forces, en nous excitant à continuer la chasse.

Notre cygne nageant à merveille, le canot le suivait avec peine: la victoire devait rester à celui des combattants qui aurait le plus de souffle. Vingt minutes d'une résistance homérique, puis l'oiseau, étendant ses ailes, ne bougea plus. Un matelot de l'avant le saisit, lui lia les pattes, ainsi que les ailes, ct le plaça au fond du canot.

De retour à la Belgicu, nous le portèmes sur le pont; mais, comme il avait repris haleine, il tâcha de s'enfuir. Se sentant prisonnier, il fit contre mauvaise fortune bon coeur.

Il était superbe, notre cygne: blanc comme neige, avec la tête et une partie du cou d'un noir de jais ( $\mathbf{I}$ ).

La description de notre excursion engagea de Cierlache à se rapprocher du glacier. A 4 heures, nous stoppions au fond de lá baie, au Sud d'une moraine contre laruclle les glaces venaient s'arrêter.

Comme le ciel était couvert, il ne pouvait être question de faire des observations astronomiques. Je repartis en chasse avec Mélacrts et les

(I) Les cyğnes à tète noire se laissent très difficilement approcher. Devenus adultes, ils ont un vol étomemment puissant. Si nous avons pu en capturer un à la course, il est évident 'lu'il s'agissait d'un jeune oiseau. 
quelques matelots qui mavaient accompagné le matin. Cotte fois, nous primes des fusils.

Au moment du départ, j'avais confié à de Gerlache, qui se rendait à terre, que jc caressais l'espoir de capturer toute la niehée de cygnes à tête noire. Ifélas! non seulement je ne vis plus un seul cygne, mais, en rentrant à bord, j'appris que notre beau captif, rompant le lien qui retenait ses ailes, s’était envolé.

La journée du lundi, 20 décembre, fut consacréc tout entière au travail.

Vers 5 heures du soir, reprenant le large, nous allons mouiller, à 9 h. I/2, dans une autre petite baie de la Terre de Feut, vis-à-ris de l'ile Chair, dans le Darwin Sound.

Malgré l'obscurité naissante, de Gerlache, Aretowsli, Racovitza et moi, nous nous rendons à terrc, où Arctowski recueille des échantillons de roche. (Duant à Racovitza, il fait une pêche si merveilleuse, que nous baptisons l'endroit Baic des Asteries.

Le lendemain, 2 I décembre, dès 4 heures du matin, nous franchissons 1c North West Arm, pour nous engager dans le Canal du Beagle. La brise souffe violemment en rafales. Enfin, à 8 heures du soir, nous arrivons devant la presqu'île d'Ushuwaïa.

Tout à coup, lc navire frémit: nous venons de toucher un banc de roche. Heureusement, la machine bat de l'arrière et nous dégage.

Étant donnée l'obscurité, nous faisons un léger détour, contournant les illes Bridges et Willic, en laissant par tribord les Éclaireurs.

Vers io heures, la nuit devient absolument obscure.

D'après les instructions nautiques, nous devions, arant de laisser tomber l'ancre, apercevoir dans un certain azimut le feu d'Ushuwaïa. Heureusement que nous mouillàmes, sans tenir compte de cette observation, au moment où la sonde ne renseignait plus que Io mètres, car nous étions tout près de la côte. Le feu d'Ushuwaïa arait, déjà à cette époque, été changé de place depuis un an ct aueun avis n'en arait cté donné encore aux narigateurs!

Voilà comment on se "mettrait au plein " sans s'en douter! 


\section{$-99-$ \\ CHAPITRE X.}

\section{Noël à bord de la "Belgica ».}

Le 22 déccmbre, la première lueur du jour nous permit de constater que nous étions trop proches de la côte. Les feux furent activés et nous changeâmes de mouillage.

Vers 8 heures, de Gerlache se rondit chez le gouverneur. Fìcheux contretemps : il était à Buenos-Ayres, et son secrétaire, à qui le commandant exhiba le permis de prendre du charbon, lui apprit qu'aucun ordrc n'avait été donné, dans ce sens, par le gouvernement de la Républiquc. Pour comble d'ennui, nous découvrûmes que le dépòt argentin ne se trouve pas à Ushuwaïa, mais à Lapatä̈a, que nous avions doublé la veille !... Heureusement, tout finit par s'arranger. Le secrétaire nous remit un ćcrit nous autorisant à embarquer du charbon à Lapataïa, et jusqu'à concurrence de Ioo tonnes. Il eut même la gracicuscté de nous prêter des sacs pour faciliter l'cmbarquement du combustible.

Pendant ce temps, Arctowski et Cook visitaient la mission protestante anglaise dirigéc par le R. Lawrencc. Ils y étaient reçus avec tant de cordialité que, dans 1c but d'étudier les mœurs des habitants indiens de la localité, ils acceptèrent de séjourner à la mission jusqu'à notre retour de Lapataïa.

Le 23 décembre, nous reprenons la mer et, quelques heures plus tard, nous mouillons dans la baie do Lapataïa.

Cette baie est longuc de trois milles environ et large d'un mille. Elle est orientée de l'Ouest-1'ord-Ouest vers l'Est-Sud-Est. A l'entrée, se trouve la jolie petite île Round.

L'accìs de la terre est facile, les caux y sont profondes, même trìs près de la côte. La baie est cncadrée de collines à pentes vives, toutes couvcrtcs d'une riche végétation. Lille se relie à Lapatä̈a par une 
vallée profonde, où coule un torrent impétueux et où le vent s'engouffre avec une violence extrème.

Le dépôt de charbon argentin, qui n'existe que depuis I896, consiste en un vaste hangar couvert d'une toiture métallique, ou sont abritées 200 à 250 tonnes de charbon. Ce combustible n'est certes pas comparable à celui de notre bassin houiller belge, mais il nous fut des plus utile et nous aurions mauvaise grâce à le déprécier, alors qu'il nous fut si généreusement offert.

Dès notre arrivée dans la rade, M. Montaldo, Argentin, et M Boursotti, Italien d'origine, tous les deux surveillants du dépôt et chefs d'une importante seierie établie à eourte distance de notre mouillage, se présentèrent à bord de la Belgica pour se mettre à notre disposition, selon les ordres qu'ils avaient reçus direetement de BuenosAyres

En dehors de ces messieurs et de la famille Boursotti, qui occupent une confortable maison de bois, on ne eompte guc̀e à Lapataïa que cing ou six ouvriers.

La scicrie est munie d'un bon outillage et fait d'excellentes affaires. Elle trouve sur place des forêts de superbes hêtres, qu'elle débite, par les transports argentins, dans toute la Patagonie et même à BuenosAyres.

Notons, non loin de la scierie, le lac Acigami, oủ nos marins firent une pêehe des plus abondante.

Dès le 23 décembre, nous commençons l'embarquement du combustible. Quel labeur! MI. Mélaerts, Somers, Amundsen et Van Rysselberghe consentent très aimablement à se convertir, qui en eharbonniers, qui en débardeurs, pour aider les matelots à entasser le charbon dans les sacs, à le transporter sur un chaland et, finalement, à l'embarquer à l'aide d'un treuil à vapeur. Les derniers jours même, afin de gagner du temps, le commandant et moi nous nous joignons aux équipes.

Le soir, lorsque nous cessons ce travail inusité. officiers et matelots fraternisent encore pour le nettoyage du pont. Puis, c'est notre tour: 
un bain complet a raison de la poussièrc de charbon qui s'est insinuée partout, sur notre corps et dans nos vêtements.

Cependant, il est juste de remarquer que lc métier de charbonnier produit un effet auquel nous étions loin de nous attendre : le poussier donne aux yeux un éclat singulièrement brillant. Avis aux belles mondaines qui, le soir d'un bal, voudraient se passer la fantaisie de se fairc souffler, dans les yeux, cette poudre d'un nouveau genre!...

24 décembrc! - Se croirait-on, grands dieux, à la veille de Noël! La journée se passe sans incident, mais le soir, vers $6 \mathrm{I} / 2$ heures, comme nous sommes cn train de souper, l'homme de veille signale, tout à coup, que la forêt est cn feu.

Arctowski, qui vient de rentrer à bord après avoir fait à pied, avec deux Indiens, le trajet d'Ushuwaïa, nous explique aussitôt que, selon lui, l'incendic a dù commencer à l'endroit où ses Indicns, pour signaler au loin leur présence, ont allumé un feu, qu’ils ont probablement éteint avec trop pcu de soin. Le foyer de l'incendie n'est pas très éloi rnć d'un dépôt de planches appartcnant à la scieric à vapeur; il n'y a eependant rien à craindre pour le moment.

In wn instant, nous sommes tous sur le pont avec des jumelles. Quel spectacle grandiose que celui d'une forêt cn feu, lorsqu'on sait qu'il n'y a aueun accident de personne à craindrc et quc la nature, prodigue dans ces régions, aura repeuplé la forêt avant que quiconque ait pu souffrir du dégàt matériel!

Cependant, il fallait cnrayer les ravages du fou. Le commandant ıne pric de faire mettre les canots à la mer. Nous partons tous, sauf de Gerlache et Amundsen.

Quellc promenadc féerique! La mer est calme, les eanots glissent sans heurt, les matelots rament en cadence, tandis que l'immense brasier colore le ciel et l'eau, comme dans un conte des mille et une nuits.

Mais le temps presse, arric̀re la rêverie! Les rameurs font un vigoureux effort et abordcnt. Chacun s'arme d'unc hache ou se munit d'un scau en toilc. 
Pendant que les uns font la chaìne, les autics s'empressent d'abattre les gros arbres en feu, afin de les isoler. Heureusement qu'il n'y a pas un souffle dans l'air : nos efforts sont couronnés de succès, l'incendic s'éteint peu à peu.

Vers ro heurcs, notre tâche est terminée, nous revenons à bord.

Une charmante surprise nous y attend: Noël a passé, illuminant la Belgica, apportant à chacun des cadcaux, des douceuts

Oh! les yeux étonnés de nos braves marins, lorsqu'ils voient les logements, le poste, le carré paroisés de drapeaux de toutes les couleurs! Quelle satisfaction ils éprouvent à palper les rêtements bien chauds que leur donne l'expédition (I)! Quelle joic naïve ct complète fait trembler leurs mains, lorsqu'ils caressent avec amour la belle pipe, le bon tabac offerts si généreusement par MI Mmes de Gerlache et Osterrieth!

Le commandant est ému de la joie de chacun. Il fait servir un grog, où officiers et matelots fraternisent gaîment.

Puis, ce sont des discours patriotiques et autres: Tollefsen parle en norvégien, Van Rysselberghe cn français, mais chacun applaudit à outrance; de Gerlachc, le dernier, prend la parole à pcu près en ces termes:

"Mes amis, nous sommes pcu nombreux, nous aurons parfois une lourde tâche à remplir, mais je suis convaincu que tous rous ferez votre devoir. Et surtout qu'aucun de vous ne vienne jamais me dire : "Je suis fatigné! " - Tous n'avez pas le droit d’être fatigué. Lorsque vous serez "malade ", cc sera différent : je vous donnerai du repos."

Là-dessus, l'état-major quitte lc poste et se rend au carré. Nous y trouvons aussi notre part de gâteries. Voici, pour chacun, un

(I) Bien que la solde de l'équipage füt dérisoire, les hommes devaient acheter de leurs deniers leurs rêtements et le linge, à l'cxcoption d'un premier équipement de parade qui leur arait été donné à Anvers. 
soyeux foulard de cou, don de Mme Ramelot; un roman enveloppé d'une superbo couverture brodéc avec une finesse exquiso par Mme Louise de Gerlache; cnfin, des gàteaux, des douceurs dont personne ne fait fi.

On rit, on plaisante. Arctowski est mis sur la sellette pour l'incendic de la forêt, dont nous le rendons responsable. Nous ne manquons pas non plus de commenter lo "malade, mais jamais fatigucé " du discours du commandant, qui riposte gaiment.

Un peu après minuit, on se sépare, chacun rentre dans sa cabine. La micnne me parait moins misérable que naguère. Mon hublot est grand ouvert: la nuit est sereine; je respirc avec volupté l'âpre souffle des mers, tandis qu'au loin, par moments, le foyer de la forêt so ranime, laissant jaillir des fusées par milliers.

Tö̈l! Noël! que nous apportes-tu dans notie soulier?

Toici venir l'ire des souffrances : nos coeurs et nos bras sont-ils prêts pour la lutte suprême?

Noël! qui éroques le souvenir de tous ceux que nous avons laissés au pays; Noël! qui nous rappelles tout ce qu'ils espèrent, donncnous la force de souffrir et de vaincre! Mais si jamais nous ne devons revoir la patrie, tu iras l'an prochain murmurer à l'oreille de coux qui nous attendrons en vain que notre pensée ne los a pas quittés!... 


\section{CHAPITRE XI.}

\section{En détresse.}

La journée de Noël et celle du lendemain, qui était un dimanehe, furent consacrées au repos. I.e soir du 26, toutefois, il fallut changer de mouillage, parce que, sous les rafales violentes, le navire chassait sur ses ancres.

Le chargement du charbon fut repris le 27 et terminé le 29, à la soiréc. Nous avions donc perdu cinq jours à ce labeur, et pour ne charger que 45 tonnes de combustible.

Le 30 décembre, tandis que l'équipage est occupé à un nettoyage général, l'état-major prend part à une excursion organisée dans la foret par MM1. Montaldo et Boursotti. Comme je dois me rendre à terre pour des observations, il est convenu que, le travail terminé, mon canot déposera Dobrowolski en un point de la côte, d'où il pourra rejoindre les excursionnistes.

Tout se passe comme nous l'avions projeté; mais, à un moment donné, Jobrowolski, voulant m'éviter un long détour, me propose de le descendrc à un autre point d'atterrissage. J'acccpte arec d'autant plus d'empressement, que j'ai hâte de terminer mcs calculs, arant l'appareillage de l'après-midi.

Ouelle crreur fut la nôtre! Je m’étais éloigné depuis peu de temps, lorsque Dobrowolslii s'aperçut que je l'avais déposé dans une île !...

Conservant son beau calme halituel, notre ami ne s'effraya nullement de se voir transformé en Robinson. Il visita son nouveau domainc, joua berger auprès des moutons qu'il y trouva installés et attendit patiemment l'érćnement qui devait le délivrer. L'estomac le tiraillait fort, la marche et la pensée du bon repas qu'il aurait dù faire lui ayant aiguisé singulic̀rement l'appétit.

Enfin, vers 3 heures, les exemrsionnistes passèrent providenticllement à proximité de l'enclroit où il sc trouvait et le rapatrièrent. 
Le 30 décembre, à 5 heures, nous faisons routc vers Ushuwaïa, où nous devons reprendre Cook, faire le plein des réservoirs d'eau douce et rendre les sacs à charbon qui nous ont été prêtés.

Ushuwaïa possc̀de la même organisation que la plupart des colonies françaises, dont la population cst presque exclusivcment constituée par des fonctionnaires.

L'ćcole - car il y a une école — n'a pas d'élères; aussi l'instituteur ct l'institutrice, qui en ont la direction, avaient-ils résolu dc charmer leurs loisirs en se mariant prochainement. Le scul moyen, pensaientils, de se maintenir dans leurs fonctions était de peupler eux-mc̀mes les classes.

Ushuwaïa ne semble pas avoir été créé dans un but commercial. I.cs Argentins ont établi cette station en vuc dc contrebalancer l'influence croissante des Chiliens dans 1c détroit de Magellan. Le sentiment de rivalité des deux peuples s'cst encore aigri, depuis que la question des frontières a ćté soulevée. La guerre même a failli éclater à divcrses reprises. Les Argentins ont, conséquemment, chcrché, dans le détroit, un endroit propice à l'établissement d'un port de guerre oi poumaient sc conccntrcr toutes leurs forccs navales. A ce point de vuc, l'emplacement est certes bien choisi : la rade est raste et profonde; elle est fermée, au Sud et à l'Est, par des îles ct la péninsule d'Ushuwaïa; l'accès peut en ĉtre rcndu impossible, du côté Sud-Ouest, arec quelques batteries qu'on établirait à peu de frais. Comme le débarquement, en cet endroit, s'opère difficilement, le gouvernement argentin a l'intention de farre construire un grand nôle, qui abriterait, en même temps, contre la mer, un certain nombre de navircs.

Le 3 I décembrc - serait-cc l'influence de notre mouillage dans un port de guerre? - l'équipage manifeste un peu d'humeur. Les lommes se plaignent de la ration ct demandent celle que l'on donne gćnéralement à bord des bâtiments de commerce. dc Gerlache se rend dans ie poste : il lcur démontre, par a plus 7 , que leur ration est supérieure à cellc que les matclots ont eux-mômes fixéc et 
que leur manque d'ordre est seul la cause de leur mécontentement.

Le même jour, Cook rentre à bord, nous ramenant un passager ! Le R. Lawrence demande à c̀tre eonduit à Harberton, où se trouve son ex-collègue, M. Bridges.

Cette escale à IIarberton n'était pas indispensable ; cependant, comme nous n'avions pu obtenir à Ushuwaïa que très peu de viande fraiehe, il était bon, surtout en présence des

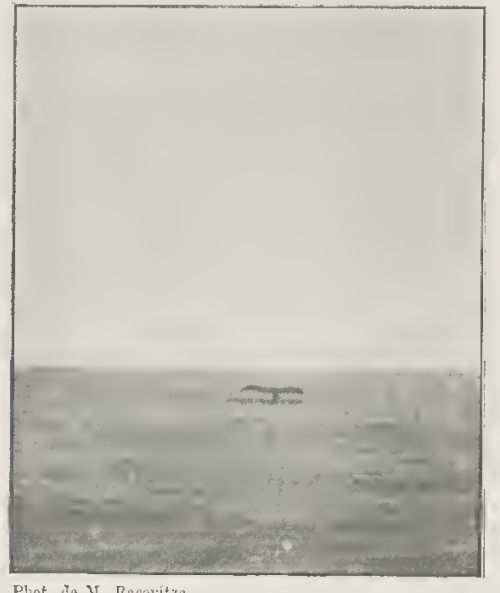

Phot. ite M. Raeovition

IIS. 9.

MEGAPTERE TYOOGEANT. récentes réclamations, d'en embarquer le plus possible arant de mettre le cap au Sud. De plus, on rendait service à $\mathrm{X}$. Lawrence, à qui Cook, et par conséquent l'expédition, était redevable de renscignements précieux au point de vue anthropologique.

Au reste, Harberton étant sur notre route, il suffisait d'y jeter l'ancre pour quelques heures.

Le dimanche, rer janvier i 898 , nous appareillons à I I heures du matin.

L'après-midi, vers 4 heures, tandis que j'étais sur la passerelle, j'aperçus au loin un immense oiseau, qui, de temps à autre, ouvrait et refermait lentement ses ailes, puis disparaissait en plongeant. Je fis aussitòt prévenir notre zoologue, qui reconnut que mon oiscau était... les nageoires caudlales d'un mégaptìre qui sondait (I)!

(I) Les mégaptères sont des cétacés de if à I8 mètres de long. Ils viennent fairc à la surface une série de courtes inspirations et expirations. Apres chaque inspiration, ils disparaissent sous l'eau à une faible profondeur. Lorsqu'ils viennent ainsi respirer, ils montrent l'évent, puis la dorsale, mais ne montrent pas la quoue. Après une série d'inspirations brèves, ils font une longue inspiration, puis sondent, c'est-à-dire qu'ils plongent, pour chasser, à une profoncleur qui peut attcindre Ioo mètres. Au moment où ils sondent, les mégaptères montrent cntièrcment leurs nageoires caudales. 
Peu de temps après, en effet, deux mégaptères défilent, à très eourte distance de la Belgica. Plusieurs d'entre nous aulaient aimé leur tirer un coup de fusil, afin de les voir "en eolère ". Raeovitza s’indigna de eette idée, ct, pour achever de nous eonvainere, il nous expliqua que nous ne verrions rien du tout, que la balle s'enfoneerait dans la graisse et... que l'animal sourirait de notrc naïreté !

Pendant cc tcmps, les monstrucuses bêtes poursuivaicnt tranquillement leur chemin.

Vers Io heures, la nuit devint obscure, ne nous permettant plus de continuer à suivre les alignements que nous avions choisis. Tous nariguions au compas. Comme nous approchions de la côte pour reconnaître l'entrée de la baie, brusquement des goémons (1) surgirent à notre avant.

La barre aussitôt est mise vers lc large, mais avant que lc narire ait eu le temps d'ćroluer, la profondeur diminuait encore, et le sondeur ne rencontrait plus que 28 ,

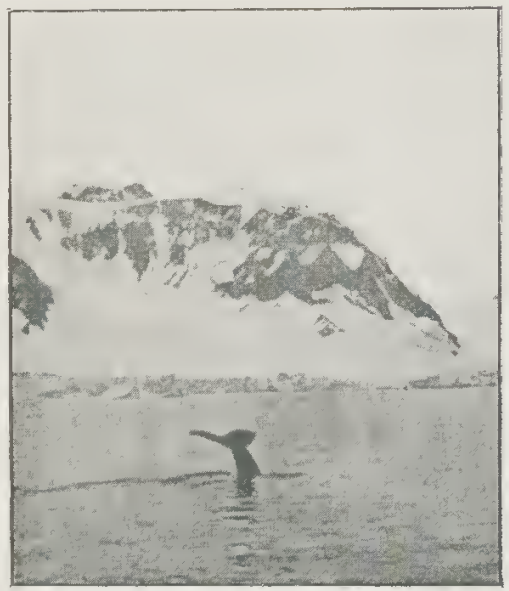

Phot, do 3I. Racovitzen

FIG. IO.

MEGAPTERT PLONGEANT. puis I8, puis 4 mètres de fond! La Belgica était cchouée sur un banc de roche!

Je sais que la bienveillance publique nous fit un grief d'avoir voulu entrer, la nuit, à Ilarberton, alors que la navigation y est rléjà diffieile en plein jour. Je me rallie entic̀rement à ces critiques et jajoute même, d'un air très entendu, qu'il est bicn plus à recommander de passer à côté de ces roches que de les aborder de front!

Mais, puis-je objecter " timidement ", les cxplorateurs ne diffèrentils pas des touristes qui royagent en paquelot? Doivent-ils toujours suivre les conseils d'une étroite prudence?

(I) Algues marines indiquant presque toujours des récifs. 
Si l'amiral Mouchez, par exemple, avait écouté l'appréhension qui cric sans cesse: "Attention, tu peux te faire mal!" aurait-il, en quelques mois, exécutć de grands travaux sur les côtes d'Amérique? N'est-ce pas aussi l'amiral Mouchez qui reconnaissait avec fierté "que souvent il avait déterminé la limite des écucils avec la quillc même du navire n!

A tort ou à raison, toujours est-il que nous étions carrément " au plein $)$.

de Gerlache me prie d'aller en canot sondcr autour du navire, afin de rcconnaitre dans quelle direction nous pourrons nous dégager le plus facilement. Il résultc des sondages que nous sommes solidement assis sur une roche conique, où le courant nous maintient.

Toutes les embarcations sont miscs à la mer, afin d'allćger le navire; puis, la machine cst actionnée à toute vapeur, tantòt en avant, tantôt en arric̀re. Rien ne bouge!

Lc commandant fait mouiller, à une centaine de mètres, une ancre à jet, dont l'aussière est ensuite tirée à l'aide du treuil à vapeur, tandis que la machine est remise cn mouvement. T'ancre est arrachće du fond, mais la Belgica résiste.

Alors Arctowski, Cook, dcux matelots et moi, nous partons en canot pour observer, à la côtc, la marche de la marće. Le jour commencc à poindre, le temps est superbe, une brise légc̀rc ride à peine la surfacc des eaux. Des goélands viennent crier bruyamment autour de notre embarcation. Cooli et Arctorslí photographient, tandis que je tiens la barre. Un fusil cst posé sur mes genoux prêt à abattrc - ou à manqucr - lc premier gibicr qui passera.

Sans inquiétude encore, nous arrivons gaîment à la còtc, où nous constatons que la marće descend assez rapidement. La courbe de niveau, laisséc par la marée haute de la nuit, semble indiquer qu'elle ne marne que d'un mètre.

Commc nous revcnons lentement, nous constatons avec étonnement que la Belgica s'incline sur tribord et mème qu'elle se couche d'une façon qui pourrait devenir inquiétante. 
Bah! la mer est belle, la marée va nous redresser! Cherchons cepen dant à nous dégager le plus vitc possible, en soutenant le navire avec des béquilles.

Tout oeeupés par ce travail, nous voyons à peine que le ciel se couvre dc gros nuages. Brusquement, nous sentons la brisc se lever, la mer devenir méchante, les manouvres avaneer diffieilement. Il ne s'agit plus de rire, il faut se hàter.

Sur ees entrefaites, M. Bridges, fils de l'estanciero d'Harberton, qui nous a aperçus, arrive en eanot. Il s'informe de la situation et repart chereher une allège. Vers io heures, la marée eommence à redresser le navire; dans quatre heurcs seulement, elle sera haute.

Le eapitaine Davis, du brick Phontom, mouillé devant ILarberton, nous rejoint avec le grand eanot de sauretage, et quclques minutes plus tard, voici M. Bridges avee un chaland ct une vingtaine d'Indiens.

Cependant la brise force et la mer grossit. Hélas! nous sommes obligés de débarquer, sur un chaland, la majeure partie du charbon de Lapataïa que nous avions embarqué au prix de si grands efforts! Nous déehargeons dans la mer notre provision d'eau douce et nous mettons dans nos canots tous les objets lourds qui sc trouvent sur le pont. M. Bridges propose de conduire vers la côte son chaland, son canot de sauretage et nos deux grandes baleinicres qui menacent de se briser sur les flanes de la Belgica. A peine sont-ils à 300 metres, que la mer et le vent menaccnt d'engloutir la petite flottillc.

La Belgica se redresse sous unc rafale, mais pour se recoucher sur bâbord. Vite, une béquille de ee eòté arec ce qui reste de nos mâts et vergues de réserve.

Le commandant, si optimiste d'ordinaire, est tris inquiet; il nous eonvoque, Amundsen et moi, dans sa chambre et nous demande si nous n'estimons pas que la Belgica est en pcrdition, s'il ne faut pas, comme dernic̀re chance de salut, jetcr d̀ la mer toute la cargaison!... 
de Gerlache est étreint, à ce moment, par une vive émotion. En un instant, il voit s'évanouir le rêve longtemps caressé. La perte de la Belgica, c'est l'anéantissement d'un long labeur, c'est peut-être la mort pour plusicurs de ses compagnons, car pourront-ils regagner la terre, par cette mer démontée, avec les deux petits canots qui nous restent?... Pour d'autres, et il est le prenier de ceux-là, leur devoir est de demeurcr à bord, quelle que soit la situation.

Après un bref, mais consciencieux examen de la question, nous sommes tous les trois d'avis d'attendre encore avant de sacrifier la cargaison.

11 nous reste un solide mât de hune : cmployons-le à béquiller le navirc par bâbord. Aussitòt fait que dit : la Belgica semble plus paisible; nous respirons!

Tout à coup, un violent coup de vent, un craquement sinistre, et notre fameux espars de bâbord, celui que je croyais incassable. se rompt comme un fétu! La Belgica glisse sur la roche en s'inclinant encore davantage; les vagues roulent sur le pont, puis embarquent des deur bords; le navire tressaute avec violcnce; toutes les béquilles sont rompues!...

Cette fois-ci, c'est bien fini! dans un instant, le navire va se briser et sombrer; l'expédition antarctique belge est anćantie avant même d'avoir commencé sa mission.

Arctowslí est à côté de moi, regardant avec angoisse les morceaux d'espars qui restent suspendus aux bastingages, tandis que d'autres, cntraînés par la mer, partent en dérive.

Je sens que le dénouement approche; je prie Arctowski d'aller chercher le pavillon belge, le beau, le tout grand, celui que nous avons arboré les jours de fête, celui qui fut salué par les navires de guerre à Rio-de-Janeiro; il faut qu'il flotte sur la Belgica : c'est notre dernier adicu à la terre!

Je rejoins sur la passerelle de Gerlache, qui tente un dernier effort. Il fait établir le petit hunier et télégraphie à la machine de marcher en avant à toute vapeur. Afin de pousser la pression à outrance, notre 
mécanicien, MI. Somers, a calé les soupapes de sùreté ct il emploie le cylindre de basse pression eomme cylindre de haute pression. L'équipage hâle le navire au guindeau sur la chaîne d'une anere de bossoir que nous avions mouillée le matin à quelque roo mètres du navire. Sur eette ancre, nous avions frappé une aussićre, que le treuil à vapeur cmbraque maintenant avec force... Les chocs violents se succedent, le treuil grince, le guindeau cric, la machine se plaint, les voiles se gonflent à tout rompre, la tempe te siffle dans les cordages, les lames se brisent avee fracas contre le navire.

La Belgica oseille autour de sa quille, se soulève, puis lourdement retombe sur la roche.

L'houre de la marée hautc est passée; lans un instant, les eaux ront redescendre, elles redescendent déjà.

Le navire va s'incliner dereehef, mais le danger sera bien plus grand que la nuit précédente, car la mer est démontée. Il va de nouveau se coucher sur un bord et alors... Mais non! le voilà qui se soulève davantage, il se redresse avec énergie, il se secone, il glisse sur la roche, il se dégage de l'étreinte... il est libre! !!

Arctowski est revenu sur le pont, rapportant le pavillon, qu'il fait hisser lentement.

Avec émotion, de Gerlacho le roit monter, il comprend ce qui s'est passé cn moi. Nos regards échangent la confidenee de bien des angoisses; nous nous scrons la main. Et, voulant cffacer le souvenipénible que l'apparition du drapeau pouvait eneore laisser cn co moment, je dis à de Gerlache avec affection et avee joie:

"Commandant, c'est dimanche; j'ai fait hisser les couleurs! "

L'équipage, lui aussi, a compris que le moment de la délivrance est venul. En un instant, il relève l'ancre de bossoir et hisse à bord les deux canots, sans même s'apercevoir des difficultés que préscnte ectte mancurre par une mer en fureur.

D'ailleurs, rien ne nous effraye plus: nous naviguons, en riant, poussés par la trimpête; nous longeons la côte de l'ile Navirin, où, 
à 7 heures du soir, la petite baie de Porto Toro nous offre un délicieux abri.

A quelque chose, dit-on, malheur est bon.

En effet, la journée du 2 janvier 1898 nous avait permis d'éprou ver, à la fois, la solidité de la Belgica et le dévouement de notre équipage.

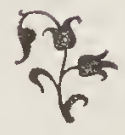




\section{CHAPITRE XII.}

\section{Les Indiens de la Terre de Feu.}

Quelle nuit réparatrice que cellc qui suivit la journće de IIarberton : Je dormis à poings fermés, comme les petits enfants, profondément, sans rêve, sans souci!

Le lendemain, 3 janvier, le réveil général n'cut lieu qu'à 8 heures et le restant de la matinée fut consacré à la remise en état de notre navire.

A midi, nous levons l'ancre pour retourner à Harberton, car il s'agit d'y reprendre le charbon, d'y refaire une provision d'eau doucc et de recueillir notre brave docteur, qui, ayant été chargé, la veille, de reconduire à terre un des chalands d'emprunt, n'avait pu regagner le bord.

Vers 4 h. I/2, nous retrouvons nos canots et nous ramenons à bord Cook et M. Bridges fils.

Il est 7 heures du soir, lorsque nous mouillons de nouveau dans la baie de Harberton.

Les habitants de la baic d'Harberton sont d'origine indienne, si l'on en excepte la famille anglaise de M. Bridges, ancien recteur de la mission protestante d'Ushuwaïa, qui abandonna l'apostolat pour se livrer à une occupation plus rémunératrice : l'élevage des moutons. Il y a quelque trentaine d'années, M. Bridges reçut gratuitement du gouvernement argentin une vaste concession de terrains, qu'il exploitc, depuis, à gros bénéfices, grâce au concours de ses misérables voisins, les Indiens.

Ces Indiens, qui constituent la population nomade de la baie d'Harberton, de la 'Terre de Feu et, en général, des terres qui avoisiluent le détroit de Magellan, appartiennent à trois familles distinetes :

Les Alacaloufs, habitant principalement les bords du Canal de Smith, 
du Sea-Reach et du Lang-Reach, vivent des produits de la pêche et naviguent dans des pirogues faites d'écorce de hêtre. Maltraités sans cesse par les Anéricains, ils montrent, pour tout étranger, une haine qui ne recule pas devant le crime. Les Américains la leur rendent et les exterminent peu à peu.

Les Yahgans se nourrissent, comme les Alacaloufs, de poissons et de coquillages, mais ils sont un peu moins sauvages.

On ne les tue pas, mais on s'en débarrasse en favorisant chez eux le développement de la phtisie. Les peuples civilisés, pour lesquels ils travaillent, trouvant immoral de les voir courir tout nus, les habillent de défroques. Or, comme on ne peut pas suspendre le travail pendant les nombreux jours de pluie ou de neige, ces misérables, trempés jusqu'aux os et n'ayant pas de haillons de rechange, doirent laisser leurs vêtements se sécher lentement sur eux.

Lorsque, primitivement, ils couraient nus, la pluie les mouillait évidemment; mais, dès qu'elle cessait, ils se réchauffaient en s'enreloppant de leur peau de guanaco (I).

Le troisième groupe, les Onas, vivent à l'intérieur de la Terre de Feu. Ils sont très peu connus. Leur haine pour l'étranger est aussi farouche que celle des Alacaloufs, et l'on peut dire qu'elle est méritée.

En effet, jadis, les Onas vivaient dans les grandes prairies de la Terre de Feu, où ils trouvaient, en abondance, les guanacos et les coquillages.

Un jour, les gouvernements argentin et chilien firent, à un grand nombre d'estancieros, la concession de tous les terrains bons pour les pâturages, et bien que, dans les contrats, il futt spécifié souvent, pour la forme, que les concessionnaires protégeraicnt les Indiens, dans la pratique, il n'en fut rien.

Les naturels furent refoulés dans les montagnes, où, bientôt, ils ne trouvèrent plus de quoi vivre. Ils firent alors quelques incursions en

(I) Espèce de chèrre sauvage. 
territoire conquis et cnleverent des moutons. La gucrec éclata, mais la gucrre la plus inégalc, la plus lâche qu'on puissc rêver!

L.es concessionnaires étaient armés de fusils et secondés par les forces militaires des gouvernements de l'Amérique du Sud; les Indicns n'avaient que leurs arcs!

I.cs massacres furcnt nombrcux; mais comme, malgré tout, les Indiens doivent mangor, souvcnt encore ils parvinrent à enlever quelques moutons. Comme conséquence, certains estancieros ont mis leur têtc à prix : 25 ou 50 francs, suivant la saison!

Dans ces conditions, on trouve des chasscurs d'hommes à volonté, et la race ona disparaît peu à peu. Bicntôt, leur nom sera rayé de la tcrre, sans que l'on possède même sur leur courte histoire des documents asscz complets!

Un campement d'Onas se trouve près de l'habitation de $\mathrm{M}$. Bridges ct un autre près de celle de son fils, sur la còte dc la Baie de l'Est.

Lc 3 janvicr, Arctowslí et Cook visitcircnt lc premier campement, qui est peu important: mais le lendemain, 4 janvicr, jc me joignis à cux pour nous rendie, cn canot, au second campement. Nous arions donné rendez-vnus à MI. Bridges fils, afin qu'il nous servit d’interprètc.

A 8 heurcs, nous arrivons chez les Onas, sans fusil ni revolver, mais avcc une boite de médicaments et des apparcils photographiques!

Nous fumcs d'abord accueillis froidement, mais nous étions si calmes et paraissions si gais, que les Onas comprirent enfin, à leur grand étonnement, que nous ne venions pas les voler. Pauvres gens!

Cook sortit de sa sacoche des bonbons, qu'il distribua aux enfants; puis, comme s'il se fût trouvé dans un hôpital, il sc mit à soigner un ou dcux petiots qui avaient mal aux yeux. Grâce à ce systène, nous fùmes bientôt tout à notre aise, ct lcs Indicns, rassurés, nous permirent de prendic des photographics.

Pcndant ce temps, M. I3ridges leur cxpliquait nos intentions. Dans quclle languc, grands dieux! Il poussait des grognements de ventri- 
loque et se contorsionnait de la gorge, absolument comme unc personne... qui a le mal de mer!

Quoi qu'il en soit, ses arguments pcu harmonieux contribuaient, certes, à donner confiance aux Onas. Olı! je ne dis pas que nous aurions été reçus de la même façon si l'habitation de M. Bridges et les fusils Winchester à répétition eussent été au loin. Nais ne faisons pas de jugement téméraire : peut-être ces pauvres créatures ne demandent-elles qu'à croire au bien.

Nous nous nuîmes à parcourir le campement. Un nombre assez considérable de chiens hurlaient à notre passage. Ces pauvres bêtes sont en liberté; mais, afin qu'elles ne s'éloignent pas trop, on leur attache une des pattes de devant contre lc cou et on ne les délivre de cette contrainte qu'aux heures de la chasse.

Un campement comprend autant de wigwams ou foyers qu'il y a de familles. Le wigwam est d'une construction très primitive. Des branches d'arbre, avec leur feuillage, sont fichées en terre et réunies au sommet comme des fusils en faisceau. Un écartement de 50 à 60 centimètres entre les branches figure la porte. Les wigwams riches sont, de plus, recouverts d'une grande peau de guanaco, qui les protège quelque peu contre la neige et la pluie.

Si l'on songe que le climat de ce pays est plus rigoureux que le nôtre, que la neige et la pluie y sont fréquentes, on s'imaginera facilement ce que peut être le bien-être physique des Onas.

Leur couche, c'est le sol humide sur lequel ils jettent quelques feuilles; leurs vêtements, une peau de guanaco attachée sur l'épaule. Pendant le jour, les femmes entretiennent dans le wigwam un feu de branchage ; la nuit, le feu est éteint. Alors, les membres de la famille se couchent, se groupent, se serrent les uns contre les autres, recouverts collectivement d'une ou de plusieurs peaux; au-dessus de cette masse humaine et grelottante, s'étendent encore les chiens immondes, qui lui apportent leur contingent de chaleur.

Le Dr Cook, qui, au retour de notre expédition, a séjourné assez longtemps chez les Onas, expose, comme suit, ce qui concerne 


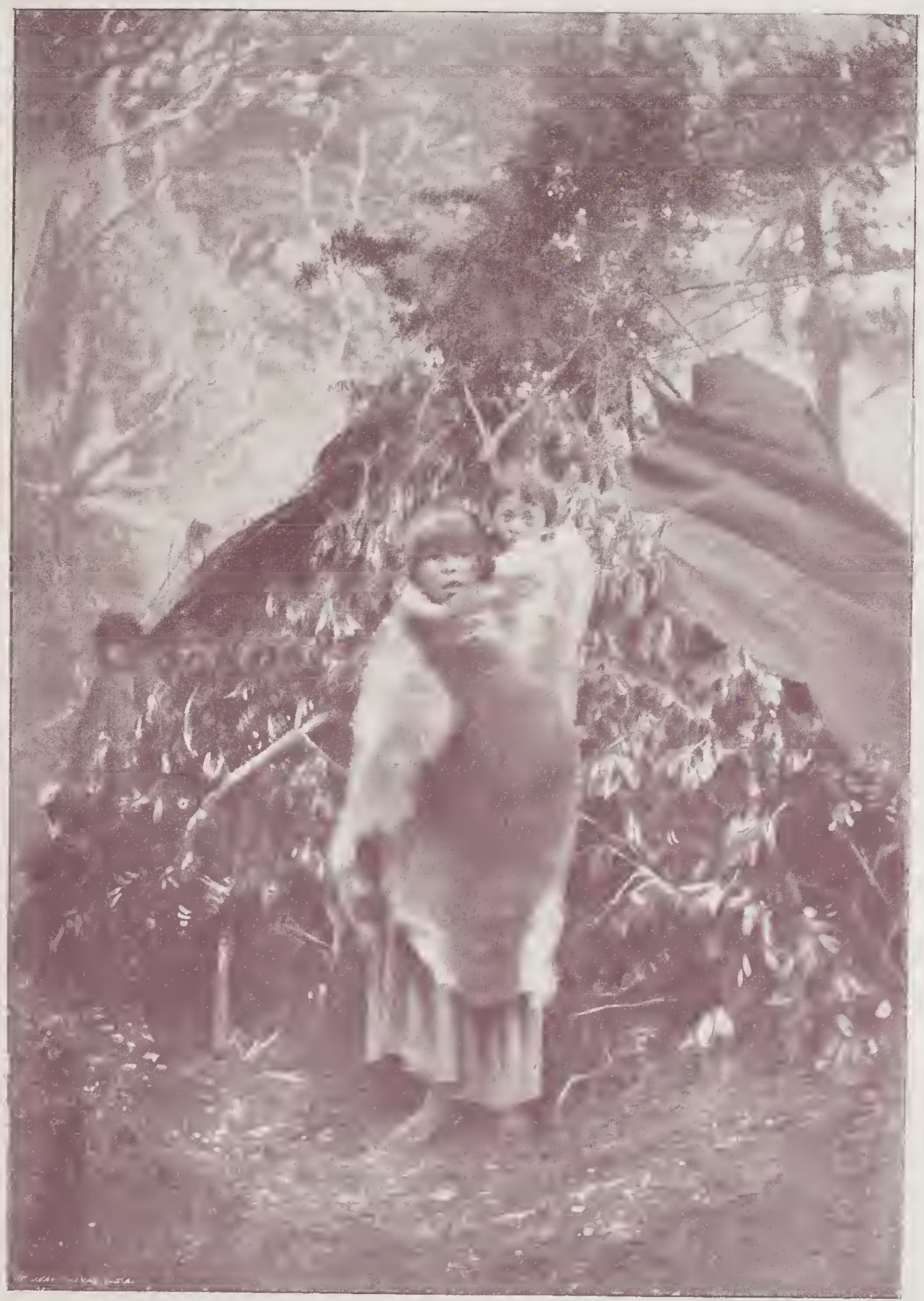

Plutegral lifo de M. I.eeointe.

IHG. I I.

HENE FEMIIE ONA. 

leurs mocurs: "Les rapports entre les femmes qui n’ont qu'un mari commun dans le wigram familial sont d'un intérèt bien nowveau. Il est de rigle qu'elles ne soient pas plus jalouses l'une de l'autre que nos enfants ne le sont entre eux dans nos propres foyers. La principale raison en est que souvent plusicurs d'entre les fommes sont soeurs. Un jeune homme prend, soit par consentement mutuel, soit à la suite d'un marché, la fille ainće d'une famille. S'il se montre bon chasseur et mari aimable, sa femme persuade à sa sœur de se joindre à elle, dans son wigwam, et elle partage avec elle l'affection de son mari. 11 arrive souvent qu'une jeune fille, devenant orpheline, est recueillic par unc famille et élevée pour devenir plits tard la femmo supplémentaire de son bienfaiteur. Dans la hutte, chaque femme a la place qui lui est assignée et elle y reste arec tout ee qui lui appartient, car la richesse du mónage n'est pas commune à tous les membres do la famille. Chaque femme a son propre panier de viande ou de coquillages, sa propre corbeille à outils, aiguilles, nerfs à coudre et morceaux de fourure, et chaque femme a ses propres enfants autour d'clle. »

I a femme ona est loin d'être jolie; mais, lorsqu'elle est jeune, son corps, qu'clle ne voile guère, se montre élégant et souple. Au cours de notre visite, nous avons déentvert dans un wigram une jeuno cnfant qui ne rappelait que de tris loin le type ona. Nous avons appris qu'elle était née d'une mère inclienne et d'un matelot allemand.

Pauve mignonne, toute blondc et bouclée, avec de jolis ycux bleus, elle tremblait de froid, bien qu'enveloppée de fourrure. Elle nous examinait avee le regard triste et résigné des enfants qui ne doirent pas vivre.

Nous avons pris la photographie du groupe de la mère et de l'cufant debout devant un wigram. (Voir fig. I r.)

Les hommes sont de visage plus sympathique que les femmes. T.cur stature cst superbe; ils mesurent deux mètres en moyenne. La chasse est leur unique occupation. Ces jours-là, ils lévent le camp, 
car, étant nomades, ils emportent arec eux tout ce qui constitue leur richesse.

Les femmes rassemblent les menus objets : les peaux de guanaco, les restants de viande, les flèches, les paniers tressés, qu'elles roulent dans une raste peau, pour en former une charge longue de deux mètres environ, pesant de soixante à soixante-dix kilos et traversée, en longueur, par une branche d'arbre. Unc lanière de cuir réunit, extérieurement, les deux extrémités de la branche.

Réellement étrange la manière dont la femme emporte ce fardeau. Elle se couche sur le dos, et, en rampant, passe la tête, puis un bras dans la courroie. Se soulevant alors peu à peu, elle se redresse en entraînant la charge sur son dos. Généralement, le plus jeune enfant, enveloppé tant bien que mal dans un morceau de fourrure, est attaché au sommet de la charge. Alors, courbée sous le faix, tenant encore à la main d'autres enfants, elle suit son mari pendant de longues marches, semées de dangers et d'angoisses.

Les préparatifs de l'homme sont moins compliqués : il s'enveloppe d'une peau, couvre sa tête d'un bonnet de forme triangulaire ct attache, à son còté, un carquoi rempli deflèches de bois dc hêtre munies d'une pointe de pierre, de verre ou de fer, lorsqu'il peut en trouver sur l'emplacement d'une station où les blancs ont séjourné. Ils se réunissent à plusieurs pour tàcher d'envelopper un troupeau de Photographlie du $v_{1}$ Cooh

I:1G. I2. guanacos. A un signal donné, les chasseurs lais- 
sent tomber leur fourrure et, entièrement nus, fondent tous à la fois sur leurs proies. Alors, ils se livrent au carnage, puis, rejoints par les femmes et les enfants, ils se gorgent de viande comme des fauves.

Le soir, on reforme le wigwam. Quand les ressources sont épuisées, on repart à la recherche d'une nouvelle capture, dans les Montagnes Rocheuses, où, malheureusement pour eux, le gibier se retire, de plus en plus, sur des points inaccessibles.

Pauvres déshérités, qui, du sommet de ces hauteurs, voient les vastes plaines où, jadis, ils vécurent dans l’abondance et la paix!

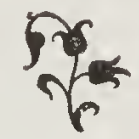




\section{CIAPITRE XIII.}

\section{C'est vous le nègre?}

Le 6 janvier, lendemain de notre visite aux Onas, nous allàmes mouiller de l'autre eôté de la presqu'ile de Harberton, où nous espérions faire de l'eau dans nos réservoirs. Malheureusement, nous eùmes bientôt la certitude que nous ne pourrions, sans grandes difficultés, parvenir en canot à l'endroit de la rivic̀rc où se trouve l'eau douee. Pour eomblc d'ennui, le ehaland, dans lequel nous avions mis une partie de nos briquettes de charbon lors dc notre éehouage, étai échoué également à la côte. Effrayé à l'idée de s'attarder eneore pour rembarquer ce eombustible, de Gerlache se déeida à en fairc présent à M. Bridges, en reconnaissance de tous les services qu'il nous avait rendus.

Nous appareillâmes done de nouveau pour nous rendre à Saint-fean, dans la Terre des États, où, d'après les instructions nautiques, nous ferions facilement de l'eau douce.

Le 7 janvier I 898 , à 3 heures, nous étions à l'cntrée clu golfe de Saint-Jean, ayant traversé le détroit de Lemaire dans d'excellentes conditions, avec vent arric̀re et jolie brise.

Dès notre arrivée, le sémaphore nous invite à nous faire eonnaitre, et, quelques instants après, l'adjudant de la préfeeture maritime, M. Fernandez, ainsi que le médeein, MI. Ferrand, se rendent à notre bord.

Nous apprenons avee une vive satisfaction que le gouvernement argentin, préroyant le eas où nous aurions besoin d'aide, a eu l'extrême graeieuseté de donner ordre à ses gouverneurs et préfets maritimes de se mettre éventuellement à notre disposition.

Dès que MI. Fernandez eonnáît nos diffieultés, il nous annonce que 


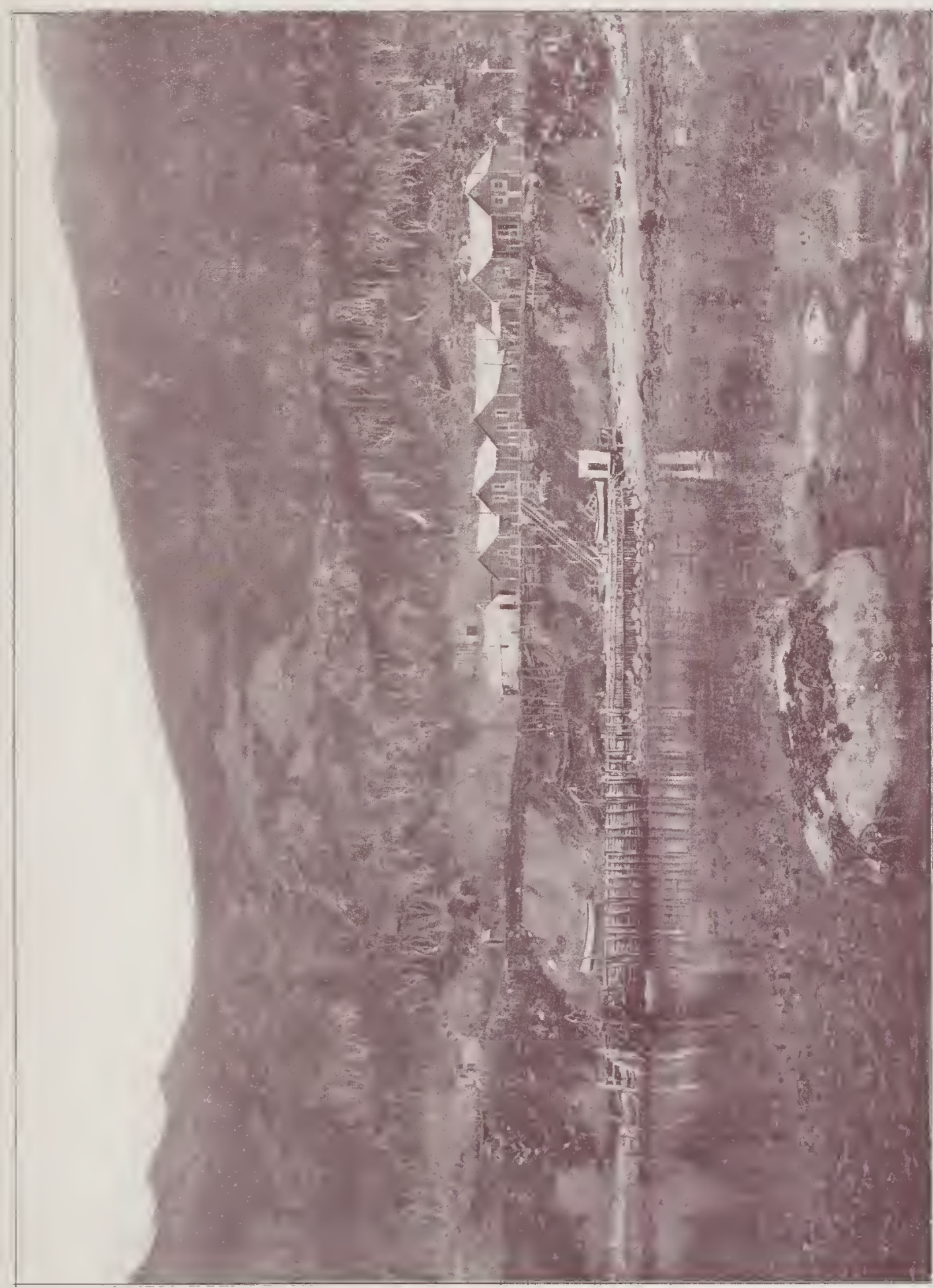



des matelots argentins allégcront la tâehe de nos marins, en apportant l'eau douee en eanot jusqu'à notre bord.

Pendant ees pourparlers, la Belgica continuait sa route, puis allait mouiller au fond du golfe. de Gerlaehe invite nos hôtes à venir se rafraîehir au carré et, pour les mieux fêter, remonte la boîte à musique. L'air est assez mélaneolique: l'Ave Maria, de Gounod.

Le Dr Fierrand éeoute avee émotion, puis, finalement, pleure à chaudes larmes! Ce chant est le dernier qu'il entendit de la voix de sa fille, à Buenos-Ayres, avant de s'embarquer pour la Terre des États. Il pense à son foyer, à sa famille qu'il a quittée depuis plusieurs mois et que, de longtemps, il ne doit plus revoir.

Heureusement, voiei la fin de la mélodie, puis, une légc̀re pose, et soudain éelate la ralse de Faust.

Fernandez rayonne, il n'est point partisan de la mélancolie : c'est l'homme le plus simple et le plus joyeux qu'on puisse rêrer; aussi, lui et moi, nous sommes bientôt amis.

Nous nous quittons à la tombée de la nuit, et, comme le surlendemain est un dimanche, nous promettons tous d'aller dîner à la préfecture.

Le samedi, 8 janvier, l'embarquement de l'eau continue. Ce travail se fait lentement, malgré le nombreux personnel. Parfois, les rafales sont si violentes, qu'il faut interrompre les manouvres. A un moment clonné, eomme le eanot aeeoste, je suis obligé, puisque seul, de laneer moi-même l'amarre. Debout sur le bastingage, je ealeule mal le poids du filin, et, dans mon brusque effort, je me jette à la mer! En un instant, je suis repêehé, mais mon jovial ami, Fernandez, ne manque pas de me railler plaisamment, en me donnant le surnom de "Chef plongeur "!

Cet incident eut une conséquenee assez sérieuse : au moment de ma chute, j'étais porteur du ehronomètre de poche, le seul que nous possćdions à bord et qui ne se remit jamais de ce bain glacé.

I.e dimanclie, un grand eanot de la préfeeturc, commandé par le 
maître d'équipage Morgan, vint nous prendre. Dès que nous atterrissons, Fernandez et son "état-major " se portent à notre rencontre. Nous sommes aceueillis avec cmpressement et conduits à la salle du festin.

Avant d'énumérer les convives, il est utile de dire que la Terre des états était (à cette époque) un lieu de déportation pour los condamnés aux peines de longuc durée et notamment à la détention perpétuelle.

Comme clle est absolument isolée et bien rarement visitée par un navire, les prisonnicrs pouvaient sans inconvénient y jouir d'une grande liberté.

S'ils s'échappaicnt, c'était momentanément, car la faim les obligcait à revenir au gîte. Et puis, le directcur ct les surveillants se montraient lhumains, n'ayant jamais recours, sans nécessité, aux mesures rigoureuses. La Terre des États était done le paradis terrestre des assassins... qui méritaient une certaine liberté.

La table de Fernandez était assez étrangement composée. Outre le Dr Ferrand et deux licutenants d'infanterie au service de la place, l'adjudant avait convié le capitaine d'infanteric C..., détcnu, et sa jeunc femme.

Cet officier avait été condamné à la détention perpétuelle pour avoir brûlé la cervelle au major commandant son bataillon. Par faveur spéciale, sa femme, une jcune et jolie Espagnole, était autorisée ̀̀ partager sa captivité. Sans doute, ce meurtro avait été la conséquence d'un drame passionnel, d'un accès de folic, car rien, dans cet homme intelligent et distingué, ne trahissait des instincts crimincls. Fernandez, tout en observant les règlements à la lettre, cherchait à adoucir le terrible châtiment du coupable et à rendre moins crucl le martyre de la jeunc femme.

Le luxe n'est pas chose très connue à Saint-Jean : le dîner fut servi dans des plats dépareillés; les assiettes appartenaient à des scrvices différents, comme dimensions et couleurs; mais nous étions reçus avec tant de cordialité, nous mangions de si bon appétit, que nous 
nous aperçumes à peine que toutes les viandes consistaicnt en inouton diversement préparé !

Un nègre nous servait. 1)’une trentaine d’années, robuste, alerte, mais bavard s'il en füt, John ne eontribuait pas peu à nous égayer. En présentant les plats, il insistait aupres des eonvives eomme s'il eut été le maître de la maison. De temps à autre, il adressait même à l'adjudant des boutades, dont ehaeun riait de bon coeur. Un père, ee Frernandez!

Pendant une éelipse de ee serveur genre exotique, Fernande\% nous eonta son histoire.

John, étant soldat, arait été mis de faction à un poste important - prés d'un magasin à poudre, je crois - et on lui avait ordonné de tirer sur quieonque tenterait d'approeher. A peine était-il à son poste, qu’un individu s'avança vers sa guérite. John, par trois fois, lui intima l'ordre de s'arrêter et de répondre; puis, voyant que son injonetion ne servait à rien, il eoucha en joue et fit feu. L'homme tomba raide mort.

Aussitôt, le pauvre nègre fut saisi d'épouvante : il a fait son devoir de soldat, mais il est devenu assassin!... Qu'allait-on dire? Le traduire devant un conseil de guerre, le condanner à mort?...

Rempli de perplexité et d'angoisse, il abandonna son poste et s'en fut se eacher. Peu de temps après, il fut arrêté et condamné à uno longue détention, non pas pour aroir tiré, mais pour avoir déserté son poste.

Après le repas et la visite du phare et du eampement, nous allons en eanot jusculau Cap Frmmeaux, examiner de près une immense rockery d'otaries ou lions de mer (r).

La chasse de l'otarie et du phoque à fourrure est assez rémunératrice dans eette île, où elle fait l'objet d'une eoneession. L'adjudant Fernandez est chargé de garder la chasse, mais il dispose d'un

(I) Le mot rockery a le même sens: que le mot ville. 
matériel de surveillance absolument sommaire : deux canots et trois petits canons, qui ne veulent pas toujours fonetionner.

Quel remue-ménage! quel branle-bas général dès que nous mettons le pied dans la rockery! Nous avons cependant le temps de photographier les animaux avant qu'ils puissent regagner la mer. Des bêtes superbes! Les mâles surtout, dont le corps est long de 3 à 4 mètres et dont la tête, ainsi quo le cou, sont garnis d'une épaissc crinière. Ils poussent des hurlements de menace en découvrant leurs crocs, mais nous n'avons pas peur... ils n'attaquent jamais l'homme.

Bientôt ils ont tous repris la mer, il ne reste plus qu'un ménagc avec deux toutes petites otaries nées depuis une couple d'heures à peine. Comme elles ne peuvent se glisser lc long des roches, le perre se place près d'elles pour nous empêcher d'approcher.

Ce serait là une jolie capture, mais nous n'avons pas de fusil. Cook et Racovitza lancent aux parents dos fragments de roche. La mère est touehće, elle saisit dans sa gueulc un dc ses enfants et se jette à l'eau. Le mâle hésite, puis, atteint à son tour, il plonge également, nous abandonnant son petit, que Cook va saisir et qu'il rapporte dans ses bras jusque dans le canot.

L'après-midi du ı janvier fut consacrée tout entière à la visite de plusieurs rockerics.

Comme nous descendions pour retrouver notre canot, Danco glisse et tombc à la mer. Décidément, l'ìle Saint-Jean est propice aux plongeons! Tout préoccupé de sa montre, il la tire de sa poche, pour l'examiner, au moment même où on venait de le repêcher. Justement, une petite lame secoure le canot et la montre de Danco, à laquelle il tenait tant, tombe à l'eau sans retour. Assurément, un sort cst jeté sur nos montres. Nous aurons, sourent encore, l'occasion de déplorer ces deux accidents.

Notre ami est trempé — on le serait à moins! — mais il refuse de rentrer pour changer de vêteunents.

Nous poursuivons donc notre ronte et parrenons à une rocliery 
d'otaries. Vite quelques coups de fusil sur les plus belles bêtes ! Pendant que Racovitza s'occupe à les examiner, à lcs mesurer, nous amarrons, à l'arric̀re du canot, une otarie superbe. Malheureusement, la mer s'étant levéc, nous fûmes obligés de lâcher notre capture, qui, par son poids, empêchait le canot d'avancer. A notre rentrée à la station argentine, Danco est encore mouillé; aussi Fernandez lui donne-t-il un habillement complet... de forçat. Danco n'en est pas plus fier pour cela!

L.e I I janvier, Fernandez vient à bord pour s'assurer de l'activité de son personnel. Son nigre, qui cumule les fonctions dc serveur avec celles de cuisinier, de valet de chambrc, etc., l'accompagne.

John se montre si enthousiasmé de la Belgira, que de Gerlache pousse la gracieuseté jusqu'à faire porter pour lui sur le pont notre boîte à musique dc sccond ordre, cellc dont les airs se débitent " au mètre courant ". John, alors, ne se tient plus de joie: il pousse des cris d'allégresse et demánde à tourncr la manivellc. Le commandant, enchanté de l'effet produit, offrc à John, en plaisantant, d'occuper à notre bord le postc de cuisinier.

Le nćgıce, lui, ne plaisante pas. Il s'écrie que son rêve scrait dc partir avec nous, mais que la chose est impossible, puisqu'il est prisonnicr! "Après tout, déclare Fernandez, John n'a plus à faire qu'un an de peine. Si le commandant veut adresser, pour lui, un recours en grâce au présidcnt de la République Argcntine, je l'appuicrai de toutes mes forces, et il est à présumer que cette rcquêtc sera exaucće, étant donné que John honorera son pays cn prenant part à l'expédition belge. "

En écoutant cette cxplication, de Gerlache est pris d'un scrupule : acceptcr, c'est enlever à Fernandez son homnnc de confiance. Mais celui-ci le rassure: il se tirera d'affaire en pcu de temps et il sera satisfait d'avoir fait plaisir à son nègrc. Sur-le-champ, on rćdige la rcquête, qui sera envoyće à Buenos-Ayres par le premier navirc de guerre abordant à Saint-Jean. Il est, en outrc, décidé que, vers la fin 
de l'été antarctique, nous reviendrons chercher Jolnn, avant de prendre nos quartiers d'hiver en Patagonie.

Cependant, les jours se passaient et nous étions encore à SaintJean : l'équipage emplissait les réservoirs et je cherchais en vain quelques minutes de soleil pour régler les compas, dont les nombreux déplacements d'objets en fer, sur le navire, avaient fait varier les constantes magnétiques, depuis notre départ d'Europe.

Impossible, par ce temps gris, de faire des observations directes. Danco et moi, nous avions, un jour, fait usage de la méthode des relèvements réciproques, mais les résultats obtenus ne furent pas suffisamment sérieux. D'un autre côté, comment partir vers le Sud avec des compas non réglés, alors que nous allions explorer une région absolument inconnue?

Enfin, comme le soleil boudait toujours, de Gerlache décida que, contte que coûte, nous partirions le matin du I4 janvier.

Le 13, dans l'apròs-midi, le soleil, que nous ne cessions de guetter, se montra pendant quelques instants. Vite nous réglons lc compas aussi bien que possible, et, à la tombée du jour, toutes les dispositions sont prises pour l'appareillage.

Le $\mathrm{I}_{4}$ janvier $\mathrm{r} 898$, à 5 heures du matin, nous défilons derant Saint-Jean. Le phare et le sémaphore de la préfecture nous envoient des souhaits de réussite et d'heureux retour, auxquels nous répondons par d'affectueux rcmercîments.

Fernandez a promis une salve de toute son artillerie. Si les pièces fonctionnent, il y aura trois coups. Ah! voici : un $!$. . deux!... c'est tout!... La troisième pièce n'a pas voulu parler!

Fernandez est sur la côte; nous lui envoyons, dans nos longuesvues, un dernier regard ami. John, placé auprès de son maître, nous fait force signaux. $\Lambda$ bientôt, ami nègre! Dans trois mois, nous viendrons te prendie!

L'homme propose et les érénements disposent. Trois mois après, la Belgica était cernée dans les glaces, d'où elle ne devait se dégager 
qu'au mois de mars I899. John, gracié par le président de la République, à la condition expresse qu'il s'embarquerait avec nous, attendit donc en vain notre retour pendant deux ans et fit ainsi un petit stage supplémentaire au bagne.

Pauvre John!... Nais qu'importe : il a dû faire de beaux rêves pendant ce laps de temps!

- Ah! c'est vous le négre? Très bien! continuez, aurait dit MacMahon, continuez... à attendre la Belgica!

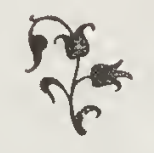




\section{CHAPITRE XIV.}

\section{La mort de Wiencke.}

Enfin, nous voguons vers l'Océan Glacial Antarctique.

Après l'expulsion d'un certain nombre de nos marins à PuntaArenas, lc manque de personnel avait astreint de Gerlache à modifier notre plan cle campagnc et à tracer l'itinéraire suivant : Faire routo rers les Shetland du Sud, en suivant à peu près le méridien de Saint-Jean, traverser le détroit de Bransfield et cxplorer le golfe de Hughes. Là, rechercher notammont si un chenal ne conduit pas du Sud dc ce golfe à la côte orientale de la terre de Graham soit directcment, soit par l'intermédiairc du détroit de Bismarck (1). Dans cette éventualité, faire une reconnaissance dans la mer de Georges IV (2). Allcr passer l'hiver au Sud de l'Amériquc, afin d'y compléter nos approvisionnements, ainsi que notre personnel, et y embarquer notre nègre. L'année suivante, retourner dans la mer de Georges IV, si notrc campagne de rcconnaissance nous y engageait et, dans le cas contraire, longer la banquise, vers 1'Est ou vers l'Ouest; enfin, prendre la mer dc Ross pour base de nos općrations.

La campagne serait alors poursuivie, ainsi que nous l'avions prévu tout d'abord : de Gerlache, Amundsen, Danco ct Arctowski ou Racovitza hiverneraient à la Terre Victoria. Je prendrais alors le commandement de la Belgica, que jc conduirais à Mclbourne pour être ravitailléc, puis j'emploicrais la mauvaise saison à faire, dans

(I) Ce détroit, d'après Dalleman, serait orienté de l'Est vers l'Ouest et découperait le Nord de la Terre de Graham; son entrée occiclentale se trouverait par environ 65010' de latitude australe.

(2) En I823, Weddell trouva cette mer libre de glace jusqu'au delà clu parallèle $74^{025 !}$. 


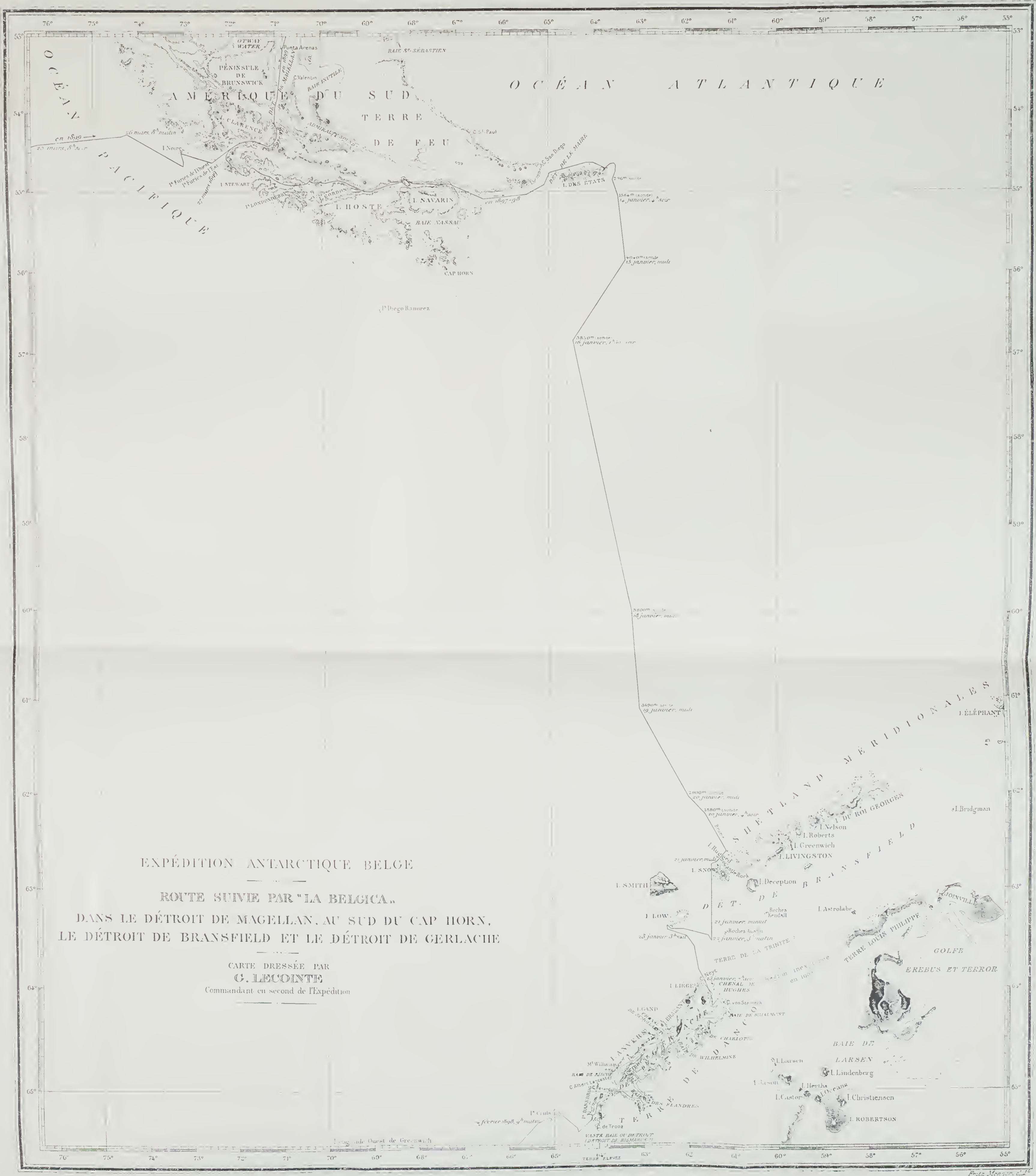



le Paeifique, une eampagne, dont de Gerlaehe me laissait la liberté de traeer l'itinéraire. L'été suivant, la Belgica irait reprendre les explorateurs à la Terre Vietoria; nous eontinuerions avee eux les études eommenećes et, à l'approehe de 1'hirer, nous rentrerions en Europe.

La durée du voyage serait ainsi portée à trois ans, au lieu de deux.

Nous n’étions pas très éloignés de la T’erre des létats, le I 4 janvier à midi, lorsque nous fìmes le premier sondage à l'aide de la maehine Le Blane.

Naturellement, les ehoses ne marehcrent pas, d'abord, sans un eertain tâtonnement, ear l'installation de tous les aeeessoires de eet engin avait été faite hàtivement et un peu au hasard dans l'Oeéan Atlantique.

Tandis que le eommandant dirigeait avee beaueoup d'adresse la marehe du bàtiment et eelle de la maehine à sonder, Aretowski, installé sur une étroite passerelle aecroehée aux flanes du navire, s'oeeupait de la sonde proprement dite et je déterminais moi-même les eoordonnées géographiques du sondage.

La brise ctait fraîehe et la mer fortement ondulée sous l'effet d'une grosse houle. Le navire roulait, à peu près, sur plaee.

La profondeur trouvée fut de $29^{6}$ mètres, et, à 5 heures du soir, un deuxic̀me sondage indiqua I,560 mètres.

Du r 5 au 20 janvier, nous suivîmes la même route vers le Sud. 'Tous les jours, nous nous arrêtions pendant quelque temps pour sonder, pour mesurer les températures sous-marines et prendre des éehantillons d'eau à diverses profondeurs, à l'aide des bouteilles de Sygsbee ou de Buehanan.

Le r5 janvier, la sonde donna 4,040 mètres; 1e I6, 3,850. La température relevée à eette dernière profondeur était de $+\mathrm{I}_{2}{ }_{2} \mathrm{C}$. Le I 7 janvier, la mer fut tellement agitée, qu'il ne pût être question de sonder. Nous en fûmes d'autant plus au regret, que nous étions arrivés 
à un point important, placé à mi-chemin entre la Terre des Ĺtats et les îles Shetland.

Le is et le I9, grandes difficultés encore pour les sondages. de Gerlache releve successivement 3,800 et 3,69o mètres, profondeur: accusant, nous dit Arctowski, thermometrc cn main, une température, dc fond, de $+0^{0} 6 \mathrm{C}$.

Le 20 , lc sondage ne put s'effectuer que grâce au filage de l'huile sur les flancs du navire, contre lesquels la mer brisait avec force. Les amplitudes du roulis étaient considérables. 'l'out à coup, le dynamomitre ( $\mathrm{r}$ ), supportant la poulic extćricure dans laquelle passait la lignc de sonde, fit un écart indiquant une diminution de force de roo kilogrammes. Les opérateurs, s’imaginant que le sondage était terminé, relcvèrent la sondc : ils avaicnt filé I,290 mètres de cordelette! de Gerlache, d'accord avec Arctowsli, fit immédiatement recommenccr lc travail, et, ectte fois, nos camarades trouvèrent 2,900 mètres.

L'après-midi, noureau sondage de I880 mètres. Commc nous relevions la ligne, le fil se rompit et nous en perdimes $r, 400$ mitres.

De l'enclroit où s'effectuait l'opération, nous pouvions distinguer, au loin, une terre dans un sccteur compris entre le Sud-Sud-Ouest et

(I) Lorsquion sonde a de grandes profondeurs, il n'est pas toujours facile de se rendre compte du moment précis ou la sonde touche le fond. S il y a crreur, la cordelette continue à se dérouler par son propre poids. Pour saisir le juste moment, on opèc comme suit : on fait passer, en dernier liet, la cordelette sur une poulie suspendue à un dynamomètre, et, à mesure qu'on en file, l'aiguille du dynamomètre indique une marche ascendante. Lorsque la sonde - qui est très lourde - touche le fond, l'aiguille indique brusquement un écart, en sens inverse. Dans la pratique, les choses ne peuvent pas toujours se passer aussi régulièrement. Sous l'effet du roulis ou du tangage, la cordelette subit des chocs qui, se transmettant au dynamomètre, réagissent parfois sur la marche indiquée plus haut. J'ar grosse mer, nous avons eu des écurts fréquents de 75 kilogrammes. Le sondage du 20 janvier indique que l'écart peut même atteindre roo kilogrammes. 
le Sud-Sud-Est. A bâbord, nous avions l'île Livingstone, et, à tribord, l'île Smith, sous la forme d'un immense prisme de glace.

Les Shetland du Sud sont comprises entre les paralletes 6 r $^{\circ}$ et $63^{\circ}$, et entre $53^{\circ}$ et $63^{\circ}$ de longitude Ouest de Greenwich. Elles sont tris nombreuses et l'aeeés vers le Nord en est défendu par un grand nombre de réeifs. Les Shetland sont presque toujours couvertes d'une épaisse enuehe de glace. Elles présentent déjà les earactères des terres plus rapprochées du pôle, clont nous parlerons plus loin.

I.a plus euricuse de ces iles, l'île Déception, a une forme presque eireulaire. La mer y découpe le port Forster, qui passe pour le meilleur de tout cet arehipel.

Au Sud, le détroit de Bransfield sépare les îles Shetland de la Terre de foinville, de la Terre Louis-Philippe, de la Terre de la Trinité, de la Terre de Danco et de lile Liége. Ce vaste détroit est formé par une partie de mer mauvaise à la navigation et où les vents soufflent eonstamment en tempête. D'une année à l'autre, l'aspect en est varié : parfois, pendant l'été austral, il est encombré de glaces défendant la route vers les terres du Sud; d'autres fois, les icebergs y sont en nombre eonsidérable, mais neentravent en rien a navigation, lorsque le temps clair permet de les éviter.

A propos des Shetland clu Sud, il me revient une histoire qu'on raeontait tout bas, en 1897 .

11 y avait une fois un litat de l’Amérique méridionale, animé du violent désir de prendre possession des Shetland du Sud, îles qui, aujourd'hui eneore, n'appartiennent à personne. Le gouvernement de eet État savait que la chasse aux cétacés pouvait devenir trìs fructueuse dans ces îles, où le phoque à fourrure semblait revenir. Mais comment faire?

Le gouvernement lança d'abord un ballon d'essai : beaueoup de narires au Sud du cap Horn étant cntraînés vers les Shetland par d'épourantables tempêtes, n'aceomplirait-on pas un acte de charité en ćtablissant un poste de sceours dans ces tristes régions? Personne ne 
fut la dupc de ces bons sentiments et un coup de fusil, tiré en l'air par une marine du Nord-Ouest de l'Europc, troua la nacelle, mais ne cıeva pas lc ballon, qui continue à planer.

Alors le gouvernement sud-américain eut une autre idée. Puisque la charité n'avait pas eu d'adeptes, si l'on essayait đe la science?

On s'informa discrètement en Norvège du prix d'un baleinier qu'on équiperait en vue d'une cxploration seientifique ct dont le capitainc recerrait une mission spéciale.

Mais la puissance maritime du Nord-Ouest de l'Europe (qui ne prend pas les Shetland, mais ne veut les voir à personne) eut rent de ce projet et ellc prescrivit à unc de scs divisions navalcs (I) de se porter vers le Sud dès que le navire exploratcur commeneerait ses inrestigations.

Sur ces entrefaites, lc gouvcrnement américain eut des difficultés avec scs voisins. Il cessa alors des préparatifs d'autant plus inopportuns, que l'appui de la puissance maritime du Nord-Ouest de l'Europe lui devenait indispensable.

Il est bien entendu que tout cela appartient à la légende! Je ne parle de ces bruits que pour montrer l'intérêt que certains États attachent à la possession des Shetland (2).

Pendant la nuit du 20 au 2 I janvier, une brume épaisse courrit la mer. La navire continua néanmoins, à demi-vapeur, sa route vers $1 \mathrm{c}$ Sud. A minuit, nous doublàmes un fragment d'iceberg (3), lc premier que nous eussions rcncontré.

Dès 5 heures du matin, lc 2I, comme nous stoppons pour remettre une bague à l'un des tubes du eondenseur, le mécanicien laissc

(I) Qui se trouvait, à ce moment, non loin de là, aux îles Falkland.

(2) La Reine d'Angleterre avait été choisie comme arbitre dans le conflit surrenu entre l'Argentine et le Chili.

(3) Les icebergs sont des glaces flottantes que nous décrirons plus loin et dont no:us expliquerons la formation au chapitre $\mathrm{XX}$ de ce récit. 
tomber la pression et nous entendons un murmure lointain provenant de la collision des glaces,

A 7 heures, la brume devient de plus en plus intense. Malheureusement, la pression est toujours faible dans la machine; s'il fallait mancuvrer hardiment, la situation scrait difficile.

A 8 h. I/2, j'étais de quart sur la passercllc, lorsque je vis droit devant moi un fragment d'iecberg. Comme il était assez volumincux et que la mer semblait nous porter de ce côté, je fis augmentcr la ritesse dc la machine, afin de sentir moins vircment l'effet du courant.

Je parvins à éviter le glaçon; eependant, le navire subit un ehoe qui me parut insignifiant et que j'attribuai an fait que nous avions probablcment "donné " sur la partic immergéc de ce fragment d'iceberg. Il n'en était pas ainsi, ear l'état-major, qui se trouvait au carré, ressentit vivement la commotion, et, en un instant, tout le monde fut sur le pont.

Presque aussitôt, nous aperecvons, à quelques mètres de notre étravc, une longue ligne de récifs. Le commandant télégraphie à la machine de marcher en arrière, tandis que, juché à l'extrémité du bcauprć, j'cssaye de percer la brume et de signalcr à de Gerlache ce qui se passe sur notre avant.

La machinc s'est arrêtée; mais, la pression étant trop faible, elle ne veut pas marcher en sens inversc. La Belgica continue done son chemin jusqu'au moment où, perdant heureusement son erre, ellc va donner doucement sur des récifs. Lc ehoe la rejette de quelques mètres en arrière, oì elle touche encore un autre banc de roche.

Alors les feux sont poussés le plus activement possible, afin dc fuir ces dangereux parages. Dix minutes plus tard, lc navire roguait vers le Nord-Ouest.

Les réeifs que nous avions abordés sont ceux qui défendent, au Nord-Ouest, l'aceès de l'île Livingstone (près de l'île Rugged).

Cet ineident, qui fut sans conséquence matérielle, nous arait per- 
mis de faire un sondage de plus... avec la quille (!) comme disait l'amiral \ouchez $! . .$.

L'ensemble de tous nos sondages effectućs entre la Terre des États et l'île Rugged permet de déduire certaines notions de géographic physique, présentées par M. Arctowski dans une conférence donnéc, le 20 décembre I899, à la Société royale belge de Géographie (I), ainsi que dans une note préliminaire présentée par MII. Renard et Arctorslì à l'Jcadémie royale de Belgique (2). Le profil bathỹmé-

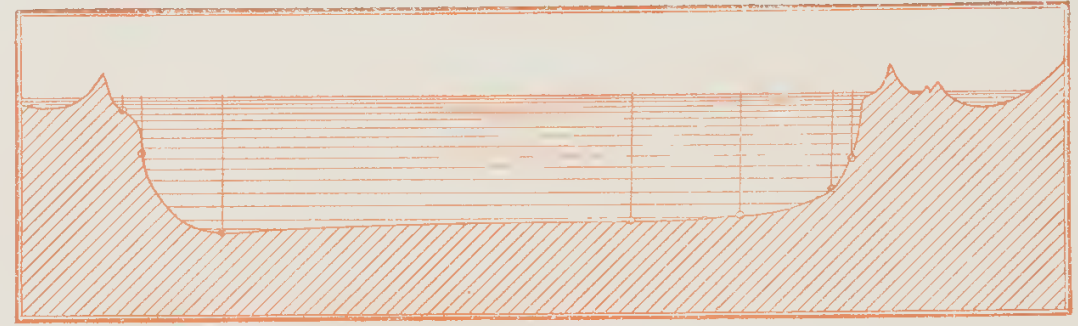

Ile des Elats.

Shetland du Sud.

TIG. If

PROIIL, DATIIMLTRIQUE, D'APRIS II. ARCTOWSKI.

trique (fig. I4), joignant l'Annérique aux Shetland du Sud, présente une curette à fond plat, qui se relève doucement vers les îles Shetland. Devant chacune de ces îles, le plateau continental forme une bordure étroite, au delà de laquelle les pentes deriennent très abruptes.

L'analyse des températures de l'eau de mer établit:

Io Qu'étant donnée une même profondeur, la chaleur s'abaisse à mesure que l'on approche des iles Shetland;

(1) Géographic physique de la Rigion Antartique aisitie far l'expédition de la Belgica. - Tome XXIV du Bulletix de la Sociéti royale belge de Géographie, $1900,10^{0} \mathrm{I}$.

(2) Notice préliminaire sur les sédinents marius recueillis par l'expédition de la Belgica - Tome LVI des Mímorres couronnés et aUtres Mémorres publiéz par l'Académie royale de Belgique, I gor. 
$2^{0}$ Qu'une couche d'eau glacée circule entre deux couches d'eau moins froides et augmente d'épajsseur à mesure aussi qu'on approche des Shetland.

Après avoir couru quelques milles au Nord-Onest, la Belgica reprit sa route vers le Sud-Ouest.

A midi 45, nous laissons, par bâbord, une roche élevée, de forme prismatique et de grande dimension. A l'entour, des roches plus petites, dont quelques-unes couvertes de neige.

Nous reconnaissons la roche Castel ct, quelques minutes après, nous voyons, du même côté, l'ìle Snow, recourerte d'une épaisse couche de neige.

Dès I heure 45, la brume s'épaissit encore.

Nous nariguons ainsi à deni-vapeur, faisant route rers le SudOuest, jusqu'au lendemain matin.

l.e 22, pendant une courte éclaircie, nous vîmes tout à coup la terre droit devant nous. 11 était 4 heures du matin environ.

A quoi bon avancer ainsi, les yeux bandés par le brouillard, d'autant plus que voici le rent qui se leve, agace la mer, la rend houleuse, méchante, au point que nous devons filer de l'huile. Le narire était dans une brume épaisse, qui rendait tout examen de la côte impossible. Il est done mis à la cápe et, tout en dérivant sous ses voiles auriques, il se dirige lentement vers le Nord-Ouest.

L'après-midi, la mer derint plus forte encore, et, comme une assez srande quantité de charbon, qui n'arait pu trouver place dans la cale, était sur le pont, le combustible roulait d'un bord à l'autre, cn cntraînant tout ce qu'il rencontrait sur son passaģe. Le bruit en était assourdissant.

Nos hommes se mirent alors à descendre le plus de charbon possible. P'endant ce travail, quelques dalots furent obstrués, de sorte que l'eau, cléversée sans cesse par les lames sur le pont, ne trouvait plus d'issue pour s'ćcouler. Ordre fut donné à l'équipage de se montrer tres prudent, et le matelot Wienelie reçut une observation de 
l'officier de quart, parce que, pour déboucher un dalot, il se tenait trop pris du bastingage.

Amundsen était de quart sur la passerelle; Cook auprès de lui. Tout à coup, un cri déchirant domine le vacarme! J'étais dans ma chambre; je me précipite sur le pont, où j'arrive en mème temps que le commandant : Wiencke est à la mer !... Malgré la défense qui lui en avait été faite, il s'était suspendu en dehors du bastingage; une laine, en passant, l'avait brusquement entraîné.

Comme le navire dérivait fortement, Wienclie, en un instant, se trouva à l'arrière (I). La ligne du loch passant près de lui, il la saisit, avec une réelle présence d'esprit, et l'enroula autour de son bras. Mais le navire continuant sa route, la corde était tirée violemment et le naufragé fut bientôt à l'extrémité de la ligne.

Pendant que le commandant prenait personnellement la direetion de la manocuvre, Amundsen examinait la possibilité de mettre un canot à la mer et Cook, qui avait saisi la ligne du loch, la tirait lentement à lui, afin de rapprocher Wiencke du bateau. Le malheureux, bien que maintenu à la surface, ne bougeait plus. Était-il paralysé par le froid ou bien à moitié asphyxié par la quantité d'eau de mer qu'il avait dû absorbcr?

Mettre un canot à la mer cût été folic, crime même : nous n'avions pas le droit d'exposer la vie de quatre ou cinq hommes pour risquer un sauvetage si peu certain.

Il n’y avait pas à hésiter; il appartenait à l'état-major de donner le bon exemple: je m'attachai une corde autour des reins; puis, avec la permission du commandant, qui, un moment, sembla indécis, je sautai à la mer.

Comme j'étais habillé, mes mouvements s'en ressentaient; de plus, l'eau glacéc (2) me paralysait. De lourdes lames m'élevaient pour me plonger ensuite dans un abîme sans fond.

(I) Wiencke, qui n'offrait pas de prise au vent, dérivait moins vite que le navire

(2) L'eau de mer ne se congèle que par 205 environ sous zéro. 
Wiencke ćtant tout contre le navire, je n'eus pas de pcine à le saisir et à l’enlacer; puis, le cour gonflé d'espéranee, je criai qu'on nous hissât à bord. Les matelots hâlìrent sur le filin, qui se raidit tout à coup sous leur effort et sous l'effet d'un violent coup) de tangage.

Je fus brusquement arraché hors de l'eau. J'éprouvai une secousse d'autant plus violente, que Wienelie était un grand et robuste garçon, dont le poids était encore doublé par l'cau imbibée dans ses vêtements. L'arrière du navire retomba dans la mer, la corde se détendit et me replongea dans la lame. Wienche était inerte, il arait les yeux grands ouverts, regardant dans le vague. I1 maintenait la bouche fermée et chassait avee force par le nez l'air qu'il respirait.

Deux ou trois fois, la corde se raidit, m’imprimant les mêmes secousses; je serrais Wieneke dans mes bras, mais mes forees me trahirent et je dus abandonner le malheureux.

Pendant un instant, qui me parut un sicele, je restai, douloureuse épave, suspendu au filin. Aretowski seul cn avait la charge; il l'avait enroulé au garde-corps de l'arrière et faisait des efforts surhumains pour m’aider.

Durant ce temps, des matelots, accrochés aux bastingages et soutenus par tous ceux qui étaient sur le pont, s'épuisaient à tâcher encore de saisir le malheureux Wienclie. Celui-ci, toujours retenu par le loch, dérivait sur le flane du navire.

Enfin, trois hommes revinrent à l'arricre et me hisscirent sur le pont.

Alors, je vis le naufragé, abandonné par la ligne, s'ćcarter lentement du bord, flotter au gré des lames, puis descendie peu à peu dans l'eau bleue, où son suroît jaune elair jetait une tache pâle... Wicncke disparut !...

Nous fûmes obligés de "fuir devant le temps " et d'aller demander un abri à l'íle Low, que nous venions d'apereevoir au noroît.

Quelle triste, triste nuit ! A bord régnait une véritable consternation. 
Un mort déjà, tout au début de notre campagne! Combien de victimes l'expédition ferait-clle? En était-il un seul d'entre nous qui reverrait le pays? A qui le tour maintenant ?

Lt durant le quart interminable que je passai sur le pont, en cette nuit de malheur, toujours je revoyais Wiencke, les yeux grands ouverts, sans vie, emporté à jamais par les flots! 


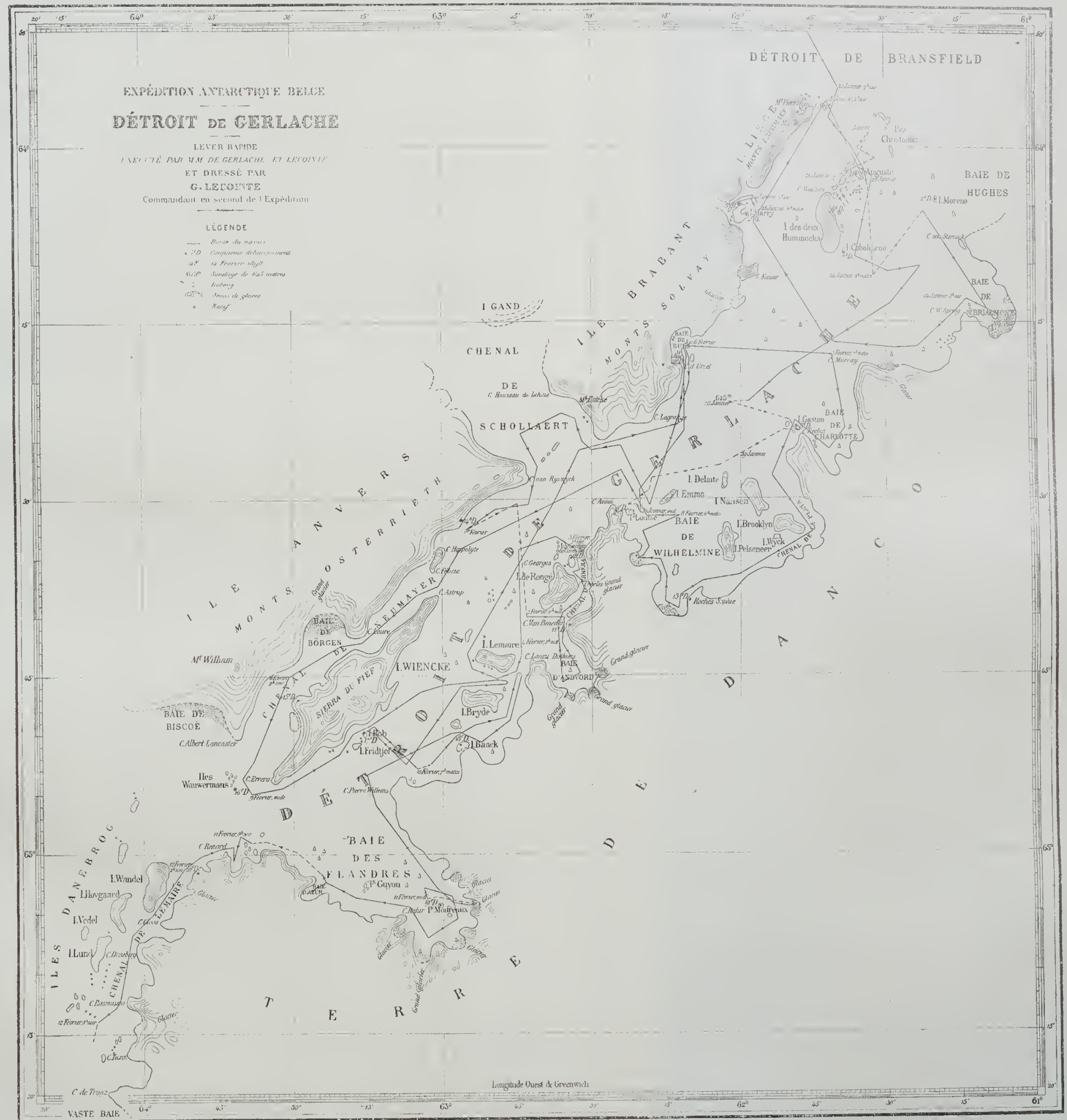

- outrolt 



\section{CHAPITRE XV.}

\section{Nos premiers débarquements dans l'Antarctique.}

Le dimanche 23 janvicr, dès les premicres heures du jour, le ciel se découvrit lentement. Vers 9 heures, il nous fut même possible d'observer le soleil et de déterminer une droite de hauteur passant par notre position.

La Belgica, endeuilléc, naviguait, vers le Sud, glissant, voiles déployées, sur une mer bleue, parscmée de superbes icebergs. I.e drapeau belge flottait à la corne d'artimon, le pavillon norvégien au grand màt, tous les deux en berne. Et chaque fois que nos regards rencontraient ces signes de deuil, nos coeurs se serraient en pensant au pauvre Wienclie.

A 5 heures de l'apres-midi, nous aperçumes un point noir, au loin, vers le Sud : la Terre de Graham.

lin un instant, nous sommes tous sur le pont, où les suppositions se croisent et s'entre-croisent. Comme un petit nuage noir plane au-dessus d'un sommet neigeux, il n'en faut pas davantage pour que l'un d'entre nous soit convaincu qu'il distingue un volcan... en aetivité! Ineontinent, un autre en voit un deuxicme, puis un troisicme! O puissance cle l'imagination!...

Pourquoi pas, après tout? N'a-t-on pas découvert, non loin de là, à l'île Déception, des volcans en activité?

En réalité, pas le plus petit volean. Nous en aequérons la certitude à mesure que nous approchons de la côte. Au reste, la vue est forcément bornée par la brume : quelques sommets émergent seuls ça et la.

Vers 7 heures du soir, après avoir doublé le cap) Neyl(1)(fig. I5),

(1) Les partics de terre et de mer, découvertes par l'expéclition, ne furcnt baptisées que jlus tard, lorsque nous étions dans la banquise. Nous les désignons, d'ores ct déjà, par leurs noms, afin que le lecteur puisse suivre plus facilement notre route sur la carte. 
nous faisons route vers le Sud-Est, laissant, par bâbord, deux sombres groupes d'îlots: les Christiania.

A 9 heures, nous sommes à proximité de l'île Auguste, où nous opérons notre premicr débarquement en "Terres Antarctiques $)$.

de Gerlaehe, Arctowski, Cook, Daneo et Racovitza se rondent à terre en canot.

A IO $\mathrm{I} / 2$ heures, tout notre monde revient à bord. J'apprends que le débarquement dans l'île ne s'est pas opéré sans diffieulté, ̀̀ cause de la levéc de la mer. Arctowski rapporte des échantillons de roche, tandis que Danco recueille, avec une sollicitude vraiment maternelle, deux jeunes manchots vivants (I).

Comme nous reprenons, à petite vapeur, la route du Sud, nous croyons distinguer une ouverture dans les terres : un détroit probablement? La brume, de plus cn plus opaque, nous dérobe bientôt la côte tout entière. La machinc est stoppée et nous cherchons à demeurer sur place.

Le 24 janvier, vers I heure du matin, l'officier de quart constate que le navire est si près de la terre, qu'il faut virer de bord et gagner le Nord-Est, afin de n'être pas drossé à la côte (2).

La nuit et une partie de la matinée s'achèvent de cette manicre, jusqu'à ce que nous atteignions l'île Moréno, où le personnel scientifique opère le second débarquement. Là, nos camarades trouvent des phoques au repos, qui, à leur approche, cntr'ouvrent paresseusement leur lourde paupière, puis la referment sans s'inquiéter d'eux, et aussi des manchots, s'indignant de cette visite inopportune.

A IO I/2 heures, les explorateurs sont de retour et nous cherchons à estimer la position du navire. Évidemment, nous sommes dans la région renseignée sur la carte anglaise sous la dénomination de Golfe de IIughes, mais impossible de constater autre chose: le navire a

(I) La description de ces oiseaux est donnée à la page 17 I de ce récit.

(2) Il est utile de suivre l'itinéraire sur la carte placée en tête de ce chapitre. 


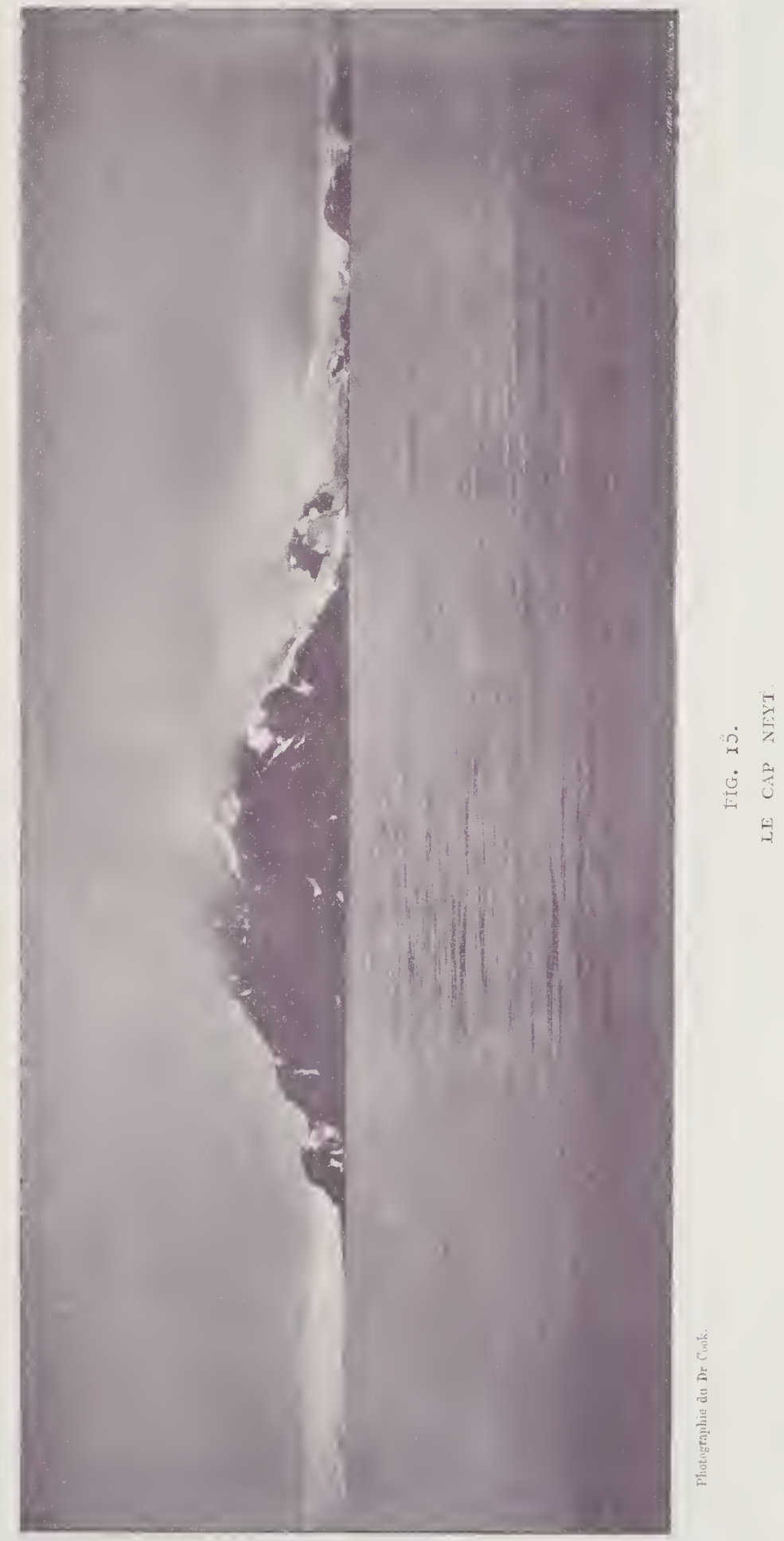



dérivé sous l'influence du vent et du courant, et le brouillard nous cnlève toutc espèce de point de repère.

Oủ retrouver l'île Auguste? au Nord? au Sud? à l'Ouest?...

Nous poursuivons notre route vers le Sud-Est et arrivons à une masse rocheuse, sans neige, que nous prenons pour un cap.

Tout à coup, le soleil pcrcc les nuages. Il est midi. Vite, mesurons la hauteur de culmination de l'astre et déduisons-cu notre latitude. Cc n'cst pas trè important comme renseignement, mais cette donnéc nous permet de fixer, approximativement, notre position et celle de la masse rocheuse. Un peu plus tard, nous constatons que cette masse est unc île de forme ovale, où pointent deux sommets cn oreilles d'àne, et séparée du cap von Sterneck par un étroit chenal. Puis, à la faveur d'une nouvellc et fugitive éclaircie, nous découvrons à notre avant la trouće cntrcvuc la nuit précédente. Nous nous y cngageons, pensant traverscr un détroit. Nullement. Après une heure de route, nous nous trouvons au fond d'une baie: la baie de Brialmont.

Nous virons de bord, longeant la côte de très près, afin que, malgré la brume épaisse, nous ne puissions passer à côté d'un chenal sans l'apercevoir. Nous relevons ainsi, par l'estime, toute la partic de la côte comprise entre le cap Spring et le cap Murray.

A 5 heures du soir, lorsque nous doublons ce dernier cap, nous apercevons deux canaux importants : l'un, dirigé vers le suroît, part du cap même; l'autre, orienté suivant le noroit, commence à l'île Harry et découpe en île la còte Nord-Ouest du détroit de Gerlache.

Le cap est mis sur le passage du noroit et nous en approchons, vers Io heures du soir. De la position que nous occupons alors, les différentes terres forment au loin une singulic̀re perspective : l'île des Deux Flummocks parait appartenir an cap von Stcrneck, tandis que le cap Kaiser (situé au Sud) semble prolonger les îlcs Nansen et Pelseneer, qui se projettent au loin sur la Terre de Danco. C'est comme si nous nous trouvions au centre d'un vaste golfe, dont l'entrée correspond au passage Nord-Onest. 
Comme, depuis notre dćpart de l'île Low, nous n'avions pu prendre qu'une seule droite de hauteur (près du cap von Sterneck) et que la brume nous avait empêchés de reconnaître l'emplacement de nos dcrniers débarquements, nous étions très incertains sur la position que nous occupions. D'un autre côté, l'importance des terres que nous côtoyions ne nous avait pas échappé.

Ces circonstances nous engagèrent donc à ne pas quitter cette région sans en avoir fait un lever, - lever rapide, car la saison avancée nous pourchassait, mais lever suffisant pour les besoins de la navigation, très restreinte dans ces parages. Il fut donc décidé que nous passerions la nuit près de l'île Harry et que, dès le lendemain, nous commencerions nos travaux dhydrographic.

Ce soir-là, vers I heures, au moment où Arctowslí et Racovitza cffectuaient un troisicme débarquement sur lcs roches situćes au Nord-Ouest de l'île Harry, leur canot rencontra une masse brune flottante, assez ćtrange d'apparence et qu'après minutieux examen on reconnut être une agglomération de glace, d'argile et de débris de roche.

Sans vouloir détailler nos travaux du lever, il convient de faire connaître les principes gćnéraux qui nous servirent de base, car ils donnent la clcf des nombreux circuits de notre route dans le nouveau détroit.

Il était tout d'abord nécessaire de fixer le choix des points importants à utiliser comme rep̀̀res. La reconnaissance rapide, fáite les deux jours précédents, ne nous avait laissé que des idées vagues sur ces îles et ces terres, dont l'aspcct varie à l'infini non seulement d'après le lieu de l'observation, mais encore d'apris les phénomènes si changeants de la métćorologic australe.

L'île Hary, à proximité de laquelle nous nous trouvions, le 25 janvier au matin, fut d'abord fixée sur la carte. I'inrent ensuite le cap Neyt, qui marque l'entrée Nord du nouveau détroit, et 1’îlc Auguste, dont la position centrale est avantageuse pour cffectucr un tour d'horizon au théodolite. 
Le 27 janvier, vers 9 heures du matin, nous apercerons tout à coup un mât qui flotte sur la mer. Nous nous en approchons en canot et constatons, avec étonnement, que c'est un mât tout neuf, un mât de perroquet ayant appartenu à un navire portant des vergues de cacatois. Aucune marque distinctive ne nous permet d'en déduire l'origine. D'où vient cette épave? I'un sinistre maritime? Mystère! qui nous laisse, un instant, tout rêveurs. Sera-ce aussi le sort de la Belgica de périr corps et biens en ne laissant d'autres vestiges qu'un tronçon de vergue ou de mât?...

Ce jour-là, vers 8 heures du soir, le navire dut stopper pour permettre au mécanicien de réparer une avarie survenue au condenseur.

Ce fut une soirée délicieuse.

Le ciel, d'un bleu indéfinissable, était parsemé de nuages dorés. Le soleil disparaissait à l'Ouest, masqué par les hauteurs de l'île Brabant, clont une des chaînes de montagnes se colorait en gris cendré, tandis que l'autre, formée de sommets plus acciclentés, passait par toutes les nuances du rose et du rouge. Les icebergs, de formes variées, jetaient sur la mer sombre une note éblouissante; ils glissaient sans bruit, pareils à de féeriques apparitions. Et le silence n'était troublé, de temps à autre, que par le craquement sourd Łle la glace qui se rompait ou par le souffle puissant des balénoptères qui venaient respirer à la surface de l'cau.

A minuit, le paysage enchanteur s'était évanoui, voilé, peu à peu, par un brouillard intense.

Le 28 janvier, la matinée entière fut consacrée au sondage, le seul que nous ayons pu exécuter dans le clétroit, ainsi qu'à des mesures de températures sous-marines à diverses profondeurs.

Pendant que nous étions ainsi occupés, des mégaptìres évoluaient tout contre la Belgica. Il nous eût été facile de les capturer, mais notre ćquipage était trop peu nombreux et, de plus, nos petits canons se trouvaient remisćs à fond de cale.

Heureusement que nos appareils photographiques fonctionnaient à 
souhait. Raeovitza recueillit toute une série de photographies et d'observations très intéressantes. C'est alors qu'il eut l'oecasion de eonstater l'odeur nauséabonde qu'exhale le souffle d'une baleine. Penché sur le bastingage, notre ami examinait les baleines, sans doute, d'une façon

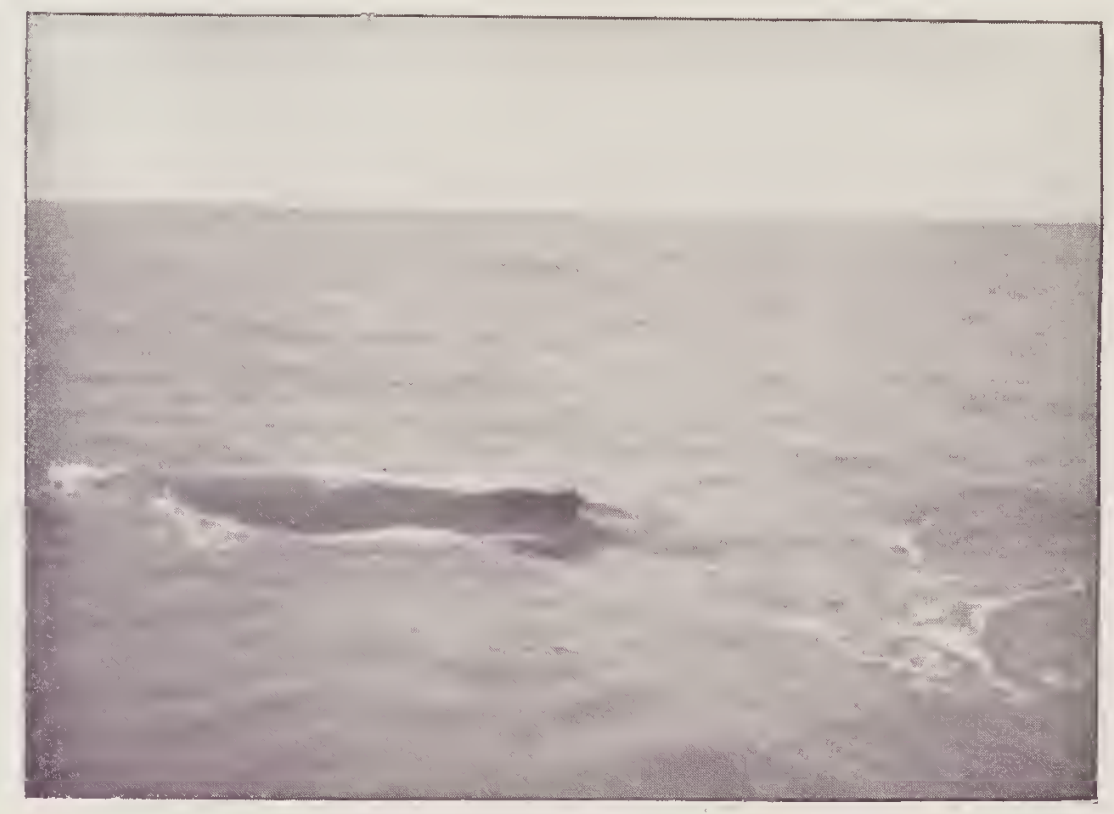

Plotegrayinit in II: Conk

IIG. IG.

DOS DF MTGGAPTTET.

trop familicre, ear elles le forcèrent à fuir par la perfidie de leur hacleine!

C'est aussi ee même jour que Racovitza m'expliqua que les protubéranees étranges qui parsèment le dos des eétaeés sont des animaux parasites profondément enfoneés dans la peau de celui qui les porte (I).

(I) Ces parasites se contentent de se faire réhiculer par les baleines; ils se nourrissent de petits animaux, qu'ils capturent dans l'eau. 
Lorsque le sondage fut terminé, nous fìmes route vers l'îlot Ciaston, où s'effectua notre luuitième débarquement; mais la brume interrompit notre travail et nous força de regagner le milieu du détroit.

La nuit du 28 au 29 janvier, nous fùmes en panne. Un seul officier pourtant resta sur le pont, tenant le gouvernail et commanuant à la machine, afin que tout l'équipage pût se reposer. La brise et le brouillard n'étaient guère rassurants, et il fallait l'optimisme de de Gerlache pour donner de semblables ordres :

Tout se passa bien; l'officier de quart n'eut pas le loisir de s'ennuyer : le service l'absorbait et un grand nombre de baleines venaient lui faire visite.

Penclant mon quart, un orque passa, avec une grande rapidité, à une très courte distance de la Belgica (I).

Le 29 janvier, vers 2 heures du soir, nous étions à proximité du cap Anna, où nous effeetuions un nouveau débarquement.

Il était alors urgent d'observer la position, afin de relier nos premiers travaux dans le détroit à ceux que nous espérions bientôt commencer; de plus, nous ignorions totalement où la dérive nous avait entraînés pendant les dernic̀res vingt-quatre heures de brume.

A I I heures du soir, comme nous étions peu éloignés de l'île Louise, j'aperçus une étoile. Je me rendis aussitòt à terre avec l'horizon artificiel, mais les difficultés de l'accostage me firent perdre du temps et lorsque enfin tout fut préparé pour l'observation... l'ćtoile avait disparu! J'en attendis vainement le retour jusqu'à I heure du matin.

Heureusement que le 30 janvier, à 8 heures du matin, le soleil me permit d'obtenir une droite de hauteur passant par l'île Louise. I á détermination des coordonnées approximatives de l'île L_ouise ne nous suffisant pas, il était nécessaire de relier ectte position à celle que nous avions déterminée antéricurement dans la partie Nord lu détroit

(I) L'orque ou ćpaulard cst un grand cétacé à dents, très carnassier, qui s'attaque mème aux baleines. 


\section{- $152-$}

de Gerlache. Il fut alors décidé que plusieurs d'entre nous tenteraient l'ascension des monts Solvay et appliqueraient la méthode de l'amiral Mouchez (I), dans le but d'opérer plus rapidement le lever de la carte et de découvrir, éventucllement, un passage vers le Sud.

(I) D'après cette méthode, on s'élèe sur une montagne dont on détermine très cxactement la hauteur au-dessus du nireau de la mer; puis, à l'aide d'un théodolite, on mesure l'azimut et la dépression cles points importants de la côte. Ine simple résolution de triangle donne les éléments nécessaires à l'établissement de la carte.

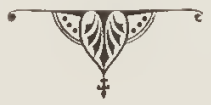




\section{CHAPITRE XVI.}

\section{En reconnaissance dans le détroit de Gerlache.}

Le 3r janvier, nous nous dirigeons donc rers la baie de Buls et, à 4 heures du soir, de Gerlaehe, Daneo, Arctowski, Cook ct Amundsen quittent le navire pour gagner les hauteurs. Pcndant eette aseension, je dois rester à bord avee Raeovitza, ainsi quc Mélaerts. Il est convenu que nous irons cn reconnaissanee rers le Sud et serons de retour, dans la baie de Buls, le 6 ou le 7 février.

Nous trouvons près du cap d'Ursel un cndroit favorable au débarquement des excursionnistes. Ceux-ei emportent tout un matériel : traîneaux, tentc, réehauds, skis, raquettes à neigc, alcool pour la fabrication de l'eau douce, instrunents d'observation, appareils photographiques, vivres en abondance, car, lorsqu'on deseend sur une tcrie antarctique, on n'est pas toujours eertain du jour où l'on viendra rous y rechercher!

Comme l'ascension n'est pas facile arec un tel chargement, il est convenu que Tollefsen et moi nous donnerons un coup de main aux camarades avant de regagner la Belgica, stoppée dans la baie de Buts.

Nous voici donc attelés aux traîneaux comme les haleurs aux lateaux, avee cctte différenee que, pour nous, le chemin est loin d'ètre de niveau! Heureusement que nous sommes tous d'une humeur charmante et que les dcux équipes rivaliscnt dc vitesse.

Vers $8 \mathrm{I} / 2$ lieures du soir, nous attcignons la première crète des monts Solvay. Tollefsen et moi souhaitons bonne chance aux eamarades et commençons notre descente. Ce n'cst pas ehose aisée, nous n'avons pas de raquettes à neige ni de cordes pour nous lier l'un à l'autre : gare aux ponts de neige masquant de mystérieuses erevasses!

IBientôt nous rcmarquons que le seul moycn dc ne pas enfoncer, c'est de mettre une plus grande partie, ile notre eorps en contaet aree la neige. Nlors, aussitòt fait que dit, nous nous asseyons sur le 
sol et, allongeant les jambes, nous sommes emportés par la pente aussi rapidemcnt qu'unc schlitte. Quellc délicieuse glissade; pas une déchirure, pas une égratignure! Le cœur tout guilleret, la têtc griséc d'air pur, nous regagnons gaîment le bord.

L'état-major n'est pas nombrcux: Mélacrts est à la fois comman-

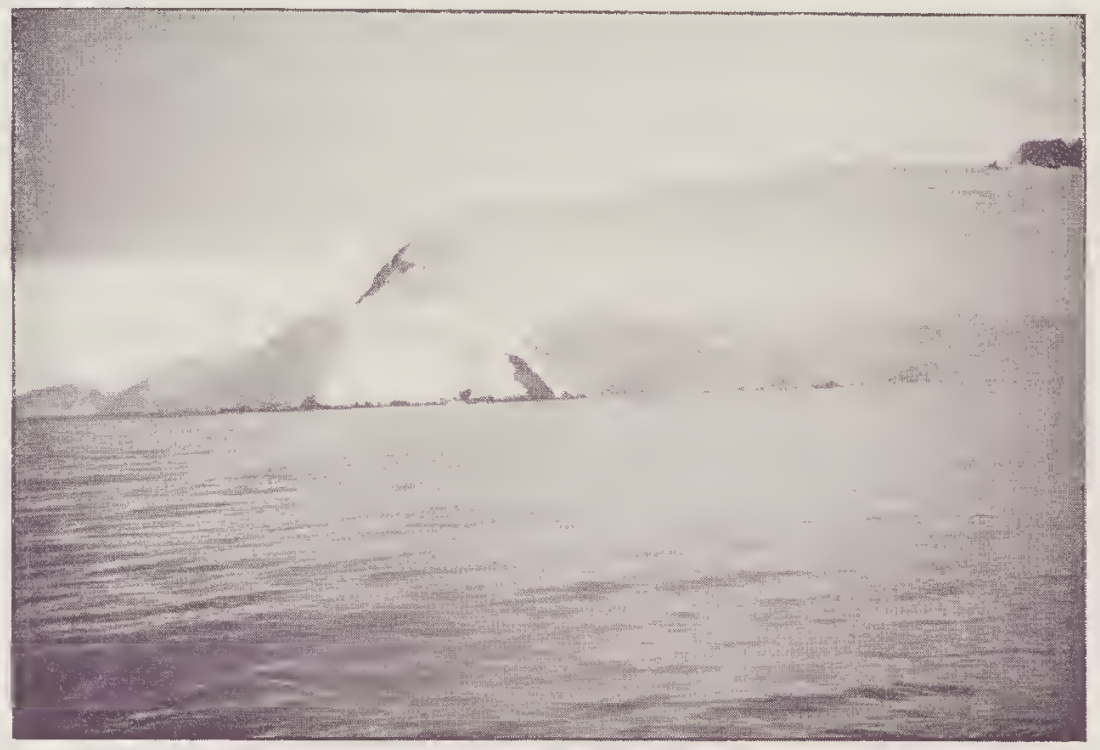

Ihotograplie du Dr Cook.

FIG. I7.

ÎLE BRABANTT. - LFS MONTS SOLV̈AY IT LE CAP D'URSEL.

dant en second, en troisieme, en quatrième... mais notre zoologuc Racovitza est un débrouillard, et je ne doute pas un instant que si un accident nous arrivait, à Mélaerts et à moi, il ne parvicnne à rctrouver l'cndroit où nous avons déposé nos compagnons.

Le lendemain, ier férricr, le navirc appareilla dès l'aube et fut conduit vers l'île Louise, où nous espérions obtenir unc seconde droite de hauteur, dcstinée à compléter nos observations du 30 janvicr. Nous devions aussi, de ce point, relever la station établie sur les monts Solvay. 
La brise et la mer nous empêchc̀rent de débarquer, nous forçant à demander un abri à l'île Brabant. Cette circonstance nous permit de découvrir le canal de Schollaert et l'île de Gand. Mais une avarie étant surrenue à notre condenseur, nous dûmcs doubler le cap Van Rysayck et prendre la cape au centrc du détroit de Gerlache.

Lc 2 février matin, nous découvrîmes la baie d'Andvord. La Belgica fut amarrée à un iceberg, dont on détachait des blocs de glace pour en faire de l'eau douce. L'embarquement de ces blocs se faisait avec animation. Penclant ce temps, Racovitza débarquait au cap van Beneden, où il passait la plus grande partic de la journée, dans un village de... manchots, dont il étudia les mours.

C'est là aussi qu'il découvrit, avec satisfaction, une petite graminée, seule plante portant des fleurs qu'on ait jamais rencontrée dans $1^{*}$ Antarctique.

Le soir venu, l'équipage organisa, sur l'iceberg, des tableaux vivants.

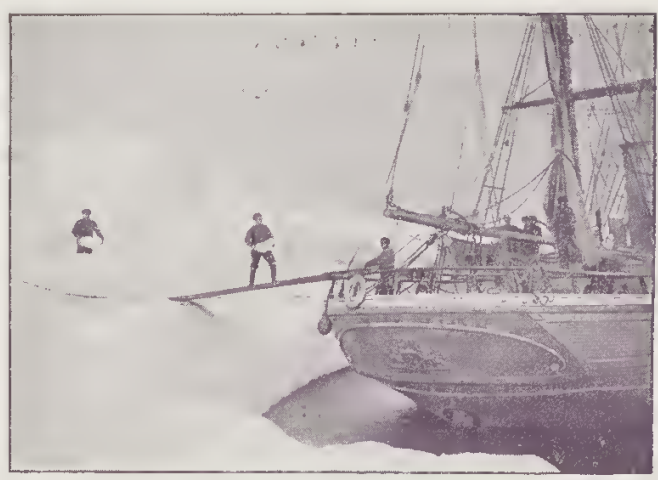

Pliotograpliu: do. Ir. Lecointe. IiT. I 8 .

EMBARQUEMENT DE BLOCS DE GL.ICE. Brusquement, la fète fut interrompue par la rupture de l'iceberg: le fragment auquel nous restions attachés nous poussait vers la côte.

Le 3 février, nous parcourons la baie d'Andvord; nous découvrons le chenal d'Errera, dans lequel nous embouquons; puis, nous nous amarrons, près de l'île de Cavelier de Cuverville, à un gigantesque iceberg, au centre duquel s'est formée une cuvette renfermant de l'eau douce (I).

Arec des tuyaux de chanvre, nous établissons un siphon, dont unc

(1) Lorsqu'une cuvette se forme à la partic supérieure d'un iceberg, l'eau douce provenant de la fonte de la neige s'y accumule. 
branehe est maintenue dans la euvette, tandis que l'autre, plaeée en eontre-bas, débouehe dans nos réservoirs. L'équipage est ravi de ee proeédé nouveau et rapide de s'approvisionner d'eau douee sains aueun effort.

Pendant ee temps, Raeovitza débarquait à l'île de Cavelier de Cuverville, où l'appelaient d'innombrables familles de manehots. Moi-même, je me rendis quelques instants dans l'île pour y tenter: mais sans sueeès, des observations à l'horizon artificiel.

A 6 heures du soir, en rentrant à bord, nous apprenons que notre albatros $(I)$, eapturé quatre jours auparavant, s'est envolé. Raeovitza est désappointé et très étonné, ear l'albatros a les ailes d'une telle envergure, que, ne pouvant les déployer sur le pont d'un navire, il devient foreément prisonnier. Sans doute que le nôtre est parrenut à se hisser sur le bastingage, d'où il a pu prendre son essor.

Le 4 février, en faisant le tour de l'ile Lemaire, nous remarquons une " apparenee » de ehenal séparant l'ile de Bryde de la Terre de 1)aneo. Ce jour même, nous pouvons aussi noter, dans le journal du bord, l'existenee d'un large passage dirigé vers le Sud-Ouest. En même temps, nous traçons la eôte orientale et septentrionale de l'île TVioncke, notant dans ees parages des roehes isolées et de nombreux ilots. Riehes de ee nouveau butin, nous retournons, le soir, à la baie de Buls, attendre le retour des explorateurs.

Je fus assez anxieux, en arrivant prics du eap d'Ursel, de n'apereeroir aueun signal sur les hauteurs.

Serait-il arrivé malheur à nos amis? Ou bien sont-ils bloqués de l'autre eôté d'une erevasse infranehissable?

La nuit tombant, nous reprimes le large, où nous fủmes arraehés à nos préoeeupations par un speetaele aussi eurieux qu'inattendu. On clit, d'une manière familière et mème un peu triviale, en parlant d'une

(r) Granci oiseau dont le corps est blanc, les ailes brunes, le bec et les pattes jaunes. 
personne qui se trémousse de joic: "Elle rigole comme une baleine! " Jamais je ne m'étais imaginé que je pourrais vérifier l'exactitude de cette comparaison. Or, voilà que, tout à coup, je vis une bête monstrueuse qui gambadait hors de l'eau, y retombait avee fraeas en soulevant d'énormes vagues, puis recommençait à bondir de plus belle.

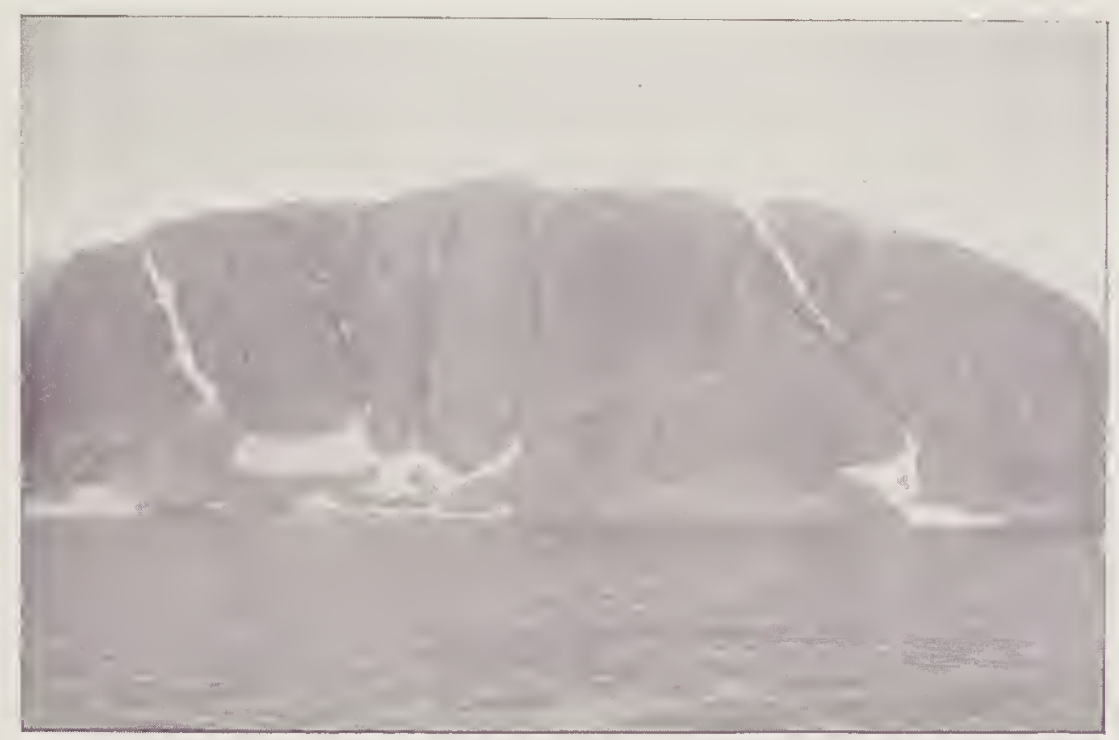

Photagraphic de M. Ieeointe.

FIG. I9.

LES FALAISLS DE L'ÎIE IJE CAVTLIER DE CUVERVILLJ.

Vite, j'appelai notre zoologue, et dame baleine eut la graeieuseté de recommeneer à "rigoler ") devant lui! Racovitza et moi, nous étions positivement sous le eharme...

Les journées du 5 et du 6 février s'éeoulèrent sans que nous eussions vu, sur les monts Solvay, le signal convenu.

Enfin, le 6 février, à 5 heures du soir, la lunette nous fit voir le drapeau planté sur un noonatak (1).

(I) On désigne sous le nom de noonatak les pointes rocheuses qui émergent au milieu d'un glacier. 
Nous fîmcs aussitôt route vers le cap d'Ursel; nos camarades remontèrent à bord, tous en parfaite santé, mais un peu soucicux, scmblait-il.

Ils firent peu honneur au souper et, transis de froid, se hâtèrent vers leur couchette!

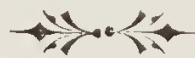




\section{CHAPITRE XVII.}

\section{Ascension des monts Solvay.}

Ce fut quelques jours plus tard seulcment que, remis de leurs fatigues, ccux qui araient tenté l'ascension des monts Solvay nous contèrent en riant leur odyssée.

Immédiatcment après notre départ, ils avaient dressé la tentc et préparé un copieux repas : soupc aux pois, biscuits des Alpes, conscrves, voirc une tasse de chocolat. La nuit fut rcposante; ils étaient bien à l'abri dans leurs sacs de peau de rennc.. .

Le lendemain, 3 I janvier, après le déjeuner, ils levircnt le camp et se remirent en route; mais, arêtés par la brume, ils durent repiquer la tentc. Par quoi tuer le temps, si ce n'est par un petit repas!...

L'après-midi, nouvclle tentative de marche, bientôt entravée encore par unc crevasse infranchissable. Nos amis furent obligés, pour se remcttre dc ces contretemps, de déguster quelques bonnes choses! Puis la nuit vint : il fallut souper et se coucher! O délices de Capoue!...

Le I $^{\text {er }}$ février, il neigeait et le vent soufflait violemment. Malgré cela, une nouvelle tentative fut faite pour gagner la seconde crête des monts Solvay.

Tout à coup, Danco, attelé avcc de Gerlache à un même traîneau, disparut sous la neige. Déjà le commandant s'arc-boutait pour n'être pas cntraîné dans l’abìme, lorsqu'il constata que la corde qui, un iustant auparavant, retenait 1)anco, était abandonnéc à elle-même.

Avec précaution, tous approchérent clu trou béant dans lequel notre ami avait disparu. 11s le virent suspendu grâce à ses longos skis, aux parois d'unc crevasse, pcu large heureusement, mais très profonde. Le sauvctage s'opéra avec célérité et Danco, ahuri par la secousse, fut ramené, sur la ncige ferme. Alors, pour lui rendre un peu de force et fèter l'émouvant sauvetagc, un joyeux festin s'imposait!... 
Le 2 , le 3 et le 4 février, le temps demeura brumeux; cest à peine si de Gerlache et Banco, juchés sur un noonatal, purent mesurer quelques angles au théodolite.

Le 5 février, la brise se leva de l'Est-Nord-Ouest et déchira la tente. Los amis furent obligés de la réparer; mais comme l'étoffe destinée à boucher un trou doit être prise quelque part, la tente diminua de surface, au moment même où le dégel, puis la pluie, la rendaient plus nécessaire. Alors nos pauvres amis, trempés jusqu'aux os, barbotant dans la neige, songèrent, une dernière fois, à jeter un regard aux provisions! Hélas! l'appétit n’ý était plus !...

Enfin, à la suite d'une nuit des plus lamentable, de Gerlache, le matin du 6 février, fit arborer le drapeau belge, destiné à rappeler la Belgica. Ce même jour, à 5 heures du soir, le navire faisait entendre sa sirène et recueillait nos explorateurs.

Ajoutons que, malgré tant de déboires et de circonstances défavorables, l'ascension des monts Solray fut loin d'être sans résultat :

$1^{0}$ Les observations faites au théoclolite nous donnèrent des contrôles très utiles pour le tracé de la carte;

$2^{\circ}$ Arctowslí rapporta d'importants échantillons géologiques ;

$3^{\circ}$ Et enfin, nos excursionnistes acquirent, au point de rue du campement, une expérience qui pouvait leur servir par la suite.

Notons encore que le campement sur les monts Solvay est le premier qui fut tenté dans la région antarctique.

\footnotetext{
rocti
} 


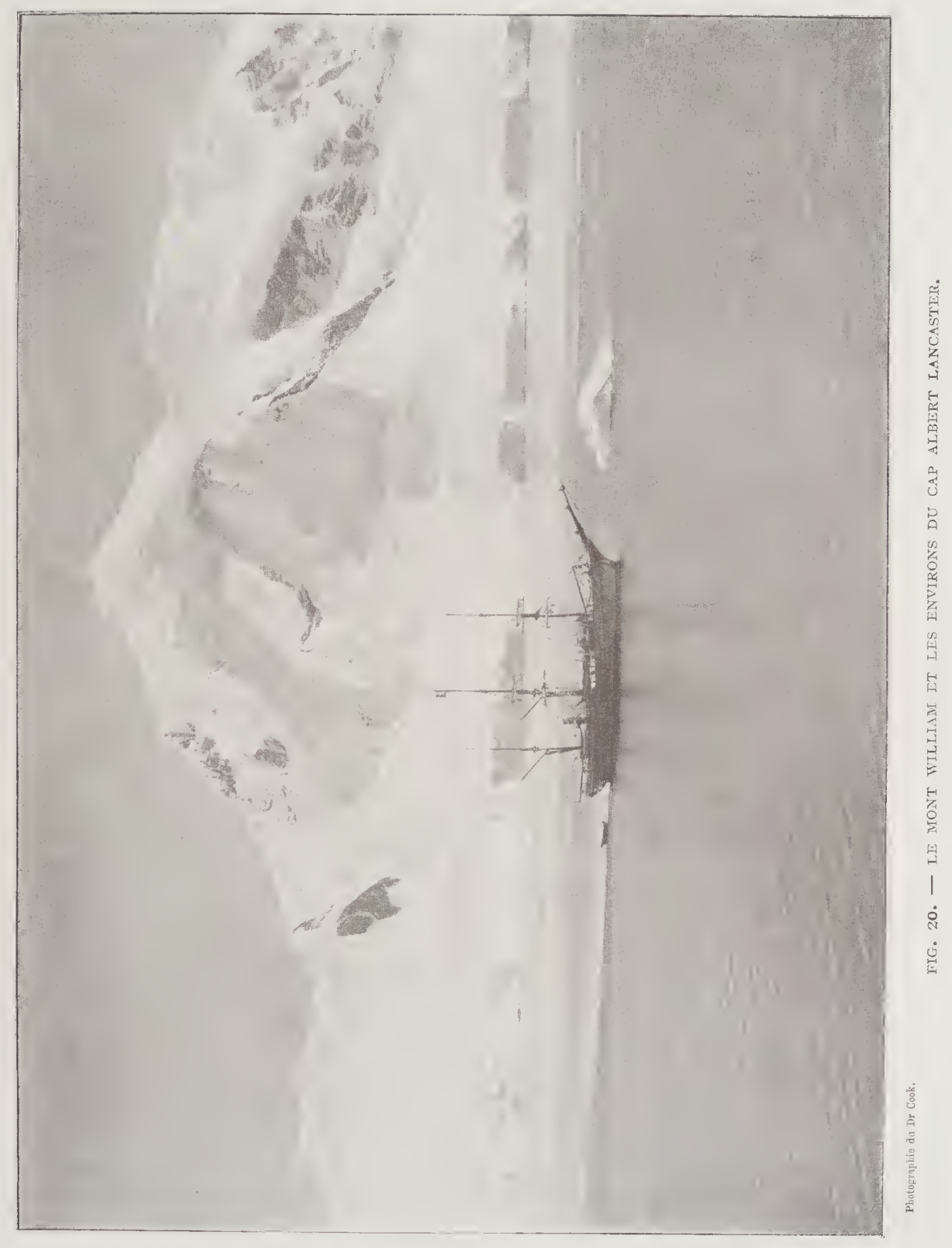





\section{CHAPITRE XVIII.}

\section{Derniers travaux dans le détroit de Gerlache.}

Lc 6 février, vers 8 hcures du soir, après lc retour à bord du petit groupe cxpéditionnaire, nous cûmes la chance de reconnaitre, au loin, l'ile des Deux Hummocks, puis le cap MLurray. Dès lors, la jonction de nos diverses stations étant faitc, nous pouvions gagner le cap Murray et longer de près la còtc orientale du détroit.

Lc 7 février, nous parcourons la baie de Charlotte, doublons le cap Reclus et naviguons dans le chenal de la Plata, en laissant, par tribord, les îles Nansen, Brooklyn, Wyck et Pelseneer.

Vers 4 hcures du soir, de Gerlachc, Cook et Arctowski débarquent au pied des roches Sophie, et, pour la nuit, nous nous mettons à la cape, à l'Est de l'ile Émma.

Le 8 février, nous doublons le cap Anna et, jugeant que la côte orientale a été rclcrée avec assez d'exactitudc jusqu'à l'ìle Bryde, nous longeons l'ile Anvers, où nous débarquons, vers midi, près du cap Hippolyte, au pied des monts Osterrieth. A cc moment, 1c soleil inonde ces monts dc mille feux : toute la chaîne en est éblouic. $\Lambda$ sscz loin, à l'intérieur de l’ìle, quelques dômes ensevelis sous la neige rappellcnt les sommets alpestres. Lc long de la côte, les montagnes pourprées s'abaissent en falaises de granit, au picd desquelles des avalanches ont amassé un glacicr de peu d'épaisseur, mais s'étendant sur toutc la longueur de l'ile.

Le soir du 8, nous nous arrêtons dans le chcnal de Ncumayer, au pied du mont William (fig. 20).

La jounnéc du 9 février fut superbc. Ellc nous permit de parcourir très utilement un long itinéraire: le matin, nous avons observé la position du quinzièmc débarqucment ct, vcrs midi, nous avons fixé les coordonnécs d'unc île du groupe Wanwermans. L'après-dìner, nous avons longé la côte orientale de l'île Wiencke; puis, tandis que 
Danco, Racovitza, Arctowslí et Cook dćbarquaient dans l'île Bob, la Belgica retournait vers l'ile Lemaire.

Pour la seconde fois et bien que notre attention fût particulièrement attiréc vers l'île Bryde, nous n'avons pas reconnu, dans la

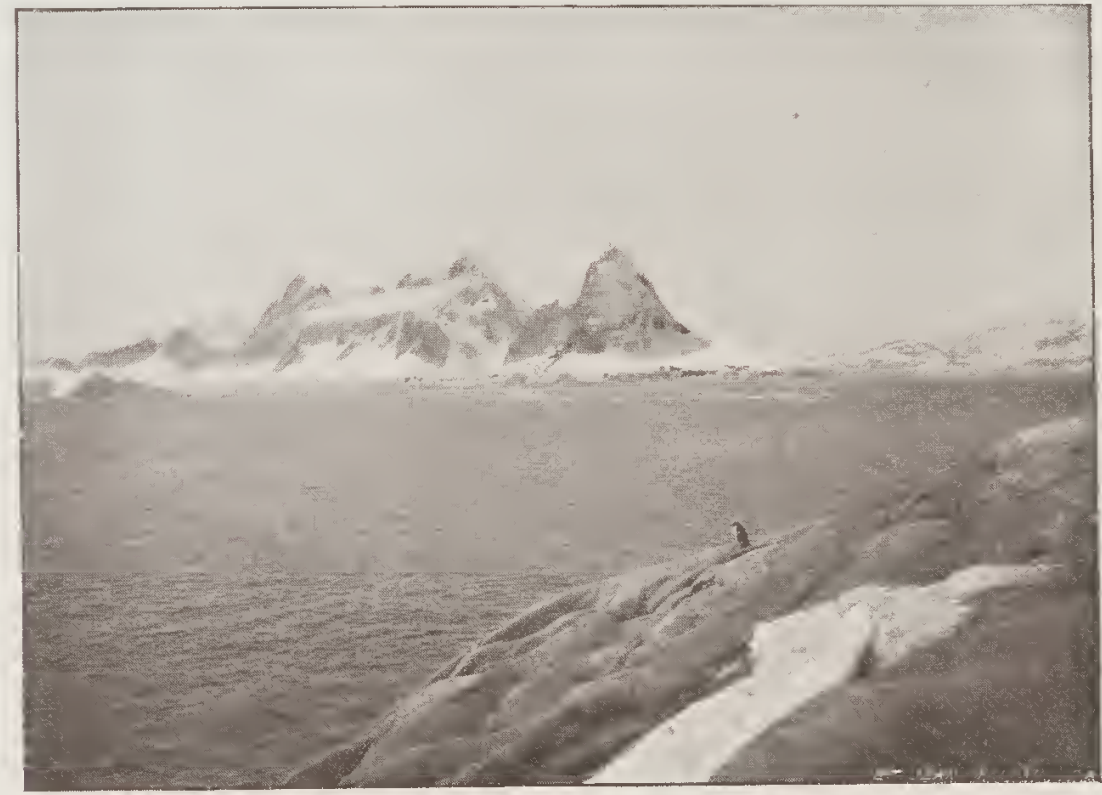

Photographie du 1) Cook.

FIG. $2 I$.

LA SIERRA DU FIEF ET L'UNE DES ÎLES WAUWTRMANS.

brume, le passage qui existe cntre cette île et la Terre de Danco; nous pensions alors qu'il n'y avait là qu'unc simple baie. Lc soir, nous sommes allés reprendre, à l'île Bob, le personncl scicntifique, que nos travaux de la journée nous avaient fait oublier quelque peu. Nos pauvres amis agonisaient de faim! Aussi, en souvenir de cette sensation peu agréable, conscrvèrent-ils longtemps à l'île Bob lc nom d'îlc Famine.

Nous nous étions abrités, pour la nuit, auprès du cap Willems, mais la dérive nous conduisit, dans le brouillard, à proximité de l'île Banck. 
Quel ne fut pas notre ćtonncment lorsque, le ro févricr, à la première éclaircie, nous distinguâmes un canal dirigé vers le I $5^{\circ}$ Nord-Est. Nous y embouquâmes et ce n'cst qu'à proximité diı cap van Beneden que nous reconnûmes que cc canal est bien celui qui séparc l'île de Bryde de la Terre de Danco et dans lequel, deux fois déjà, nous nous étions cngagés.

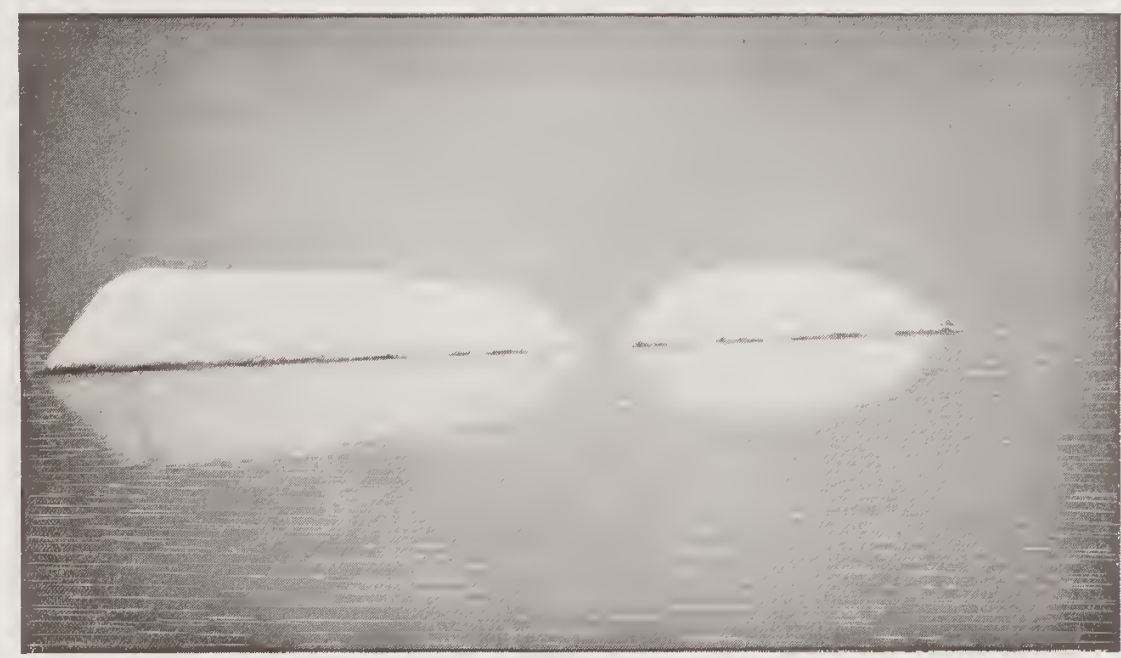

Mrotingralive du Iro Cook.

IFIG. 22.

LES ÎLTS MOLRTAUX.

Alors nous retournons au cap Pierre Willens et parcourons la baie des Flandres, ou nous débarquons, le I f février, dans unc des îles Moureaux.

Enfin, après avoir doublé lc cap Rahir ct reconnu les îles Guyou, nous longions la Terre de I)anco, lorsque nos regards furent attirćs par la teinte bleue que présente une échancrure de la côtc. Curieux, nous allons de ce côté et nous pénétrons dans une baie d'azur. Oh! spectacle enchanteur! les glaces, la mer, le navire, la mâture, les roiles, tout est blcu, de ce bleu pâle mourant qui n'existe que dans les régions polaires. Nous nous attardons à rêver dans cet azur...; puis nous évoluons adroitement pour gagner la pleine mer, car nous 
sommes entourés d'ieebergs. Pas assez adroitement eneore : un eraquement sinistre nous avertit que la Belgica vient d'en aborder un de front.

Heureusement, le mal n'est pas grand : la guibre seule est brisée; le beaupré, par miracle, sort indemne de eette eollision.

Nous passons la nuit près du eap Renard, que le r 2 février, au matin, nous voyons peu à peu sortir de la brume. Ce eap marque d'une façon précise l'entrée Sud-Ouest du détroit de Gerlaehe. C'est une falaise de granit longue et mince, qui, du côté de la mer, élève, haut dans l'air, une aiguille roeheuse dentellée comme la flèehe d'une eathédrale. C'est près le ce eap que nous opérons notre vingtième débarquement. Nous y déterminons les eoordonnées géographiques de l'entrée du détroit; puis, après avoir franehi le chenal de L_emaire, nous allons attendre le jour en vue du eap de Trooz.

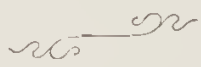




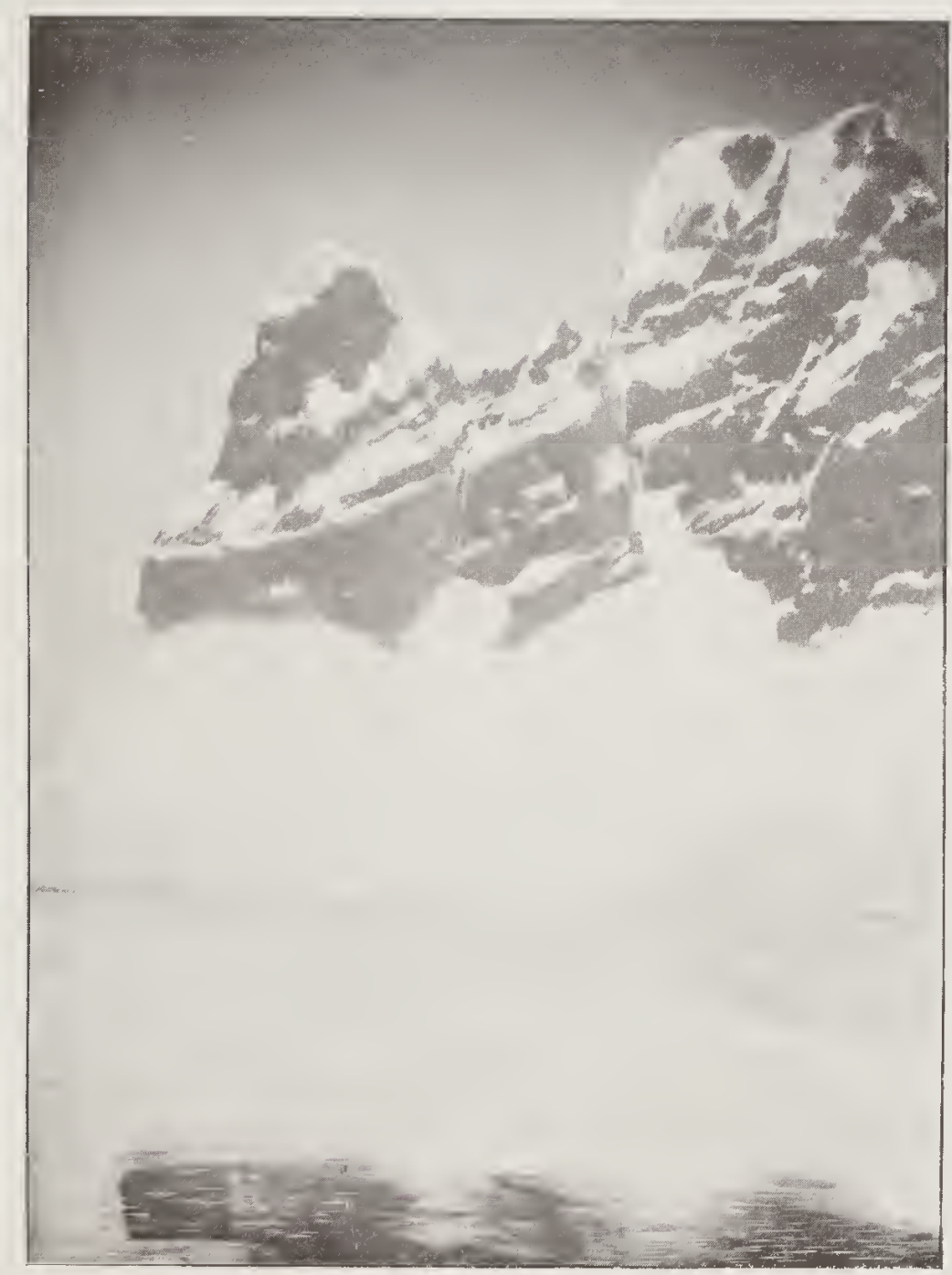

Plotographio du Dr Cook,

FIG. 23 .

LE CAP RENARI). 


\section{CHAPITRE XIX.}

\section{Quelques particularités du détroit de Gerlache.}

L’itinéraire suivi par la Belgica indique avec quel soin le "terrain »a été fouillé. Le parcours du détroit a duré vingt jours, pendant lesquels nous avons noté, avee unc scrupuleuse attention, tous les renseignements qui pourraicnt intéresser, dans ees parages, les futurs naviguteurs.

Parmi les ćchantillons rapportés par M. Racovitza, le naturaliste dc l'expédition, à qui je suis redevable des renseignements relatifs à la zoologie et à la botanique, je puis faire mention d'un diptère (Belgica antarctica n. g. n. sp.), de trois puces de neige (Achorictoïdes antarcticus n. g. n. sp.,Cryptopygus antarcticus n. g. n. sp. et Isotonca sexoculata n. sp.) ct de cinq acariens nouveaux. Cc sont les premiers animaux terrestres découverts dans l'Antarctique.

Parmi les animaux microscopiques, nous avons trouvé des infusoires, des rotifères, des nématodes et des tardigracles, qui vivent dans l'eau douce provenant de la fonte des neiges. Les flanes des roehers, sans cessc labourés par les glaces, ne peuvent servir de refuge aux animaux littoraux. Pour le même motif, les algues sont rares dans cette région. On n'y trouve, dans les endroits abrités, que des algues de petite taille, sur lesquelles vivent de rares cspèces d'animaux marins.

Les parois à pic des rochers qui ne reticnnent pas la neige sont parfois couvertes de lichens, qui ont fourni 55 espèces et, dans les endroits humides, croissent des mousses qui sc répartissent en 27 espèces, la plupart nouvelles.

Dans quelques abris, on découvre des touffes d'une graminéc (Itira antarctica), qui cst la scule plante à fleurs vivant dans ces parages.

Les phoques que nous avons rencontrés dans le détroit appartiennent à deux groupes différents: le phoque crabier (Lobodon carcinophaga) de tcinte verdâtre uniforme (fig. 24), et le phoquc de Weddel (Leptonychotes 


$$
=
$$


Weddelli) gris fer taeheté de jaune (fig. 25). Tous les deux se nourrissent de erustaeés.

Viennent ensuite les eétacés: la jubarte (Megapteraboops) (fig. I6) et le rorqual (Balaenoptera Sibbaldi) qui mesurent jusqu'à 25 mètres de longueur. Le prix en est peu élevé : 6,000 à 8,00o franes, tandis que la baleine franehe peut se vendre jusqu'à 70,000 franes. Cette

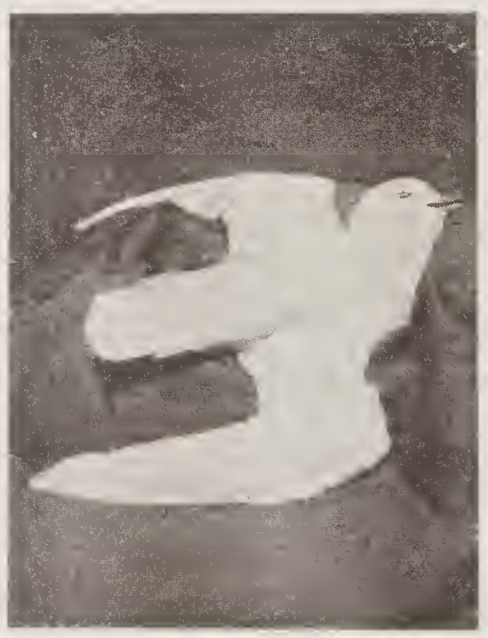

FIG. 26.

PAGODROMA NIVEA. différenee de valeur provient de ee que les fanons de la baleine, extraordinairement développés, sont utilisés pour différents artieles de la toilette féminine et se vendent très eher. Nous n'avons pas reneontré de baleine franehe au eours de notre voyage.

La jubarte est pourvue d'une petite nageoire dorsale et de longues nageoires antérieures; le rorqual, au eontraire, a une longue nageoire dorsale et de courtes nagoires antérieures.

Enfin, rappelons que nous arons aperçu dans le détroit un orque, ennemi intime des baleines, qu'il attaque en s'aeerochant à leur mâehoire inférieure.

Arrivons aux oiseaux.

De nombreux eormorans niehent tans le détroit. Parmi les goëlands, se trouvent le goëland brun (Megalestris antarctica) et le goëland dominieain (Larus dominicanus), grand oiseau au eorps blane, aux ailes brunes, au bee et aux pattes jaunes.

Parmi les pétrels, nous avons vu le pigeon du Cap (Daption capensis), le pétrel des neiges (Pagodroma nivea) (fig. 26) et le tris grand pétrel (Ossifraga gigantea), qui dépèee les eadavres (fig. 27).

Enfin, mentionnons le bee-en-fourreau (Chionis alba), le seul oiseau à pattes non palmées de la région. Nous ne l'arons aperçu que dans 
l'ile Auguste, où il eache son nid dans les anfractuosités des rochers.

De tous les oiseaux qui habitent le détroit, les mancliols sont certes les plus intéressants ( $\mathrm{I}$ ). Droits et raides sur leurs: courtes pattes, ils ont l'air de petits bonshommes vêtus de pardessus noirs à capuehon. Ils trottent en se dandinant et en tournant la tête avee des contorsions

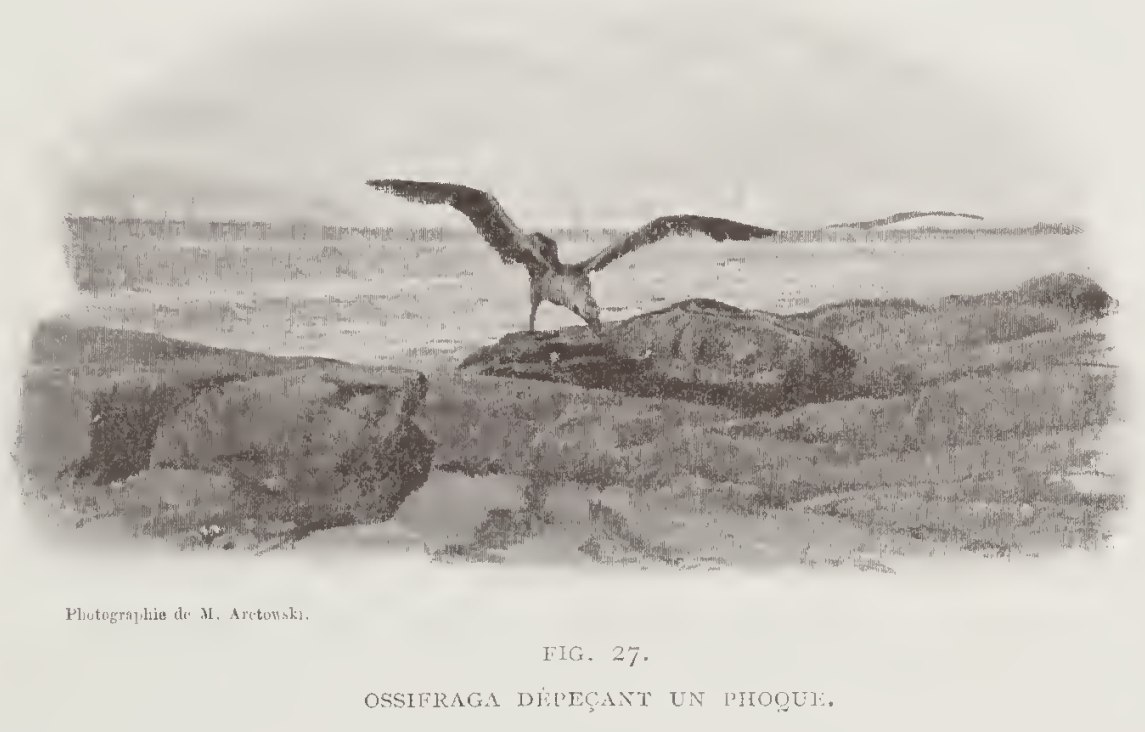

bizarres, agitant leurs petites ailes qui semblent des moignons de bras et constituent, pour eux, des nageoires dont ils se servent à merveille. Deux espèees de manchots habitent le détroit de Gerlache: le manchot papou (Pygoscelis papua) ct le manchot antaretique (Pygoscelis antarctica).

Ils ont, tous les deux, le cou et le ventre blanes, tandis que la tête et le dos sont du plus beau noir. I.e second ne differe du premier

(I) Ils sont parfois désignés aussi, mais improprement, sous le nom de pingouins du Sud. 
que par un bee rouge au lieu d'un bee noir et une aigrette blanehe qu'il porte gracieusement sur la tête; mais, dans leur manière de vivre, ees deux oiseaux diffèrent essentiellement.

Les manchots papous (fig. 28) vivent nonchalamment en commun, élevant leurs cnfants à la spartiate.

Les jeunes sont tous réunis dans un même endroit, sorte de mursery où ils sont surveillés par un certain nombre de vieux manchots. Si l'un des petits reut s'émancipcr, le gardien le ramène au bercail à coups cle bee. Aprc̀s un certain laps de temps, un des gardiens pousse un cri, auquel répond un autre eri, et de nouvcaux faetionnaires vicnnent rcmplaccr les premiers, non sans avoir grommelé de la plus belle façon, tandis que ceux qui sont relevés dc garde poussent des cris de joie et se jettent à la mer avec transport.

Cc manchot papou, dont la vic s'éeoulc, comme celle de certains fonctionnaires, dans une continuellc uniformit', ne se donne pas la peine de se défendre quand on l'approche. Il regarde d'un air hébété, cn serrant avec effroi ses deux petites ailes.

Les manchots antarctiques (fig. 29) sont, au contraire, pleins d'esprit! Certes, ils ne sont pas toujours commodes et se disputent parfois avec acharnement; mais quclle énergie, quelle vivacité, quelle mine intelligente!

Leur courage égalc leur amour maternel; ils défendent hardiment l'approche de lcurs nids: le bec tendu et menaçant, les plumes hérissées, ils livrent bataillc et sc font noblement tuer plutôt que d'abandonner leurs petits.

Nous avons fait vingt débarquements dans le détroit et plusieurs se sont effeetués avec difficulté.

En effct, indépendamment des instruments fragiles qui eneombraient lc petit canot, sept personnes devaient y trouver place: Racovitza, Aretowski, Cook, Daneo, Dobrowolski et moi, plus un matelot pour garder l'embarcation, pendant le travail.

Quelques-uns d'cntre nous devaient done se mettre aux avirons, 


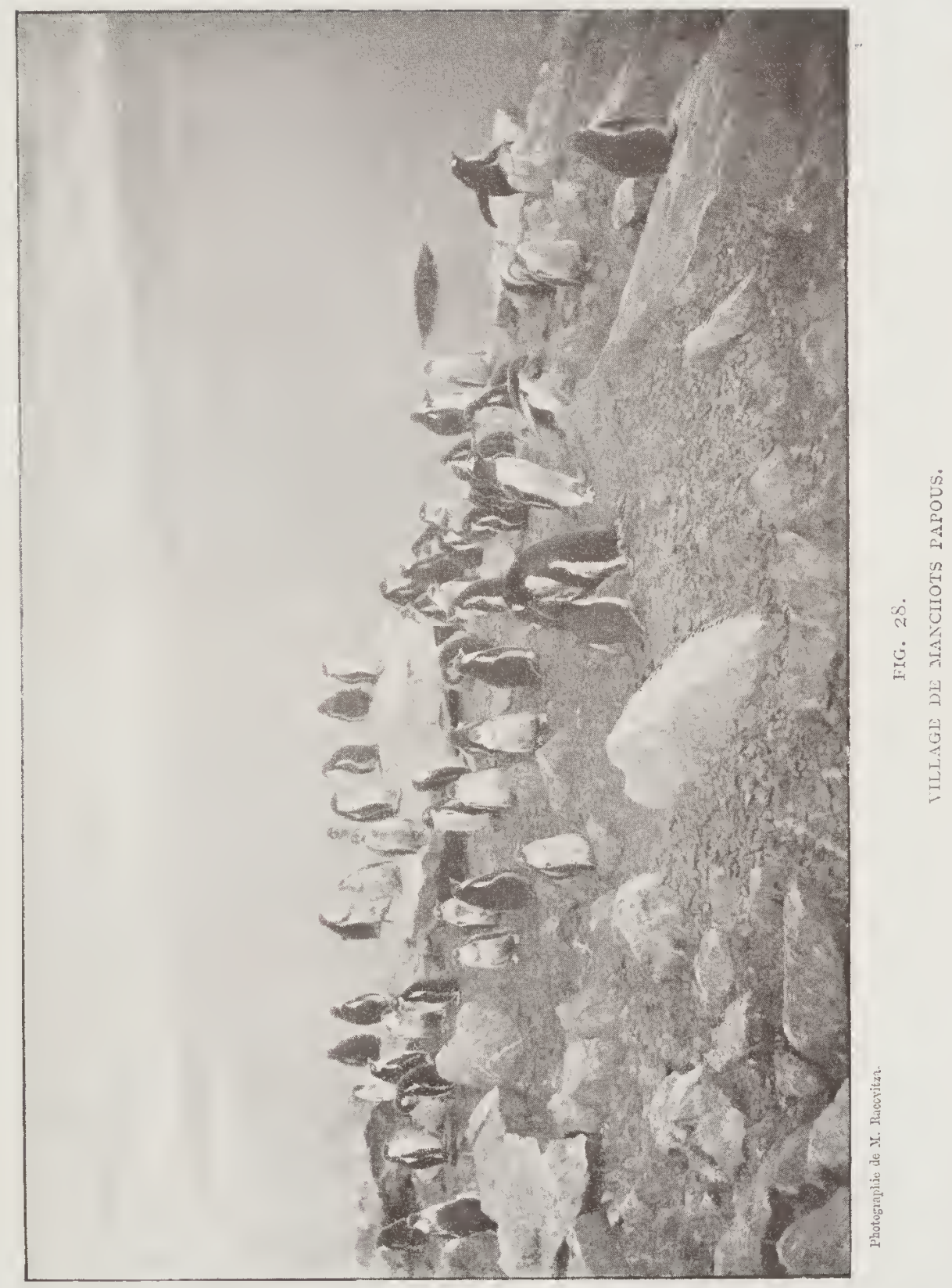



travail fatigant pour les mains et qui les rendait impropres à manier des instruments de précision.

Quant à opérer sueeessivement plusieurs débarquements et à nous faire aider par des hommes d'équipage, il n'y fallait pas songer: nous cussions perdu de la sorte un temps considérable, alors qu'il fallait

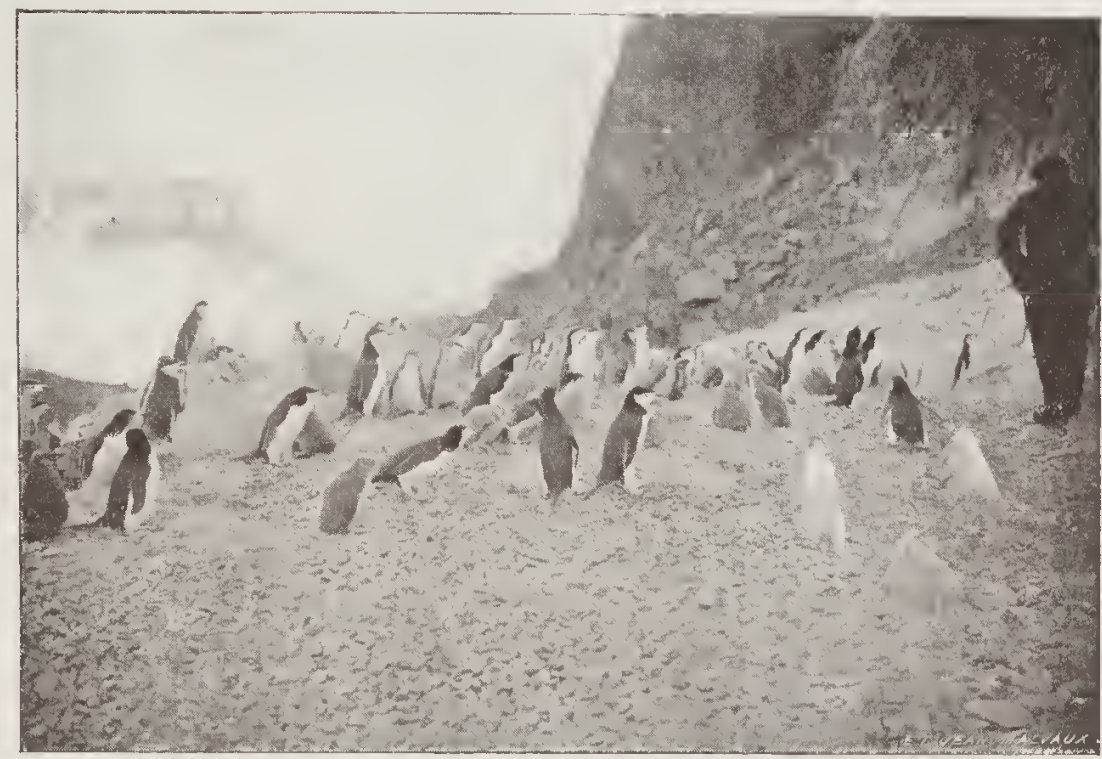

Plotographio de M. Rateritzo.

IIIG. 20 .

VILTAGE, DT MANCHOTS ANTARCTIOUES.

opérer rapidement, et notre personnel, peu nombreux, n'était que suffisant pour le service du bord.

Les difficultés se multipliaient encore lorsqu'il s'agissait de fixer le lieu de débarquement.

La côte dans l'Antaretique est presque toujours abrupte. Ou bien nous nous trouvions au pied de vastes glaciers dont les murailles verticales s'élevaient plus haut que la mâture du navire, eomme au cap Lancaster; ou bien la roche apparaissait à nu et absolument droite, telles les roches. Sophie. Parfois, la terre semblait d'un aceès 
plus facile; mais, en approchant, nous constations qu'elle était défendue par des récifs sur lesquels notre canot courait le risque de se briser: ce fut le cas dans l'îlc Louisc.

D'autres fois encorc, la côte rochcusc formait une succession dc dômes peu élevés, mais dont les parois, polics par le frottement dés glaces, étaient si glissantcs, qu'on ne s'y aventurait qu'avec prudence. Les îles Wauwermans préscntaient cet aspect. Ajoutons que certains endroits, très accessiblcs en tcmps calme, devenaient inabordables dès qu'il y avait de la houle.

Ainsi, au pied du mont Allo et du mont Pierre, à proximité du cap Neyt, se trouve unc petite baie au fond de laquelle s'étend une grève. Le débarquement s'est opéré facilement en cet endroit, parce que la mer était calme; mais le retour à bord préscnta un sérieux danger : la mer s’était lcvée et menaçait de rouler notrc canot.

Dans l'île Augustc, l'action de la mer se faisait sentir plus violemment encore. Dans d'autres îles, telles que les Guyou ct les Moureaux, l'espacc non couvert de neige était si petit, que les instruments devaient être échelonnés au bord de l'eau.

Tous les points des côtes, hcureusement, n'étaient pas aussi défavorables, mais il fallait les découvrir peu à peu.

Au cap van Beneden, par exemplc, un canot pouvait atterrir par tous les temps.

C'est dans l'île de Cavelier de Cuverville que nous avons débarqué avec le plus de facilité. Dès qu'on avait dépassé lcs falaises rocheuses, la côte s'étendait très saine, formant un véritable quai.

Une particularitć encore du détroit de Gerlache, c'est la rapidité avcc laquellc la mer se forme sans cause apparente. Nous en avons eu un excmple étonnant dans la nuit du 6 au 7 février : vers 8 heures du soir, l'atmosphèrc ćtait calme, lorsque, brusquement, unc grossc houle se leva. La brise ne se fit sentir quc cinquante minutes plus tard, et, bien qu'elle durât peu, la mer n'en dcmeura pas moins fortc. 
Ce phénomène est d'autant plus curieux, que nous nous trouvions dans une partie relativement étroite du détroit et qu'il semble presque inexplicable qu'une houle aussi forte puisse se soulever entre deux côtes peu éloignćes l'une de l'autre et parallèles aux crêtes des lames. 


\section{CHAPITRE XX.}

\section{Les glaces.}

Disons un mot maintenant des différents aspects que présentent les glaces.

Les terres des régions voisines des pôles sont généralement recouvertes, sur presque toutc leur étendue, d'une épaisse couche de glace, dont le pouvoir diffusif est énorme. Cettc couchc de glace projette, vers le ciel, un reflet jaunatre, qui s'aperçoit à de très grandes distances et qu'on nomme landblink.

A mesure qu'on pénc̀tre dans l'intérieur des terres, les aspérités du sol disparaissent; les vallées sont comblćes par des neiges qui se durcissent, se compriment pour former les glaces éternelles, recouvrant peu à peu tout le sol. Cette couche de glace prend le nom d'inlandice.

Les glaccs s'accumulent sur l'inlandice, exerccnt continuellement une poussée vers les côtes et finissent par se déverser dans la mer comme de véritables fleuves qui portent le nom de glaciers (fig. 3o).

Comme la poussée augmentc constamment à l'intérieur des terres, des blocs de glace descendent ainsi dans la mer, où, entraînés par le courant, ils flottent parcils à des épares : cc sont des icebergs.

L 'iceberg est donc formé par la glace de terre et composé exclusivement d'cau donce. Cette glace est d'un beau bleu et d'une dureté extraordinaire. Lorsqu'un iceberg est de formation récente, on peut constater sur certaines de ses faces latérales des lignes horizontales montrant la stratification des diverses couches de neige (fig. 3 I).

Lc glacier qui forme l'iceberg ayant une face supérieure plane, l'iceberg type de l'Antaretique est cn forme de table et porte le nom d'iceberg tabulaive. 


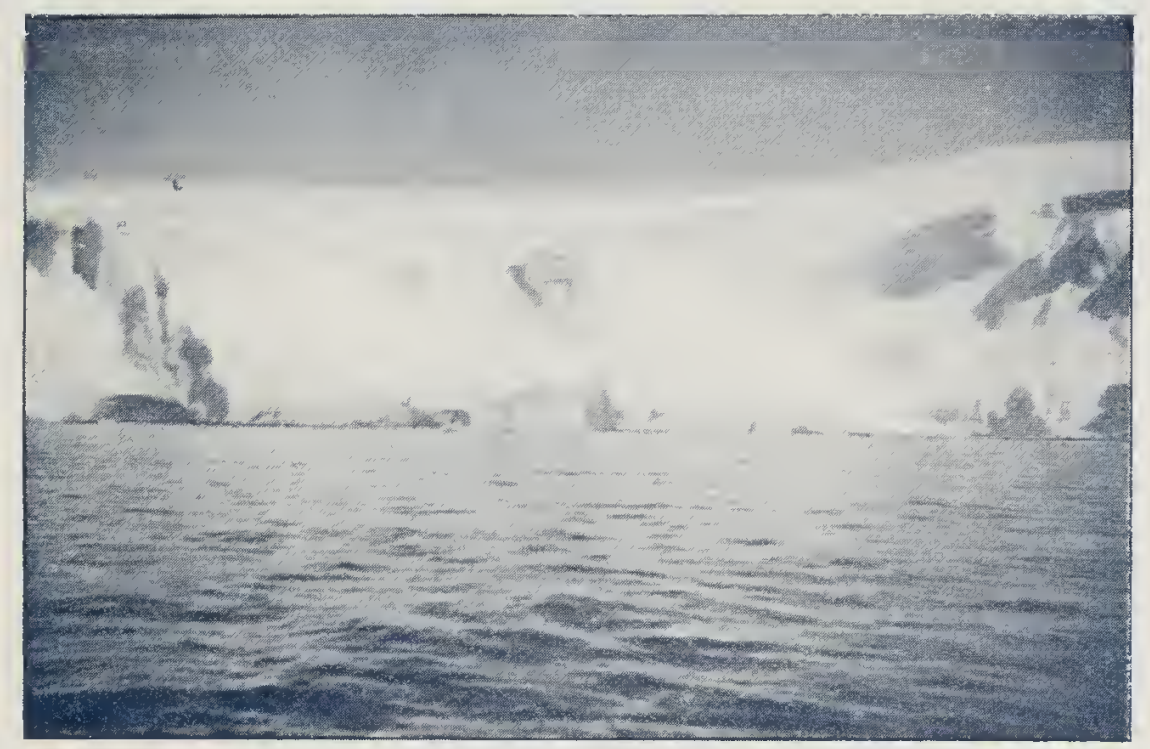

Photograjlice du J)r C $\mathrm{mk}$

FIG. 30

GLACITR DE LA TERRE DE IANCO

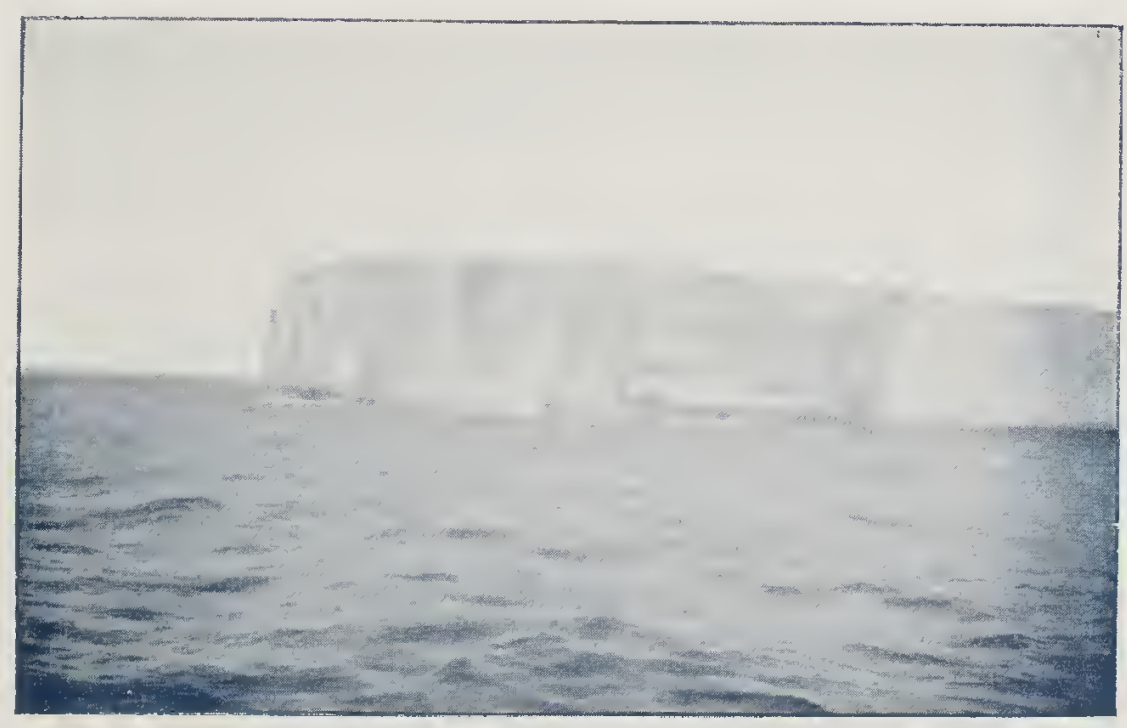

Plotographlic du Dr Cook.

FIG. 3I.

ICEBERG TABULAIRE. 
Ajoutons que les ieebergs peurent se détaeher aussi du flane de roehers abrupts, et, par eonséquent, affeeter, dès leur naissanee, des formes très variées.

Examinons maintenant l'ieeberg qui eommenee à flotter.

La mer l'arrose, l'agite, le seeoue, le fait tanguer : la glaee, sous ees

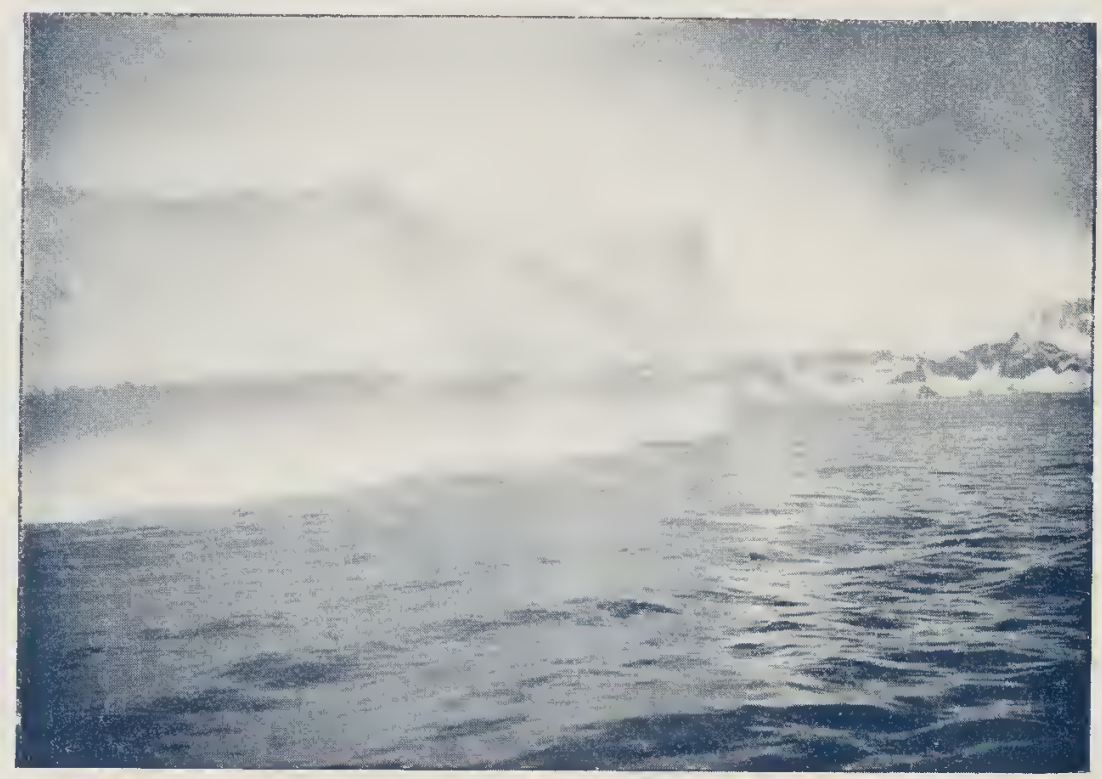

Photographice du Dr Cook.

FIG. 32.

ICEBERG RONGÉ A IA BASE PAR LISS VAGUES.

seeousses, s'arrondit, se polit ou se ereuse, jusqu'à la hauteur atteinte par l'eau de la mer (fig. 32).

Parfois aussi des erevasses se forment, dans lesquelles les vagues se préeipitent, y déeoupant des grottes, des eavernes mystérieuses (fig. 33). Les ieebergs ainsi travaillés offrent de ravissants aspeets. La base, sous l'eau, semble d'aigue-marine; les parois éelairées par le soleil ont la blaneheur seintillante du eristal; eelles qui lui sont opposées prennent un reflet d'azur, tandis que l'intérieur de la grotte est d'un bleu sombre et insondable. Puis, si l'eau eontinue à ronger, la galerie se ereuse de part en part eomme une arehe ou un tunnel (fig. 34 ). 
La hauteur des iccbcrgs au-dessus dc lcur flottaison atteint jusqu'à 60 mètres. En tenant compte de la différence de densité de l'eau de mer ct de la glace de terre et en admettant qu'un de ces blocs flottants ait la forme prismatique, on peut conclure qu'un iceberg, qui émerge à 60 mètres, a unc hautcur totale de 660 mitres environ. Nais les

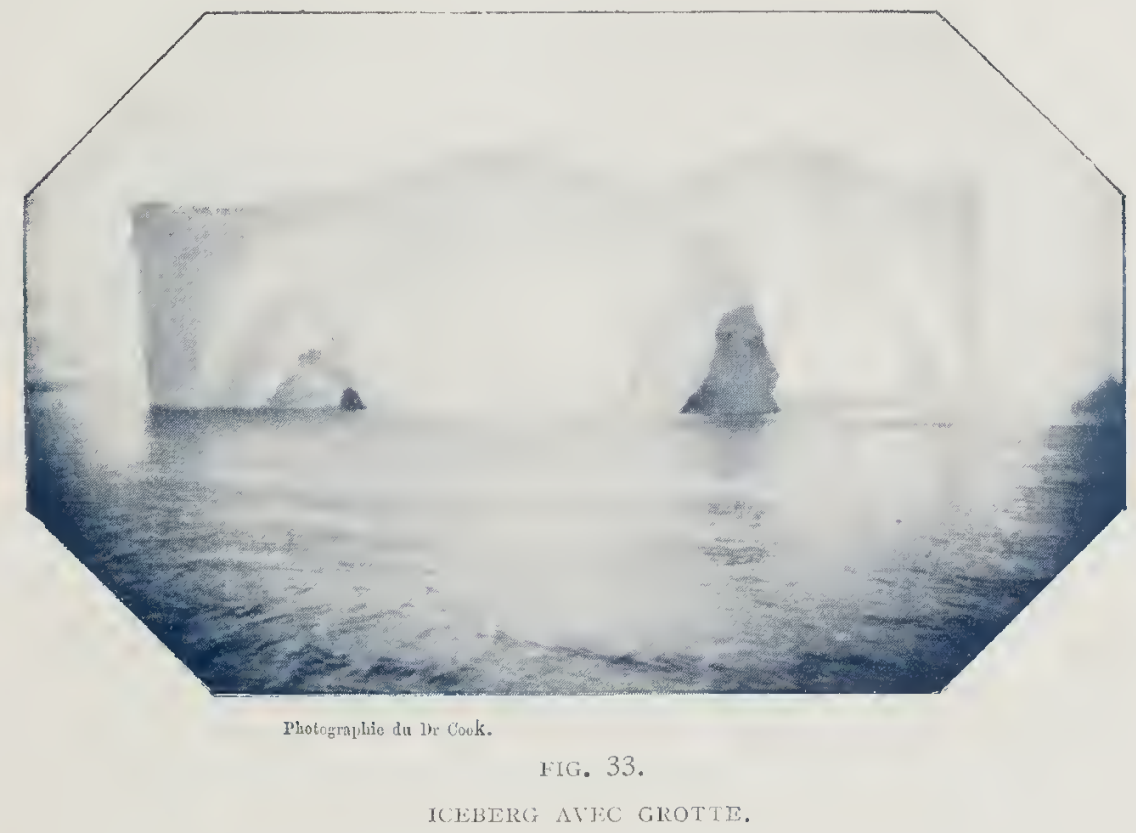

iccbcrgs n'ont généralement pas la forme prismatique; la base en cst parfois tris étenduc. Il n'cst malheureusement pas possible de mesurer l'épaisseur maxima dc la partic immergée, car il ne pourrait être qucstion de tircr unc conclusion quelconque de ce qu'on serait parvenu à passcr un fil de lignc sous l'iccberg mêmc, puisqu'on ne connaitrait pas la courbe décrite par la ligne.

La partie immergée de l'icebcrg ćtant si importante, on comprondra facilement qu'un courant sous-marin, ayant prise sur cettc énorme base, peut entraîncr l'iceberg dans une dircction opposée au vent, puisque ce dernier' n'agit quc sur la partic hors de l'cau. 
Dc même aussi un iceberg pourra résister à un courant de surface et jouer le rôle de barrage.

Dès que l’iecberg s'est éloigné considérablement du glaeier où il a pris naissance, les collisions avcc les autres icebergs lc transforment eneore sérieusement. Enfin, lorsqu'il pénètre dans des eaux moins

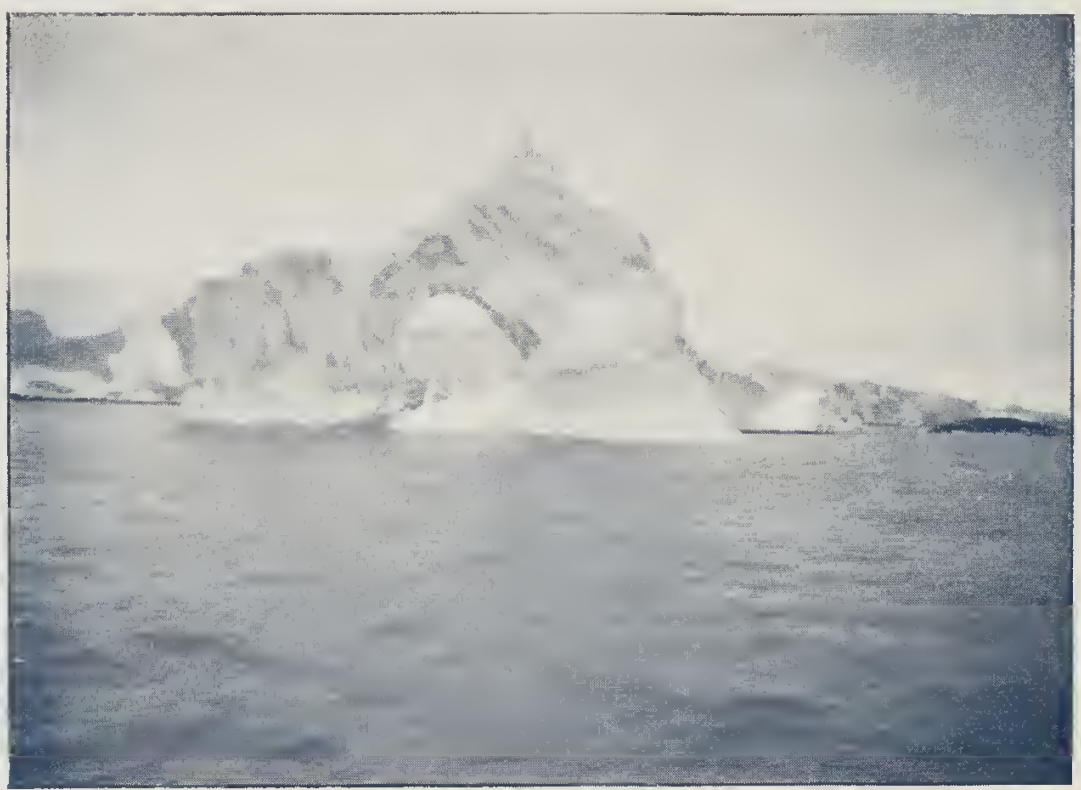

Photographie dir Dr Cook

FIG. 34 .

ICEBERG EN FORML D'ARCADE.

froides, un changement d'équilibre se produit: il ehavire, il se dissout, il devient un fragment, qui, peu à peu, se fond dans l'océan.

Comme certains ieebergs mesurent trois à quatre kilomètres de longueur et de largeur, sur unc épaisseur de plusicurs centaines de mètres, on peut sc figurer lc danger que prćsentc, pour un navire, la collision avec une semblable masse ( Ijanimée d'une vitesse pouvant

(I) Un grand icebers peut aroir 4,000 $\times 4,000 \times 400$ soit $6,400,000,000$ mètres cubes. 


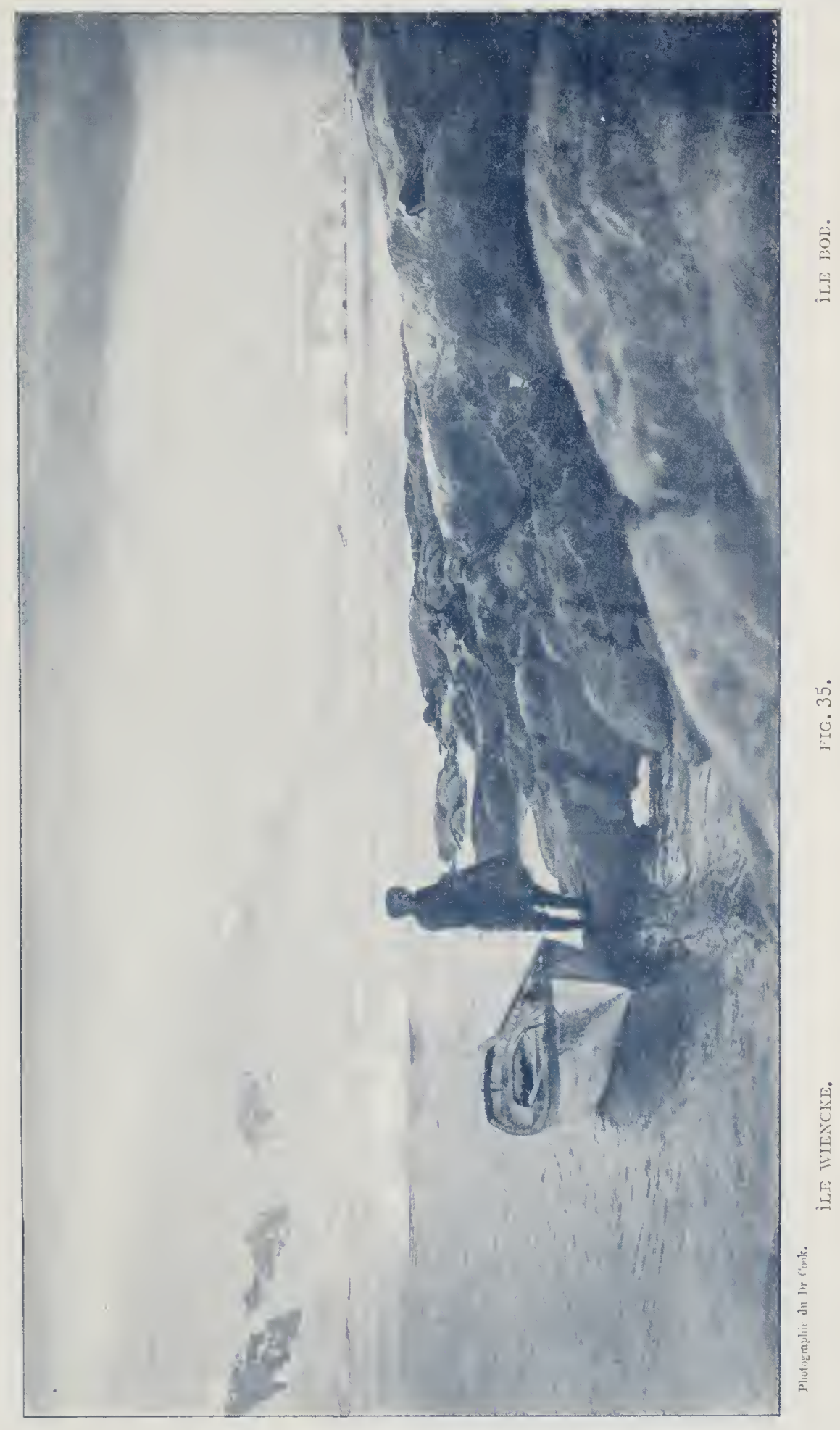



atteindre plusieurs nœuds. Les plus grands cuirassés pourraient ètre brisés comme un fétu de paille!

Nous derons eonstater ici que notre royage dans le détroit de Gerlache fut particulićrement favorisé, car, malgré la présence d’un grand nombre d’icebergs, nous y avons circulé librement fig.35), à une époque de l'annće où Mcddell avait trouvé toute lá région encombréc de glaces.

Nous venons de parler de la glace de terre; disons un mot de la glace de mer et de la banquise en général.

Les glaces éparses projettent aussi, dans le ciel, des reflets de lumière blanche diffuse appelés iceblink.

S'il se trouve, dans la banquise, un espaee d'eau libre, le ciel au-dessus prend une teinte bleue très foncéc: le avatersky. L'aspect du watersky peut ccpendant induirc séricusement en erreur: paıfois l'étendue en est considérable et scmble indiquer une grande surface d'eau libre, alors que, en réalité, il n'y a qu'un petit lac; d'autres fois encore des nuages gris-blcu, qui ressemblent au watersliy, peurent faire croire à la présenee d'eau libre là où il n'y a que de la glace.

A mesure qu'on approehe de la banquise, l'ieeblink devient plus marqué, plus étendu. On aperçoit ensuite de très petits blocs de glaee épars ou alignés en rubans et qui constituent la glace de dérive (fig. 40).

En avançant vers le Sud, on voit les blocs devenir de plus en plus grands: ils atteignent alors 20 ct 30 mètres de longueur et prennent le nom de plaques ou nappes.

Vers le Sud, les plaques deviennent encorc plus étenducs, ayant jo et So mètres de longucur. Elles forment alors des champs de glace dont l'ensemble, a vee les iccbergs et fragments d'icebergs, portc le nom debanquise.

Jes phénomènes multiples mettent sans cosse la banquise en mouvement. Lorsque ces mouvements durent longtemps, les glaces se resserrent et produisent la pression.

Au contraire, lorsque le calme se rétablit, les glaces se dirigent vers la mer libre; elles se dégagent et produisent la détente. 
Pendant la pression, les blocs énormes nc pcrdent leur force d'inertic qu'après s'être brisés dans de fréquentes collisions. Ils forment ainsi de véritables amonccllements appelés hummocks (fig. 37).

L'eau de mer se congèlc par $2^{0} 5$ centigrades environ sous zéro, mais il ne s'ensuit pas que la surface de la mer se congcle lorsque la température est même légirement inférieure à ce chiffic: les mouvements ondulatoires de cettc surface retardent la congélation. Nous avons vu, notamment, des lacs d'une étendue assez considérable avoir, par temps calme, une surface libre de glace par i $5^{\circ}$ au-dessous de zéro. Mais il s'agit là d'une exception, car lorsque la banquise n'est pas en mouvement, l'cau des lacs et des crevasses se fige, puis se congèle par des températures supérieures à r 50 sous zéro.

Lorsque la glace se forme, l'aspect de la mer est parfois vraiment étrangc (fig. 38) : au-dessous d'une mince plaque de cristal, l'eau de mer paraît toute noire, tandis que, dans une multitude d'autres endroits, des fleurs de neige, le rassol, transforment le champ de glace en un parterre ravissant. Dès qu'un léger mouvement ondulatoire sc produit, la couche de glace, encore peu résistante, se brise en pctits fragments qui s'accostent, se heurtent et, pour peu que le mourement se poursuive, se transforment en disques plus ou moins réguliers. Alors, dès que le calme ramène la détente, ces disques se disjoignent et flottent sur l'eau comme des feuilles de nénuphar (fig. 36).

Si, alu contraire, la couche de glace a le temps de s'ćpaissir, la neige, qui tombc Fresquc toutl'hiver, se transforme en glace, s'accumulc ct forme les plaques, ainsi que les champs dont nous venons de parler. 


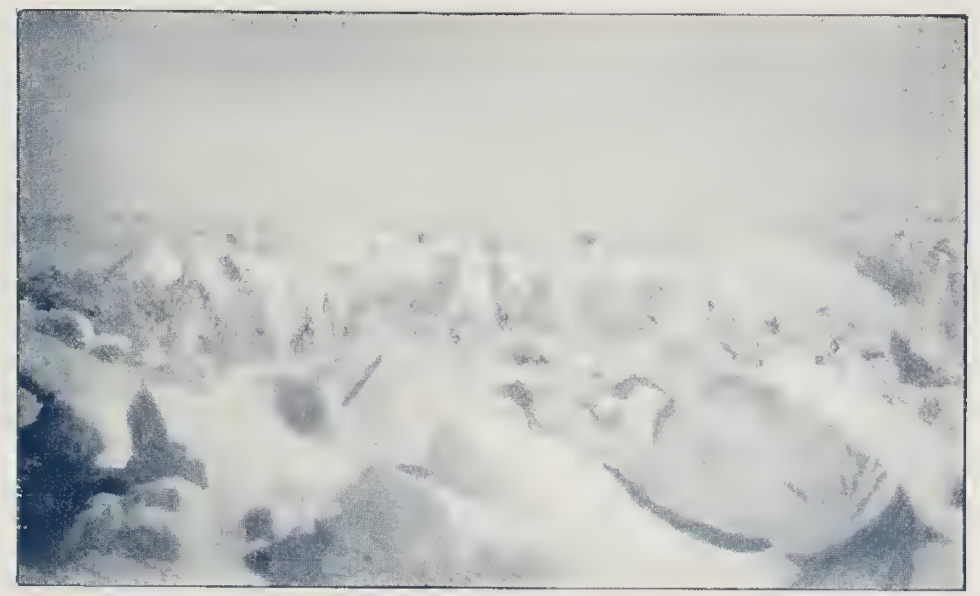

Photogrmplice dut Dr Cook.

IG. 37 .

LES PRESSIONS - LTS HLMLIOCKS

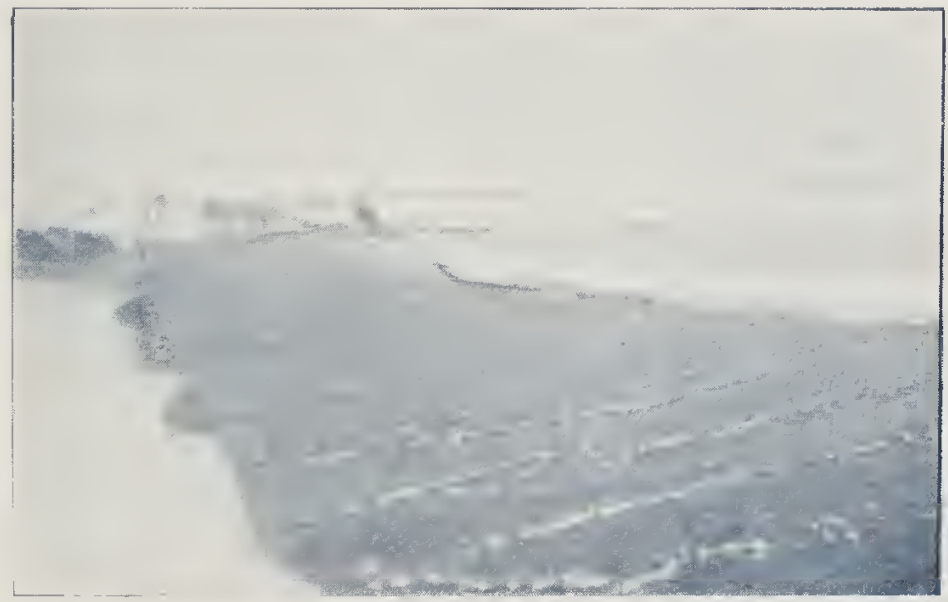

Plotograllúe du Dor Couk.

IIG $3 S$.

VOIE 1)HAC RECOLYTRTT DI: JJUXE GIACI IET VORILATIOY WT ( RISGOL ). 


\section{CHAPITRE XXI.}

\section{Un ouragan dans la banquise. - Bloqués.}

Nous avons laissé la Belgica, le iz février i 898 , dans le chenal de L.cmaire, non loin du cap de Trooz.

L.e lendemain, r3, nous cherchàmes à pénétrer dans la partic de mer qui se trouve au Sud de ce cap, afin de constatcr si nous étions en présence d'une baie ou du détroit de Bismarck. La densité de la banquise nous empêcha d'avancer; nous fùmes obligés de battre en retraite.

De 4 à 7 h. 30 du soir, nous longeons la banquise, laissant par bâbord les deux petites îles Cruls élevées de quelque trente mètres au-dessus des eaux. A peine les relevons-nous au Sud que nous constatons autour de nous la présence de nombreux récifs dont les sommets pointent dans le creux des lames. La mer est agitée, il vente tris frais, les brisants deviennent plus nombreux et nous ferment la route vers l'Ouest. I Ieureusement que de Gerlache, placé dans le nid de corbeau, ne perd pas de vuc les récifs et peut diriger la route d'une façon relativement sûre (I).

Vers 9 heures du soir, nous sortons enfin de cettc impasse, apres avoir rangé de très près un fort mauvais récif. Tout danger paraissant écarté, un seul homme reste en vigie auprès de l'officier de quart, qui a pour instruction de laisser aller le navire à la dérive, sans trop s'écartcr de deux icebergs échoués sur un banc de roche (2).

Or, vers 4 heures du matin, la brume fit perdre de vue à l'officier

(I) Dans les endroits où les récifs sont très nombreux, l'officier de quart se tient dans la màture. Il reconnaît alors à la couleur de l'eau les enclroits où se trouvent les roches.

(2) La présence des grands icebergss annonce toujours une certaine profondeur de la mer, étant donné que, par suite de la différence de densité entre la glac d'iceberg (nlace d'eau douce) et l'eau de mer, un iceberg émeryecul de 50 mètres à un pied immergè à une profondeur qui peut atteindre 500 mètres. 


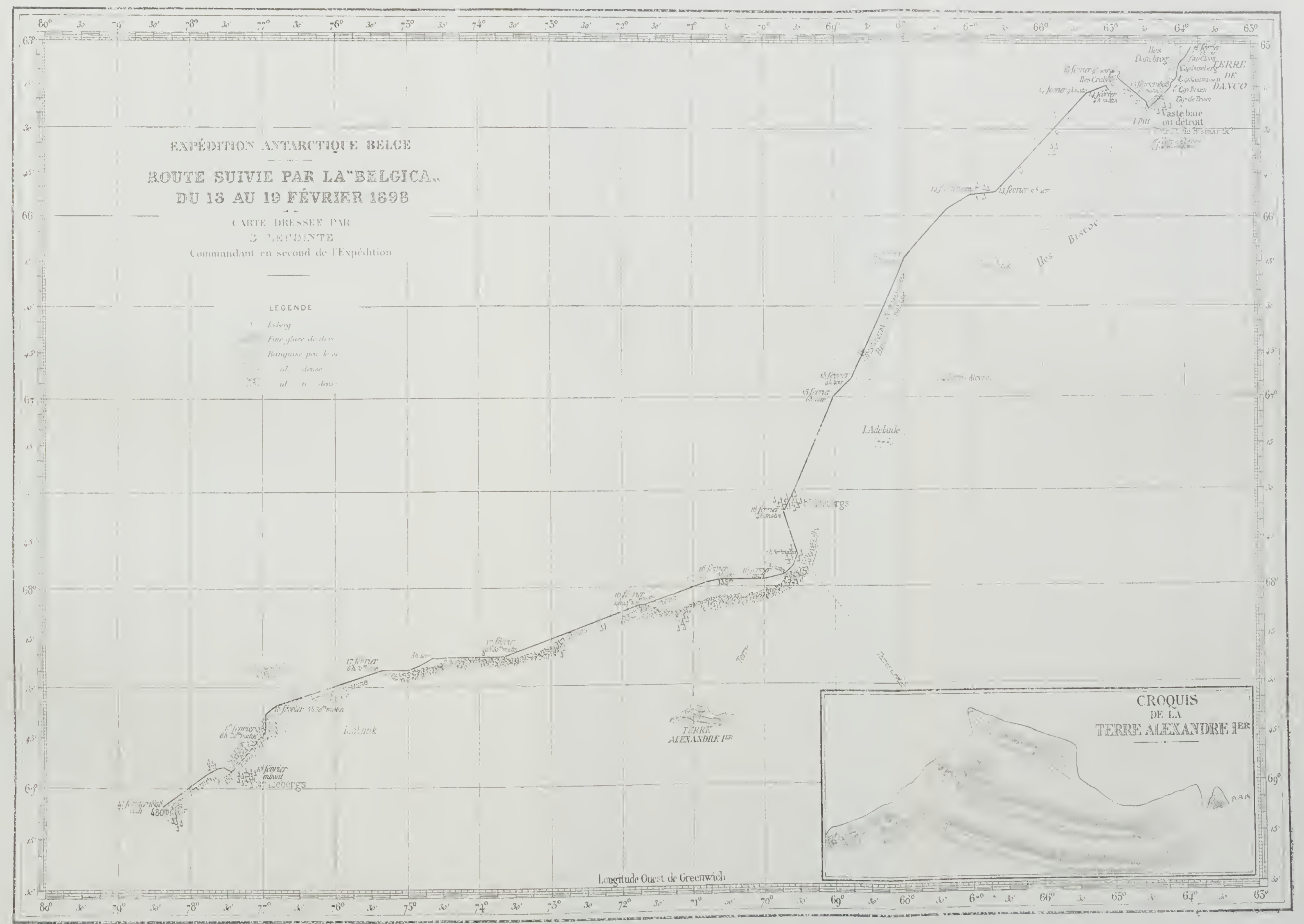



de quart les icebergs échoués. Chose étrange, le navire alors partit en dérive, évoluant au milieu des récifs qui nous avaient préoccupés la veille et sans se laisser effleurer par un seul!

Du i 3 au i 6 février, nous fûmes presque continuellement dans la brume, longeant la banquisc par bâbord. Parfois, au loin, vaguement, nous apercevions une terre dont les glaces nous isolaient, tandis que dans le cicl l'iceblink paraissait constamment. Nous croisions aussi fréquemment des icebergs, et nous traversions de longs rubans de fine glace de dérive orientés du Sud-Sud-Est au Nord-Nord-Ouest.

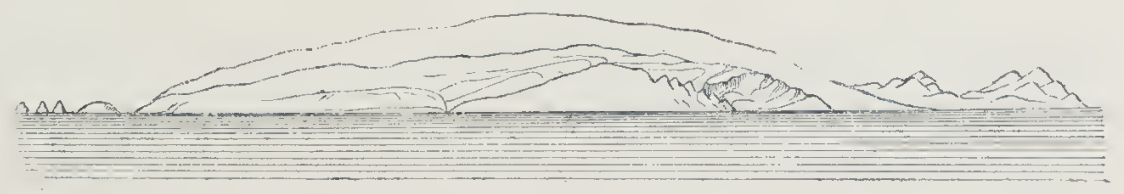

FIG. 30.

TUE DE LA TERRE ALEXANDRE.

Le I6 février, nous apercevons la Tcrre Alexandre, découverte, en I82I, par Bellingshausen. Nous en sommes si éloignés que nous ne pouvons même en apprécier la distance (fig. 39).

Devant la Terre Alcxandre, se trouvent de nombreux icebergs ne présentant pas la forme tabulaire caractéristique : quelques-uns sont capricieusement découpés; d'autres imitent la flèche gothique de nos cathédrales.

La densité de la banquise nous défend l'approche de la terre. La lisière des glaces est orientée dans la direction Est-Ouest et formée de petits fragments d'iceberg et de glace de mer.

Du i6 au 28 février, nous concentrons tous nos cfforts pour forcer la banquise; mais, à peine le navire a-t-il gagné quelques milles dans le Sud qu'il est ressaisi et immobilisé par les pressions.

Que faire? Remonter vers lc Nord et mettre l'hiver à profit pour compléter notre ćquipage et nos approvisionnements? C'était lc seul 
parti à prendre; mais l'idée que nous allions, peut-être, quitter l'Antarctique un jour trop tôt pesait lourdement sur quelques-uns d'entre nous.

Une circonstanee imprévue nous traça soudain notre ligne de eonduite.

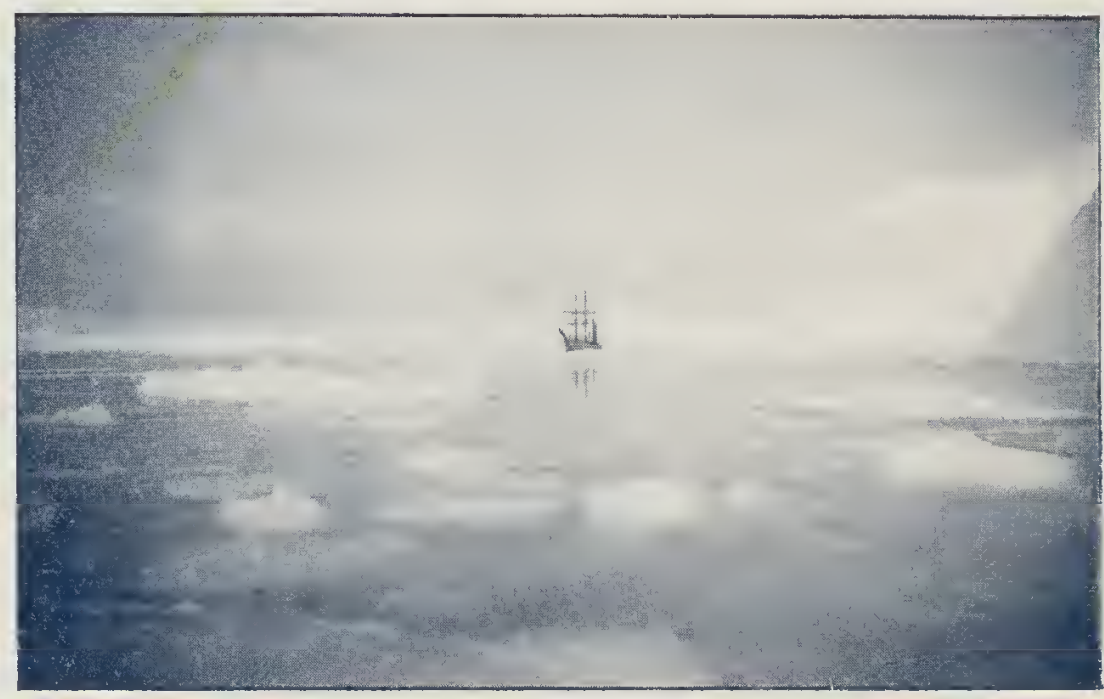

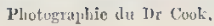

FIG. 40.

LA “ BELGICA 》 A L'ENTRÉE DE LA LANQUTSI: ANTARCTIQUE.

Le 28 féviier, une tempête se déchaîna, mettant toute la banquise en mouvement.

Les blocs de glace soulevés par la mer se heurtaient avee bruit. Des fissures se formaient dans la glace, puis allaient s'élargissant en rivières, en lacs sur lesquels le navire bondissait éperdu. Puis, les glaçons se rapproehaient à nouveau. Lorsqu'une détente se produisait, la Belgica filait avee rapidité, se frayant elle-même un ehemin. Parfois, sous l'influence du vent, elle aequérait une vitesse eonsidérable qui, brusquement, eessait à la lisière des laes.

Le vent soufflait de 1'Ist-NTord-Est; rien n'ê̂t été plus simple que de nous écarter de la banquise. 
Nais l'oecasion ćtait unique et il fallait profiter de cette dislocation des glaces pour courir vers le Sud. de Gerlache vint me trouver sur la passerelle : notre conversation fut courte; elle se termina par un vigoureux shake-liand, et, avee unc joie profonde, je transmis, au timonier, l'ordre de mettre le cap au Sud!

Nous ne nous dissimulions pas, ceperidant, les risques de notre téméraire entreprise. La mauvaise saison allait nous eondamner à un hivernage, pour lequel nous n'étions qu’ineomplètement équipés. Si nous succombions, qui rapporterait au pays les locuments précieux que nous avions déjà reeueillis?

Mais n'était-ee pas en affrontant maints dangers que Ross avait reconnu la 'Terre Vietoria, eroisé sous les volcans Erebus et 'Terror' et ouvert le ehemin qui eonduit au pòle magnétique austral? Ce que Ross avait tenté avec cles navires à voiles, ne devions-nous pas l'entreprendre avec un navire à rapeur? Oui, de Gerlache savait que nous risquions notre vie, mais il regardait la mort en faee et ne nous faisait point l'injure de se montrer- timoré pour nous.

l.e 2 mars, la banquise, qui s'etait ouverte sous l'influence de la tempête, se referma soudain. Ivec la plus grande peine, le navire avança encore de deux milles vers le Sud.

Bientôt la température baissa, surtout la nuit, et une jeune glace se forma, soudant ensemble les anciens champs.

Le 3 mars, nous tentons vaincment de nous déplacer: la banquise est trop eompaete, elle ne se laisse plus entamer. Enfin, le 4 mars I898, la Belgica était cnserrée de toutes parts, comme dans un ctalu.

Oui, de toutes parts s'étendait la banquise. Le soleil cependant ne nous avait pas eneore quittés; il éclairait même, dans tous ses détails, le spectaele grandiose et féerique que nous avions sous les yeux.

Partout, à l'infini, les glaces s'étendent, en champs très anciens et en champs de la dernicre formation. Tous portent encore les blessures le la récente tcmpête : leurs eassures sont droites et nettes; les pres- 
sions n'ont pu eneore les modeler. A droite, à gauche, des icebergs et des glaçons se heurtent contre ees champs en les ehas. sant devant eux. Cà et là brillent quelques lacs, dont l'eau eommenee à se figer; la neige, ou plutôt la fleur de neige, y festonnc tout autour une collerette de dentelle.

Ils se complaisent dans cette dernière parurc, car voici l'hiver qui va les eongelcr à jamais. Déjà les glaces se meuvent en s'aceostant mystérieusement. Elles jettent des cris ressemblant à des vagissements humains : c'est la voix de la jeune glaee qui se forme, c'cst l'enfant qui dit ses premiers mots. Plus tard, la banquise parlera cncore; elle hurlera de fureur, pcndant la tempête, ou bien elle exhalera une mélopée triste comme un ehamp funèbre, lorsque le soleil de l'été recommencera à la miner sourdement et à la disloquer.

Aujourd'hui, le ciel est radieux; il passe par les nuances les plus variées et les plus délieates : le vert pàle succide au bleu d'azur, le rose remplace le violet. La banquise sc colore sous ce voile changeant: voici un iceberg dont la base est vert d'eau, tandis que les faees latérales sont d'un bleu très foneé; là-bas, à l'horizon d'un gris perle infiniment doux, un autre ieeberg tout rose sous la pourpre du soleil couchant. D'autres eneore semblent noir, les perfides, eomme pour fcindre la présence d'une terre.

Et la vie anime ces régions ou l’on croirait que rien ne peut naître. Voiei des phoques couehés paresseuscment sur une nappe éblouissante. Des manchots étonnés poussent des cris aigus en s'approchant du navire, qu'ils contemplent longuement. Une volée de pagodromas, semblables à de blanches hirondelles, se groupent sur un vieil ieeberg et jacassent en famille. En famille !... Brusquement, le soleil disparaît, ct la lumière erépuseulaire du pôle éclaire, longtemps eneore, l'espace qui, lentement, se couvre de brume.

Alors la vie semble s'éteindre : les phoques s'endorment, les manchots appuient langoureusement leur tête sur leurs petitcs ailes, les pagodromas eux-mêmes se taisent : ils ne se content plus des poèmes d'amour! 


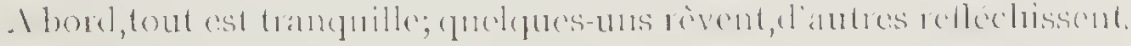

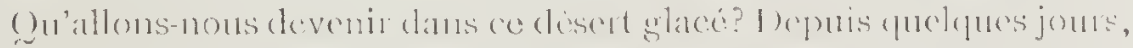

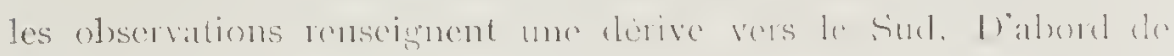

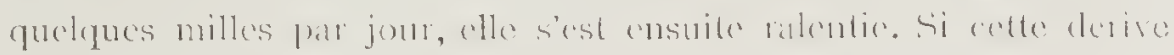

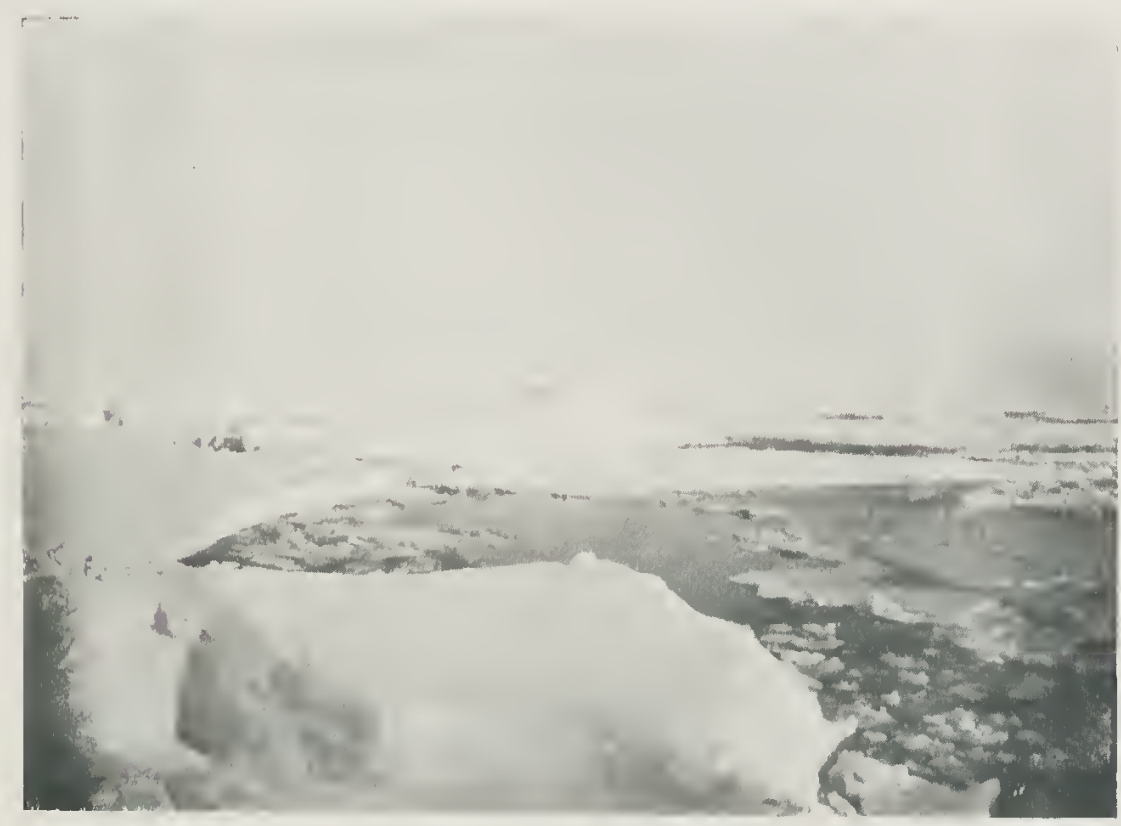

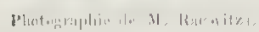

I. Wi 11

INSIMIII,I: I,I: I A IIANUU ISI .

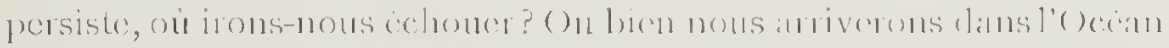

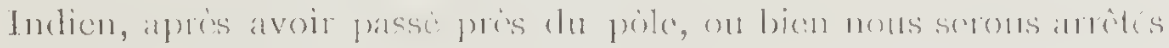
pall un continent.

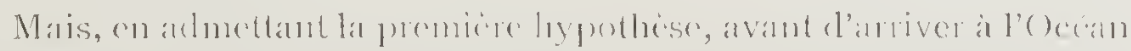

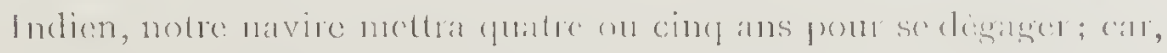

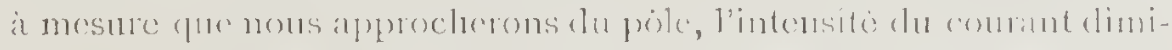

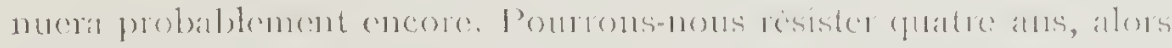

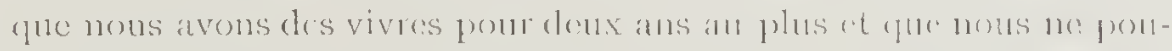

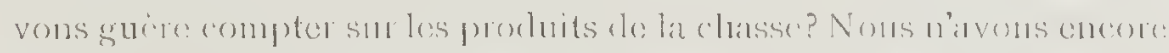

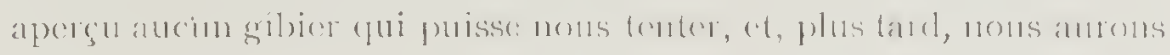


moins de chance cncore d'en rencontrer. Mais eette hypothise est inadmissible : les terres australes ne sont-elles pas là pour nous arrêter?

Dans l'Océan glacial aretique, on peut souhaiter voir la terre qui possćde du gibier comme l'ours, le renne; qui est fréquentée par des navires ehasseurs de phoques et de baleines; qui, enfin, est habitée par des Esquimaux. Mais dans le Sud, le continent antaretique est absolument désert et stérile. Aueune chanee de salut pour nous vers ces terres inhospitalières...

Chassons ces noires idées; arrêtons-nous à unહ perspective plus clémente. Pourquoi les pressions, qui arrivent des terres, ne feraientclles pas dévier notre route vers l'Ouest? Un bienheureux liasard nous cntraînerait peut-être dans la mer de Ross, aprés nous avoir eharriés au travers des 3,600 kilomètres qui nous en séparent! Dans ces conditions, nous mettrions un temps considérable avant d'être dégagés, mais nous pourrions faire de grands et utiles travaux et nous aurions plus de probabilités de salut qu'en dérivant vers le Sud.

Ce qui peut encore se produire, c'est qu'il n'y ait pas de courant et jue notre dérive momentanće soit due exclusivement à la tempête qui a soufflé les jours précédents. Dans cette hypotliese, nous nous ráplacerons avee la banquise: tantòt allant au Nord pour revenir vers le Sud, et pour repartir ensuite vers l'Est ou vers l'Ouest. Insensiblement, nous gagnerons la lisire des glaces que la poussée du Sud rejette toujours finalement vers le Nord. 11 est viai que notre séjour dans la banquise peut être long...

Et si les pressions trop fortes brisaient le navire? Elh bien! nous ferions un suprême effort. Nous avons des vivres, des vêtements, des tontes, des eanots, des slis et des raquettes que nous jetterons sur un champ solide, et nous tàcherons désespérément de gagner le détroit de Gerlache, puis de franchir le détroit cle Bransfield en canot. De là, deux ou trois d'entre nous s'efforceront d'atteinclre le cap Horn avec une de nos frêles embarcations.

()ucl projet chimérique! Il faut y croire pourtant. 11 faut donner à tous confiance et espoir. 


\section{CHIPITRE XXII.}

\section{Débuts de l'hivernage.}

L.e 7 mars 1808 , la dérive vers le Sud devint certaine, les observations astronomiques la renscignaient nettement.

A ce moment, nous nous trouvions, de Cierlache et moi, dans une grande perplexité. F'allait-il cxpliquer immédiatement lá situation à l'état-major ou bien attendre encore fuelques jours?

Longuement nous discutons lá question. Il est évident que nos compagnons ne sont pas tous partisans de l'hivernage. Mais comment retomner vers le Nord, alors qu'un watersliy tres étendu semble indicfuer, vers le Sud, une mer libre de glace?

Pourtant, de Gerlache croit devoir se résoulre à cette alternative, en présence de la "pression " qu'exercent sur lui plusieurs membres de l'expérlition.

Un moment mème, il se demande si ses ordies ne seront pas méconnus, dans le cas ou nous poursuivrions notre route. Je le rassure en lui disant, en riant, que si cette éventualité se produit, jo n'hésiterai pas à affoler le compas liquide avec de gros aimants, et à remplacer la rose du compas-étalon par une autre de réscrve que je pounai, en un clin d'ueil, aimanter en sens inverse. Le timonicr croila faile route vers le Nord et, en réalité, il s'avancera vers le Sud.

Cotte proposition égaye quelques instants de Gerlache, sans mettre un terme à son indécision.

Mais le lendemain, 8 mars, le watersky a disparu, cmportant notre rspoir d'une mer libre. Alors notre programme se trouve modifić: nous allons tenter de faire route vers l'ile pierre Ier.

Ce "nouveáu " projet est accucilli froidement par nos camarades. Les menbres du personnel scientifipue y sont même carrément hostiles, et, au cours d'une conversation intime avec l'un d'eux, mon interlocuteur me déclare que nous ne pouvons, de Gerlache et moi, 
nous arroger le droit de prendre une aussi importante détermination sans avoir demandé à chacun un vote affrmatif, étant donné qu'avant le départ d'Europe, il a été décidé qu'on ne chercherait pas à hiverner avec le narire. "Comment, apres les leçons qui viennent dc nous être données, pouvons-nous encore nous obstiner à rester au milicu des glaces? Ne pas fuir au plus tôt, c'est se faire emprisonner volontairement dans la banquise, c'est vouloir à tout prix un hivernage pour lequel nous sommcs trop incomplètement préparés. Voyez, me dit-il en terminant, ce petit calepin oì j'inseris mes notes scientifques : je l'ai choisi tout petit, afin qu'il ne soit pas encombrant le jour où, le navire étant écrasé, nous devrons errer sur la banquisc! Vous riez, Lecointe, mais rira bien qui rira le dernier ! "

Ce discours m'était servi très correctement, très froidemcnt, par un homme absolument convaincu que j'avais tort.

Le Io mars, il neigeait; le ciel, d'un gris de plomb, cachait toutes ses étoiles: impossible de reconnaître si, sous la poussće de la tempête, nous voguions vers le Nord ou vers le Sud.

A proximité du navire, des crevasses se sont ouvertes, formant quelques pctits lacs. Ce ne sont pas ces sillons humides qui nous permettront de sortir de la banquise; mais, pour donner satisfaction aux membres de l'état-major hostiles à l'hirenage, il est décidé qu'une tentative va être faite dans ce sens. Notre provision de charbon nous permet cet essai, qui n'exige pas plus de 500 lilogrammes de combustible.

L'apparcillage a lieu, mais sans aucun résultat. De plus, on ne nous tient aucun compte de notre bonne volonté: d'aucuns prétendent que l'effort a été tenté mollement, avec l'arrière-pensée de ne pas réussir !...

Comment répondre à cette accusation? Il est certain que nous avons homietement essayé de retourncr vers le Nord, mais il certain aussi que, dc Gerlache ct moi, nous avons été heureux de l'échec de notre tentative. 
Et nous avions les motifs les plus sérieux pour justifier ectte attitude.

En effet, si, avant de nous engager dans la banquise, de Gerlache avait consulté l'état-major, le vote n'eut eertes pas été en faveur de l'hivernage et le commandant se serait mis dans une situation difficile en ne tenant pas eompte du résultat du scrutin.

Si, au contraiıe, il s'était rallić au vou géuéral, que devenions-nous une fois hors de la banquise?

Nous allions tristement attendre, en Amérique, le retour de l'été et... l'argent néeessále pour continuer la eampagne l'année suivante.

Cet argent, nous l'aurait-on envoyé, alors que nous n'avions pas eneore aecompli quelque action d'audace?...

L'expédition ne possédait plus que i6,00o francs. Eun ajoutant à cette somme le montant des lettres de crédit dont disposaient, à titre personnel, quelques-uns d'entre nous, nous aurions eu à peine de quoi remettre le navire en état et nous réapprovisionner.

Et puis l'équipage nous aurait donné encore, sans cloute, de nouvelles préoccupations, car si nos hommes se conduisaient bien à la mer, sur terre ils redeviendraient très indisciplinés. Jamais nous n’aurions trouvé à renouveler ou à compléter notre équipage dans ce coin reculé du monde, ou viennent échouer tant de déclassés.

Instinctivement done, nous craignions plus de ventrev en Amérique que de tenter le premier hivernage dans les régions antarctiques.

Le soir du io mars, l'atmosphire s'éclaircit et le coucher du soleil fut superbe. Le disque de l'astre, particllement voilé par une gaze légòre, était d'un rose pâle très doux. Dans le lointain, émergeaient (puelques iccbergs. Peu à peu, vers le Sucl-Ouest, le ciel devint aussi d'un rose tendre qui, s'atténuant du eôté du zénith, arriváit au blane duveté, éblouissant.

Une demi-heure plus tard, le ciel d'un gris brun uniforme n'était plus éclairé que par un iceblinli assez étendu. Vers I I heures, la lune se leva, jetant sur la banquise les paillettes d'or de ses rayons. 
Du I I au I 5 mars, les esprits demcurent agités et mécontents. I1 est évident, pour chacun de nous, que la Belgica est prisonnicie : plus unc crevassc autour du navire; lcs glaces se sont soudées, enserrant leur proic de plus en plus.

Ieurcuscment quc les aménagements en vue de l'hivcrnage apportent un dérivatif puissant à la nervosité de chacun. Nous voilà tous transformés en charpentiers, et couvrant le pont, depuis l'arrière jusqu'au laboratoire, d'une immense carcassc de bois, protégée, à son tour, par du carton bitumé. Dame! nous ne sommes pas très habiles par ce froid qui paralyse les mouvements et engourdit les mains : le martcau, fréquemment, manque le clou pour attcindre les doigts.

L'animation renaît, la gaité se fait jour en saillies amusantcs! On rit, donc on est désarmé ! Le soir, la fa tigue cst telle que, sans discours, sans embages, chacun sc hàtc de regagner sa couchette.

Le dimanche, 3 mars, grands essais de slis sur la banquise. Ceux qui en connaissent l'usage daignent donner un conseil, voire une leçon. T es Norvégicns se dandinent avec gràce sur ces longs patins, mesurant de 2 à 3 mètres; de Gerlache ct Danco sont très présenntables : ils se sont cxcrés en Norvìge; mais nous... C'cst grotesque!

M. Somcrs, absolument découragé après quclques instants de contorsions, déclare qu'il n'a aucunc disposition pour ce genre de sport, que c'est de l'atavisme, que jamais, au grand jamais, aucun

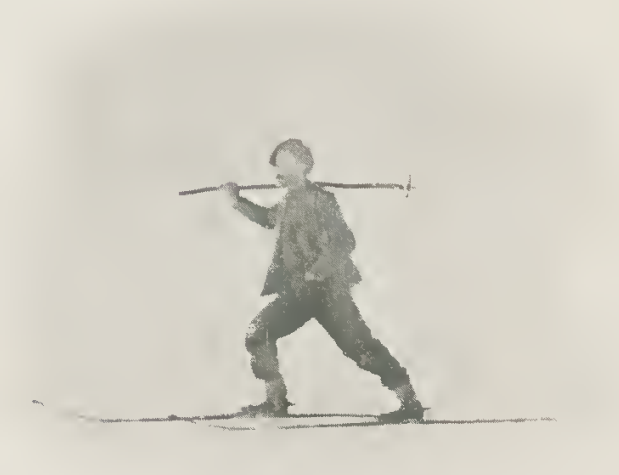

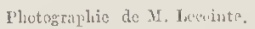

FIG. 42 .

RACOTITZA A SKIS. de ses ancêtres n'a réussi dans... Patatras! Somers s'étale lourdement, la pointe de ses patins enfourchée dans une vieille boîte à conserve! Et lc voilà qui se démène comme un bcau diable en s'efforçant de se relever. Sans cesse les skis s'cntre-croisent et le rejettent sur la neige. L.es cama- 
rades viennent à son aide, mais Somers erie, tempète et jure bien haut que jamais plus il ne ehaussera ees ridicules engins... à moins de nécessité absolue.

Ce fut le r4 mars, au soir, que, pour la première fois, l'aurore polairc nouts apparut. Déjà, le i i et le I2, quelques lueurs s'étaient montróes dans le Sud magnétique, mais elles ne m'avaient produit aucune des impressions profondes que ressentent généralement les voyageurs qui les contemplent pour la première fois. Quoi de plus naturel?

J'étais encore sous l'influence des leetures m'en décrivant les fécries; j'arais aussi, dans la pensée, un mot de de Gerlache assistant, à Anvers, au feu d'artifice qui avait elôturé la fête militaire organisćc pour l'expédition antarctique.

II. ITenri Cogels s'était donné énormément de peine pour assurè la réussite de cette fête. Comme le bouquet avec sa gerbe de ferı illuminait le cicl, il s'approcha du commandant en lui disant : "C'est réussi, n'est-ce pas? J'ai fait de mon mieux, car, de longtemps, vous n'aurez occasion d'en contempler. "

de (icrlaehe, impassible et eneore sous l'influence de réeits extraordinaires - car je suppose qu'jl n'arait jamais vu d'aurore - avait pris un petit air suffisant pour répondre: "Nous aurons micux : ... l'aurore polaire! \#

Alors M. Cogels était resté bouche bée; les journalistes s'étaient rapprochés vivement, prenant des notes; les jeunes filles avaient frémi d'admiration, tandis que $M$ me Osterrieth, "notre mère adoptive à tous ", arait eu sur les levres un sourire de satisfaction en contemplant ses ehris enfants!...

Taturellement, notre imagination à tous avait enfanté des merveilles, et, tout naturellement aussi, les ehétives aurores du i I et du I 2 mars nous avaient apporté une cruelle déception. Ce n'était là heureusement qu'un faible prélude; la premic̀re belle aurore que nous vîmes fut extle du r4 mars r 898 .

11 ćtait ro $\mathrm{I} / 2$ heures clu soir, lorsque le ciel, qui était d'un blen 
sombre absolument serein se teinta, vers le Sud, d'une lueur d'un blanc laiteux, phosphorescente.

Cette lueur disparut un moment, comme si le rideau se baissait après le prologue; puis elle reprit plus vive et dessina un long ruban moiré qui semblait onduler au gré des vents.

Bientôt le ruban devint plus net, plus brillant, dardant des rayons vers un même point du ciel, vers le zénith magnétique.

Tout à coup, il s'étire, s'élargit, s'allonge, se raccourcit pour s'allonger encore indéfiniment, en formant une arche dont les deux extrémités touchent la banquise. La portion du ciel, à l'intérieur de l'arehe, reste d'un bleu sombre, presque noir. Mais voici des groupes de rayons qui s'élancent; ils sont d'or avec, parfois, des reflets verdâtres. A certains moments, ils semblent s'éteindre pour reparaître bientôt plus brillants. Ils se meuvent, se déplacent, s'écartent, se rapprochent. L'arche elle-même se plisse, s'ondule, se déforme, en projetant des rayons vers le zénith magnétique.

Enfin, comme si l'effort qui l'agite devenait soudain trop violent, le ruban se rompt et se dédouble en deux longues traînées lumineuses, qui, à leur tour, s'affaiblissent, se décolorent, s’éteignent... c’est la nuit!...

Mais non! brusquement, un ruban reparaît encore, et il scintille et se déploie jusqu’à former une draperie phosphoresccnte, au bas de laquelle des rayons semblent dessiner une frange. C'est le rideau qui termine la féerie : il cst d'une telle ténuité, que les étoiles brillantes le traversent de leurs regards curieux. La lunette astronomique nous permet d'en compter des millicrs et de comparer l'infini de là-haut à notre petitesse d'ici-bas.

Car quelles sont ces lueurs étranges qui cireulent ainsi dans la nuit (I)? La science explique ou cherche à expliquer ee météore,

(I) Parmi les théories qui ont eu cours, jusqu'à présent, sur l'aurore polaire, en voici une qui semble la plus rationnelle.

Considérons un tube de Geisler traversé à ses deux extrémités par deux bouts de fil de platine isolés l'un de l'autre. Si nous faisons le vide clans le tube et si nous 
mais devant le speetaele lui-même, on est saisi par le merveilleux, le mystire... : on se tait, on admire!...

Les dernières lueurs de l'aurore s'éteignirent vers 3 heures du matin, aux premiers blanchissements du jour; mais, dès 2 heures, mon attention avait été foreément détournée par un autre phénomène qui devait se passer à 2 h. 20 environ : l'éelipse du premier satellite de Jupiter. Cette observation avait une réclle importanee pour nous, ear, en notant l'heure exacte de la disparition du satellite, nous pouvions régler les ehronomètres. Aussi, dès 2 heures, la lunette astronomique était-elle montée sur le pont, tandis que Dobrowolski, installé avee ses chronomètres à la fenêtre entr'ouverte de la cuisine, attendait mon signal.

Comme je ehangeais de plaee, un instant, pour me réehauffer, je vis, à quelque einquante mètres du bord, un corps long et noir qui remuait sur la banquise.

"Pas de doute, pensais-je, e'est un phoque qui cherche aventure."

Vite je eours au earré, je prends mon fusil que je charge; mais, avant d'épauler, les préoeeupations du métier me font jeter un eoup d'xeil à la lunette.

Le satellite va disparaître: impossible de tirer le phoque sans eompromettre mon observation. Je me recroqueville sous ma lunette et suis tellement heureux de saisir l'astre au moment où il s'éteint dans le eòne d'ombre de Jupiter, que mes instincts deviennent aussi paeifiques qu'ils étaient belliqucux quelques minutes aupararant. Je

mettons chacun des fils en contact avec les pôles d'une machine électrịue en activité, le courant traverserá le tube ef rendra incandescent l'air raréfié 'pu'il contient: on aura une aurore polaire artificielle. L'incandescence des gaz des hautes régions de l'atmosphère, dans la direction où se manifeste une aurore, est nettenent démontrée par l'analyse spectrale.

La vaporisation d la surface de la terre et l'induction unipolaire transportent de l'électricité dans l'atınosphère.

Cette électricité peut revenir à la terre, dans la zone torricle et les zones tempérces, brusquement, par une décharge qui produit la foudre.

D'un autre côté, la position réciproque de la teure et de la couche atmosphérituue 
déeharge le fusil, que je renvoie au earré, et tranquillement je eonlinue à observer les derniers restiges de l'aurore polaire, tout en jetant, de tcmps à autre, un regard proteeteur au phoque, devenu immobile sur la banquise.

Or, le lendemain matin au déjeuner, eomme nous échangions nos impressions sur la nuit préeédente, Cook tout à coup se plaignit du froid, déelara qu'il n'avait pu fermer l'oil de la nuit, paree que ses cheveux et sa barbe collaient à son sae de couehage!

Tous nous relevons la tête et le eonsidérons avee stupéfaetion !... - Mais oui, continue-t-il, la nuit était si belle, le paysagc si pittoresque, que je me suis étendu sur la glace dans mon sae de eouchage. Malheureusement, la vapeur d'eau, se condensant, puis se eongelant sur le sac, avait fini par m'y mouler! C'était très désagréable!

- Comment! c’était vous le phoque! m’éeriai-je, épouvanté.

Cook protesta avec une eertaine indignation.

Nous nous expliquàmes...

Pauvre et eher ami Cook! sans l'éclipse du premier satellite de Jupiter, je vous fusillais eomme... un phoque!...

pour laquelle la pression est de omoo5, occasionne une accumulation d'électricité vers les pôles.

Ld̀, le retour à la terre se produit par un éconlement lent au travers des paillettes de glace en suspension dans l'atmosphère et qui servent de conducteur.

Cet écoulement, qui n'est pas lumineux dans les parties basses de l'atmosphère - c'est-a-dire à forte pression - le devient dans les sphères élevécs.

Les arcs Iuminenx superposés s'expliquent par la présence de couches d'air de pression variable, et cette hypothèse permet d'expliquer la grande mobilité du phénomène, puisqu'une modification dans les positions relatives de ces couches d'air change les conditions dans lesquelles s'effectue l'éconlement de l'électricité.

I1 reste à expliquer pourquoi les rayons ont des tendances à darder vers le zénith magnétique du lieu où se produit l'aurore.

Ce fait est dù à ce que la résultante des forces qui conduit l'électricité dans l'atmosphère cst, dans ce lien, perpendiculaire à la direction de l'inclinaison (application de l'induction unipolaire par Edlund) 


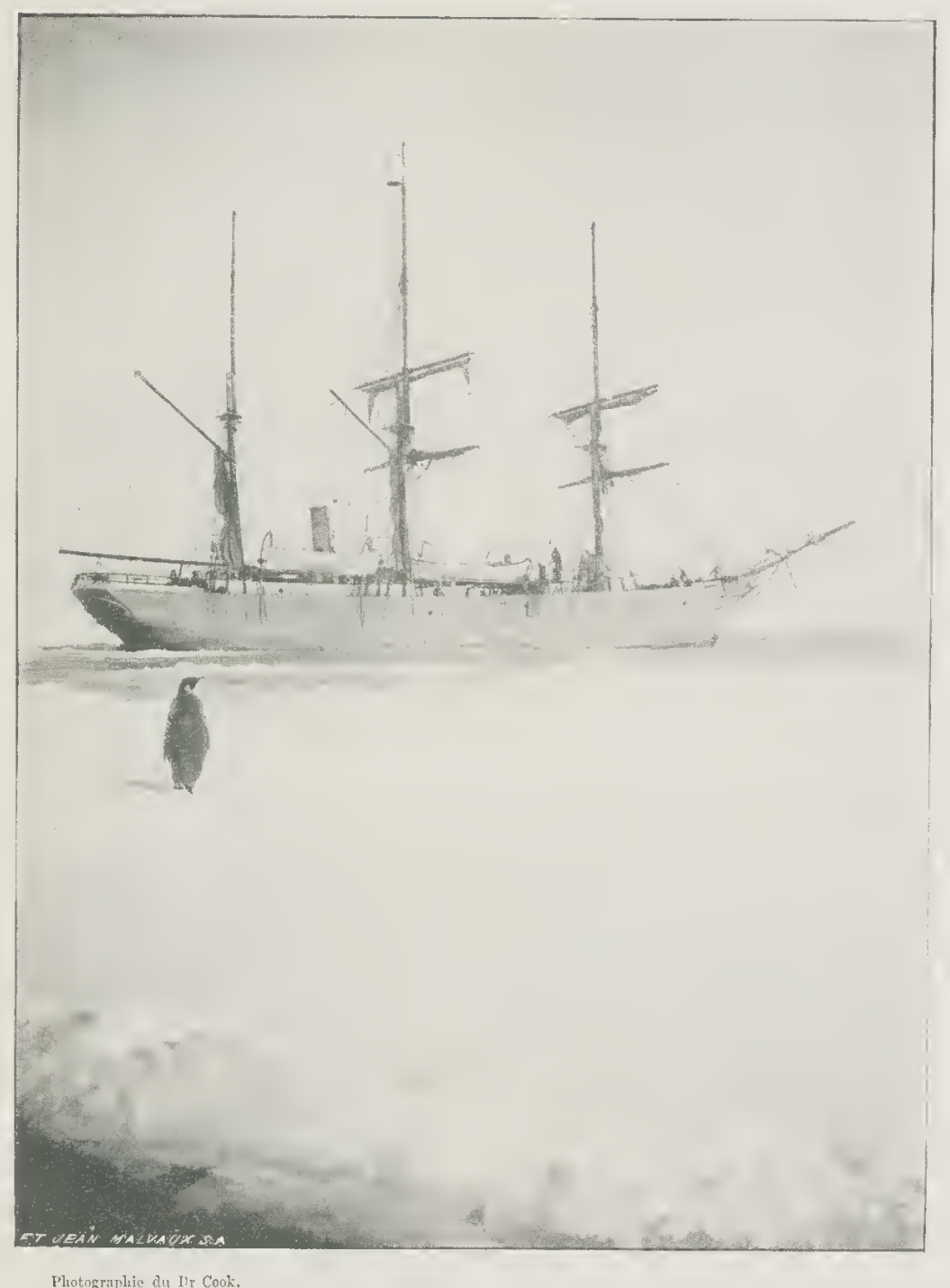

Plotograplice du Ir Cook.

FIG. 43 .

LA ( BELGICA ) DANS LA BANOUISE. 



\section{CHAPITRE XXIII.}

\section{Tout le monde grincheux!}

Le lendemain, I 5 mars, nous commençâmes nos constructions au dehors. Danco et Dufour élevèrent un observatoire magnétique ; Cook, Amundsen et moi dressâmes l'observatoirc astronomique, puis, avec l'aide de Van Rysselberghe, une sorte de hutte qui pût, au besoin, servir aux observations d'ćlectricité atmosphérique.

Pendant co temps, de Gcrlache, sccondé par lc lieutenant Mćlaerts et l'équipage, retournait pour la $(\hbar+I)^{\text {me }}$ fois, les caisses à provisions, que l'on transportait vers l'arrière où devait s'édifier la cambuse.

Le r6 au matin, je rejoignis ce dcrnier groupe, ct nous voilà sciant, clouant, dans le compartiment de l'arrière, n’ayant pour tout ćclairage que des bougies fixées sur de petites planches. C'est miracle que nous n'ayons pas fait sauter le navire, car dans un réduit voisin du nôtre, et que nous devions fréquemment traverser, se trouvaient 500 kilogrammes de tonite.

Cet explosif n'avait pas été emballé comme cela se pratique dans l'artillerie; los paquets de tonite avaient été empilés dans des caisses quelconques très minces, en vulgaire bois blanc, et les couvercles en avaient été fixés avec des vis cn fer. Cette tonite avait déjà subi, pendant notre longuc traverséc de la zone torride, un commencement d'avarie qui devait se poursuivre activement dans l'Antarctiquc, grâco à l'humidité du local où elle se trouvait.

A côté de la tonite, gisaient les charges de poudre des canons lanceharpons, dans des boittes dont plusieurs n'avaient pas de couvcrcle. Plusieurs de ces charges s'étaient rompues et de gros grains de poudre noire formaient, à certains cndroits, un véritable tapis. Enfin, six petites caisses en bois, dont deux éventrécs, contenaicnt des milliers de cartouches avec amorce au fulminate de mercure... 
Et malgré cela, nous traversions ce compartiment avec la plus grande sérénité du monde, ne prenant même aucune précaution pour protéger les bougics coulantes, à l'aide desquelles nous projctions un peu de lumière dans ce coin obscur.

Dans l'cntrepont, un réservoir de benzine était placé au milieu des caisses, sans précaution spéciale; il était même légèrement fendu à la partie supérieure. Ton loin de là, enfin, étaient réunis une dizaine de futs contenant l'alcool destiné à la conservation des échantillons zoologiques.

Si un incendic de quelquc importance avait éclaté dans le navire, c'eût été un feu d'artifice stiperbe, avec bouquet, semblable à ceux qu'organisait notre ami, Henri Cogels. La pompe à bras ne fonctionnant plus depuis des mois, le col-de-cygne de la bouche de refoulcment du petit-cheval sur le pont, n'ayant jamais existé, nous aurions pu combattre l'élćment destructeur avec nos seaux, nos carafes et nos verics de table!

I) u 17 all 20 mars, la banquise devint cncorc plus compacte, le froid s'accentua, le vent souflla en fréquentes rafalcs, chassant une neige finc ct perlée comme du sable sec.

Malgré cc temps ćpouvantable, 1)anco et quelques matelots cherchèrcnt à ćtablir un condncteur de cuivre lc long du mât d'artimon, pour les observations d'électricité atmosphérique. Ils furent obligés d'abandonner cet essai : les cordages, rccouverts de givre, glissaicnt entre leurs doigts et ne leur permettaient pas de se hisscr jusqu'au sommet du mât.

Impossible d'ailleurs d'exécuter au dehors, par cette tourmente, un travail scientifique quelconque; nons dumes nous contenter de besognes manuelles, nous préparant à la lutte contre l'hiver.

Lc 22 mars, il y a de l'oragc dans les esprits : l'énervement est génćral!... Un matelot refuse de vaquer au service de propreté du postc, sous prétexte qu'il y a des marins plus jeunes que lui. Les 
membres de l'état-major, qui hivernent à contre-currr, ne laissent échapper aucune occasion de constater combien peu nous sounmes préparés à batailler contre les éléments. J'entends dire que le bateau n'a jamais été définitivement armé; que lá machine à sonder n’est pas entretenuc; que la machine motrice de la bobine d'enroulement est dans un piteux état; que le grand treuil à vapeur s'abîme; que plusieurs tuyaux à fuites subissent, comme réparation provisoire, une simple liure au filin, etc. Je dois avouter que ces remarques m’impressionnent un peu, parce qu'elles sont débitées avec calme et mesure. Et puis, en mon for intéricur, comment ne pas convenir que tout cela est exact?

Le 23 mars, mon tour arrive aussi de perdre na sérénité. Comme je vais observer les déviations du compas-étalon, je le trouve encombré de ferrailles, de carton bituné et de mille autres choses. MIême désarroi dans les environs du compas liquide. Alors, ronchonnant ferme, je regagne mon logis.

J'ai tort de dire "logis $)$ : il n'y a pas de mot en français pour désigner ce qui me sert de chambre.

bans cette espéce de caveau éclairé faiblement par un hublot et un prisme de verre que j'ai fait ajouter à mes frais, tout parait noir et salc. Le plafond est fendu sur toute la longucur des joints; il porte autant de traces noires que de fois j'ai allumé ma bougie! A certains endroits, la résine du bois s'est frayé un passage, coulant le long de la muraille en traînées luisantes et visqueuses, qui tachent les vêtements que j’ai le malheur de penctre là.

Tous les efforts tentés pour rendre mon taudis riant et coquet ont tistement échoué!

L'ourtant les photographies du Magenta, de la Melpomine, du Terrible, (lu Dupily de Lome voilent en partic les murs, me rappelant mon houreux séjour dans la flotte françaisc; des doigsts de fée m’ont brodé rideaux, portière, courte-pointe : des lézards d'or couchés paresseusement sur du satin de laine d'un vert glauque comme l'cau de mer; 
un pinceau habile a retracé un paysage me rappelant des souvenirs charmants; une âme généreuse m'a offert la jolie glace qui reflètc le petit bout de ciel passant derrière mon hublot!...

Mais comment entretenir l'ordre et le bon aspect dans un réduit où doivent s'accumuler les choses les plus disparates?

La nuit, lorsque je me déplace dans mon lit, je me heurte de tous les côtés. Et quel tour de force, d'adresse, de rusc même pour parvenir à travailler dans ce taudis!

Il n'y a pas de chambre de cartes: le laboratoire est à peine suffisant pour Arctowsli et Racovitza et il ne peut être question de fairc une bcsogne sérieuse au carré, oì l'on cntrc et sort à tout moment. J'ai dû user de stratagc̀me pour caser tout mon matériel.

Les cartes dont je nc me sers pas couramment sont roulées et attachées au plafond, où sc balance également l'ćlcctro-aimant à l'aidc duquel se transmettcnt les signaux horaires.

Au plafond cncore est maintenu par des ficclles un énorme carton qui, à mon appel, vient se poser sur mon lit pour former table dc travail.

Enfin, du plafond toujours, descend un trapèze, mon unique siège pour écrire ou pour dessiner, et que je suis obligć de remonter quand je veux faire le moindre mouvement. Pas très reposant cc genre de chaise ct combien peu stable !...

Plus j'examine mon capharnaim, plus ma mauvaise humeur s'accentue. Alors, pour fairc diversion, je me décide à demander un brin de causette à l'ami Danco.

Pauvre vicux! c'est lui qui pourrait se plaindre dc sa cabine, ou plutôt de leur cabine, car il la partage avec Racovitza, Cook et Arctowski!

Longue et étroite comme un couloir, elle prend l'air ct la lumière par deux hublots, dont un seul peut s'ouvrir. La fenêtre carrée du côté de l'avant est peu avantageuse pour lc renouvellement de l'air', car elle donnc sur la machine et n'apporterait éventuellement que des émanations d'huile chaude ou d'oxyde de carbonc. Deux sérics 
de couchettes, composée chacune de deux lits superposés, s'alignent le long de la muraille. Les couchettes de la première série mesurent Im8o; celles de la seconde ont dû être allongées de Io centimètres pour Danco et Racovitza! Vis-à-vis des lits, le mur est occupé par des armoires à tiroirs multiples, où s'entassent pêle-mêle les objets les plus divers. Deux microscopiques lavabos remplissent les coins non envahis. Au-dessus de chacun d'eux, une sorte d'étagère portant un bidon et une éprouvette de laboratoire : le bidon est censé contenir de l'eau douce; l'éprouvette sert de verre à boire!

Un passage, large de $\mathrm{O}^{\mathrm{m}} 4 \mathrm{O}$ environ, reste libre au milieu de la chambre. C'est là que ces messieurs peuvent s'habiller et se déshabiller, à condition toutefois d'évoluer avec une extrême discrétion. Point de banc ni de chaise, mais au fond du passage, contre le mur, une planchette mobile forme une sorte de siège minuscule pouvant supporter tout au plus la moitié de ce que la Nature accorde, poul: s'asseoir, à tout individu!

Les matelas, les literies, étaient soignés, mais une circonstance imprévue avait obligé certains do nos amis à les mettre au rancart. La cabine étant peu élevée et l'espace entre deux couchettes superposées très restreint, ces messieurs ne pouvaient se soulever sans se heurter à une paroi ou l'autre. Ajoutons que le manque de place les obligeait à introduire sous leur matelas leurs vêtements pliés, au fur et à mesure qu'ils se déshabillaient, ce qui augmentait considérablement la hauteur du matelas.

Arctowski, lui, n'avait pu réaliser, dès le début, ce désidératum, attendu que sa pelisse pliée occupait une trop grande place dans son lit. Il avait donc pris le parti de se coucher le dernier et de jeter tous ses vêtements sur le pont de sa chambre.

D'un autre côté, afin de se heurter moins souvent à la couchette superposée, Cook avait rejeté successivement ses draps, puis ses couvertures, puis son oreiller, tant et si bien qu'un beau soir il supprima courageusement le matelas et disparut dans un sac de couchage!

On s'imagine facilement l'aspect de ce réduit vers 2 heures du matin. 
Les sacs de fourrure, les pelisses, les vêtements de laine, les onze pipes de Daneo répandent une odeur moins qu'hygiénique. L'absence de ventilation rend les respirations laborieuses, pénibles même; les eauchemars agitent les dormeurs. Il paraît que, justement la nuit précédente, Raeovitza a débité un discours aux phoques et aux manehots; Danco, bouillant artilleur, s'est démené en huilant: " $\mathrm{Si}$, si, il faut augmenter le contingent! " Cook s'exclamait : "All is right! " tandis que le pauvre Arctowski gémissait douloureusement, rêvant de thermomètres brisés ou de bouteilles à eau qui ont une fuite!

Ces détails, racontés avec humour, parviennent à me dérider. Je me décide à retourner sur mes pas, tout en jetant un coup d'œil, en passant, à la case des officiers Amundsen et Mélaerts.

"Ces derniers sont vraiment encore plus mal lotis que nous, me dis-je en rentrant ehez moi; j'aurais mauvaise grâce de eontinuer à me plaindre! "

Alors très gaîment, je saisis mon petit trapèze, je deseendis mon carton-pupitre sur mon lit et me plongeai dans mes calculs de réduetion. 


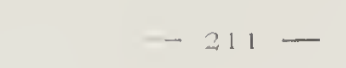

\section{CHAPITRE TNT}

\section{"Alea jactal est ".}

Oui, lesort en est jeté! Chácun a pris son pánti d'un citat de choses que nulle volonté humaine ne: peut plus nodifier à présent.

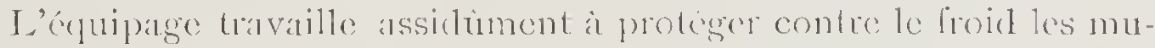
railles du navire par un parapet de neige, cat, hien (pue nons soyons relativement peu éloisnés de lá mor libre, nous sommes loin d'avoit un " climat maritine ". Le vent qui nous arive tu Nord est relativenent doux, mais colui qui nous vient du Sud s'est glacé en labourant le champ immense ales noiges éternelles. I, as attributions de tous sont nettement définies; chacun a drvant soi un trop) vaste champ) d'éturles pour connatue jamais les loisiss de l'ennui.

Aretowsli observe les plénomines météorologrigues el scrute les mouvements des glates; Iobrownlski s'oceupe des nuages, fle lat neige, du grivre; Ráreovitzá s’intéresse à la vie animale oi qu'elle se tronve,

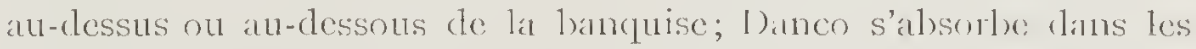
mesures magnétiques; moi, enfin, je me consacre aux olservations astronnmicues, en dehors de mes fonctions de commandant en second. Pour cette double tâche, je suis particulièrenent favorisé, car de Gerláche, anxieux de me donner loute latitude pour mon travail seientifique, prend généreusement à sá chárge les nombreux ot multiples détáls chu service, pour lesefuels il est d'ailleurs tris hemensement secondé par les lieutenants Amunrlsen of Méalerts.

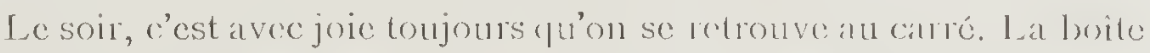
a musiefue, regulierement mise ì eontribution pendant une lueure aut

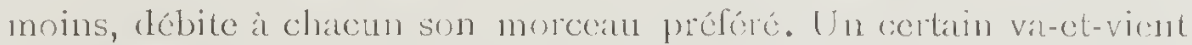
s'étallit entre le carré, le labresatoire et le pont, oi se font, d'heure en houre, les observations nétéorologriques. Ces allés et venues produisent fune heureuse diversion à la monotonie de notre nouveau uene de vie. 
Pourtant, il ne fait pas trop chaud à l'arrière! Le poĉle n'est pas encore placé; nous ne recevons là que quelques calories venant de la machine, dont les feux ne sont pas encore éteints, mais simplcment couverts, afin d'économiser le combustible.

Du 20 au 23 mars, la neige tomba presque constamment en fin poussier, que les rafales chassaient avec violence et qui pénćtrait partout, sous les vêtements, dans les obscrvatoires par les moindres fissures, dans les logements par les plus petits joints des portes et fenêtres.

Pendant ces journées maussades, Cook eut le don de nous dérider par ses intcrrogatoires amusants sur la psychologie de chacun de nous :

"Que regrettez-vous davantage, au pays?"

"A qui, à quoi rêvez-vous le plus souvent?"

Et avec un sćrieux imperturbable, il consignait, sur ses tablettes, les rćponses les plus saugrenucs.

"Sommc toute, s'écria-t-il un jour, comme si ses yeux s'ouvraient enfin à la lumière, on soupire après des lettres de mère, de sour, ct surtout... de sour des autres !...»

Cette réflexion montre combien notre brave docteur s'était transformé dcpuis son arrivée à bord. Au début, Cook était le plus rigide Américain que lc nouveau monde eût jamais porté: il goûtait peu lcs plaisanteries " à la française » et, comme nous avions remarqué que les calembours avaient particulièrement l'heur de l'exaspérer, nous cn faisions d'ćpouvantables, mélanges exotiques de mots français, anglais, norvégiens ! Cook, avec dédain, nous répétait sans ccsse: "Ne vous exhibez jamais à New-York avec de semblables manières, car il n'y aurait qu'un cri pour vous conspuer : A la porte, à la porte! "

On s'habituc à tout, dit-on: peu à peur, Cook se fâcha moins, goûta même nos plaisanteries, dcvint lui-même d'une gaîté charmante et s'associa finalement à toutes nos fantaisies. 
Le 26, les feux des ehaudières sont éteints; le grand panneau de la maehine est reeouvert d'un planeher, où l'on installe un poêle, dont la cheminée débouehe sur le pont, tout contre le màt d'artimon. Ce foyer central ehauffe à la fois les eabines et le earré, mais à eondition d'être maintenu en pleine aetivité. Comme le foyer du poste, il consomme du eharbon anthraciteux d'origine belge. Une énorme bouilloire remplie de neige, se trouvant en permanenee sur le feu, nous approvisionne d'eau douce.

En règle générale, bon nombre d'entre nous ne se donnent pas suffisamment de mouvement, hors du narire. Comme le confinement est absolument pernieieux, on foree les réealcitrants à respirer l'air du lehors, en saisissant toutes les occasions possibles de les faire travailler sur la banquise. - Ils s'y rendent, mais... en trainant un peu la patte. La seule, Ja véritable attraetion qui les arraehe à leur frigidité, e'est la chasse. Aussi bien, l'hiver est à la porte, il est temps de nous

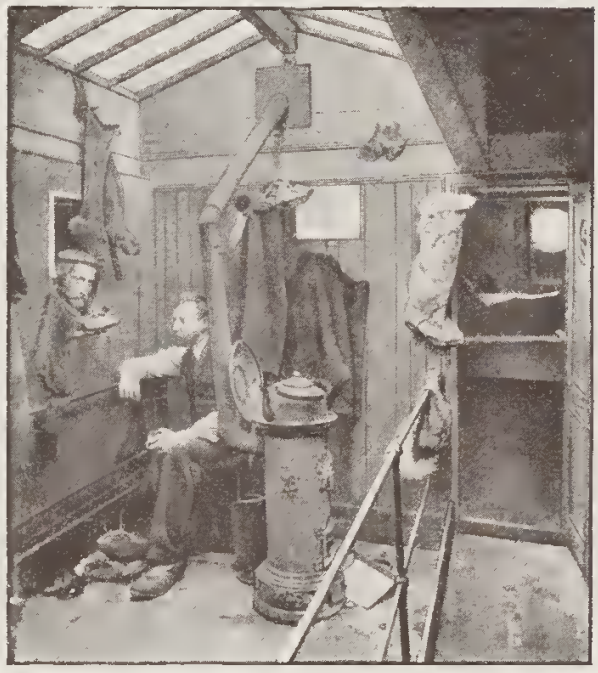

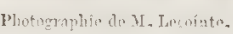

$$
\text { Fici. } t \text {. }
$$

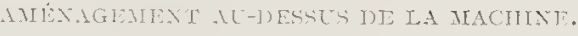
approvisionner de virres. Comme la banquise est encore assez peuplée, on tue à peu près tout ce qu'on reneontre en fait de phoques et de manehots. Il faut voir Raeovitza, après ees jours de earnage, le tablier au eou, un grand eouteau à la main, éventrant les eadavres encore chauds pour en examiner l'estomae, les intestins, voire les résidus de nourriture! Et quelle joic lorsqu'il découvre un embryon! Il l'emporte comme s’il s'agissait d'un trésor inestimable.

Les espices de phoques que nous reneontrons sur la banquise sont au nombre de quatre: le phoque erabier (voir fig. 24) et le phoque de IVeddel (voir fig. 25), que nous avions vus déjà dans le détroit 
de Gerlache et que nous avons décrits précédemment; le phoque de Ross (voir fig. 45) et le vrai léopard de mer (voir fig. 46).

Lc phoque de Ross (Ommatophoca Rossi) n’a été aperçu qu'en été, et nous n'en avons compté que treize. Il diffère essentiellement des autres espèces par des membres excessivement réduits, tandis que la tête et le cou sont particulièrement développés. La voix est gutturale commc le son d'une cornemuse ou, mieux encore, comme la voix de Cook... lorsqu'il parle la langue des Onas!

Lc pouroir voeal spécial de cet animal lui cst donné par des saes à résonnances que ne possèdc aucun autre phoque.

Le vrai léopard de mer (Ogmorluyms Leptonyx) a plus de trois mètres re long; il se déplace avec agilité sur la banquise, et 1'histoire naturelle lui prête des méfaits qui justificnt son nom. Il va, paraît-il, jusqu'à s'attaquer aux manchots (I).

Lorsqu'un phoque a ćté dépecé, son eadarre, abandonné sur la banquise, attire les ossifragas, ees grands équarrisseurs des régions froides. La faim les tenaillant, ils sc jettent sur les cadavres, se plongent jusqu'au cou au milicu des chairs meurtries, dégustant de préférenee les intestins de phoque! Par moment, curieux de voir ce qui se passe aux alentouıs, ils relèrent la tête, l'agitent légèrement pour en fairc tomber le sang ct les matières fétides, puis, rassurés par notre immobilité, ils continucnt leur hideux festin.

Si un ennemi approchc, ils ne se décident qu’à grand'peine à quitter leur proie: ils s'éloignent lourdement, car le poids de lcur estomac trop cmpli les empêche de voler; mais si on les poursuit, ils font un dernier sacrifice, rejettent sur la neige des matieres innommables et, géants de plus de deux mètres d'envergure, s'envolent au-dessus de nos têtes en poussant des plaintes affrcuses. 1ls nous contemplent de là-haut avcc voracité, supputant, semble-t-il, les chances qu'ils peuvent avoir de nous dévorcr un jour!

(I) Ce fait n'a pas été vérifié par l'expédition, mais Racovitza a v'u deux léopards de mer qui se disputaient une carcasse de manchot que nous avions jetée par-dessus bord. 


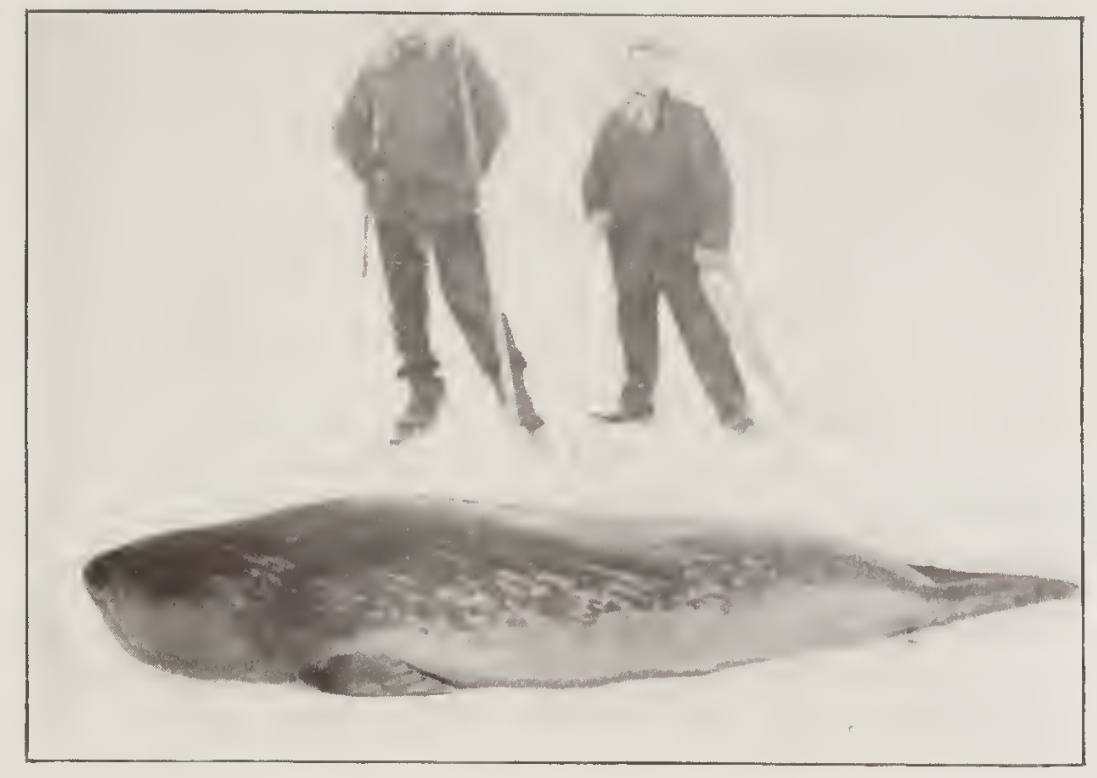

Plotogrnjitio du br fouk,

जik: 45

1.100) 101: 11: Ross.

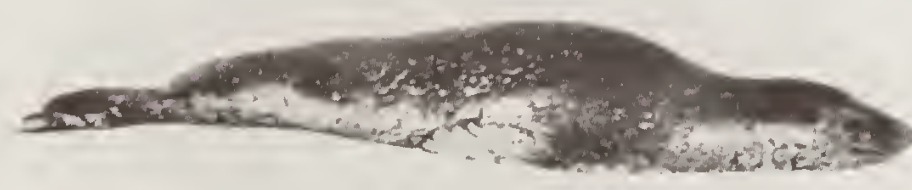

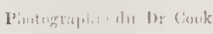

IIG. 4 (\%)

VRAL I,IOPARI, IOF, MIER. 
Les manchots que nous avons rencontrés sont de deux espèees. le manchot de la Terre Adélie (Pygoscelis Adelia), et le manehot de Forster (Aptenodytes Forsteri) ou manehot royal.

Les premiers ressemblent beaucoup aux manehots antaretiques du détroit de Gerlaehe, mais ils ont les côtés de la tête noirs et la gorge noire ou blanehe; de là, une variété a gorge blanehe et une variété à gorge noire.

Les manehots royaux sont superbes; ils mesurent plus d'un mètre et leur poids peut atteindre 40 liilogrammes. Ils portent haut la tête,

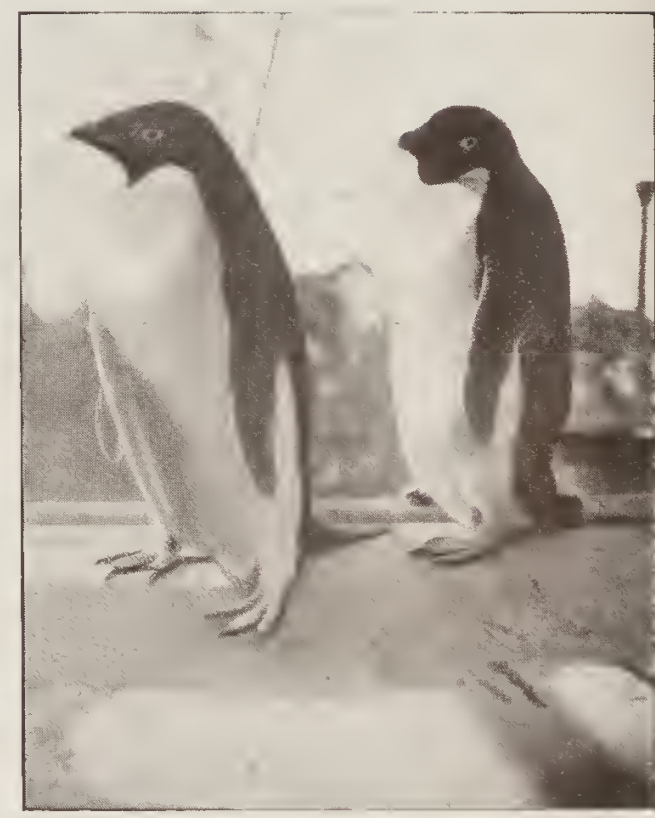

Photomarth hîe dut Itr Cook. IIG. 47.

MANCHOTG I)T: LA TFRRE ADÉIE.

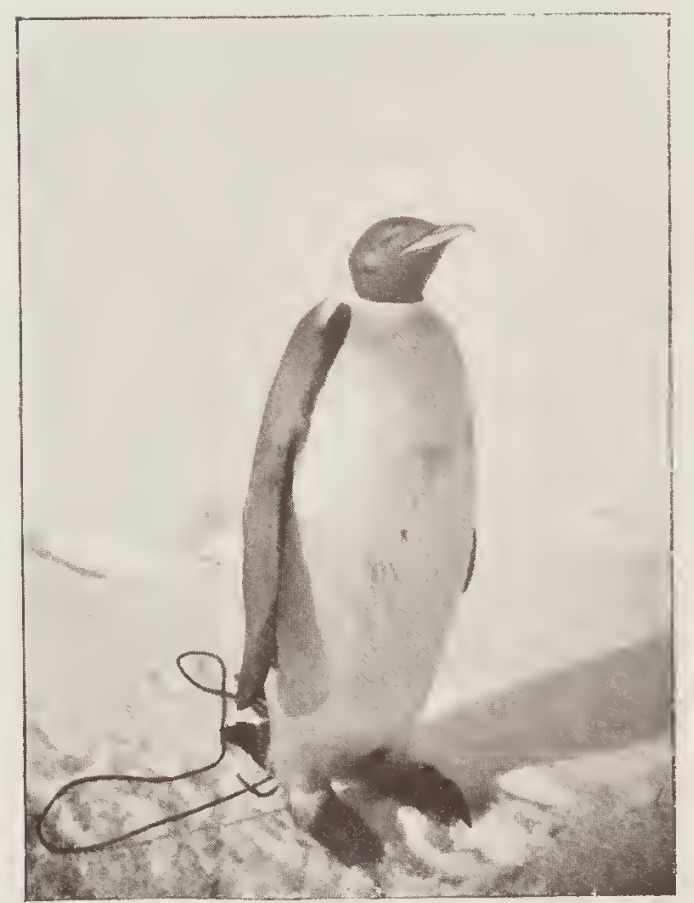

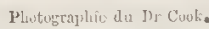

FIG, 48. qu'ils ont fort petite, et ne la meuvent que lentement, afin de bien voir ee qui se passe autour d'eux. La tête est noire au-dessus et d'un magnifique jaune d'or sur le côté. Le bee est long, généralement noir, exeepté à la base, ox il est strié de pourpre et de bleu. L'œil est petit, il reflete le ealme le plus absolu. La poitrine et le ventie sont d'un blane de neige, mais le dos d'un bleu sombre avee quelques reflets gris. Autour du eou, un eollier de plumes blanehes. 
Le manchot royal possede la dignité qui convient à sa haute noblesse : il marche lentement, sans se préoceuper de ce qui se passe autour de lui, jette par instants un coup d'oil admirateur au soleil, puis continue sa promenade jusqu'au moment où l'appétit l'engage à plonger. Il descend alors à la mer, se gave d'euphausia et retourne faire la sieste pendant de longues heures. De temps à autre, il jette un rauque appel, puis reprend son somme, heureux de vivre dans un monde béni où il ne compte pas un seul ennemi.

Combien agréable d'être manehot royal !...

Le petit manchot de la Terte Adélie est d'une vivacité surprenante; e'est, de plus, un musicien de tout premier ordre. Van Mirlo avait tout particuliciement le don de les charmer en sonnant du clairon. Installé à l'avant du navire, il soufflait dans son instrument avec une ardeur inquiétante jusqu'au moment où les jeunes manchots

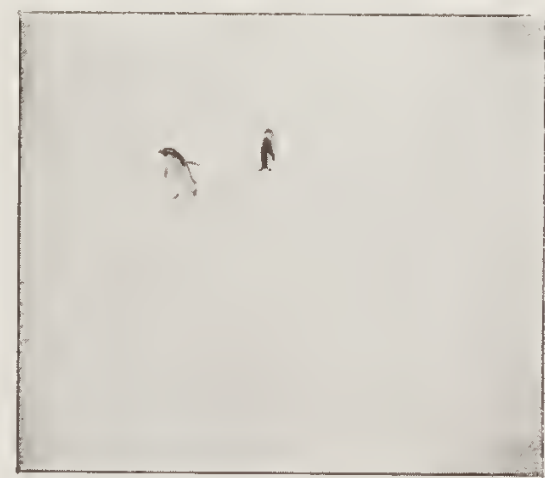

Plotogrinhis du Ir Couk II IG 49 . MANCHOT 1)E I.A TERRE AJI:LIE ACCOURANT FERS SON AMI TAN MIRLO. aecouraient vers lui en se dandinant. Alors, à un signal donné, nous fondions sur eux, le gourdin à la main. Les pauvres étaient si effarés de cette attaque, qu'ils croyaient se tromper, mais lorsque, épcrdus, ils revenaient vers nous, nous les massacrions sans pitié.

Quand ils n'étaient pas en nombre, ils se montraient plus prudents : au premier coup de baton, ils se jetaient sur le ventre et fuyaient avee une vitesse vertigineuse. Il est arrivé un jour à quatre d'entre nous d'en poursuivre un, courageux jusqu'à l'hérö̈sme. La chasse dura plus d'une heure, et lorsque la pauvre bête tomba enfin inanimée, elle avait reçu trois balles de revolver et deux balles de fusil, sans compter les nombreux coups de massue. 
Nous étions, nous-mêmes, exténués. Semblables chasses étaient cruelles, je le sais, mais nécessaire, hélas! C'était la lutte pour la vie dans toute son intensité; la lutte contre le froid, contre la maladie, contre la mort! 


\title{
CHAPITRE XXV.
}

\section{Kjoedbollers, Kjoedpolsers... et lapin d'Australie.}

\author{
¿'n mets, qui répand la terreur, \\ Mets que le cicl en sa fureur \\ Inventa pour punir les crimes de la Terre, \\ Le Kjoedboller, c'est en norvegien son nom, \\ Capalile d'amaigrir en un jour un cochon, \\ Faisait aux hiverneurs la guerre.
}

Ils n'en crevaient pas tous, mais tous étaient frappés.

Les Kjoedbollers sont originaires de la Norvége. Ca n'a pas de sexe, ça se rend tout préparé dans des boîtes de fer-blane hermétiquement eloses. L'analyse la plus minutieuse n’a jamais pu en révéler la com. position : Racovitza y retrouvait des éléments du régne animal et du rìgne végétal; Arctowslí n'hésitait pas à en elasser la source dans le rigne minéral; Cook les déclarait échappés d'une morgue; quant à moi, il me semblait que, bolides refroidis d'un astre sans atmosphère, ils étaient tombés, un jour, dans une easserole infernale!

Cependant, Amundsen, qui les connaissait de longue date, me eertifiait que ce mets consiste en boulettes de viande de chat, hachée, broyée avec la fourrure, les dents et les os!... Horreur!...

()uoi qu'il en soit de leur provenance ou de leur origine, les kjoedbollers nagent dans une sauce nauséabonde ayant un gô̂t prononcé de "soulève le coeur ".

Le mot kjoedboller prit bientôt à bord un sens international, et il servit à désigner toute chose particulièrement mauvaise.

Voulait-on mettre un camarade en garde contre un acccident quelconque, il nous suffisait de lui dire : "Attention! kjoedboller! " Ce terme nous était aussi très commode pour nos conversations en langage mixte - anglais et français - arec le I)r Cook. 
D'autre part, l'appellation "kjoedboller " constituait une injure grave. Chacun de nous eutt, à la riguieur, toléré que, dans un moment de vivacité, on l'appelât " canaille ", mais " kjoedboller " jamais!... Pourtant, le cas faillit se produire, un jour, dans une circonstance néfaste, dont nous parlerons plus loin.

Les Kjoedpolsers ressemblent beaucoup aux kjoedbollers; seulement, le hachis extraordinaire dont ils se composent est tassé dans des boyaux de chat de gouttière. Ils forment donc des espèces de saucissons.

Les Fricadellers, norvégiens comme les précédents, sont de gros lijoedbollers ou de petits kjocdpolsers, quant aux dimensions; pour la saveur et la qualité, c'est "lif-kif "!

Les Fiskebollers, dont le berceau est en Danemark, diffèrent des précédents en ce qu'ils ont pour base, non la viande, mais le poisson. Flottant dans une crème blanche, ils ont la grosseur et l'aspect d'un cuf dur, mais, en réalité, ils sont plus épouvantables au goùt que tous les kjoedbollers et kjoedpolsers de la création! Ils ont, de plus, lo grave inconvénient de se gâter, même par les plus grands froids. 1)ans ect état, ils dégagent une odeur si pestilentielle que si nos souliers venaient à en effleurer un sur la banquisc, tout le monde s'en apercevait dès la rentrée à bord et fuyait le personnage ainsi contaminé.

Je n'ai pas ćpuisé la liste: il reste le lapin d'Australie, plus exécrable encore!

Au point de vue zoologique, ce fameux lapin doit être lo bàtard issu d'une union monstrucuse, car janais lapin des régions connucs ne pourrait dégénércr, mème en boìte, jusqu'à un goùt si détestable.

Lorsque le plat, entouré d'une auréole de pruneaux, apparaissait à table, Racovitza et moi, nous frissonnions jusqu'aux moelles. Cc (lernier imagina un true fort ingénieux pour nous aider, tous les deux, à cette absorption difficile. Dès que le plat était signalé, Raco m'excitait à une discussion politiquc. Entrainés par la défense de nos theses respectives et bouleversant, de fond en comble, l'ancien 
et le nouveau monde, nous avalions, sans nous en apercevoir, le fameux lapin. Chose singulière, à peine le dernier morceau était-il ingurgité, que nos idécs redcvenaient pacifiques.

Cependant, vcrs la fin de notre hivernage, notre estomac ne se laissait plus leurrer, même dans nos discussions les plus orageuses.

Un jour, perdant toute mesure, je m'oubliai au point de m'écricr : "Mais Racovitza, vous êtes un anarchistc! " Raco bondit sous 'injure et riposta : "Oh! kjoed... ! " la fun du mot demeura dans son gosier; il s'était heureusement arrêté à temps! S'il eut ajouté " boller $»$, un duel à mort s'ensuivait!...

On pourrait s'étonner dc l'insistance avec laquelle je décris ces produits hétéroclites; mais, si souvent, hélas! ils rcvenaicnt sur notre table, surtout pendant la longuc traversée de l'Atlantique! Gràce au Ciel, vers le milieu de l'hivernage, ils ne furent plus servis et constituèrent notre fonds de réscrve pour les jours de famine.

Il ne faut pas conclure de ce qui précède que le commandant avait agi à la légère en achetant ces conserves. Ayant mangé ces aliments frais en Norvège, il lcs avaitjugrés excellents; de plus, un explorateur polaire de renom les lui avait fortement recommandés. Ajoutons qu'un cuisinier habilc aurait peut-être réussi à les accommoder à notre goùt; mais, si Michotte représentait un brillant soldat de la Légion étrangère, il était, par contrc, un pic̀tre cuisinier. C'était par pur dévoûment qu'il avait accepté, depuis Punta-Arenas, les fonctions de coq. Il préparait presque tous les plats de la même manièrc, avec peu d'eau ou beaucoup d'eau, selon le degré de consistance voulu. A part cela, l'honnêteté mềne : jamais il ne s'offrit la moindre ration supplémentairc, alors cependant qu'il cn avait toutes les facilités.

Aussi de Gerlache avait-il pour Michotte une sympathie toute particulièrc. Ces fonctions dc "cuisinier malgré lui » évoquaient le temps où, lui-même, embarqué comme simple matelot, avait reçu un jour l'ordre du capitaine de faire la cuisine. S'en était-il acquitté mieux que Nichotte?.. Il est probable que non, ct de là son extrême 
indulgencc. Comme il avait fait du chemin le petit mousse, devenu commandant d'un navire et chef d'une expédition vers le Pòle!

D'ailleurs, comment ne pas aimer le brave Michotte, qui faisait l'impossible pour nous satisfaire? Un jour même, il se mit à nous faire du pain, un pain pas très léger que nous dénommions le " painplomb n! Puis l'ambition du mćtier le poussant, il s'attaqua à la pâtisserie et, une fois par semaine, nous servit une " galette-plomb " sur laquelle il étendait une légèrc couche de confiture. Oh! le travail de mastication que devaient fournir nos màchoires avant de présenter ces aliments à nos estomacs fatigués !...

Pendant les repas, nous ne manquions jamais de plaisanter le menu, ce qui navrait profondément notre brave commandant.

Un samedi que nous étions tous en gaîté, Arctowski et moi déclarons à de Gerlache que si les kjoedbollers ne sont pas mangeables, il faut s'en prendre à la manicre dont ils sont préparés. Nous ajoutons que s'il veut nous donner cartc blanche, tout le monde, le Iendemain, se régalera des kjoedbollers. "Moi, dis-je, je m'engage, d'ores et déjà, à en mangcr quatre!... ". de Gerlachc ouvre des ycux éblouis et nous autorisc à prendre, à la cambuse, tout ce que nous voulons.

Le lendemain matin, un dimanche, Nichotte vient prendre nos ordres. Arctowski, sans se déconcerter, lui ordonne de préparer deux bouteilles de Madìre, trois grandes boites de kjocdbollers, cinq biscuits de mer, unc boite de saindoux, et de porter le tout à la cuisine.

Dix minutes plus tard, nous sommes dcrant les feux; les boites sont ouvertes et le saindoux fond dans une casserole.

Alors, pour nous donner du cœur, nous débouchons le Madère et trinquons avec Michotte. Un camaradc passe, puis un second, puis un troisième... on les appelle et l'on retrinque!...

Mais l'heure du dîner approchc, plus une minute à perdre!

Le biscuit de mer, réduit en chapelure, saupoudre les kjoedbollers enveloppés de farinc ct arrosés d'un filet de Madère - il n'en restait 
pas davantage! - puis le tout est préeipité dans le saindoux bouillant. Miehotte agite, laisse égoutter, et nous suit au earré, où nos amis, ì table, nous attendent avee impatience. Quelle entrée triomphale! Cook a saisi la manivelle de l'orgue de barbarie et joue une stridente Brabançonne; de Gerlaehe sourit avee bienveillanee. Pour lui, e’est un grand jour, c'est la fete des lijoedbollers.

Ouelques instants après, changement à vue : personne ne songe à dissimuler la plus horrible grimaee qu'un mets exéeré puisse jamais amener sur visage humain! Aretorrski et moi jouons l'étonnement le plus eomplet. Bon gré, mal gré, il fallut m'exéeuter et avaler quatro (le ees holreurs!

Chose étonnante, je les digérai!

Et dire que j'ai cela dans le sang! Pourvu que, par atavisme, mon fils ne s'avise pas d'avoir une passion folle pour les kjoedbollers!...

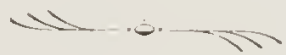




\section{CHAPITRE XXVI.}

\section{Concours de beauté.}

Depuis que je l'avais pris pour un phoque, Cock s'abstenait prudemment de passer la nuit sur la banquise, étant donné surtout qu'il sc trouvait beaueoup mieux dans sa cabine, quelque médiocre qu'elle fût. Cependant, ses lauriers préeédents troublaient Daneo, qui se déeida, au eommencement d'avril, à eoucher dans son observatoire magnétique.

A tort ou à raison, il comptait sur ce régime pour se fortifier la poitrine et s'aguerrir eontre le froid, dans le eas où le navire serait brisé et où nous serions forcés à séjourner sur la banquise !

Le 2 avril done - pas le rer, de peur des poissons! - Daneo nous souhaite une bonne nuit et se retire; mais, vers 5 heures du matin, il rentre à bord à moitié gelé. Le camarade est un peu penaud de l'aventure : il cherehe à nous expliquer " qu'il se trouvait très bien sur la glaee, mais cu'un défaut de son sae de eouehage l'a empèehé de fermer l'œil ).

Le 3 au soir, ehaeun s'empresse autour du sae de Danco, afun d'y porter remède ; puis, avee la générosité ironique dont la jeunesse cst capable, nous nous intéressons si fortement aux expérienees de notre ami, que, vers les I I heures, il doit se décider à renouveler scs tentatives de la nuit préeédente.

Même rctour eneore, le lendemain, de bonne heure! "Sa nuit a été épouvantable, et, eette fois, e'est à cause de la porte de l'observatoire."

Néanmoins ees deux essais ont mis une telle sourdine à son amour. propre qu'il nous avoue, sans plus d'ambages, qu'il n'y a rien de tel que de dormir à bord et qu'il sera temps eneore de s'entraîner à la belle étoile, lorsque la Belgica ne sera plus!

En général, l'état des esprits à bord est plutôt bon; cependant, de 
temps à autre, un souffle de mélancolie passe sur quelques-uns d'entre nous : aussi est-il nécessaire de saisir toutes les occasions possibles de nous égayer.

Le 7 avril, comme nous étions occupés à chercher des documents importants, l'un de nous mit au joul une dizaine d'albums illustrés - don d'un ami d'Anvers - représentant les femmes les plus célèbres des théâtres de Paris.

Aussitôt l'idée nous vint d'organiser, avec ces portraits, un "Concours de beauté »!

La proposition est acceptée à l'unanimité, et le concours fixé à la soirée du dimanche, io avril.

Comme il est nécessaire de donner une grande importance aux attributions de chacun, il est arrêté, en principe, que nous nommerons un roi et un prince royal pour patronner le coneours, et un ministère qui se chargera d'en régler toutes les opérations.

En conséquence, Arctowski est proclamé roi, sous le nom d'Artocho Ier, Souverain des Glaces, tandis que le lieutenant norvégien, Roald Amundsen, devient son Altesse Royale Roald, princo des Kjoedbollers, duc des Kjoedpolsers et comte des Fischbollcrs. Jesuis recr:unu Ministre des Beautés, et je choisis Raeovitza comme chef de Cabinet. de Gerlache, Cook et Mélaerts deviennent de simples électeurs.

A peine les attributions de chacun sont-elles déterminées, qu'une scission formidable se produit au sein mème du ministère. de Gcrlache et moi, ayant eu l'imprudence de déclarer que Clara W..., la trop célèbre princesse de jadis, l'emportait de bcaucoup sur toutes les autres concurrentes, Racovitza s'indigne et riposte avec emportement que Cléo de M..., l’illustre danseuse parisienne, est certes la plus digne de tous les suffrages.

Conme tout ministre qui se respecte, j'élaborai le régime électoral le plus compatible avec mes intérêts; puis, dans un mème ordre d'idée, j'arrêtai les conditions du concours. 
Les affiehes suivantes furent done plaeardées:

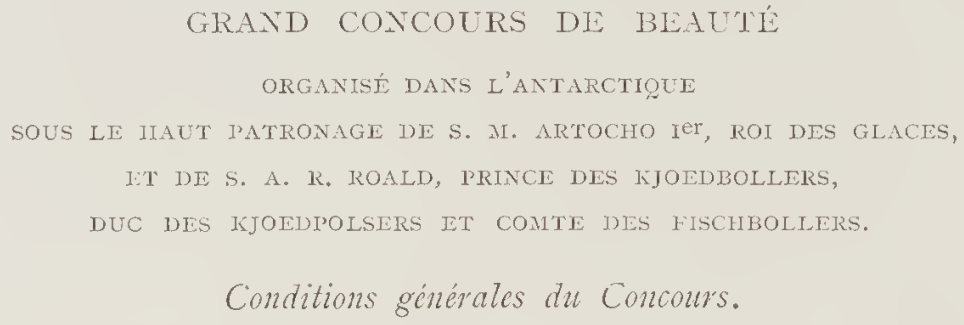

Article premier. - Les portraits des beautés les plus parfaites - 464 exemplaires - ont été réunis dans les vastes dossiers du ministère. Ils portent des numéros qu'il eonvient de substituer aux noms de l'état eivil.

ArT. 2. - Les déeisions du jury devront satisfaire aux conditions suivantes: il y aura deux tours de scrutin pour l'obtention de chaque prix; les beautés mentionnées au premier tour aequerront les cotes d'importanee : trois pour le premier prix; denx pour le deuxième prix; un pour le troisième.

Le ballottage, pour le ehoix unique et définitif, aura lieu entre les six beautés qui auront obtenu les eotcs les plus élevées. Le nombre six pourra être majoré.

N. B. - Les réclames et les eorruptions électorales sont autorisées.

Distribution des récompenses.

Dès le retour de la Belgica dans un port, le Ministre des Beautés fera parvenir un brevet à la femme que le jury aura proclanée la plus belle.

Le eoneours eomprendra quatre parties:

I. Concours d'ensemble (aspect général);

II. Concours de détail (les plus beaux yeux, les plus jolies mains..., ete.);

III. Coneours de bonheur. Pour le coneours de bonheur, MM. les éleeteurs désignent, dans les diverses eolonnes, les beautés qu'ils jugent les plus aptes à faire le bonheur de ehacun des membres de l'expédition. 
IV. Prix d'honneur. - Le prix d'honneur scra déccrnć à la beauté qui aura réuni le plus grand nombre de mentions.
Le Chef de Cabinet,
(Signature.)
Le Ministre des Beautés, (Signature.)

Dès le début des opérations, je m’étais imaginé qu'en ma qualité de ministre j'aurais assez de pouvoir pour faire triompher mon choix: que Mme Clara IV..., le no 209 du cataloguc, battrait sans lutte Nille Cléo de M..., le no 64 .

Nais, ainsi que je l'ai indiqué plus haut, dès le lendemain de l'ouverture des travaux, mon chef de cabinet devint mon plus violent adversaire. J'eus beau faire des menaces de révocation, ce fut en vain!

Racovitza continua son indigne politique et se rallia Amundsen, puis Danco, tandis que, moyennant force promesses, de Gerlache et moi, nous ne parvenions qu'à nous attacher le docteur Cook. Mélaerts et Arctowski demcuraient indécis, se réservant, en élccteurs pratiques, de faire le choix qui leur rapporterait davantage.

Il est curicux de remarquer combien facilement l'homme redevient cnfant: ne voit-on pas les officicrs de l'école de gucrre renouveler les gamineries mêmes qui, jadis, les ont amusés sur les bancs de l'écolc militaire!

Pour nous, c'était exactemont la même chose : pendant les heures consacrécs au travail, les visages étaicnt sérieux; mais, dès que le moment du repas arrivait, des affiches surgissaient dans les chambres, dans le carré, sur la table, partout!...

"Il n'y a qu'une seule belle femme sur la terre, c'est le 6.4!

Électeurs votez pour elle! "

"Le zoo n'est pas une fomme, c'est un ange!"

"Électeurs, on vous trompe : le 64 seul est digne de vos suffrages éclairés!"

Et un jour, ne vit-on pas, au diner, apparaître un vol-au-vent sur lequel Racovitza, narguant le ministre, avait fait inscrire au blanc d'ouf: Vive le $6+$ ! 
Enfin, le ro avril atriva.

Inmédiatcment après le souper, le commandant annonce l'ouverture officielle du concours. Dès lors, brouhaha indescriptible : tout le monde parle à la fois, on n'cntend rien du discours solennel quc j'adresse aux concurrentes...

Pour comble, lc plus arrogant dc tous est mon chef de cabinet, qui ose déjà prédire ma chute prochaine et pousse l’indélicatesse jusqu'à cn témoigner une joie débordante!

Sur ces cntrefaites, Arctowski se laisse indignement acheter par Racovitza pour la somme énorme de trois monstrucux bouchons de liège, dont il avait besoin dans son laboratoire!

Par contre, le brave Mélaerts se rattache à mon pouvoir chancelant et je le nomme aussitôt grand-cordon de l'Ordre de la Sardine!

Cook cst absolument abruti : il ne comprend pas un mot à tout ce qu'on raconte; c'est un grand avantage pour moi : il en devient incorruptible! Dc plus, nc ménageant ni ses peincs, ni ses poumons, il ne cesse de crier : " 209 , Clara, first prize! "

Enfin, on dépouille le scrutin.

Victoire! le 209 l'emporte!...

Je bondis vers la boîte à musique, où je place le rouleau de la Brabançonne; mais, dans ma précipitation, je l'ai mis à l'envers, de sortc quc la cacophonie musicale se mêle à la cacophonie des défenseurs du 64, qui nous accusent d'avoil falsifié les listes. C'est un tintamare épouvantable.

Alors de Gerlache, pour rćconcilier tous les partis, fait déboucher le champagne et nous vidons nos coupes en l'honneur de " toutes les beautés ») qui nous ont valu cette superbe fète.

A ri licures, chacun se rctire, mais nous nc pouvons trouver le sommeil. A la gaîté momentanéc dc ces derniers jours succède unc profonde mélancolie.

Demain, c'est lc jour de Pâqucs, fôte chérie en Belgique! Pâques 
qui ramène le printemps, les fleurs, les eloches! Oh! entendre encore le son des cloches, au Pays, alors que les petits enfants s'empressent de toutes parts, pour déeouvirir les trésors de jouts et de sucreries qu'elles laissent tomber dans leur voyage aérien!...

Minuit sonne, mais à la cloche du bord, et elle résonne comme un glas funèbre!...

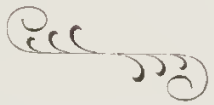




\section{CHAPITRE XXVII.}

\section{Travaux scientifiques.}

Dès le lendemain de ce joyeux divertissement, le travail nous a tous ressaisis. Rien de plus naturel, car chacun a devant les yeux une importante série de questions à résoudre, questions des plus intéressantes, des plus absorbantes même, puisque toute observation faite dans ces régions inexplorées a pour nous le charme puissant des choses absolument neuves. Dans ces conditions, toute recherche scientifique est attrayante, même lorsqu'on n'y parvient qu'au prix des plus grandes difficultés matérielles.

Nous avons đétaillé précédcmment les multiples obstacles dont sont semécs les observations astronomiques sur la banquise : l'observatoire, dont la fragibilité est extrême; lcs instruments, clont l'instabilité provoque maintes expériences ratées; les doigts qui, sans gants, sont raidis par le froid ou brûlés par le contact des pièces métalliques et qui, avec gants, deviennent d'une maladresse complète pour manier les objets délicats; enfin, les lourdes fourrures qui entravent la marche et la liberté des mouvcments.

Puis d'autres ennuis encore : si l'on approche le visage d'une lentille, la vapeur d'eau contenuc dans l'air expiré se condense sur les objectifs ou les oculaires, s'y congc̀le et les ternit.

Immédiatement après les observations, viennent les calculs que l'on transcrit dans des registres spéciaux. Il faut prévoir les surprises : la mort peut nous enlever sans avis préalable.

Danco ne chôme pas : sans cesse, il est plongé dans d'interminables calculs préparatoires aux séries d'observations ou dans les nombreuses mesures des valeurs absolıes des éléments du champ magnétique terrestre.

Plusieurs d'entre nous concourent aux observations météorologi- 
ques dirigées par iretowski. Toutes les heures au moins, il faut noter la foree et la direction du vent, la température, la hauteur baromé trique indiquée au baromètre marin et la pression renseignéc aux anéroïdes, enfin la nébulosité du eiel.

Dès qu’un phénomène météorologique se manifeste, Aretowski est sur la brèehe. Rien ne peut alors le distraire ni l'arracher à son travail. Si on lui dit un mot, il répond d'un ton see : "Ne me parlez pas, j'observe! "

Dobrowolski ne se ménage pas davantage: le nez en l'air, il suit pendant des heures l'apparition, la marche, la transformation et la disparition des nuages. D'autres fois, il examine à la loupe tout eo qui tombe du ciel, neige ou givre.

Sur la banquise, des jalons fiehés en terre déterminent la quantité de neige tombée.

Tes pressions et les détentes de la banquise, la formation des hummoelis, des erevasses et des laes, tout est analysé : Aretowslí mesure mème l'épaisscur de glaee gur se forme après une heure, deux heures... ete., selon la température.

Le travail le plus fertile en surprises est certes eclui de Raeovitza; laissons done la parole à notre naturaliste :

" Les animaux flottants, le plancton, furent eapturés en grande abondanee; mais si lc nombre des individus était considérable, le nombre des espèces était relativement restreint. Ainsi pour ne eiter que les Copepodes, qui sont si variés dans les planetons des mers tempérées, on ne trouva que ringt-quatre espèces toutes nouvelles de ees petits crustaeés.

"Les algues pélagiques étaient fort abondantes, surtout au voisinage immérliat de la surface et sur les parois immergées des glaees. Flles sont représentées, dans ees régions, surtout par les Diatomées et forment de véritables prairies marines, qui fournissent, directement ou indireetement, la subsistance à tous les êtres qui habitent l'Antaretide.

1) La faune de fond, reeueillie sur un plateau eontinental dont le 
niveau se maintient entre 300 et 500 mètres, est des plus variée et des plus intéressante. Malgré la faible profondeur de son habitat, elle montre un earaetère nettement abyssal (I). Toutes les espèees déjà étudiées sont nouvelles et beaucoup ont fourni des genres non eneore décrits. Le caraetère abyssal de eette faune s'explique par la basse température de l'eau dans laquelle elle vit. "

La maehine à sonder a ćté gréée d'une façon plus pratique que pour nos premiers sondages, mais clle n'est pas utilisable, non plus que le treuil destiné à relever les dragues et les lignes. Nous les réservons pour le moment où nous serons en mer libre (!), car ees engins exigcraient le mainticn sous pression de notre grande chaudière, qui eonsommerait un charbon préeieux.

Nous avons eependant un appareil à sonder, de eonstruetion grossière, mais précis, maniable à la main, que de Gerlaehe, avec le eoneours d'Aretowski, d'Amundsen, de Mćlaerts, de Johanscn et de Somers, a fait installer sur la glace.

Le virage des lignes de pêehe se fait également à la main ou à l'aide d'un petit cabestan à bras, auquel s'attellent deux ou trois hommes.

Pas un seul d'entre nous qui ne soit attiré par le mystère du fond des eaux! Dès que l'un ou l'autre peut disposer de quelques instants, il se préeipite du eôté de Raeovitza, soit qu'il pèehe à fleur d'eau aree un filet d'étamine de soie, soit qu'il racle le fond des mers avec le faubert, soit eneore qu'il jettc la clrague plus puissante pour remonter des échantillons de toute naturc.

La pêehe terminéc, notre naturaliste se trouve en présenee d'une formidable besogne pour laquelle il ne peut malheureusement disposer d'aueun aide sérieux.

Notre bon doeteur n'est pas inaetif non plus, bien que l'état sanitaire du bord reste satisfaisant jusqu'à présent. Il prend notre température à l'aide de petits thermomètres qu'il nous plaee dans la bouehc

(1) Signifie des grands fonds. 
pendant quatre à cinq minutes; il note le nombre de nos pulsations, nous pèse sur une balance installée par lui au-dessus du panneau de la machine; il examine nos lèvres, nos gencives, nos dents, nos yeux, retourne nos paupières, puis consigne scrupuleusement dans ses tablettes toutes ses observations. Lorsque nous nous plaignons d'un

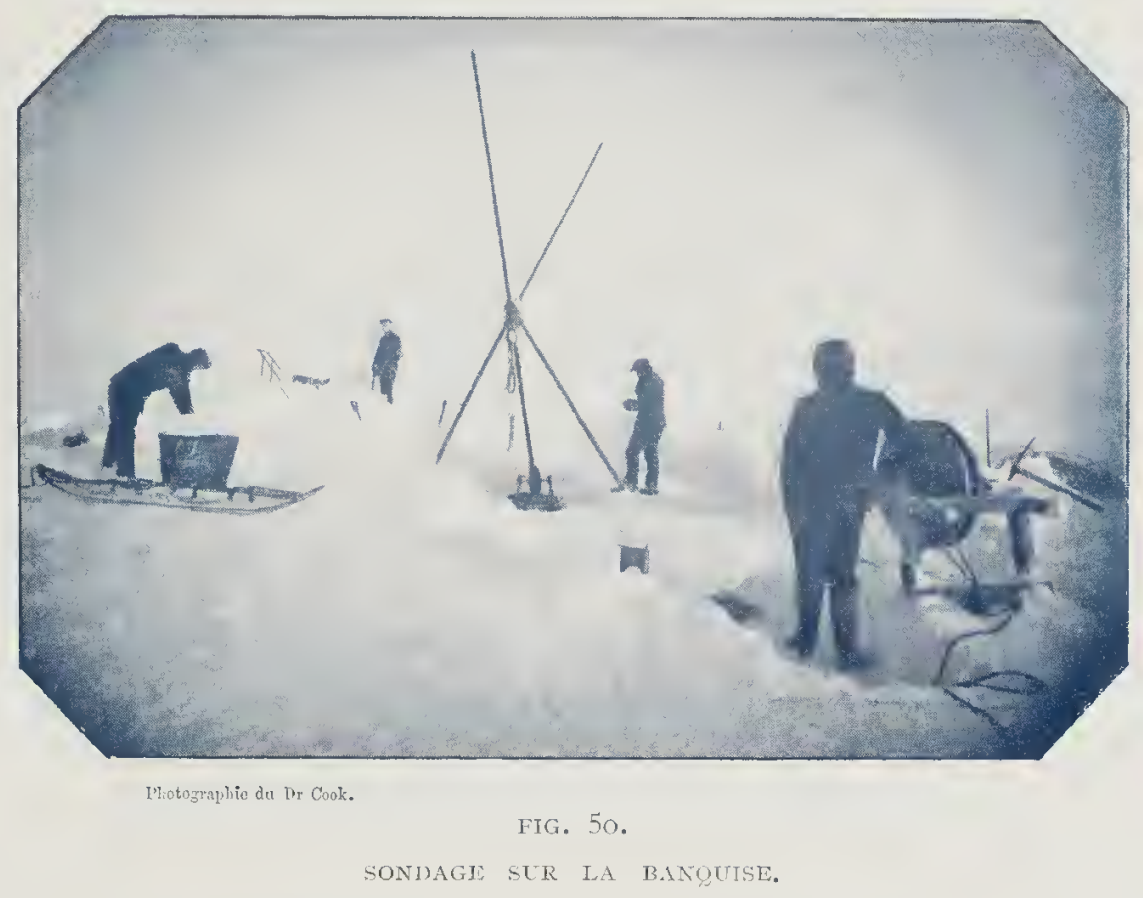

malaise, il nous dit avec conviction: "Si vous étiez, à Ncw-York, mon client payant, je vous donnerais un médicament; mais ici ce n'est pas la peine : vous guérirez tout aussi bien sans cela!"

Amundsen et Mélacrts surveillent les travaux journaliers du bord; de plus, le premier est chargé de l'installation et de l'entretien des engins de pêche, tandis que le second s'occupe du matériel des sondages.

A u poste, la discipline laisse encorc parfois à désirer : un tel se plaint qu'il doit trop nettoyer, un autre s'endort au lieu de faire le quart, un troisième refuse de se lever à l'heure; mais, en somme, rien de grave. 
Les matelots sont fiers de collaborer aux travaux scientifiques: Korcn préparc les oiseaux; Tollcfsen raclc et fait séchcr lcs peaux; Johansen entretient l'observatoire astronomique; Dufour, enfin, rcnd maints services à Danco.

Ainsi, grâcc au travail incessant, grâce au travail qui chásse l'ennui dans les jours calmes ct rćconforte dans les jours de tristcsse, le temps s'écoulc avec rapiditć.

Pourtant, il est bien pâle, ici, lc solcil d'automnc !...

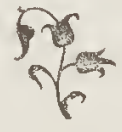




\section{CHAPITRE XXVIII.}

\section{Derniers jours de soleil.}

Le 25 avil r8g8. - Chaque jour, le soleil s'élève un peu moins audessus de l'horizon, la température descend à 2605 sous zéro, des ouragans violents se succèdent, chassant avec furie la neigc arrachée à la banquise et dont le tourbilion se confond avec la neige qui tombe.

Dans les moments d'accalmie, la glace se détend : "nn lac s'est même formé vers l'avant du navire, mais bientôt il s'est congelé.

Les champs de glace se soudent, ne formant plus qu'une immense plaine, où les cétacés ne trouvent plus d'endroits pour venir respirer. Les balénoptc̀res et les phoques brisent alors avcc leur tête la glacc fragile de formation récente; ils demenrent quelque temps sur place pour aspirer longuement, puis disparaissent.

Une certaine apathie s'empare de nous: quclques membres du personnel ne veulent même plus sortir du navire pour la promenade quotidienne. Des ordres formels doivent être donnés pour les moindres détails du service : il faut fixer à chaque homme le jour du bain hygiénique ou du lavage du linge.

L'eau douce des réservoirs étant conservée pour la réserve, il est nécossaire d'en dcmander, chaque jour, à la neige. En conséquence, les mécaniciens ont disposé le distillateur sur le pont, en dessous de la toiture nouvellement construitc.

Tous les matins, un groupc d'hommes va chercher, avec des traineaux, lcs blocs de ncige qui n'ont pas été foulćs aux pieds. Ces blocs sont découpés et précipités dans le distillateur. Lc combustible se compose de graisse de phoque à laquellc on ajoute un peu de houille. Grâce à ce systèmc, notre provision de charbon ne s'épuise pas, - car on peut difficilement se faire une idée et de la masse énorme de neige et de la quantité de chaleur nécessaircs pour rccueillir deux à trois cents litres d'cau. 
Un changement assez important s'est produit depuis peu, à bord : la cuisine, laboratoire chimique de Michotte, est descenduc d'un étage ; de Gerlache l'a fait établir dans l'entrepont, près du poste. J'aurais aimé à m'installer dans l'ancien local pour y travailler plus à l'aise,

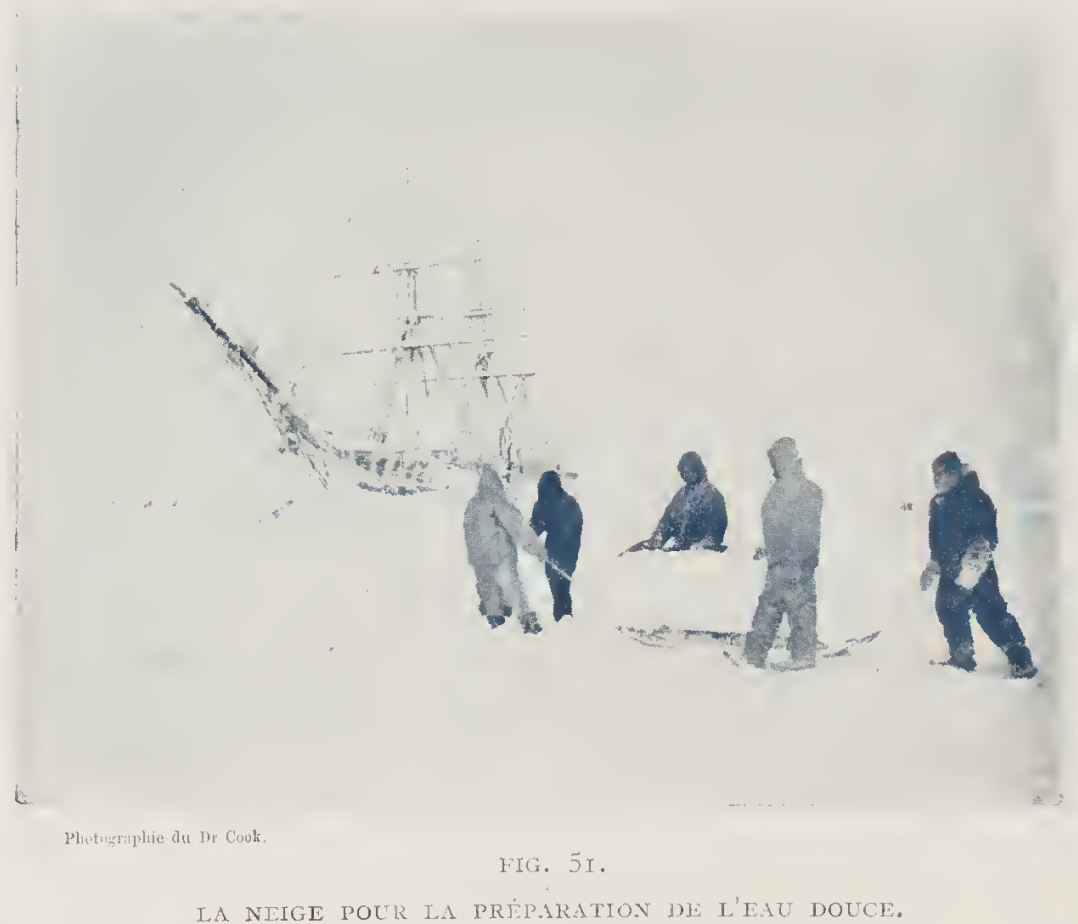

mais le commandant, gardant une respectueuse admiration pour le temple des kjoedbollers, m'a fait comprcndre qu'il tenait à conserver cette cuisine vierge de toute autrc destination...

Le $2 S$ avril. - Dcpuis quelques jours, s'est glissé dans nos rangs un sourd mécontentement qui se manifeste en vivacité mal réprimée, dès qu'une contrariété ou une contradiction se place sur notre chemin. Une seule chose rcste pourtant intacte, c'est l'empressement arec lequel on s'entr'aide pour le travail scicntifique : chacun de nous se met en quatre, dès qu'il s'agit de rendre service à un camarade qui doit recourir à ses soins. 
Le Ier mai. - Grand jour pour X..., notre socialiste araneé du bord; il y va de sa petite manifestation et organise, à lui tout scul, sur la banquise, un imposant défilé, dans lequel il remplit tous les rôles. I1 est d'ailleurs très intéressant X...; il dit, avec beaucoup d'esprit, " son fait » à la classe dirigeante : d'après lui, point n'est besoin de chefs pour dirigcr la société, les hommes et les femmes devraient jouir d'une parfaite égalité! Pas très eompliquée, sa politique génćrale!

Il convient de remarquer ici que, selon l'usagc de bord ct en vertu du grand principe de la liberté de conscience, aucune qucstion poli. tique ou religieuse ne fut jamais agitée entre nous. L'un ou l'autre pouvait émcttre une opinion en toutc liberté, mais il ne recevait ni approbation, ni contradiction. X... put donc manifester à son aise et, comme il insistait sur l'importance de ce jour de fête à son point de vue à lui, on lui accorda même une faveur quclconque.

Mais ce qui fera connaître complètement la doctrine socialiste de notre ami, c'est le petit incident suivant, qui se passa un peu plus tard. X..., un beau jour, fut attaehé à la machine en qualité dc graisseur. Le sccond mécanieien, Van Rysselberghe, ćtant devenu malade, le graisseur dut, pendant un quart, faire fonction de mécanicien, et on lui adjoignit, cn sous-ordre, le chauffeur Koren. Or, on vit se passer ce fait inouï : X..., devcnu maître à son tour, fit peser, sur son subordonné, un véritable joug. Une demi-heure ne s'était pas ćcoulée qu'il vint me demander une punition sévère pour Koren, qui ne déployait pas assez d’activité : "Est-ce que cc gaillard ne se mêle pas de me répliquer, clamait-il, et de diseuter mes ordres! Sans obćissance au chef de service, il n'y a rien à fairc! " Je ne sais si X... fut converti par ce fameux essai. Dans tous les cas, je souhaite aux ouvriers de n'avoir jamais affaire à un maitre aussi despote.

Le 2 mai. - Est-ce l'effet des théorics séditieuses de X...? Sont-ce mes mauvais instincts qui se font jour? Je suis aujourd hui d'humeur belliqucuse. Après le dìncr, jai un long entretien avec de Gerlache : je lui expoșe que tous les hommes d'ćquipagc témoignent du mécontentcment aus sujet de la nourriturc; qu'ils ont raison et que ce serait 
mauvaise politique que de lasser leur patience. Je déplore que, malgré mes fonctions de commandant en second, je n'aie jamais été mis au courant de la quantité de vivres qui se trouve à bord, et je lui pose ce dilemme : ou bicn les vivres font défaut, et j'ai le droit de le savoir; ou bien les vivres sont abondants, et les rations doivent être augmentées.

Cette déclaration produit sur de Gerlache un vćritable coup de foudre! "Certes, nous avons des vivres, mais que dira la "presse " lorsque, plus tard, elle parlera de nous! Ne nous accuscra-t-elle pas d'avoir abusé de la situation pour faire trop bonne chère?"

J'aroue tout simplement que je me moque pas mal d'une presse - surtout cellc de l'Antarctique! - qui scrait aussi mesquinc et que je suis d'avis de donncr une ration suffisante, sans nous occupcr des canards des régions tempérées!

Après $u n$ assez long entretien, nous nous sćparons et, ainsi qu'il convient à la suite de l'examen d'une question épincuse, sans avoil rien décidé! Mais le lendemain, au diner, de Gcrlache exhibait unc longue liste de menus, dressćs avec un soin extrême et indiquant des rations qui, cette fois, donnaient pleine satisfaction à nos estomacs fatigués.

Dimanche \& mai. - Le temps est superbe. Repos général pour l’équipage, car aucun travail urgent ne doit

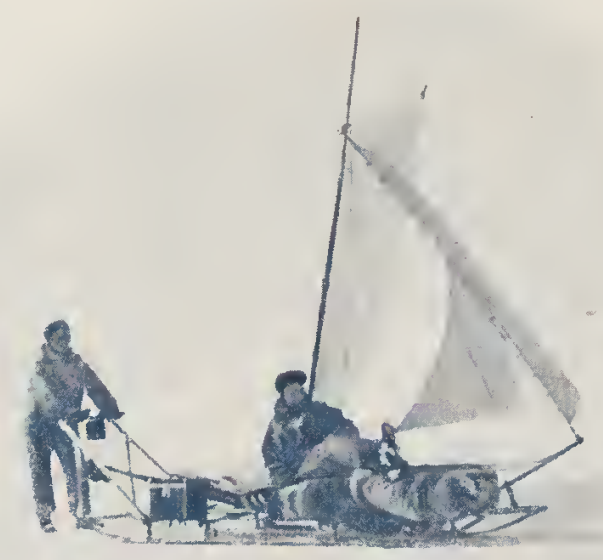
être exécuté.

Sur la banquise, Cook achève de monter la mâture d'un traìneau à voiles. Le véhicule est superbe au repos : la brigantine et le foc, taillés dans la toile de plusieurs draps de lit, sont de vaste envergure. Les 
draps sont de rechange à bord, car de Gerlache et moi, nous sommes les sculs qui en fassions encore usage.

Le traîncau est terminé, une douce brise gonfle les voiles : e'est joli au possible, mais... ricn n'avanee! Le vent est trop faible, ce sera pour plus tard; en attendant, pour juger de l'effet, poussons le traîneau.

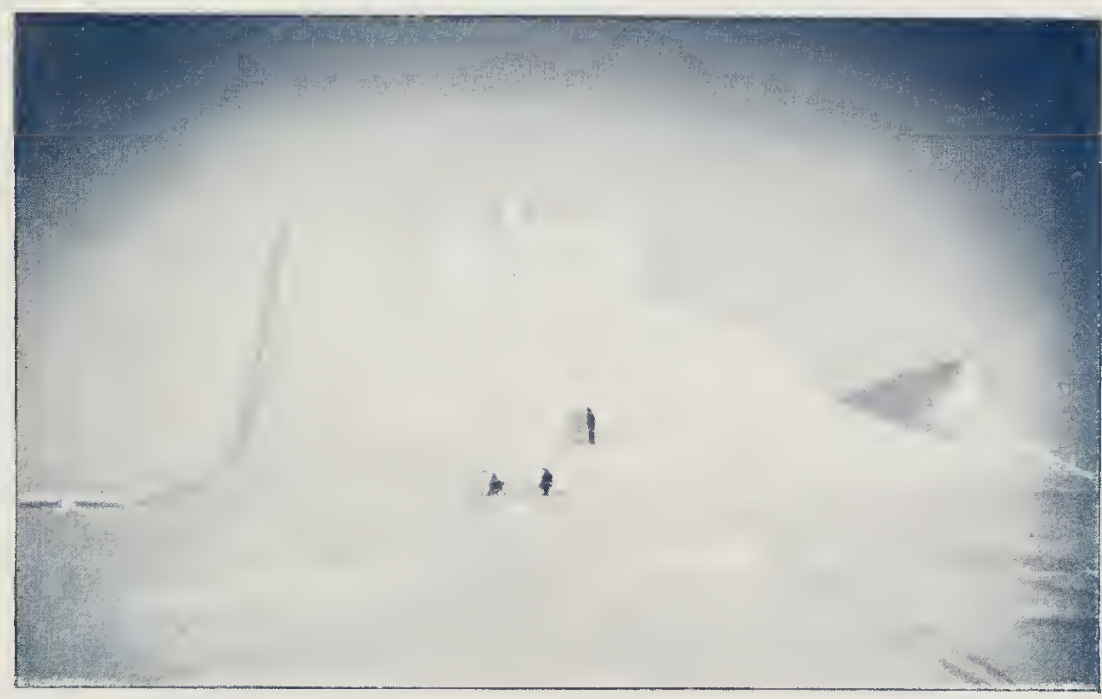

I'lotol replie du Im rnot.

IIG. 53.

TN ICEBERG DANS IA BANQUISE.

Holà! il se renverse : 1e centre de gravité et le eentre de voilure étant situés très haut. Cook, piqué au jeu, le leste, afin d'abaisser le centre de gravité, puis recommence en vain de nombreux essais. Et pendant ce temps plaisanteries et quolibets ront leur train...

L'après-midi, nous nous rendons, nombreux, à un petit iceberg situé à deux milles environ du navire. Cet iceberg, soudé à la banquise, est de forme trìs graeicuse: on dirait un rocher de la jolie baie d'Along, dans le golfe de Tonkin. Une de ses faees présente une série de plans inclinés sur lesquels on peut monter à skis. Parvenu au sommet, on se laisse redescendre sur la pente rapide, lorsqu'on a quelque habitude de ce genre de patins. Mais que de 
chutes pour la plupart d'entre nous! Iet puis, arrivés au bas de l'iecberg, nous devons redoubler de prudenee: il y a, en eontre-bas, un fossé profond de deux mètres. Laneé à grande vitesse, on franehit le fossé, si l'on maintient les skis bien horizontaux; mais si la vitesse est moindre, la pointe des patins se fiche dans la berge, et l'on fait une formidable eulbute.

Peu à peu, nous nous enhardissons à descendre par groupes de deux ou trois, en nous donnant la main. Hélas! l'un de nous, perdant l'équilibre, entraîne tous les eamarades! C'est alors, dans un tourbillon de neige, un enehevêtrement de skis, de têtes, de bras et de jambes à n'en pas finir.

Pour augmenter l'ardeur des hommes de l'équipage auxquels cet exereice en plein air est des plus salutaire, nous organisons des courses de vitesse, sauts de fossé, d'obstacle, et nous donnons en prix des bons de 25, 30, voire 5o franes, payables à la première escale.

Le soir, à bord, la gaîté est générale ; il y a du bonheur dans l'air et des rayons de soleil dans notre âme!

Le to mai est marqué par un aceident regrettable. Pendant le sondage, le fil se rompt, entraînant dans l'abîme une des bouteilles à éehantillon d'eau, ainsi que le gros plomb de sonde, arrangé d'une façon spéeiale pour rapporter des échantillons de grand fond. Notre pauvre ami Aretowski est profondément navré de cette perte, très importante pour lui, et en reste même un peu grineheux toute eette journée-là.

Le I2 mai. - de Gerlache est mélaneolique depuis quelques jours; e'est à peine s'il paraît au carré, en dehors des repas. Seul dans sa eabine, il remet au eourant son journal de bord. Après le souper, nous restons ensemble quelques minutes sur le pont, puis il se retire de nouveau jusqu'au lendemain matin. Son état de santé n'est pas bon : il éprouve eonstamment de violentes pressions dans les tempes. 
Rien d'étonnant: il se ressent maintenant de l'activité surlıumaine qu'il a déployée pendant les trois années préeéđlentes pour mettre sur pied son expédition; sans eompter les vexations que lui ont attirées des amis maladroits, les préoeeupations et les ennuis que lui a créés l'équipage pendant la traversée de l'Atlantique.

Le is mai. - Jour néfaste! Le vent a souffé avec violenee; les champs de glace se sont rompus et une erevasse s'étant formée au pied de mon observatoire, la petite eonstruetion s'est écroulée comme. un ehâteau de eartes. Amundsen et Cook m’ont prêté main-forte, de sorte qu'une partie de mon matériel a ćté sauvée.

Danco, très amusé de mes lamentations, m'a expliqué, par $a+b$. que j'avais mal ehoisi l'emplacement, que j'aurais dû faire comme lui et éviter de m'établir pròs d'une ancienne crevasse.

Comme, pour mieux appuyer sa théorie, il m’entraînait vers son observatoire, nous ne fümes pas peu surpris de eonstater que ee dernier, semblable à une île flottante, s'écartait lentement de notre champ de glace.

Immédiatement, prenant ma revanche, je le eompare à une cabane à eanards, au milieu d'un étang; puis, par dix raisons plus mauvaises que bonnes, j'explique à mon eamarade qu'il est seul responsable de cet aeeident, qu'on ne s'installe pas impunément sur un aneien hummoek, ni près d'une aneienne lagune!

Le ry mai. - Grande fète nationale pour les Norvégiens! Le poste est pavoisé aux couleurs belges et norvégiennes, et nos amis du Nord sont l'objet de toutes nos attentions.

Pourtant, un regret ineonscient pése sur nos esprits : le soleil se montre aujourd'hui pour la demière fois! Il est déjà sous l'horizon, nous ne le voyons plus que par réfraction, et ses rayons mourants ne nous en semblent que plus chers!

Voiei midi vingt, et e'est déjà la nuit!

Adieu, soleil! Adieu pour seize cents heures, astre qui nous donne la ehaleur et la vie! Oue deviendrons-nous sans toi? 'T'e reverronsnous jamais?... 


\section{CHAPITRE XXIX.}

\section{La mort de Danco.}

Le 23 mai 1898 . - Malgré le froid glaeial qui a régné tonte la journée, 'Tollefsen, Johansen, Amundsen et Cook ont installé une ligne télégraphique reliant mon nouvel observatoire au navire. Cette mesure était bien nécessaire, car les ehronomètres se seraicnt détćriorés complètement, si l'on avait eontinué à les transporter par ces grands froids. Grâce à ce nouveau système, les signaux horaires sont transmis télégraphiquement dans ma chambre, où Dobrowolski sc tient penclant les observations. Lc petit télégraphe fonctionne à merveillc.

Le même soir, Danco, qui est un peu souffrant, et moi, nous sommes demeurés seuls au earré. Lc commandant, Amundsen ct Mélaerts sont dans leur chambre; Racovitza, Cook et Arctowski, dans lc laboratoire.

A la pâle lueur d'une bougie, j’ai raceommodé mon veston qui tombait en ruincs, tandis que I)anco me lisait, à haute roix, quelques pages de l'ouvrage de Tissot: Aupays des Triganes ou la Hongrie inconme.

Si nos ancicns amis du régiment nous avaient vus ainsi, ils auraicnt trouvé la scène plaisantc : j'avais l'air d'une jeune femme qui coud, près du foyer, sa premic̀re layette, pendant que Ianco, le modèle des maris, légaye par une intéressante lccture.

Le z̧ mai. - Comme nous ćtions au carré, de Gerlache et moi, lc docteur vient nous dire que Daneo est plus sérieuscment atteint qu'il ne l'a cru tout d'abord : l'affection eardiaquc fait des progrès effrayants ct lá faiblesse est extrême, étant donné le manque d'appétit. Le malade ne consent à prendre qu'un peu de lait condensé et des peptones de Liebig. Cook défend que Danco sorte du navirc, de crainte d'une pneumonic.

Notre pauvre ami sc désespère à cause de ses observations magné- 
tiques. Alors, sans rien lui dire, je le remplace pour ce travail, me réjouissant à la pensée que, lorsqu’il scra guéri, je lui remettrai ses carnets completement au courant.

Hélas! le 29 mai, le mal cmpire. Danco me fait appeler le matin et me pric de faire scs observations, qu'il craint de ne pouvoir reprendrc de longtcmps. Je le rassure de mon micux ct lui promets de les lui communiquer chaque jour : il pourra même, si cela l'intércsse, faire les réductions. Il accepte tout d'abord, mais il a trop présumé de ses forces: il doit renonecr à toute fatiguc.

L'après-midi de ce même jour, Cook vient me rejoindre sur la banquise; il a l'air si préoccupé que, pressentant un malheur, je l'interroge anxieusement. Il m'explique que la maladic fait che\% Janco de tels ravages, que rien ne peut plus le sauver. A la suite d'unc analyse minuticuse, il a constaté, comme nouvellc complication, unc fortc albuminuric. Je suis anéanti ! Je ne puis croirc à la réalité. Je pensais bien que notre pauvre ami était gravement attcint, mais le perdrc si vite, si vite, ccla me scmble impossible!

Le z jum. - Oh! le doulourcux révcil! de Gerlache vient de me dire que le dénoûment fatal arrive à grands pas : il mo clcmande de vouloir bien me charger de la cruclle mission d'avertir le mourant. L'avertir? 1e. faut-i1? Ce coup ne va-t-il pas hâter la fin? Et puis, Danco n'a aucun parcnt; toutes scs dispositions testamentaires sont réglées: mais avons-nous lc droit de lc laisser s'étcindre doucement, inconsciemment? De commun accord avec de Gerlache et le docteur, nous convenons d'attendre encore.

Le 3 inim. - Oucl froid! $30^{0}$ sous zéro, et pourtant je m'cmpresse d'aller observer au dehors, afin de quitter un moment le carré ou notrc pauvrc ami souffre ct gémit, étcndu sur le canapé.

La banquise cst superbe, éclairéc par la lunc qu'aucun nuage ne voile: alle est hérisséc de hummocks. Les silhouettes de quelques nombres de l'ćquipage sc détachent toutes noircs sur le fond d'allaatre. Le commendint ct Cook profitent de cctte nuit screine pour photographier la Belgica au clair de lune. 
Le 4 juin. - Le temps est radieux; toute la matinée, nous nous dégourdissons les membres sur la glace, nous relayant auprès du malade. L'après-midi, le ciel se voile, une neige épaisse tombe lentement. Cook endosse ses vêtements de fourrure et, se couchant sur la banquise, se laisse peu à peu ensevelir sous la neige.

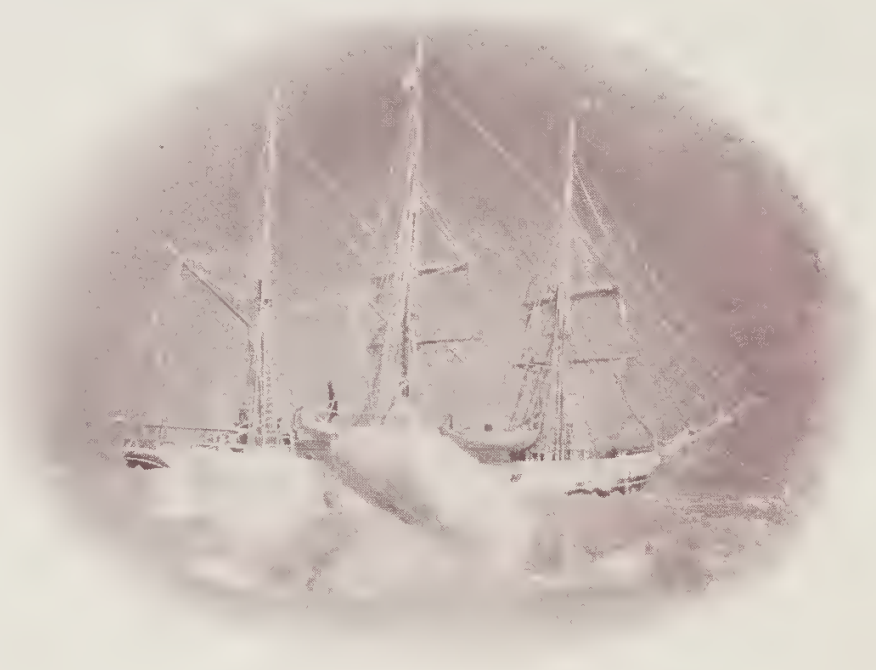

Photographie do MI. de Gerlache ot Cook.

FIG. 5 .

LA « BLLGICA » AU CLAIR I)E LUNE.

Vers la snirée, Danco est plus mal : la faiblesse est telle qu'il ne peut plus absorber qu'un peu de jus de citron. Le docteur ayant remarqué que l'oppression du malade augmente dans l'obscurité, deux bougies sont constamment allumées dans sa chambre. Et nous éprouvons la triste impression de veiller déjà dans une chambre mortuaire!

Pauvre Danco ! il nous est si reconnaissant du peu que nous pouvons faire pour lui! Une chose nous console: il ne voit pas venir la mort. Il parle du retour ; il veut être le premier à revoir la terre : il ira la guetter dans le nid de corbeau!... 
Cette douee illusion est-elle sinecre? ou bien, par une exquise délicatesse de son âme génćreuse, veut-il nous donner le change, afin de ne pas nous attrister davantage?

Le dimanche 5 juin. - Notre malade est si mal que Cook lui fait, le matin, une injection de morphine. Vers 4 heures de l'après-midi, il se réveille; il n’éprouve aueune douleur, mais sa respiration est halctante. Vers 5 heures, il est nécessaire de faire une nouvelle piqùre de morphine; le dénoûment suprême arrive à grands pas !

Le soir, le souper n'est pas servi au carté, mais dans la eabine de de Grrlache. Vers 7 heures, le docteur vient nous prévenir que l'agonie a commencé.

Tous, nous nous rendons au carré. Daneo est étendu sur le canapé; il balbutie avec peine quelques mots; il ouvre, par moments, ses yeux tout grands, puis les referme lentement; un long ràle sort de sa poitrine oppressée.

Le docteur me demande de parler au mourant, mais les mots ne viennent pas! C'est un ami dévoué, un frère đui est étendu là; j’ai le cour scrré comme dans un étau...

Que dire? De qui parler à ce pauvre enfant sans famille? Tout à eoup, je me rappelle le culte quil professait pour son régiment, le $2^{\text {me }}$ d'artilleric; l'affection reconnaissante et vive que lui inspiraient deux de ses aneiens professeurs, les frìres Lagrange, ses sages conseillers après la mort de son père; enfin le lieutenant d'artillerie Henrion, son meilleur ami, presque un frère.

Comme dans un rêve, j'évoquai pour lui, un à un, tous ces noms aimés, et je sentais, à une légc̀re pression de sa main, que ces souvenirs touchaient encore son cœur.

'lout à coup, le râle cesse : une dernière fois, Danco ouvie les yeux, puis les referme à jamais...

Il etait 7 heures du soir, le 5 juin 1898 .

Même jour, 9 heures du soir. - Cook, Amundsen et moi avons fait la toilette du mort. Il repose, calme et beau, dans les plis d'un drapeau national. 
Les hommes de l'équipage, prérenus par le commandant, viennent, un à un, s'incliner devant le cadavre : la consternation, le regret se lit dans tous les yeux!

A la nuit, de Gcrlache nous demande s'il n'y a pas lieu de faire embaumcr le corps et de le déposer, dans un cercueil, sur la banquise, afin de le reprendre, le jour où nous serons délivrés, pour le faire enterrer au pays.

Cook, à qui incombera la tàche la plus pénible, s'abstient d'émettre son opinion; Racovitza et moi, nous insistons, avec énergie, pour qu'il n'en soit pas ainsi : si d'autres morts se succedent, pourronsnous toujours conserver la dépouille?

Danco scra donc immergé le mardi, 7 juin, après le délai légal. Le commandant, Amundsen et moi vcillerons le mort.

11 est minuit, c'est mon tour de veille. Une misérable bougie éclaire la chambre mortuaire, absolument glaciale, car, par mesure hygićnique, nous avons entr'ouvert un hublot. Le silence le plus complet régne autour de moi, et rien ne peut détourner ma pensée de ce cadavre couché là dans ce drapeau. Pourtant, je n’éprouve plus cette angoisse qui m'étreignait lors de son agonic : je sais qu’il jouit maintenant de l'éternel repos.

Lamdi б juin. - Tout est sombre, tout est gris, le ciel se confond avec la banquise. Le silence n'est interrompu que par les craquements sourds de la mâture ou de la coque du navire. Tout travail est suspendu, excepté pour Johansen et Krnudsen, qui cousent le funibre sac dans lequel sera ensevelic la dépouille mortelle.

A 4 heures de l'après-midi, tout est prêt. Amundsen, Cook et moi faisons appel à toute notre énergic pour procéder à l'ensevelissement.

Au moment où nous achevons notre funçbre besogne, on frappe à la porte : Van Rysselberghe nous apporte quelques fleurs séchées, dernier souvenir de sa mère au moment du départ de Belgique. "Il avait promis de les garder toujours, mais il se sent dégagé de sa promesse s'il les donne, comme suprême adieu, à celui qui nous a 
quittés. "Avec émotion, nous plaçons les flcurs et refermons le linceul. Puis, lc corps est descendu sur la banquise et placé sur un traîneau jusqu'au lendemain matin.

La nuit du 6 au 7 juin est rayonnante de beauté : lorsque, d'heure en heure, nous nous rendons sur la dunette pour les obscrvations, nos regards ne peurent sc détacher de cette sombre civiere qui est là, tout près du bord.

Le 7 juin, à I I heures du matin, le froid est tel (quc les hommes ont toutes les peines du monde à hisser, dans les haubans, le drapcau bclge cravaté de deuil. $35^{\circ}$ sous zéro ct avec une bisc les plus violente.

Des matelots pratiquent clans la glace une ouverturc pour l'immersion du corps, mais dìs que les fragments de glace sont coupés, ceux-ci se congèlent et se réunissent à nouveau.

Le travail n'avance pas, on va même l'abandonner lorsque, brusquement, une détente se produit, rouvrant une ancienne crevasse. Aussitôt les hommes s'aticllent au traìneau funèbre, que nous suivons tols.

Arrivé à la crcvasse, on attachc les boulcts à la partic inféricure du sac, mais au moment ou Mélaerts veut les pousser ver's l'ouverture, la glace se rompt sous son poids! Déjà unc de scs jambes plonge dans l'cau glacée, lorsqu'on parvient à lc ressaisir !

Tout le monde se découvre; le commandant s'avance pour parler, mais il est si profondément ému qu'aucun son ne parvient à sortir de son gosicr contracté. Après quelques moments, il peut enfin prononcer les douloureux regrets et l'adieu éternel.

Alors, les boulcts sont poussés dans la mcr; sous cettc traction, lo cadavre se redresse brusquement, commc s'il reprenait vie! 'Tous, nous frémissons, saisis d'unc mystćricusc horreur, tandis que lentemcnt, très lcntcment, lc sac se remplit d'eau, glisse, s'enfonce et disparaît sous la banquise, qui, pour mieux garder sa proie, se referme.

Ohl cette banquise d'albâtre tant de fois rêvée par Danco! cette banquise qui lui scrt de mausolée, dans son beaut rêve, sans réveil cette fois, et qu'il voit se poursuivre indéfiniment dans la mort!... 
Émile Danco naquit à Malines, le 27 novembre I 869 . Il fit ses études à l'Institut Saint-Louis, à Bruxelles, puis, à l'àge de I7 ans, fut admis à l'ĺcole militaire, section des armes spéciales. En r888, il fut admis en qualité d'élève sous-lieutenant à l'ícole d'application.

A l'âge de Ig ans, 1)anco avait encore le caractère d'un enfant, et

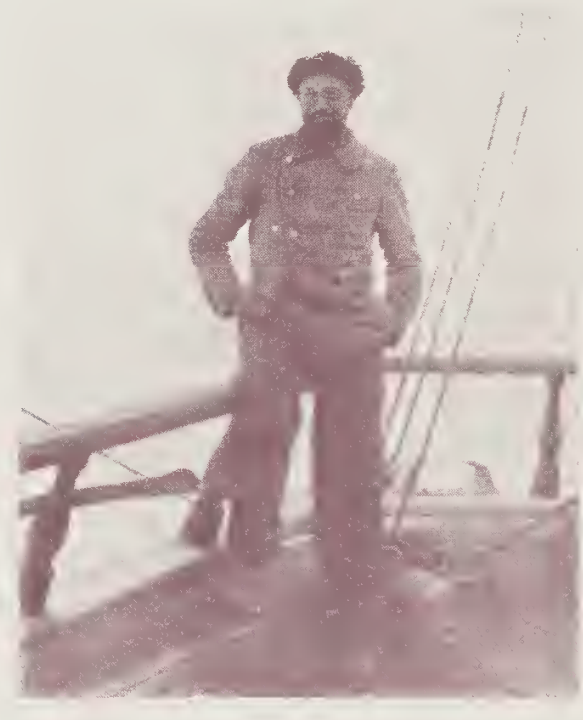

FIG. 55. - DANCO. ce fait était dû̀ à la sollicitude affcctueuse, mais étroite de son père, le lieutenanteolonel Danco.

Jamais Emile, bien que déjà offieier, ne pouvait sortir seul : dès qu'il quittait l'École d'application, il devait rentrer che $z$ lui en ligne droite, et ses promenades avaient lieu toujours sous 'œ 1 vigilant de son père.

Inn vain notre ami essaya-t-il de tirer " la earotte ", toujours des circonstances fortuites le faisaient prendre en flagrant délit! Découragé, il se résigña, et, à sa scconde année de l'École d'application, n'essaya même pluss de jouir d'une liberté quelconque sans en avoir, au préalable,

obtenu l'autorisation. Cette sévérité excessive, tout en l'empêcliant de se préparer à la lutte pour la vie, eut cependant le résultat heureux de le faire travailler sérieusement : il sortit deuxième de la section d'artillerie.

En I89r, il fit son entrée au régiment de Malines et, peu de temps après, il eut la douleur de perdre son père qu'il adorait.

Émile Danco, dont la mère était morte lorsqu'il était au berceau, se trouva done seul au monde. Il possédait une assez belle fortune, il jouissait de l'estime de ses chefs et de l'affection de tous ses eamarades. Chose exeeptionnelle, il n'avait pas un seul ennemi.

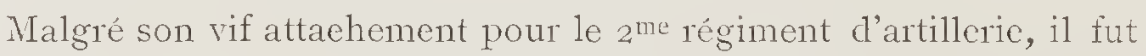
pris soudain du violent désir de quitter la Belgique. A la suite de quelle 
circonstance - peut-ètre romanesque - cette décision fut-elle prise? je l'ignore. Toujours est-il qu'il m'écrivit plusieurs fois, en France, m'exprimant son espoir de faire un stage dans la flotte française, comme de Borchgrave et moi.

Ses démarches fuxent malheureusement inutiles, le gouvernement belge ne voulant pas envoyer à l'étranger un troisicme officier.

Sur ces entrefaites, de Gerlache venait de faire connaitre son projet d'expédition au pôle Sud. I) anco alla vers lui et, avec une insistance extraordinaire, le pria de l'admette clans son ctat-major. Ie brave gárçon souscrivait par anticipation à toutes les exigences du service, à toutes les volontés du chef de l'expédition, et mettait mềne à sa disposition une somme de plusieurs milliers de franes. de Gerlache cependant hésitait : non qu'il doutât des capacités ct du conrage de Danco, non qu'il dédaignàt l'argent mis à sa lisposition et dont il avait le plus grand besoin, mais parce qu'il savait que Danco avait la poitrine tries délicate. Enfin, en présence de l'insistance obstincée le notre ami, il funit par céder.

Mais alors se montra, dans l'armée, une vive opposition. Tous les chefs emirent un avis défavorable, et particulicrement l'inspecteur général de l'artillerie, le lieutenant-général de Cuyper, ancien ami du lieutenant-colonel I)anco. Il déclara (que laisser partir le fils serait l'envoyer à une mort certaine; que, de plus, ce serait priver l'expélition d'un nnembre ayant les mèmes capacités, mais une santé plus robuste pour résister au froid.

1)anco, inébranlable, tenta une démarche auprès du Ministre le la Guerre; elle échoua. Désespéré, il s'adressa à l'A Archerêque de Malines, qui voulut bien plaider sa cause à la Cour.

L'autorisation tant rêvée arriva enfin; Celui qui l'avait fait accorder admettait que "l'homme qui possède une réelle vocation et qui poursuit un but humanitaire ou scientifique a le droit de payer de sa vie la gloire de rendre service à la science et à ses semblables n.

1)anco, triomphant, se mit aussitòt à l'ouvre.

Guiclé par les fic̀res Lagrange, il se prépara aux observations 
magnétiques; sous la direction de M. Lancaster, il étudia le service météorologique dans lequel il devait scconder Arctowski.

Il alla cn Autriche où il fit des mesures pendulaires sous la conduitc du colonel von Stcrneck; ; il se rendit à Wilhelmshaven, où le Dr Borgen lui donna de précieux conscils sur les méthodes à employer en mcr pour les obscrvations magnétiques; cnfin, il passa quelques jours cn France, à l'Observatoirc du parc Saint-Maur, pour voir déterminer les coefficients de températurc des aimants.

Il fallait encore s'cntraîncr physiquement. Dans cc but, il séjourna asscz longtemps en Norvège, où il se fortifia, au grand air, dans les excursions à slíis. Là aussi, avec le dévoûment, l'abnégation la plus complète, il aida de Gcrlache qui faisait ses préparatifs dc départ.

Danco fut l'ami le plus dévoué, le plus cnthousiaste de l'expćdition. A bord, il donna, en tout ct toujours, l'exemple dc la plus stricte disciplinc.

Comme travaux scientifiqucs, il a effectué une série de mesures pendulaires à Rio-de-Janeiro; il a détcrminé les éléments magnétiques dans différentes stations du détroit de Gerlache; enfin, il venait do commencer une importante série d'observations magnétiques lorsque la mort l'cnlcra.

L.e nom de Terre de Danco a été donné à la partie de terre resserrant, au Sud-Est, le détroit de Gerlache.

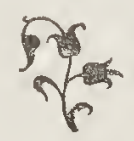




\section{CHAPITRE XXX.}

\section{Interminable nuit : nos âmes et nos corps languissent.}

Les jours de deuil, que nous venions de traverser, furent néfastes à la plupart d'entre nous. La clépression morale, jointe à l'anémie polaire, exerça de plus en plus ses ravages : nos forces diminuèrent scusiblement, une sorte de lassitude s'empara de nos membres; nous exéeutions encore nos travaux avec ponctualité, mais machinalement, sans goût. Si nos rapports communs restaient courtois, un mécontentement sourd, inconseient, n'en accueillait pas moins toutes les mesures d'ordre général. D'un autre côté, de Gerlache s'isolait davantage, se montrant sombre et taciturne.

Le Io juin, la fête de Cook ramène momentanément la gaîté parmi nous: chacun s'empresse de témoigner, d'une façon quelconque, sa reconnaissance à notre bon docteur.

Lee soir, un petit festin nous rassemble. J'endosse mon habit et noue ma eravate blanche - devenue jaune. Cook ne veut pas êtı̃c en reste de courtoisie ct exhibe une queue de morue, qui s'est, depuis des mois, tant soit peu défraîchic à fond de cale.

A l'heure des toasts, je demande la parole pour lire au héros de la fête un petit discours en ánglais, à la rédaction duquel j'ai consacré deux heures de traduction littérale.

J'en suis arrivé à produire ceci :

\section{1)octeur Cook,}

I male fast the occasion from your anniversary in order to you exprime all the sympathy who you suggest to me. 
In proof from that friendship and beeause that great day, I talie the engagement to mend one eouple from your linit stokings (I).

Dixi

\section{G. LECOINTE.}

Oeéan glaeial antaretique, S. Y. Belgia, io juin I 898 .

Cet anglais genre nègre met Cook à la torture: il lui faut bien dix minutes pour eomprendre et je m'en sens profondément humilié.

De son eôté, le doeteur eroit de son devoir de répondre en franęais, ct il bredouille une suite de mots qui n'en finit plus et que personne ne eomprend. Tout s'arrange pourtant: Cook lève son verre en signe de remereiment, tandis que nous vidons le nôtre avee des hourras.

Afin de micux aeeentuer ma satisfaetion, je revêts un simple pardessus et vais observer la position astronomique.

Nous sommes par $71^{\circ} 02^{\prime}$ de latitude Sud, et par $87^{\circ}$ I $8^{\prime}$ de longitude Ouest de Greenwieh. La température est de $20^{\circ}$ sous zéro! Je rentre grelottant au earré, en me promettant bien de ne plus reeommeneer semblable extravaganee.

Le 22 jum. - Nous voilà au solstiee d'hiver : le pôle Sud est dans l'ombre jusqu'au eerele glaeial antaretique. I a moitié de notre longue nuit est aehevée, mais nos jounnées les plus sombres vont se sueeéder : journées pendant; lesquelles midi et minuit se eonfondent, pour ainsi dire. Pour nous distraire, nous ne manquons pas d'exploiter eette situation au détriment d'Aretowski qui, travaillant de 6 heures du soir à 6 heures du matin, doit néeessairement se eoueher pendant le jour.

Un matin done, qu'il dort depuis deux heures à peine, Raeoritza

(I) Docteur Cook,

Je saisis l'occasion de rotre annivercaire pour rous exprimer toute la sympathie que vous m'inspirez. Comme preuve de mon amitié et à cause de ce grand jour, je prends l'engagement de raccommoder une de ros paires le bas. 
va le réveiller brusquement: "Vite debout, paresseux, vous avez oublié de venir aux repas, et voilà que vous oubliez de faire le service !”

Aretowski est tout étonné: il lui semble qu'il vient à peine de $\varepsilon e$ coucher! Et tout en se levant, il s'extasic sur le profond et reposant sommeil qu'il a dû̀ goûter pendant ces dernières douze heures!...

A mesure que la nuit devient plus profonde, les crevasses se ferment et les animaux se retirent vers 1e Nord. Parfois encore, nous aperevons un phoque ou quelques manchots de la Terre Ackélie, rarement un manchot royal. Cette pénuric de gibier nous donne à réfléchir : que ferons-nous si notre fonds de réserve s'épuise?...

Par moments aussi, les pressions deviennent tres violentes, secouant énergiquement le navire, qui se souleve et craque dans toute sa membrure. On les entend venir de loin comme un roulement d'artillerie de campagne au galop : les champs s'accostent, se heurtent, se morcellent, puis se tassent les uns sur les autres.

On se prépare activement à l'évacuation éventuelle de la Belgica, pour le eas où le navire serait écrasé. de Cierlache, Amundsen et plusieurs membres de l'équipage emplissent de vivres et de vêtements res caisses et des sacs, qui pourront être, à l'occasion, déposés sur la glace. Il est décidé aussi que, si nous devons nous séparer, nous formerons deux équipes. La première, commandéc par de Gerlache, comprendra le lieutenant Amundsen, le I) Cook, Van Mirlo et les quatre matelots norvégiens: Joliansen, Knudsen, Tollefsen et Koren; ils disposeront du canot de tribord. La seconde, placéc sous ma direction, réunira le personnel scientifique, Racovitza, Arctowski et J)obrowolski, ainsi que le lieutenant Mélaerts, les mécaniciens Somcrs et Van Rysselberghe, le cuisinier Michotte et le matclot I)ufour.

Le 30 juin. - I epuis quelques jours, Arctowski est souffrant : le pouls est tries faible. Le 26 juin, il a dû rester au lit presque toute la journéc; le 28, il était fort nerveux; aujourd'hui, il est moins bien encore. Il se rend d'ailleurs parfaitement compte de sa situation, ce qui ne provoque chez lui ni émotion, ni crainte. 
Ce même jour, de Gerlache me fait part d'un projet qu'il a formé.

Il me propose de partir en campagne, rers le Sud, dès le retour du soleil avec deux ou trois de nos compagnons, notamment Amundsen et Cook.

Le raisonnement très logique fait par de Gerlache était le suivant:

La Belgica étant emprisonnée dans une banquise trés vaste, dérive avec cette banquise dans toutes les directions. Or, comme les sondages renseignent d'une façon catégorique le plateau continental, nous pouvons ĉtre eonduits à une distance relativement faible d'une terre, sans nous en apereevoir. Ne serait-il donc pas avantageux, lorsque le navire sera de nouveau entraîné vers le Sud, qu'un petit corps expéditionnaire fit route le plus rapidement possible de ce eôté, en se déplaçant sur la banquise? Après une marche de quinze jours, on rejoindrait le navire.

de Gerlache me laissait toute latitude pour organiser cette marche, et je lui suis trés reconnaissant de la confiance qu'il me témoigna en eette occasion. Mais s'il était aisé d'abandonner le navire pour courir vers le Sud, il n'en serait pas ainsi, probablement, lorsqu'il s'agirait de rejoindre la Belgica!

J'aeeeptai eependant sans hésitation et je fis part de ce projet à Cook et Amundsen, qui consentirent à se mettre en route, dès que les circonstances nous le permettraient. Toutefois, il fut arrêté que nous ferions des essais préliminaires, afin de nous entrainer quelque peu, et de choisir, avee discernement, le matéricl à emporter dans cette campagne.

Le 4 juillet étant le jour anniversaire de l'indépendance des États. Unis, nous profitons de cette occasion pour témoigner encore toute notre sympathie à Cook, et nous passons la soirée en discutant sur la politiclue internationale.

Cook est l'ennemi des armées de terre et de mer; il estime - et ses ilées étaient alors celles de tous les Américains du Nord - que l'Europe se ruine par ses armements de plus en plus puissants. "Les États-Unis, déclare notre ami, vont arranger tout cela en s'alliant avec 
l'Lspagne et, dès qu'ils auront pied sur le vieux eontinent, e'en serat fait des armées permanentes : il n'y aura plus que les litats-Unis d'Europe alliés aux Etats-Unis d'Amérique! "

Et tandis que Cook nous faisait de semblables diseours, les litatsUnis ćerasaient militairement l'Espagne; puis, au lieu d'entrer dans la voie de réduetion des armements militaires, ils s'empressaient de voter un formidable erédit pour l'accroissement de leurs forees navales.

Il faut se trouver dans l'Antarctique pour eroire à la réalisation d'une semblable utopie: l'extinction des haines, la suppression des jalousies, l'indifférenee de l'or, la paix universelle, quoi !... - avee ou sans Conférenee internationale de La Haye!

Le 6 juillet. - Aretowski ne va pas bien du tout; son état s'aggrave sans que sa sérénité en soit ecpendant troublée. Ce matin, je me promenais gravement: il maborde en riant et me demande où je suis. - "Oh! tris haut, trìs haut, au milicu des étoiles, dans la constellation des rêves! - C'est le contraire pour moi, me dit-il, je suis bien bas... presque au niveau de la mer! ") Il faisait allusion à son immersion finale, qu`il eroyait prochaine.

Le g juillet. - Depuis plusieurs jours, mes jambes me font souffrir, et je me demande avee anxiété si mon tour de maladie arive. In prenant mon bain, je eonstate que mes ehevilles sont toutes gonflées. J'appelle Cook, qui m'examine avee soin, et je vois, à sa figure contristće, que mon ćtat l'inquicte. Au reste, ee soir nous sommes tous démoralisés: de Gerlaehe se plaint de douleur de tête et va se coucher aussitôt après le souper.

Le ro juillet. - Ouelle nuit je viens de passer! Pas une heure de sommeil! Ma tête est lourde comme du plomb et mes tempes battent aree violenee. Cook déelare que, eoûte que eoute, je dois nanger de la viande fraìche et propose à de Gerlaehe de me faire préparer un beefsteak de manehot.

Nous avions eu, jusqu'à ee jour, une si grande répugnanee pour eette viande d'aspeet noirâtre et eoriace c pu'aueun de nous n'avait pu se résouclie à en manger. 
Amundsen, qui se sent très faible, n'attend même pas l'heure du souper pour essayer ee nouveau régime et déguste, vers 5 heures, un filet eru de manehot.

Comme je suis de serviee à partir de minuit, je me eouehe à 8 heures du soir, mais sans parvenir à trouver le sommeil. Nes jambes enflent de plus en plus, et ma main gauehe eommenee à suivre leur exemple.

De minuit à 4 heures du matin, j'assume mon quart et les observations météorologiques. J'espère, en me reeouehant, que la fatigue m'apportera le sommeil dont j'ai si grand besoin. Il n'en est rien. Immobile sur mon lit, les yeux fixés au plafond, j'éprouve une sorte de torpeur. Vers le matin, je veux ehanger de position, et je eonstate avee épouvante que mes deux jambes et mon bras gauehe sont paralysés. Que faire? Crier serait oeeasionner une véritable panique à bord, et d'un autre eôté dois-je demeurer ainsi seul, sans seeours d'aueune sorte?

Le I I juillet.-Vers 6 heures du matin, je réussis à me traîner jusqu'à Cook. Il est visiblement inquiet; il me donne une pilule (!) et m'aide à rentrer dans mon lit.

Je me sens si faible que je pense que la mort va venir! Par ma porte entrebaillée, un souffle de ehaleur arrive du earré, et j'entends le bruit eonfus des premiers serviees du bord. J'appelle Amundsen : je lui explique où sont placés mes doeuments eoneernant l'expédition; je lui montre une eassette dans laquelle se trouvent quelques souvenirs et les lettres que je destine aux miens; je lui donne mes dernières reeommandations. Le paurre garçon, atterré, me regarde, m'éeoute en silenee, puis se retire en essayant de eaeher son émotion.

Alors, l'esprit en repos, regardant par mon hublot le petit bout de ciel sombre qui se eonfond avee le sombre de la banquise, je me laisse ressaisir par la torpeur. Je pense eneore, mais eomme dans un rêve, et il me semble que la mort n'est pas ehose terrible, puisque je m'en vais ainsi tout doueement, sans lutter et même presque sans souffrir... 


\section{CHAPITRE XXXI.}

\section{Un voyage d'agrément sir la banquise.}

Le 13 juillet 1898 . - Je ne suis pas mort !... Le coma dans lequel j’ai été plongé hier n’a mème pas duré fort longtemps. J'en suis sorti pour manger machinalement un petit filet de manchot et, quelques heures plus tard, je me suis éveillé beaucoup plus solide.

Ce même après-midi, une jolie surptisc a achevé de me donner du cceur: de Gerlache a découvert, dans son magasin, un sac contenant une boîte avec cette inscription : "A ouvrir le jour de Noël. "Stupéfaction et euriosité générales devant ce mystéricux cadeau, oublić depuis sept mois. Le commandant y a trouvé, pour chacun de nous, deux petits paquets soigneusement ficelés. L'un ronfermait un superbe porte-crayon cn argent avec l'inscription : "Noël dans les Mrrs Antarctiques - Souvenir de L. O. (Léonie Osterrieth) n; l'autre, une chaîne de montre, munie d'un cachet artistique aux armes de la ville d'Anvers et portant la devise: Audaces fortuna juvat, don clu lieutenant-général et de Mme Wauvermans.

Cette trouvaille fit sur nous l'effet de la boite de Pandore : on cût dit que l'Espérance s'en était échappée et planait de nouveau sur nos âmes! Une joycuse conversation s'cnsuivit, sur le pays et les amis. Comme un grand enfant, je saisis tous les prétextes possibles pour faire usage de mon porte-crayon, et j'imaginai toute une série le lettres à cacheter, afin d'y apposer le sceau d'Anvers et la devise hardic.

Et aujourd'hui mon petit coeur ne bat presque plus la breloque!... Cook ne compte que quatre-vingt-dix-huit pulsations; il m'annonce avec joie qu'avant huit jours je serai complètement rétabli.

Pourtant, le brave Cook no croyait pas encore beaucoup à mal guérison, car ses tablettes portent, à la date du I4 juillet: " I.ecointe 
a perdu tout espoir de se relever; il a dicté ses dernières volontés. Son cas me paraît désespéré et je erains que ces pronosties défavorables n'attaquent fort le moral chez tous. "

Le I\& juillet. - Cela va de mieux en mieux. Je ne prends plus de pilules et j'ai recommencé à faire mes observations. Il n'en est pas de même pour tous, malheureusement: Cook vient de faire devant moi une analyse établissant que de Gerlache est séricusement menacé; Knudsen a les jambes très enflées, surtout les ehevilles; Mélaerts compte cent cinquante pulsations à la minute; Cool et Racovitza ne sont guère plus brillants.

Le $2 I$ juillet. - Fête nationale en Belgique! Pour nous, paurres exilés, grand jour d'espoir : demain, le soleil reparait!

Le commandant accorde à l'équipage trois jours enticrs de congé et lui fait donner du champagne au diner de midi. Tous sont dans une grande joie et légèrement aussi dans les vignes du Seigneur, étant donné que depuis des mois ils n'ont plus pris d'alcool.

Le 22 juillet. - Si le temps est clair, aujourd'hui, le soleil nous apparaîtra quelques instants par réfraction, rers midi. Aussi, dès I I heures, regardons-nous anxieusement vers le Nord. Hélas ! rien : de gros nuages cireulent et nous cachent l'astre tant désiré !

Le 23 juillet, à Io heures du matin, nous nous éparpillons sur la banquise ; chacun a choisi, depuis plusieurs jours déjà, le point d'où il veut observer le lever du soleil.

de Gerlache, Amundsen, Cook et moi, nous nous dirigeons vers un petit iceberg, but habituel de nos promenades d'automne. La gaîté est sur tous les visages, il n'est plus question de la nerrosité de ces dernicrs jours.

Oh! combicn nous avons besoin de lumière et de chaleur! L'anémie polaire a laissé sur nous des traces de profonds ravages : nos traits sont tirés, des rides les sillonnent; notre teint est verdâtre, nos yeux ternes et sans vie; il n'a pas fallu plus de I,60o heures de nuit ininterrompue pour faire de nous des vieillards (fig. 56).

11 nous faut près d'une heure pour atteindre le sommet de l'iceberg; 

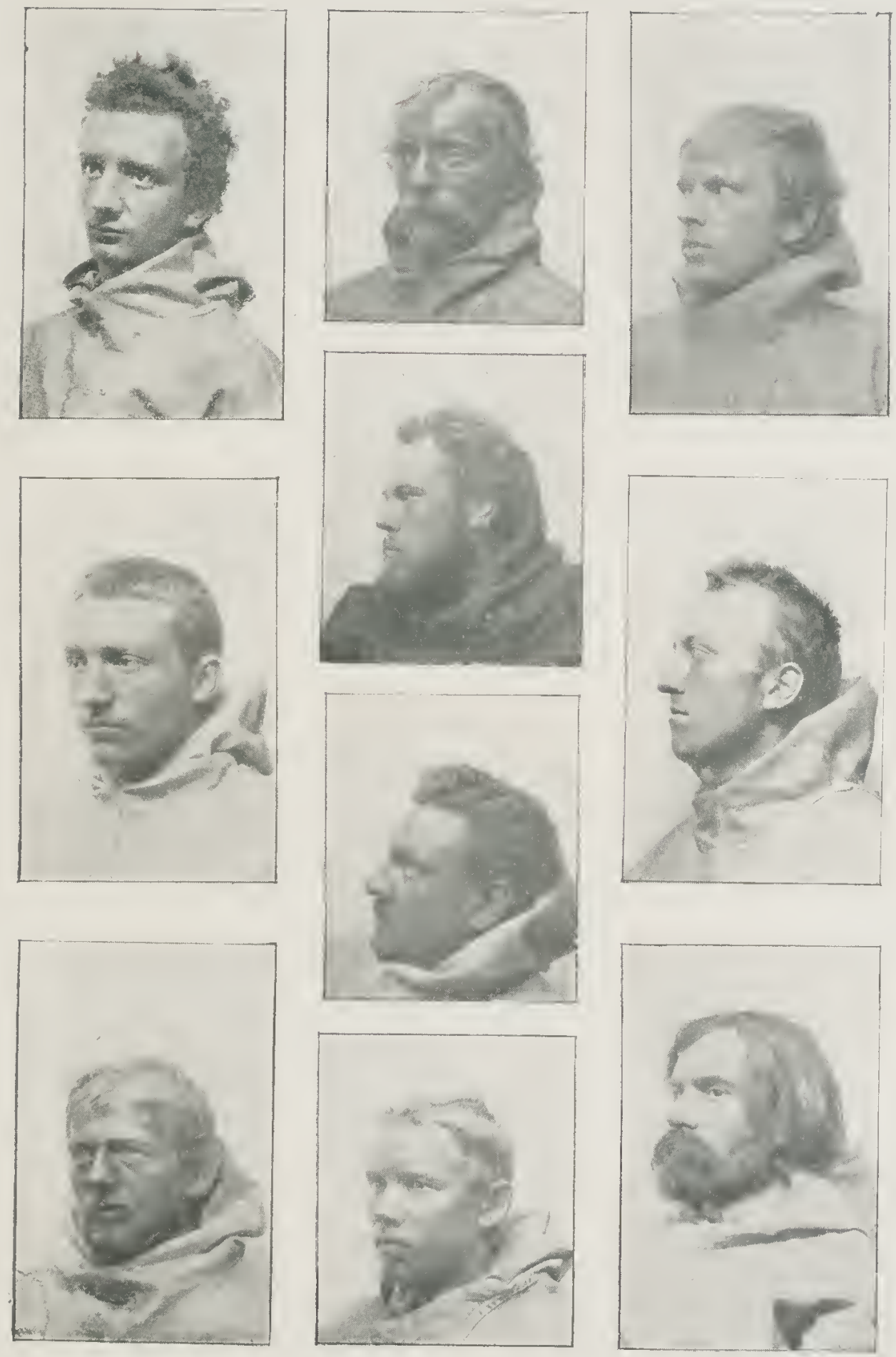

lij 5.56 .

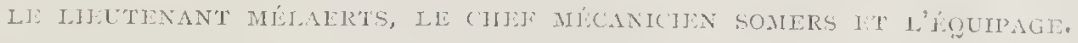
VAX JRYSSTLIJJEGHIE KIORI:N TOLLEISIEX ALLATIRTS JOIIANSEN SOMIIRS SAN MIRLO DUFOUR MICIIOTTE 

ear, tous les cent pas, nous stoppons pour reprendrc haleine. Arrivés là, nous jetons les yeux autour dc nous.

Lc ciel, vers le Sud, est d'un beau bleu pâle; vers le Nord, il est voilé d'une brume gris-perle. Au zénith, s'allongent des cirrus duveteux.

La banquise est radieusement blanche et un mirage y produit les cffets d'optique les plus extraordinaires : certains icebergs, qui en réalité sont très loin, scmblent planer en l'air au-dessus de l'horizon; d'autres donnent une double image : l'une réelle, tandis que la seconde, virtuelle, reproduit l'iceberg renversé; un autre iceberg présente aussi l'image renverséc, mais à quelque vingt mètres au-dessus de l'image réelle. L'œeil doit s'habituer peu à peu à ees phénomènes déconcertants.

Tout à coup, l'un de nous s'écrie : "Le voilà! c'est le soleil! "

Et avidemcnt nous contemplons de tous nos yeux lc petit rectangle de feu qui se montre à l'horizon. Il s'élèvc peu à peu et au-dessous paraît un second rectangle, absolument rouge, qui se transforme en piédouche. A midi, les trois quarts d'un beau soleil d'or cmbrasent la banquise : les hummocks, dont les sommets sont rosés, allongent des ombres qui n'en finissent plus, tandis quc dans le lointain la Belgica se dresse, toute petite, mais toute fière d'avoir échappé à l'hiver antarctique!

A midi quarante, le soleil avait déjà disparu, mais nous rentrions à bord le cocur content et l'âme en fête.

Le 27 juillet.-Amundsen, Cook et moi avons eu, ce matin, un séricux entretien. Notre état de santé étant satisfaisant et la saison propice, il nous semble que le moment est venu d'entreprendre, vers le Sud, sur la banquise, l'cxpédition que de Gcrlache m'a proposée, il y a quelques semaines.

Nous nous réjouissons à l’icéc de ee changement de milicu et nous décidons que, sans tarder, nous ferons un stage d'entraînement.

En conséquenee, nous commençons les préparatifs d'une expédition préliminaire. de Gerlache nous approuve fortement ct pousse l'ama= 
bilité jusqu'à nous prier d’indiquer les vivres que nous voulons emporter : la cambuse nous est ouverte toute grande!

Cette générosité nous émerveille et, sur-le-ehamp, nous dressons une liste de tous les aliments que nous préférons. Comme nous suppo sons que notre absenee sera courte, nous prenons plutôt l'agréable que l'utile : du beurre, des fruits eonservés, du ehoeolat et autres petites friandises!

Notre enthousiasme eroit à mestre que le moment du départ approehe; eela devient une véritable parodie du voyage de la Belgica: nous annonçons avee emphase que nous ferons des déeouvertes géographiques "épatantes " et des observations scientifiques "inattendues "! Notre joie ne tarde pas à gagner tout le monde, étátmajor et équipage.

Le 29 juillet. - Depuis deux jours, e'est une véritable fic̀re à bord; on ne travaillc plus que pour "lcs grands explorateurs ": on aelicve la tente, on monte les lits-saes en poil de renne; on empile les vivres dans des caisses, on remplit des bidons d'alcool; on hisse la roile du grand raineau de Cook; on nettoie nos fusils... ear nous partons armés eomme Tartarin de Taraseon!

Dimanche 30 juillet. - Dès 8 heures du matin, le traineau est ehargé, surchargé même; il disparaît totalement sous les énormes ballots que nous cntassons avee peine. I1 n'y a pas de vent, mais e'est égal : nous déployons la voile!

A. 9 h. 45 , tout est prêt, nous faisons des adieux pathétiques à nos eompagnons, qui nous ovationnent eomme au départ de la Belgica!

Alors, avee solennité, j'attaehe au cou du I)r Cook la eroix de Commandeur de l'Ordre des Kjoedbollers, tandis que j'épingle sur la poitrine d'Amundsen la croix d'Offieier du même ordre. Ces deux bijoux ont été eiselés par Van Rysselberghe: ils eonsistent en un placard brillant - fond d'une boìte de eonserve! - de ro centimètres de diametre environ, dont la faee porte un manehot royal avee eette inscription : Rapidité!! Privations!! et le revers : Expéalition scientifique ster la banquise. - 30 juillet $x 80 s$. 
A ro heures 30, nous apparcillons: A mundsen et moi sommes attelís à la bricole ct montés sur des skis; Cook est chaussé de ses raquettes canadiennes et dirige le traîneau. L c commandant nous accompagne un bout de chemin, puis il nous quitte, en nous répétant encorc los signaux à faire de part et d'autre, en cas d'alarme. Une dernière poignée de main et nous rcpartons allegrement, en ayant soin de relever, de temps à autre, la Belgica au compas, afin de nous orienter le mieux possible. Allègrement n'est pas exact, c'est misérablement quc nous traînons nos cent vingt kilogrammes de charge, sur une couche de neige peu résistante, tombée la nuit précédente.

1)e temps à autre, nous nous arrètons pour reprendre haleine. Nous pourons alors admirer la banquise, superbement éclairée par un délicieux solcil. Le temps est sec et froid.

Vers midi, nous nous trouvons devant un immense lac gelé. Un effet de mirage nous montre la banquise à une distance énorme. Au Nord-Est dir lac. s'ébattent des balénoptères, d'innombrables phoques et quelques manchots.

Comme la glace devient trop fragile, nous regagnons la lisicre du lac ct arrivons dans une région bouleversée par les pressions. Le traìneau y glisse mieux, la neigc étant très durc, mais il garde difficilement l'équilibre, à cause des inégalités de la glace.

Vers 3 heures, nous parvenons à une grande crevasse, qui ne peut être contournée qu'à la condition de faire un énorme détour. Le solcil est d'ailleurs près de l'horizon, nos estomacs cricnt famine, nous nous décidons à camper.

Nous dressons la tente et Amundsen commence à préparer lc repas. Quant à moi, je suis lamentable : 1'un de mes pieds est à peu près gelé. Cook attribue cet état de choses à mes souliers trop étroits pour une température de 350 sous zéro. Il me frictionnc avec unc tellc énergie que j'cn crie de douleur; et mes cris lui font plaisir, car il en conclut que mon picd n'est pas insensible et, par conséquent, non gelé complètement, auqucl cas l'amputation ê̂t été nécessaire!... 
Au bout de quelques minutes, tout danger a disparu, mais comme je grelotte eneore, je me couche dans mon sae en peau de renne.

Amundsen et Cook font le ménage : d'abord de la soupe aux pois; puis, dans la même casserole, sans la nettoycr, ils rôtissent de la viande de manehot; enfin, et toujours dans le même récipient, ils préparent du choeolat!

Comme je suis un peu souffrant, vite on me sert la première tasse.

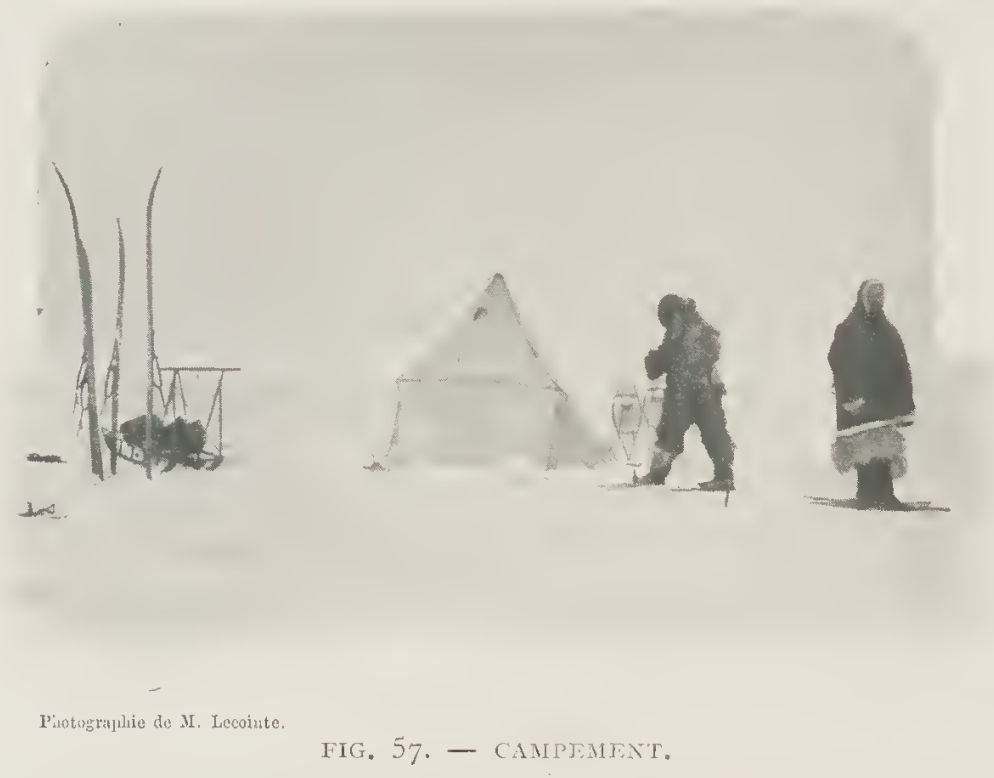

Pouah! c'est ignoble!... cela goùte la soupe, le beure, l'huile de manehot, le chocolat et même les poils de renne de nos saes et les herbes (I) de nos ehaussures, que le vent a sans doute chassés dans 1a easserole!

La tente est fort petite; nous devons, poury tenir à trois, nous reeroqueviller d'une façon extraordinaire. De plus, la vapeur d'eau prorenant de nos respirations et du réchaud à aleool se condense sur les parois de la tente et retombe sur nous en fine neige.

(1) Cette herbe est le sénégrasse qu'on place dans les souliers et les lottes pour maintenir la chaleur aux pieds. 
Peu à peu, les conversations se ralentissent, nous nous assoupissons.

Le 3 I juillet, nous ne nous éveillons qu'à 9 heures. Après une lćgìre collation, nous nous décidons à laisser la tente toute dressée, ct à contourner sans impedimenta la grande crevasse, afin de gagner 1un superbe iceberg qui se trouve à quelques milles sur l'autre rive. Mais à peine sommes nous cn route, que la brume se lérc. Tite nous regagnons la tente : qu'arriverait-il si le brouillard nous cmpèchait de la retrouver?

Pour charmer nos loisirs, nous construisons une maison de neige, où nous nous proposons d'attendre confortablement le retour des 1)eaux jours!

Notre logis est terminé quelques minutes après le coucher du soleil.

L'architecture en est simple, mais d'un gout parfait. Il est de forme circulaire : $2^{\mathrm{m}} 50$ de diamètre. Les murailles, formées de blocs de neige, ont $\mathrm{I}^{\mathrm{m} O \mathrm{OO}}$ de hauteur sur om5o d'épaisseur. Elles soutiennent un dôme cintré en ogive, au centre duquel une étroite issue cntretient la ventilation. Les interstices, entre les blocs, sont bouchós avec de la neige jetée à la main. La porte et la fenêtre ne font qu'un : e'est, à la base, une ouverture étroite par laquelle on se glisse en rampant et qu'on referme bien vite, avec un bloc de glace.

A quelques pas de la maison, la tente, qui renferme nos provisions, se dresse toute noire sur la banquise.

Pour inaugurer solennellement notre nouveau local, nous faisons les dépenses folles : nous allumons jusque trois bougies à la fois et nous nous hâtons au dehors pour juger de l'effet de toute cette clarté. Combiẹn féerique est notre palais de cristal! Les rayons lumineux filtrent par toutes les fissures et donnent à nos murailles transparentes les reflets changeants de l'opale.

La brume s'est dissipée : le firmament est entièrement dégagé de nuages. La lune scelle son disque d'argent dans un ciel bleu pâle qui, 
vers le Nord, est illuminé par les feux rouges du crépuseule, scmblables à un vaste incendic. Cà et là, des astres jettent une note éblouissante. Sur la banquise, les hummocks sortent à demi de l'ombre, rompant l'uniformité des champs de glace. Au Nord-Est, lo ciel se mire dans le lae où des phoques et des balénoptères viennent

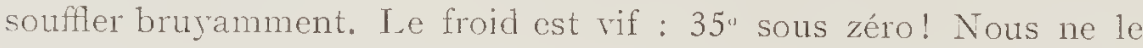
sentons pas; longtemps, nous demeurons à contempler la banquise.

Le lendemain, hélas! le beau ciel s'était de nouveau eaché sous une brume épaisse. Au bout de quelques jours, nos provisions menaçant de s'épuiser, il fallut se décider à rentrer à bord.

Penclant notre marche, nous avions soigneusement noté, à l'aide d'un petit compas, la route suivie. A cet effet, nous arrêtions le traìneau, nous prenions des points de direetion et nous marchions ainsi de hummock en hummock.

Lorsqu'il s'agit de retourner. la situation était autre: le compas nous indiquait bien la route; mais nous ne pouvions prendre des hummoclis de direetion, parce qu'ils étaient perdus dans la brume et qu'on les distinguait à peine à trois pas!

D’un autre côté, le eompas, attaehé sur le traîneau, ne donnait plus aucune indieation pendant la marche : la rose, affolée par des secousses violentes et continuelles; tournait sans eesse. Nous derions nous arrêter après avoir pareouru vingt mètres et attendre l'immobilité de l'aiguille.

Ces arrêts fréquents amenaicnt des erreurs qui nous inquićtaient, car nous sentions fort bien qu'un écart de quelques centaines de mètres suffirait pour nous faire passer, sans la voir, à côté de la Belgica! 11 ne pouvait être question d'imiter les Esquimaux, qui marchent à la file et à courte distance l'un de l'autre, corrigeant ainsi réciproquement leurs écarts. Pour que ce système de marche soit applicable, il faut au moins être trois. Dans ces conditions, un seu1 d'entre nous aurait dù s'atteler au traîneau, que nous remorquions déjà aree peine lorsque nous y étions attelés tous les trois! 
Le soir, il fallut eamper. A ce moment même, toute la banquise s'ouvrit; les glaees se mirent en mouvement; notre ehamp se erevassa de toutes parts! Finalement, nous ne reneontrâmes plus que de petites nappes. Nous fimes choix de la plus solide que nous pûmes trouver par cette brume et nous $\mathrm{y}$ avions à peinc installé la tentc, que notic radeau se brisa à son tour!

En un instant, la nappe qui nous portait clevint si exiguë, qu'elle suffisait à peine à l'emplacement de la tente. Comme nous ćtions occupés à la eonsolider, une détente se produisit et... nous partîmes à la dérive!

Ouelle nuit! Tous fimes le quart en permanenee. L'unique bongic allumée dans la tente lui donnait un aspect funèbre; la glaee blanche sous nos pieds semblait un lineeul. Des balénoptères venaient souffler tout près de nous, tandis que des phoques se réfugiaient sur l'étroit espaee demeuré libre autour de notrc abri.

Le lendemain matin, brusquement, dans unc éclaircie, nous apercevons la Belgica, qui scmble voguer en mar libre ( 1 ).

Nous voilà pris d'une soudaine angoisse : puisque nous voyons à peine le navire, nos compagnons nous distingueront-ils! S'ils sont en mer libre, ne vont-ils pas s'éloigner, nous abandonncr?

Nais de Cierlache était en vigie lans le nid de corbeau. Il découvrit notre détresse et nous envoya des matelots qui, amarrés les uns aux autres, passèrent de nappe en nappe et, ̀̀ la faveur d'une pression, parvinrent à nous rejoindre. Nous dûmes nous hâter au point d'abandonner tout notre matériel sur notrc îlot flottant! Les "grands explorateurs ") rentrìrent à bord, eneliantés de trouver du repos dans un bon lit!

L'analyse des faits qui vcnaient de se passer nous eonduisit à d'utiles conclusions; elle nous montra notamment la témérité absurde qu'il y aurait à tenter, vers le Sud, une marche à grande distanee du navirc. Car de quellc manière aurions-nous pu régler cette marehe?

(I) In effet d'optique élargissait considérablement une petite crevasse. 
En admettant même, chose absolument improbable, que le temps restât clair et que, par des relèvements successifs, nous fussions parvenus à traccr exactement la route de l'aller, notre retour à bord nc se serait pas opéré sans de sérieux obstacles.

D'abord, nous aurions dû posséder un kayac (I), puisque de larges crevasses se formaient très rapidement à cette époque de l'année. Or, nous n'avions pas d'embarcation de ce genre et nous ne disposions guère du matériel nécessaire pour en construire. D’un autre côté, les icebergs utilisés comme repères à l'aller auraient changé d'orientation sous l'effet de la dérive et seraient devenus méconnaissables.

Le navire aurait pu dériver dans une direction autre que certains iceberøs utilisés comme rcpères et, dans ces conditions, devenir complètement introuvable.

Quant à donner un rendez-rous au personnel resté à. bord de la Belgica cu un point du globe dont on aurait fixé rigoureusement les coordonnées géographiques, il n'y fallait pas songer davantage. Ce programme de campagne nous aurait astreints à emporter sur la ban. quise des chronomètres, un sextant et un horizon artificiel, que les plus légers incidents du royage pouvaient mettre hors d'usage.

La Belgica étant entraînée par la banquise, le personnel du bord dcvrait lui-même rester sans cesse en relations avec le point đu globe choisi; en fin de comptc, nous eussions été tous éparpillés sur la banquise!...

Non seulement une semblable marche serait une chose insensée pour ceux qui l'entreprendraient, daus les conditions spéciales oì nous nous trouvions, mais encore elle compromettrait la sécurité générale en réduisant encore l'cffectif du personnel, déjà trop restreint.

Et elle ne foumirait aucun résultat si, à ce moment, la banquise dérivait vers le Nord plus rapidement que nous n'avancions vers lc Sud.

(I) Le kayac est une frèle embarcation dont les Esquimaux font usage 


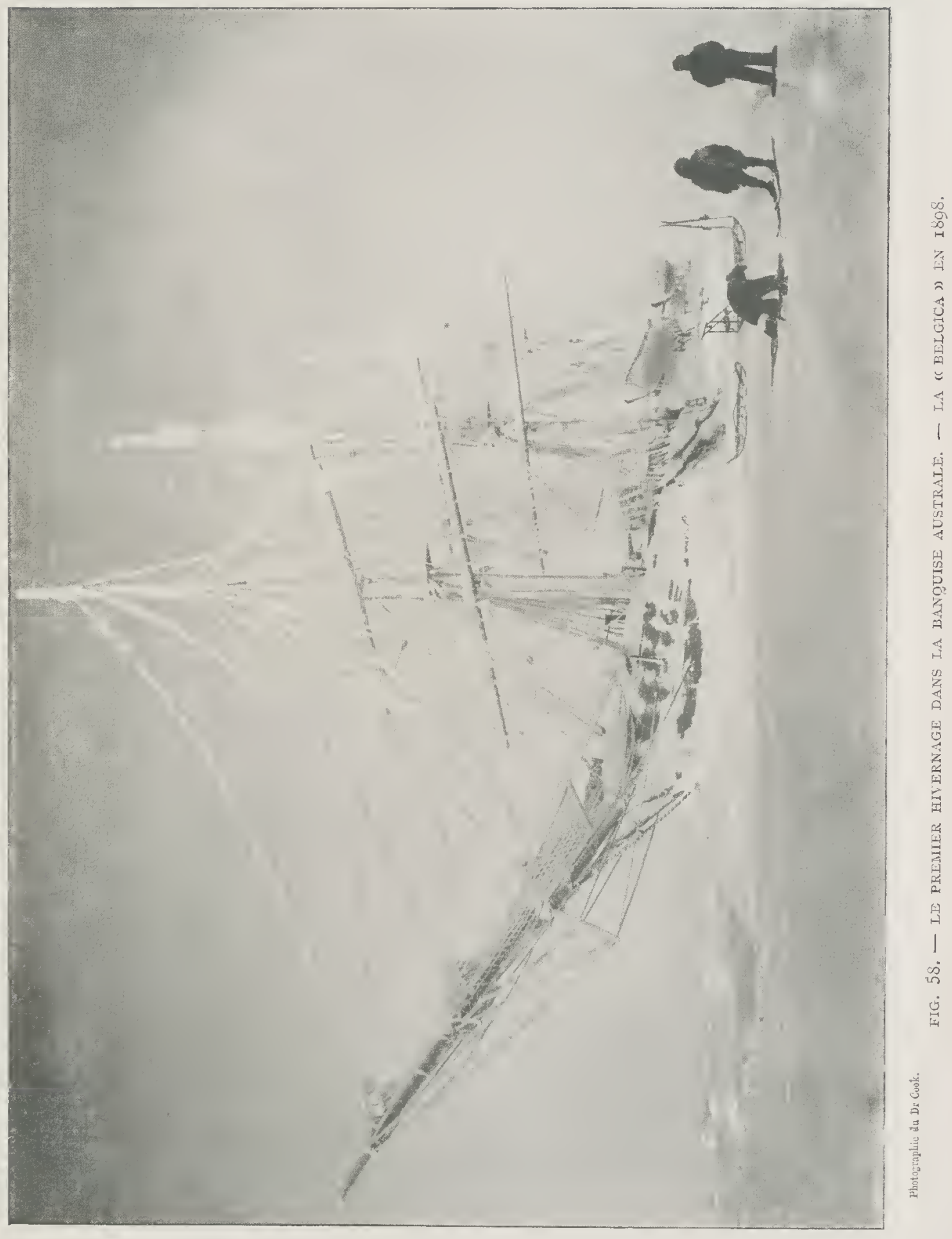





\section{$-271-$ \\ CHALITRE XXXII.}

\section{Tristesse et sourire.}

Le 7 aoit, au moment où l'équipage se levait, le matelot X... 1rúsentà à Van Irysselberghe un papier sur lequel il avait éerit ces mots: "Je n'entends plus, je ne sais plus parler! "Van Rysselberghe, ébahi, crut d'abord à une mystifieation et posa au matelot un certain nombre de questions; mais, voyant que eclui-ei demenrait impassible, il se rendit en hâte auprès du docteur.

Cook, ayant exaniné longuement ee nouveau malade, déclara que le matelot entendait parfaitement et samait parler, s'il le voulait, mais qu'il avait le cerveau atteint et 'qu'une crise aiguë pouvait se poduire d'un moment à l'autro. Il ajoutait que le mal serait peut-être passager.

Une garde spéciale fut done organisce pour surveiller diserctement le matelot, même la nuit.

Cet incident nous affecta tous péniblement. Non seulement nous devions craindre les éléments conjurés eontre nous, mais eneore cet lomme irresponsable de ses actes.

Ce même jour, tout le monde à bord ressentit d'une façon plus aiçuë les effets de l’anémic polaire. Nous avions espéré que le soleil, cn reparaissant, nous apporterait la guérison. Or, si j'avais la joie d'ètre eomplitement rétabli, il n'en était malheureusement pas de même de la plupart de mes compagnons; au contraire, ils devenaicnt chacue jour plus lás et plus faibícs.

Le 8 aoui, Johansen ef Knudsen ont les jambes fortement gonflies ot les batements de leur eour sont fort irréguliers : ils ont jusqu'à 150 pulsations à lá minute.

Par esprit de contradietion peut-être, le pouls d'Aretowslí s'est ralenti d'ume fargon triss inquiétante ( 40 à 48 à la minute); de Cicrlaehe 
c'est le docteur qui nous tond et nous moleste pár la mème occasion : grands coups de ciseaux, arrachcments à la tondeuse, laquelle, graissée d'huile et le pétrole, nous empeste l'occiput! Parfois aussi, en véritable commerçant qui, n’ayant pas de concurrent, craint peu de perche ses pratiques, il taille les cheveux cl'un côté et refuse de tailler de l'autre... se payant ainsi nos têtes!

Ce soir, nous avons joué au whist. Comme nous n'avons pas d'argent, chacun de nous clispose d'une bourse de haricots. On commence par jouer raisonnablement, puis l'enjeu monte à des sommes fantastiques. Alors, la débâcle, lá fálllite pour plusicurs's! Aussitòt, nos instincts civilisés se réveillent: nous n'avons plus de haricots, mais qu'importe! nous lançons du papier: "lion pour cent mille haricots ! " - "Bon pour un million!" - "Bon pour un milliard! " - Et, naturellement, plus nous devenons cniagés joueurs, plus nos spéculations parodient celles de la haute finance...

Mais tout lasse... ()uelques jours plus tard, nous ne tronvions plus d'agrément à ce jeu. Nous décilàmes donc de déchirer tous les bons et de rendre les haricots "fonds de roulement "a de (ierlache.

I.e lendemain de ce vote, la loi contre les jeux fut promulguéc et appliquée. Je fais donc remartuer que les membres de l'expédition antarctique belge ont été, en r\&og, les promoteurs de ce gonre de loi. Cetle gue nos Chambres viement de voter entie à peine en vigucur.

Le résultat de cette loi fut déplorable: Nichotte se hàta d'utiliser dans la cuisine les haricots qui avaient circulé un pou clans lous les coins, et, durant une semaine, il nous servit des fayots à prescpue tous les repas!

Le is aoht. - La question des vêtements à réparer commence à nous donner pats mal de tintouin : les uns sont fortenent usés, les autres rétrécis pál les laváges. Riocovitza, si ingénieux en tout, se montro asse\% pictre talilleur: au début, il recousait les boutons manquants et ajustait des pièces; maintenant, il ne s'occupe plus des boutons et ferme les trous avec un morceau de cuir. (Ce n’est pas beaucoup) plus difficile à coudie et c'est bien plus solide. Son pantalon tel (puel 
éprouve de vives pressions dans la tête, près des tempes; Cook et Racovitza languissent. Ce dernier, qui jadis arait une physionomie des plus sympathique, est devenu franchement hideux. Dobrowolslii s'affaiblit à vue d'œil et Amundsen ainsi que Mélaerts souffrent du coeur... J'étais redevable, je crois, de la chance qui me farorisait à la quantité de viande fraîche que je consommais journellement. Wichotte avait imaginé une préparation toute particulière, enlevant à la chair de phoque son goùt d'huile si désagréable : aussi, dès que j'eus constaté la force que me donnait cette nourriture fraîche, j’en fis une consommation énorme.

Malheureusement, plusieurs d'entre nous ne parvenaient pas à en ingurgiter un morceau; Mélaerts, Van Rysselberghe et Dobrowolsli étaient de ceux-là; de Gerlache saisissait aussi toutes les occasions possibles de ne pas manger son phoque; mais, sur notre reproche amical, il avalait couragetisement sa part.

Le II woút. - A... s'est enfin décidé à parler! Il a la manie des inventions et, à ce point de vue, on pourrait même le trouver très amusant, si les circonstances n'étaient aussi pénibles. Après ces quatre jours d'une étroite surveillance, Cook a reconnu que le matelot est atteint de crise d'hystérie, ne présentant aucun danger. L'équipage est toujours aussi éprouvé. Cook nous dit que si nous devions subir un second hivernage, plusieurs d'entre nous succomberaient certainement.

Le I2 aout. - Depuis notre excursion sur la banquise, le temps nous avait empêchés d'aller reprendre le matériel que nous avions dù abandonner sur notre îlot flottant. Ce matin, le ciel étant plus clément, nous sommes partis à la recherche de nos bagages et les arons rapportés dans la soirée.

Le I3 aout. -- Aujourd'hui, grande séance chez le coiffeur et le barbier! Racovitza, lui, se tire d'affaire tout seul, et fort adroitement, ma foi! Cook laisse croître, jusque sur ses épaules, sa blonde chevelure fine et soyeuse, qu'il retient au front, par un cercle de ruban. Mais les autres et moi, nous sommes incapables de nous passer de figaro: 
cst un véritable poc̀me! La question du linge ne le préoccupe pas non pius outre mesurc. Il a converti en jours le temps probable que nous resterons cncore dans la banquise - cn admettant que nous

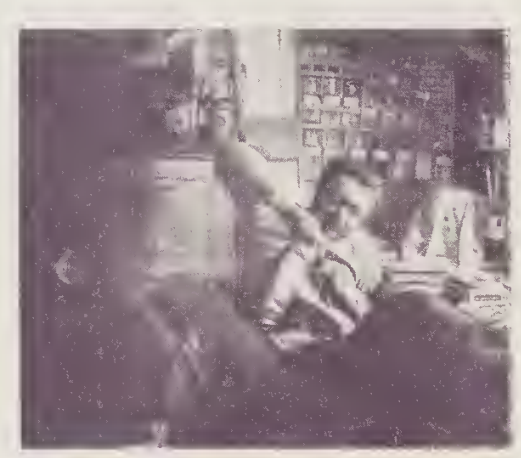

I'hut in tor couk.
IIG. 50 .

RACOVITZA CORDONNIJR. soyons dégagés cette année : il a divisé ce nombre de jours par le nombrc de chemiscs, de caleçons, de gilets qüil possède, et a détcrminé ainsi qu'il devait porter une chemise quinze jours, un caleçon dixhuit, ctc. Il envoie à fond de cale le linge porté, et, si nous ne sommes pas déliviés en temps roulu, il fera remonter le tout et cxécutera une lessive sérieuse.

Comme il roulait doubler le nombre de ses bas, il les a coupés à hauteur du mollet pour en former des chaussettes; puis, liant avec une ficclle l'extrémité des morceaux de jambes enlevés, il s'est fabriqué ainsi de nourelles paires de chaussettes. Il se confectionne enfin une superbe paire de bottes!

Chacun cie nous a d'ailleurs un système particulier pour éviter de faire la lessive. Dobrowolski ne change de linge que lorsqu'il n'y a plus moyen de faire autrement. Il transporte alors les objets sales dans la màture, comptant sur la ncige et lc girre pour les rafraîchir! Comme, au bout d'un certain temps, il finit par s'aperceroir que la neige ne lavait rien du tout, il se déciđa à faire la lessive comme les autres... mais avec quelle répugnance!

Cooli change tous les huit ou dix jours et, lorsque son stock est épuisé, remct le linge qu'il a porté quelque temps auparavant : cela donne l'illusion du changement.

Lc système d'Arctowsli est celui d'un vrai savant : s'il sait ou tout se trouve

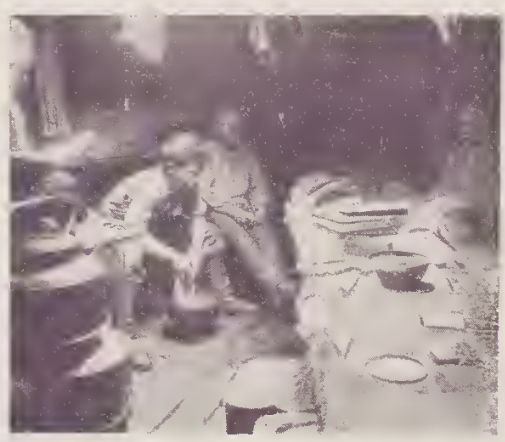

i) o: du 1): Cook: IIG. 60. - 1.A LISSIIE. 
dans son laboratoire, en revanche il ignore cc qu'il posscide dans ses malles. Parfois, cn cherchant un document, quelqucs chemises ou quelques gilcts lui tombent sous la main. Sans perklre de temps, il se rafraîchit plusieurs fois en huit jours; puis attend, pendant des semaines, qu'un hasard heureux vienne lui incliquer d'autres ressources.

Quant à de Gerlache et moi, je dois avouer que nous sommes terriblement gàtés : le brave Michotte lave ct entretient tout notrc linge et, avec une attention pleinc dc clélicatesse, profite de nos moments d'absence pour ranger le tout dans notrc armoire.

Le I6 août. - Un incident asscz inattendu s'est passé aujourd'hui. Racovitza prenait la tcmpérature d'un jeune phoque. A cet effet, on avait, non sans peine, ligoté l'animal sur une pièce de bois; puis notre ami lui avait placé sous la queue un petit thermomètre. Conme il attendait que l'instrumont ait eu le temps de marquer la température, lc phoque poussc tout à coup une espèce de grognement et... avale le thermomctre!... On s'imagine la péniblc surprise de notre naturaliste! Cependant, il ne perd pas son sang-froid : il fait chercher un nouveau thermomètre et, cette fois, prend la précaution de l'attacher à une ficelle avant dc le confier au phoque!

Le I 7 aoùt. - Michotte nous a fait, ce matin, un café détestablc: il paraît que le sac s'cst déchiré au dernier moment. En présence de la consternation générale, j'annonçai que j'allais réparer le désastre.

Je possédais, cn effct, dix flacons d'extrait de café, que m'avait offerts ma future belle-maman, à la veille dı départ d'Europe. Ces flacons, de marques différentes - anglaise, française et belge — prorenaient d'une des promicres maisons d'Anvers. Je les avais conservés jusqu'alors, les réservant pour les jours cle disettc. J'en pris donc un de marque française et, avant de quitter ma chambrc, je lus avec soin les indications suivantes :

"Prendre un demi-litre d'eau bouillante et verser unc cuillerée à bouche d'cxtrait de café. Aussitôt l'arome se dégage, et l'on a 
un excellent café, qu'on peut sucrer au goût du consommateur. " $\Lambda \cdot B$. - On remplacera arantageusement l'eau bouillante par du lait très chaud. )

Rentré au carré, j’attendais l'eau commandée à Michotte, tout en escomptant déjà les félicitations dont on allait m'accabler.

Enfin, voici la bouillottc. Alors, contrefaisant la roix de mon

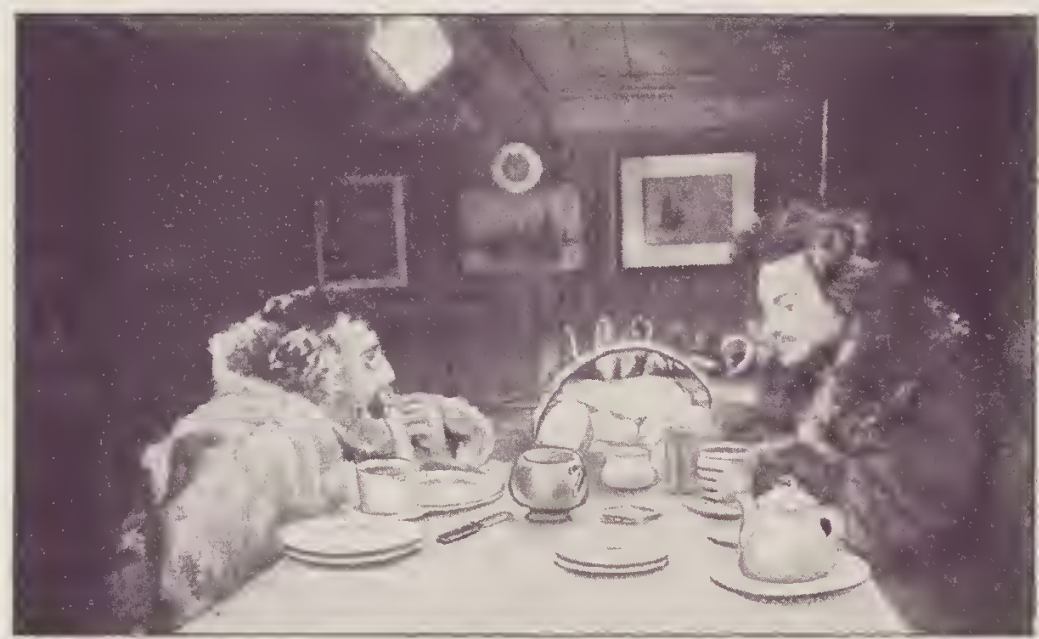

Photogtaphìe du ]

ATUNDSEN.

I.IG, 6I.

IACOTITZA.

IE PREMIER DEJIEUAER,

ancien professeur de chimie, lorsqu'il nous expliquait ses expériences — qu'il ratait d'ailleurs toutes très conscicneieusement - je détaillai ma préparation :

"Vous le voyez, Messieurs, je prends un demi-litre d'eau bouillante, j'y verse une cuillerée à bouche de cet extrait remarquable : aussitôt l'arome se dégage et vous avez... "

1)e stridents éclats de rire me coupent la parole, ear une odeur de mauvaise chicoréc cmpeste toute la chambre!

Je bondis. Comment! Déjà un tour de belle-maman! C'cst trop tôt, ce n'est pas possible. Je prends ma tasse et... mon courage à deux mains pour gouter le breuvage. 11 est infcet! 
Alors, coup sur coup, j'essaye les deux autres marques, mais toujours avec le même résultat découragcant!

A dater de ee jour, l'expression " c'est de l'extrait de café ") serrit à désigner toutc odeur particulièrement désarréable! de Gerlache seul eut la générosité de se taire : sans doute, parce cu'il avait encore les lijoedbollers sur lá conscience!

Le Io aouit. - Lc commandant se sent tris aecablé. Cook l'examine longuement et ne me cache pas que, si les douleurs de tête continuent, de Gerlache sera atteint de troubles nerveux très sérienx. I1 prescrit la viande fraiche et le plus d'exercice possible au dehors. Je suis navré de ces tristes nouvclles. de Gerlache, lui, semble calme; il s'efforce de suivre les eonseils de Cook. Je passe avec lui la plus grande partie de la journée, en tàchant de le distraire.

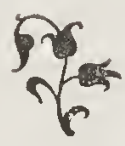




\section{$-258-$ \\ CHAPITRE XXXIII.}

\section{Projets.}

Le 20 août, de Gerlache me fait savoir que je peux disposer de l'ancienne cuisine pour mon usage personnel. J'en suis ravi : cette chambre est plus grande ct la fenêtre donne sur le pont.

Je commence aussitôt mon déménagement; Mélacrts et Johansen ont la gracieuscté de m'aider. I1s peignent mon nouveau logis avec de la belle couleur blanche, qu'ils viennent de découvrir dans la cale. Je profite de tout ce remue-ménage pour faire placer mon lit un peu moins proche du plafond!

Aujourd'hui donc, je vois tout cn rose. Je devrais dire plutôt en couleur espérance, car j'ai sorti mes beaux rideaux et ma courtepointe en satin vcrt-de-mer, ou courent les petits lézards d'or. Ils ornent à merveille mon nouveau home.

Et, toute la journće, nous travaillons avec acharnement, comme si j'avais cn vue une réception grandiose!

Le 22 août. - Je me suis occupé, aujourd'hui, du rapport que j'adresse à de Gerlache sur le projet que Cook, Amundsen et moi avons formé d'aller en reconnaissance, l'année prochaine, à la 'Terre Victoria. De là, nous tenterions une marche forcée vers le Sud, dans l'espoir d'atteindre le pôle magnétique austral. Pendant ce temps, de Gerlache croiserait dans la mer de Ross jusqu'à la fin de l'été, époque à laquelle il nous retrouverait au cap Gauss. Dans le cas où nous n'y serions pas, il passerait l'hiver en Australie et retournerait nous attendre au cap Gauss, l'annće suivante. Dans tous les cas, en prérision d'un hivernage ou d'une attente forcće au cap Gauss, nous y installerions un campement, un canot et un matériel scientifique important, tandis qu'une station secondaire de secours avec grand canot démontable serait également établie au cap Adarc. 


$$
-d
$$



Afin de pouvoir cxécuter notre programme, il a été dćcidé que Cook fournirait à ses frais une partic du matéricl de marche, Amundsen unc partie du matéricl de campement et moi la plus grande partic des instruments de précision.

Mon rapport cxpose done le but scientifique de l'expédition et son utilité; il traite de la question des voies et moyens pour atteindre le pôle magnétique austral; enfin, il contient un devis estimatif des frais qui incomberaient à l'expédition antaretique belge. Cc deris a été établi de concert avec Cook et Amundsen.

de Gerlache, ayant $1 u$ mon travail avec soin, sc rallic à nos conclusions, tout en faisant ses réserves sur le chiffre de la dćpcnse. Il s'cnsuit donc, entre lui et moi, une correspondance assez rolumineuse sur cette question, correspondance nécessaire dans tous les cas analogues, afin d'éviter tout malentendu.

Le principe même de la campagne étant adnis, Cool, Amundsen et moi en parlons tris longuement, chaque jour. I)e là une très licureuse diversion dans notre vic commune, non seulcment pour les intéressés, mais pour nos compagnons. I.équipage même sc passionne pour nos projets, ct ces braves gens qui, à l'heure actuelle, sont à moitić morts viennent encore mettre généreusement à notre disposition ce qui leur reste de forces.

Le 2.3 anut. - I a santé d'Aretowski est peu satisfaisante. I'appétit demeure bon, mais il mange un tas de choses qui lui sont nuisibles. 11 désarme le docteur par son sang-froid : si l'on sert un plat dont il doit s'abstenir, il commence par avaler, coup sur coup, quatre et même six pilules destinées à combattre préventivement le mal; puis il se scrt aussi copieusement que la ration lc permet. Arctorsli n'est pourtant ni gourmand, ni gourmet, ainsi qu'on va le voir.

Discutant un jour avec Racovitza, il lui soutenait que le beurre est bien moins nourrissant ct agréable de goùt que le saindoux. Le prenant au mot, nous avons prié de Gerlache de nous en remettre unc boîtc, qui fut placée, à table, devant Arctowslí. Au dincr suivant, 
notre ami s'en fait une tartine, qu'il ingurgite sans trop faire la grimace. Racovitza, piqué au jeu, s'empare de la boîte, la vide aux trois quarts et $y$ introduit une égale quantité de vaseline, de bello vaseline blanche destinée à ses préparations. Au souper suivant, Arctorvski, préoccupé par son travail, mange distraitement plusieurs tartines de vaseline. Le lendemain, même comédie et ainsi de suite, pendant plusieurs jours. Or, chose étrange, Arctowski ne ressentait aucun malaise!

Bref, à la fin de la semaine, la boîte allait être vide. Arctowslí vante à nouveau les propriétés du saindoux. Sans mot dire, Racovitza se rend au laboratoire et en rapporte un énorme pot de vaseline, qu'il place devant Arctowski. En un instant, ce dernier comprit tout; mais, loin de se fàcher, il s'amusa de la plaisanterie, avec la meilleure grâce du monde. Il se portait d'ailleurs beaucoup mieux! Avis aux médecins : il y a là peut-être une idée à creuser ....

Le 24 aout.-Depuis que nous consommons tant de chair de phoque, nous leur faisons une guerre continuelle, chaque animal ne donnant pas plus de trente à quarante kilogrammes de bonne viande. Dès qu'un phoque est tué, il faut le dépecer tout chaud, sinon il se congèle et derient tellement dur, qu'on ne peut plus le débiter qu'à la hache, - encore la chair vole-t-elle par petits éclats.

Or, ce matin, nous avions abattu cinq phoques, et, comme le massacre avait eu lieu loin du bord, tous les hommes étaient réquisitionnés pour le transport de la viande et de la graisse. Le matelot X..., dont les crises d'hystérie ne sc renouvelaient plus, portait une charge d'une dizaine de kilos, lorsque, tout à coup, il revint vers moi, épouvanté : "Capitaine, s'exclamait-i1, il vit! il vit encore! "

Le morceau de viande qu'il me montrait, appartenant au dos de l'animal, subissait encore, en effet, des contractions musculaires, de sorte que le brave X... s'imaginait que le phoque vivait et souffrait encore !

L'après-midi du 24, nouvelle correspondance, avec de Gerlache, au sujet de notre campagne à venir. Pendant ce temps, Cook et 
Amundsen ne restent pas inactifs: le premier retaille nos vêtements de fourrure, afin de les rendre plus pratiques pendant les longues marches; le seeond, aidé par Johansen, travaille à un grand sae de couchage, dans lequel nous pourtons dormir à trois.

La question des vêtements et du sae de couchage est d'une importance extrême : rien ne doit être laissé au hasard.

Le caleçon, la ehemise et les bas seront de laine; les bottes, très larges et en fourure, doivent être tapissées intérieurement, ainsi que nous l'avons dit, d'une eouche d'herbe norvégienne appelée sénégrasse. La eulotte, qui descend un peu au-dessous du genou, sera munie à sa partie inférieure d'une coulisse permettant de régler le clegré de circulation de l'air: préeaution indispensable si l'on veut éviter que la transpiration du corps ne s'aceumule à l'intéricur du vêtement pour y former des glaçons, au moindre coutact de l'air, La vareuse (l'anolak), très ample, sera de même nature que la eulotte. Nous nous fabriquerons ainsi trois complets : un, en laine moelleuse et légère, pour les froids ordinaires; un autre, en toile, à revêtir en temps de neige au-dessus du précédent; enfin un troisième, en fourru1e, que l'on porte poil en dehors par les grands froids, et poil en dedans - e'est-à-dire en retournant le vètement - par les froids extrêmes.

Même prineipe pour le sae de couchage qui est en fourrure. On s'y introduit avee un costume de laine et on se garde bien d'y mettre la tête, attendu que l'air expirć par la bouche s'y convertirait en glaçons.

Cook s'oceupe aussi de modifier la tente que nous avons expérimentée sur la banquise. Je ne puis dire que je me rallie enticrement à ee modèle; mais, comme je n'y relève auem défaut sérieur, je n'y fais pas opposition.

Ainsi le temps s'écoule et nos projets s'échafaudent.

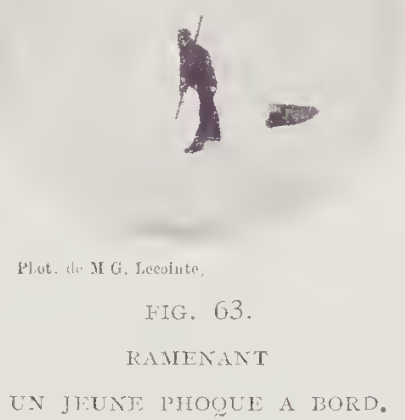




\section{CHAPITRE XXXIV.}

\section{Deux matelots égarés sur la banquise.}

\section{Les rats. - La tonite.}

Le 25 aout. - Le soleil est toujours bas à l'horizon; il se montre très rarement. Ce matin eneore, le vent vient du Nord et l'épais brouillard qui l'aceompagne généralement enveloppe toutes choses. Sur la banquise, cette lumicre diffuse produit d'étonnantes illusions d'optique : les hummocks, ne projetant aucune ombre, ne s'aperçoivent que de trìs pris, tandis que les objets de rebut, qui se trouvent jetés non loin du bord, paraissent être à une distance de 200 à 300 mètres.

Impossible, par ees jounnées de brume, de s'éearter de la Belgica. Les matelots le savent et pourtant aujourd'hui Koren et Van Mirlo se risquent à une promenade, sans prévenir personne.

Lorsque, rers 5 heures, leur absenee est remarquée, une certaine inquiétude règne à bord : il fait déjà très obseur et le brouillard empêehera, eertes, les deux matelots d'apercevoir les fanaux placés dans la mâture comme signal de rappel.

Vers 6 I/2 heures, plus de doute pour personne: ou Koren et Van Mirlo ont été vietimes d'un accident ou bien ils se sont égarés.

Deux équipes sont formées sans retard : Amundsen et moi explorerons le seeteur compris entre le Sud-Est et le Nord-Ouest; Arctowsli, Cook et 'Tollefsen, l'autre secteur.

Chaque équipe emporte une trompette d'alarme, un fanal allumé et une boitte de secours.

Nous eonvenons de signaux spéciaux aree le bord, où l'on a hissé trois grosses lanternes et d'où, à intervalles réguliers, un matelot sonne du elairon.

Nous emportons une petite boussole, mais eomment s'en servir, 
puisque nous ne pouvons distinguer aucun point de reprie? I Bicntòt même nous perions de vue les feux de la Belgica et ne percerons plus la direction des sons du clairon.

Nous avançons cependant, cherchant sur la neigse un indice, une trace de pas. En roici une, qui semble fraiche: nous la suivons et. apres de multiples zigzags, elle nous conduit au bord d'un lac list-ce là que s'est dénouć le drame?...

Nous foutlons la banquise, nous jetons des appels : rien que le silence! Nous croyons qu'il est prudent de revenir sur nos pas, lorsque soudain nous distinguons une lucur tres loin a l'horizon. Se peut il que nous soyons si éloignés de la Belgica? Nous nous diriśneons de cc côté et, en un instant, nous rejoignons la lueur, qui n'est autre que ic fanal du groupe Cook et Arctowsli. Ils n'ont pas été plus heureux que nous; ils sont déjà retounés une fois à borel prentre des nouvelles. 1ls nous indiquent la Jielgica du côté de l'Est, álors que nous la croyions au Sud-Ouest. I)one, les petits écarts de lá route suivie nous ont déjà fáit dévicr d'un angle de route de plus de go dergrés!

Iin présence des difficultés insurmontables qui s'opposent à nos recherches, nous retomrnons à bord. Le commandant décicle que le lendemain une équipe formée par de Gerlache, Cooli, Racovitza, Tollefsen et Van liysselberghe partira, dis la premicre heure, tandis que je ferai préparer un materiel de campement, qui serér porté auprés d'un iceberg déterminé, où l'équipe pourra passer la nuit.

Chacun va done se concher, mais une inquiétude continuelle nous tenaille. I a nuit n’est pas froide, heureusement : $8^{\circ}$ sous \%éro. De plus, vers 3 heures, la brume se dissipe en partie, cévoilant la lune, qui jette un pâle celat sur la banquise.

15 licures du matin, au moment ou l'écpuipe de recherches wa partir, Koren ct Van Mirlo apparaissent tout à coup à nos yeux!

líen que trés mécontent de leur désobéissance, de Gerlácle ne tarte pas a leur partonner, car, cn somme, les deux jeunes gens ont falit preuve d’une réelle prisence d'esprit. S'étant, en effet, trop éloignes du borl, ils n’avaient pas tar dé à constater l'impossibilité de regagner 
la Belgica. Alors, se rappelant la position du navire par rapport à la direetion du vent au moment de leur départ, ils araient jalonné des bloes de glaee dans cette direction, afin de la retrouver le lendemain matin; puis, ils araient élevé un mur de neige pour s'abriter contre le chasse-neige. Ils souffrirent eruellement de la faim et du froid, ear ils ćtaient très légèrement vêtus. Peu à peu, le sommeil les gagnant, Van Mirlo arait eu le tort de eéder à la fatigue, en s'asseyant sur la neige. A son réveil, il arait en vain essayé de se lever : il était soudé à la glaec. Alors, nerveusement, avec un grand effort, il s'était dégagé, mais, ô eatastrophe! en abandonnant à l'ennemi tout le fond de... sor1 indispensable!...

Et, pour achever d'attendrir le commandant, Van Mirlo, se tournant à demi, exposait la nudité cle... son malheur.

Le 28 aout. - Oh! les rats! les rats! quelle engeance!

A Punta-Arenas, eomme nous étions amarrés eontre la Martha, pour embarquer du charbon, quelques rats, à l'esprit aventureux, avaient clandestinement pris passage pour les régions polaires. Peu nombreux d'abord, ils n'avaient pas tardé à faire souche, puis leurs petits, se multipliant à leur tour, avaient fini par envahir tous nos bas-fonds. Pendant toute la journée, ils se contentent de s'offrir, dans le magasin aux vivres, des repas pantagruéliques; mais, le soir venu, organisant des "evening parties ", ils exécutent mille "entrechats" sur les conduites à vapeur, sur les échelles et jusque dans les foyers de la ehaudière. S'enhardissant davantage encore, dans le calme profond des nuits, ils montent à l'étage, cireulent dans le carré, sur la boîte des ehronometres, dans les chambres et parfois mème poussent l'insolence jusqu'à gambader sur le nez des dormeurs!

Raeovitza et Cook sont surtout l'objet de leur sympathie, de sorte que, eertaines nuits, nos camarades organisent des chasses furibondes.

Cette nuit, particulièroment, le vacarmc était effrayant. Furieux de ce que les rats ne se laissaicnt point prendre dans les pic̀ges ingénieux, fabriqués en collaboration avee Van Mirlo, nos camarades renouve- 
lèrent le truc du chat enfariné. Ils firent semblant de dormir et, lorsqu'ils entendirent les rats réunis au carré, brusquement ils en fermèrent la porte. Puis Cook fit un long tuyau de gros papier brun qu'il plaça dans un coin de la chambre. L'n rat traqué s'y étant réfugié, Cook fermait le tuyau aux deux extrémités, tandis que Racoritza assom-

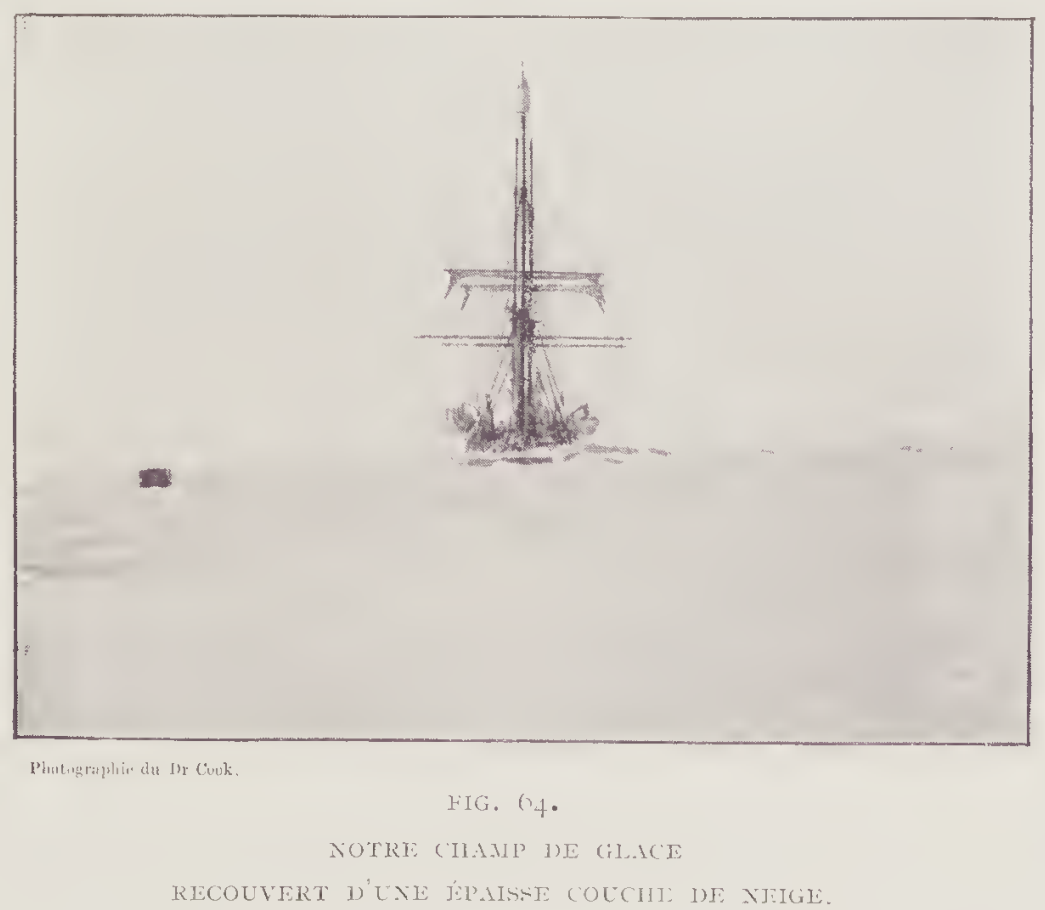

mait le prisonnier. Un grand nombre de rats subirent le même sort. Nlalgré cette hécatombe, qui se renouvela de temps à autre, les rats n'en devinrent que plus nombreux; ils évitaient davantage le carré, mais pullulaient dans lá machine, qui leur fournissait un repaire inexpugnable.

Le 5 septembre. - La glace est redevenue très épaisse et, bien que le soleil monte chaque jour darantage sur l'horizon, la température reste très basse. La neige s'accumule donc toujours et refoule dans la mer, par son joids énorme, le champ de glace dans lequel est rivé le navire. 
Arctowski, désirant faire plusieurs cxpéricnccs, a demandé ce matin qu'on lui ouvre une tranchée dans la glace. Comme nous n'avons obtenu aucun résultat par la pioche et la scie, nous allons avoir recours à la tonite.

C'est à moi, artilleur, qu'incombc lc soin de conduirc les opéra-

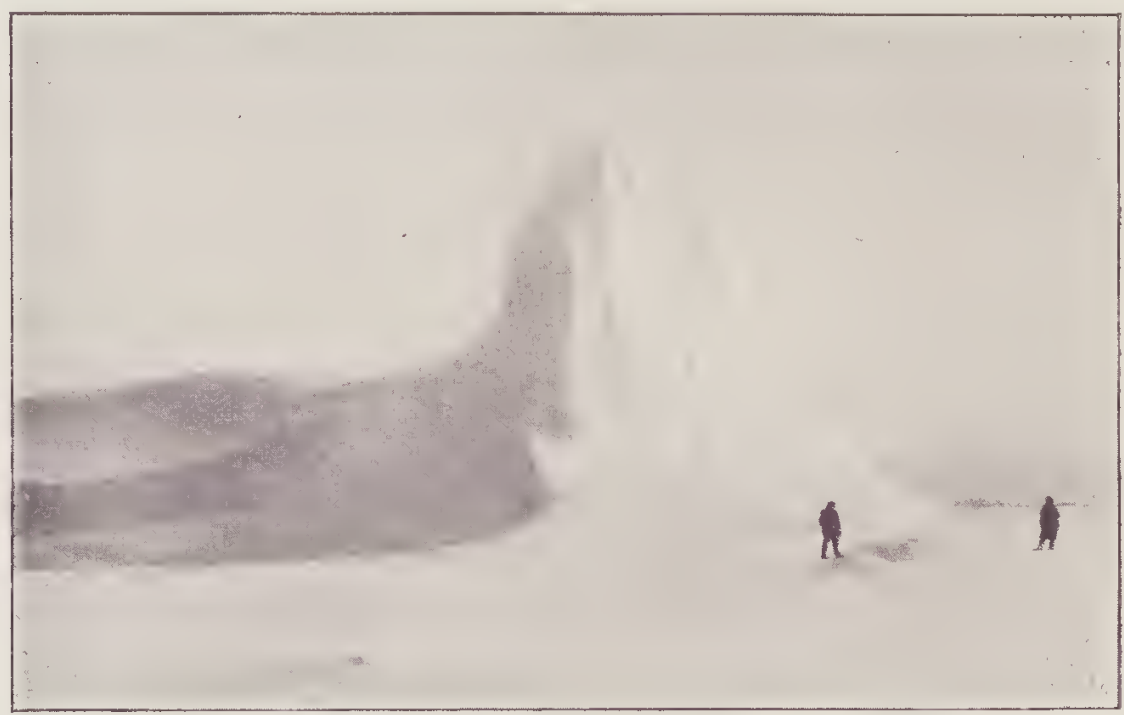

I'lutograplite thu Dr Cook.

ILL. 65 .

EN ATTINDANT LA TERRIBLI MPLOSION :

tions. J'examine donc avec soin la tonite ct je conclus qu'une grande partie est avariće et hors d'usage. Les mèches égalcment sont gelées; elles se cassent comme des tuyaux de pipe. Je m'assure de la durée de combustion par mètre courant: l'expérience me démontre que cette durćc est absolument variablc d'un morceau à l'autre.

L'après-midi, nous plaçons à une grande distance du navice I6o cartouches de tonite, amorcées par trois grosses capsules de fulminate dc mercurc; puis nous allumons unc fort longue mèche; après quoi, nous détalons à toutes jambes vers un iceberg, d'où nous assisterons à la terrible explosion!

Tandis que, haletants, nous attendons, j'annonce un choc formi- 


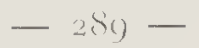

dable, une projection superbe, ete. Mes instincts clattilleur se réveillent.

Au bout rle vingt minutes, je deviens inquict: ast-ec que lexpórirnce aurait raté?

Au même moment, une petite llammo vive apparait, semblable it

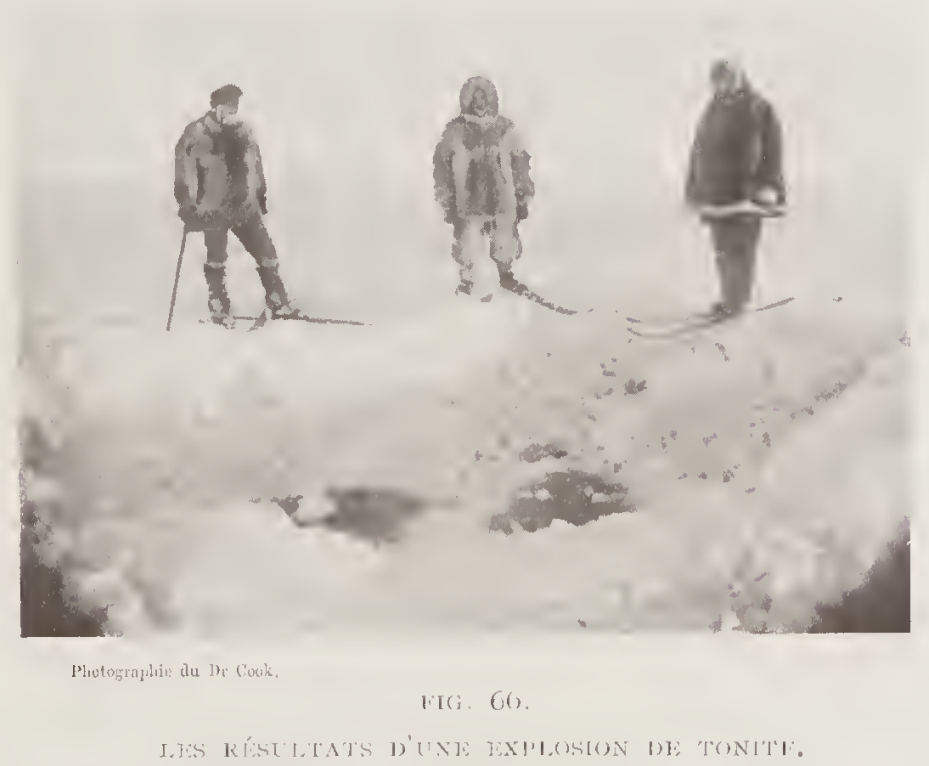

celle que produitait une boite d'allumettes chimiques ! P'uis uno assez forte colonne de fumće, puis plus rien!

Nous nous rendons sur les licux et nous constatons gue lo's 160 cartouches de tonite ont découpé clans la glace un entomnoir de deux mitres de rayon sur un mitre el dremi environ te profondeur. I.e choc a été à peu pris 1mul, cál, aux envirous de l'entonnoir, la glace est intacte.

\lors force quolibets à l'adresse de l'artilleur, qui déclate que la tonite était sans doute avariée, mais que, le lenelemain, il pronclia sa revanche.

I.c o septembre. - Eh bien, elle est belle ma revanche!

J'avais établi une mino contenant plus rle 500 cartouches, chorsiess 
parmi les meilleures. Lorsque l'amoree au fulminate a déflagré, la lonite s'est enflammée et, pendant un eertain temps, a brûlé sous la neige. Alors, nous avons vu une belle lumière blanehe, jaune, verte, puis plus rien, pas la moindre explosion! C'ćtait humiliant au possible !...

Le 8 septembre. - En présenee de ees résultats nćgatifs, je me suis dit qu'il fallait dégeler la tonite. J'en ai mis I6o cartouehes dans mon lit ct je les ai réehauffées dans mes bras, pendant toute la nuit. Je crois que le dégel est suffisant, car lcs cartouehes se séparcnt bien plus aisćment et un corps blane laiteux coule sur les bords.

Afin dc nc pas leur laisser le temps de se recongcler, je prépare une nouvelle expérience et, cette fois, j'amorce arcc cinq mèches très courtes, allumćes en mĉme temps. Prcsque aussitôt, le phénomène se produit: comme la veille, une petite flamme sort d'une cheminée qu'elle s'est creusée dans la glace !

J'ai donc perdu toute confiancc dans la tonite. Cook est le seul qui trouve un léger dédommagement à notre déception : il eomplète son vocabulairc français! Pour lui, kjoedboller désigne un mets désagréable; extract café se dit d'une odeur infeete; enfin, tonite s'emploie pour une chosc absolument ratée.

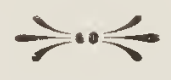




\section{CHIPITRE XXXV.}

\section{Le scorbut. - La folie.}

Le o septembre 1898 . - Ce n'est franchement pas encourageant : nous voilà presque à l'équinoxe et nous avons eu, cette nuit, $43^{\circ}$ I sous zéro! Dans ces conditions, la neige fondra-t-elle janais? Ce qui scmble un comble, c'est que la dérive nous a ramenés à proximité de la lisière de la banquise, presque à l'endroit où nous nous trourions en février dernier.

Nous avons une légère compensation à cet état de choses : aux rares occasions où nous buvons du champagne, il est ultra-frappé ef il suffit d'exposer quelques minutes à l'air les boites de fruits conservés pour que ceux-ci deviennent délicieusement glacés. Nême au carré, le champagne ne fond que lentement: de temps à autre, on peut en retirer un petit verre à liqueur !

Le 20 septembre. - de Gerlache recommence à éprouver de riolents maux de tête. Il est triste et taciturne, recherchant la solitude. Aujourd'hui, il s'est couché à six heures, sans prendre aucune nourriture. Au reste, tout le personncl est atteint d'une anémie qui va croissant : Dufour, Johansen, Knudsen, Mélaerts et Van Rysselberghe souffrent sćrieusement du cour ; Tollefsen, bien que ne présentant guère de symptômes extérieurs du mal, est, selon Cook, plus fortement atteint que les autres. Il s'isole complitement et semble en proic ì une terrible frayeur, chaque fois que des pressions se produisent. l’ourvu que nous soyons bientôt dégagés!

Le zi septembre. - I 'état-major s'est réuni, cette après-midi, sous la présidence du commandant de Gerlache. Nous avons arêté le programme des travaux de cette année et il a été décidé que la campagne, projetée par Cook, Amundsen et moi, aurait lieu l'année prochaine... si nous sommes délivrés et si nous en avons les ressoutces! 
Dans le but d'obtenir du gouvernement belge les fonds néccssaires à l'entreprise, il a été décidé que, dès le retour de la Belgica dans un continent quelconque, je partirai pour Bruxelles ct tiendrai télćgraphiquement de Gerlache au courant de la marche des négociations.

Le 9 octobre. - Quelle nuit! Nous avons ćtrenné le sac de couchage à trois places. C'est peut-être plus léger et moins encombrant de n'avoir

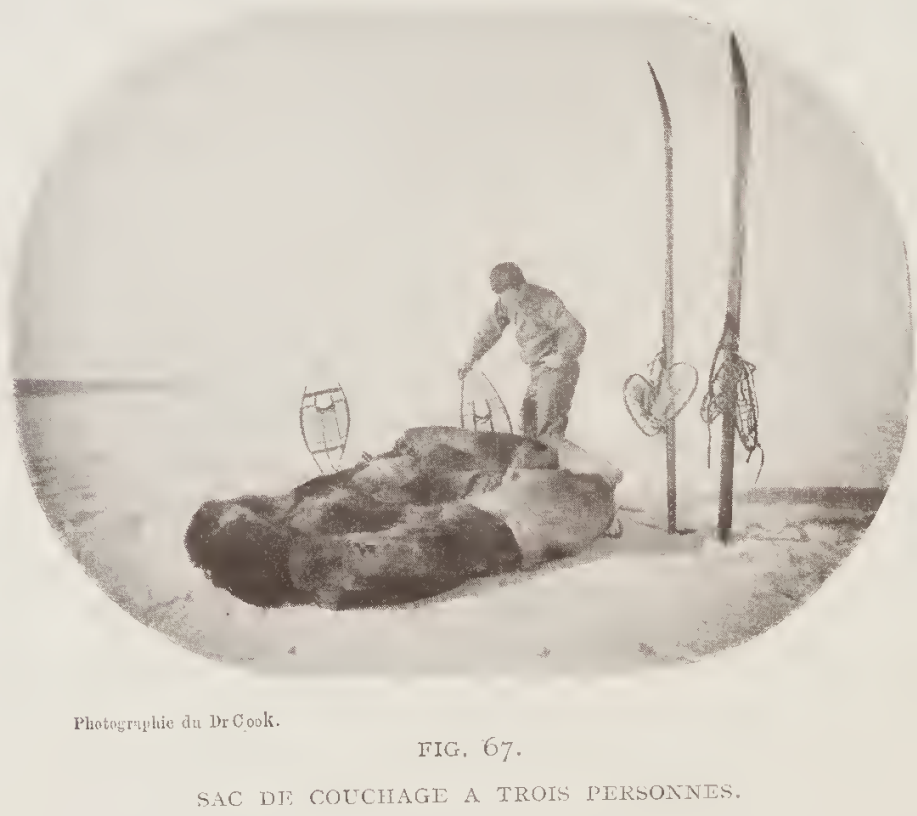

qu'un sac pour trois, mais au dormir, c'est autre chose! Dès qu'un de nous bougeait, il réveillait les autres et, comme toujours l'un ou l'autre bougeait, personne n'a dormi! Nous ne désespérons de ricn cependant: l'habitude est une seconde nature; après quelques nuits, nous dormirons tris bien, surtout par les jours de grande marche.

Quant à la tente, Cook continue à la trouver remarquable. Moi, in petto, je conserve l'impression du contrairc : je la trouve trop exiguë et pourtant je ne suis pas grand. Ce que les deux autres devront s'y trouver mal lotis!

Le I2 octobre. - Un grand nombre des membres de l'équipage 
désircnt faire partie de l'expédition vers le pôle magnétique. Cook, Amundsen ct moi examinons dans unc séancc solcnnelle les différentes candidatures. Notre choix est d'autant plus difficilc à faire, qu'il ne comporte qu'un seul individu. Il faut être peu nombreux pour ces marches rapides, afin de n'être pas arrêtés par les impedimenta. Notre choix sc porte sur Michotte; mais, comme de Gerlache désire le conserver à bord, nous remettons l'examen de la question à plus tard.

Le 15 octobre. - de Gerlache et moi sommes dans une anxiété sans nom! Cook vient de nous prévenir que Mélacrts ct Michotte préscntent tous les symptòmes néfastes du scorbut. Il nous pric de ne point communiquer cette mauvaise nouvelle, afin de ne pas augmenter la détresse morale de l'équipage Le commandant est tellement impressionné, qu'il se demande, avec angoisse, si sa conscience n'est pas responsable de tous ces maux!

Le 25 octobre. - L'état de de Gerlachc a brusquement cmpirć à la suite de toutes cos secousscs. Ce matin, Cook a cru de son deroir de lui annoncer qu'il avait une atteinte de scorbut.

Le commandant a reçu cctte nouvelle arec beaucoup de sangfroid. Le soir, nous nous sommes promenés longuement ensemble bras-dessus bras-dessous ct, comme cc bavardagc, cet ćreil dc souvenirs a paru lui fairc du bien, nous avons décidé que chaque jour nous passcrions deux heures ensemble. Cette diversion dans les idées lui a été si salutaire, qu’il a passé une fort bonne nuit.

Le 4 novembre. - Les crises de X... ont complètement cessé, mais un autre matelot a l'esprit troublé par la manie des grandeurs et par des terreurs folles. Singulicr mystère, le mot "chose " l'exaspèrc! Lui, qui ne connait pas le français, il s'imagine que "chose » signific tuer et que scs compagnons sc sont donné le mot pour l'exécuter. Il évitc le poste, puis à la nuit tombante, à peinc vêtu, sans couverture, il va sc cacher dans l'entrepont, au risque d'attraper une pneumonie! Il faut donc le surveiller de près, et c'est X..., à peine remis lui-même, qui désire se eharger de ce soin! 
Pcu à peu, le malheureux Y... devient absolument inconscient : il ne parle plus, il roule des yeux dans le vague, et la seule besognc qu'on puisse lui confier est le raelage des peaux de phoque. Encore n'avance-t-il guère dans ce travail : au bout de dix minutes, il tambourine sur la peau avec son racloir, regardant d'un air effaré dans la direction des hummocks de pression.

Si l'un ou l'autre passe près de lui, il frémit et courbe instinctivement la têtc comme pour recevoir le coup de grâce!

Paurre garçon! il nous fait pitié à tous!

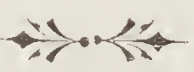




\section{$-295-$}

\section{CHAPITRE XXXVI.}

\section{Le Soleil de Minuit.}

Le 6 novembre. - Nous avons eu, en oetobre, vingt-einq journćes eonséeutives de neige. Le navire en est totalcment envahi, surtout à l'arrière, où un hummoek de pression monte jusqu'à la hauteur de la dunette.

Aijourd'hui, le vent a ehassé une telle quantité de neige sous la toiture, sur le pont, qu'on ne peut plus eireuler. L'équipage a dù travailler toute la journée au déblaiement et la moitié, à peine, de la besogne est aeherée. Ce qu'il y a de plus déeourageant, e'est le penser que si une nouvelle tempête survient, tout ee labeur sera réduit à néant.

Le 13 novembre. - Nous avons tenu, aujourd'hui, une séance plénière de l'état-major, séanee très eourte à eause du mauvais état de santé du eommandant. I)iverses questions d'ordre général ont été examinées.

Le I6 novembre. - A partir de ee jour, le soleil éelairera notre région pendant de longues semaines sans interruption. Malheureusement, l'astre n'est guère visible eneore, étant enntinuellement voilé par une brume épaisse. Pourtant, e'est bien le jour perpétuel : une même elarté diffuse règne à midi et à minuit. Les animaux reviennent plus nombreux, la banquise s'agite, des laes se forment au loin. Sont-ce les premiers symptômes du bouleversement qui amènera la déli: rranee?

Le 22 novembre. - Il est grand temps de dégager le navire, dont les flanes sont maintenant enfouis sous la neige jusqu'à la partie supérieure des bastingages.

La Belgica, ayant ćté saisie par une pression, a été soulevée et céposée sur le ehamp de glaee. Elle est assez inelinée sur tribord. 
Tout l'état-major et l'équipage creusent, autour du bâtimcnt, un large fossé. La neige est transportée avec des cuves amarrées sur des traîneaux, puis déverséc à unc certaine distance. Elle forme là un monticule sur lequel je comptc ćlifier un nouvcl observatoire.

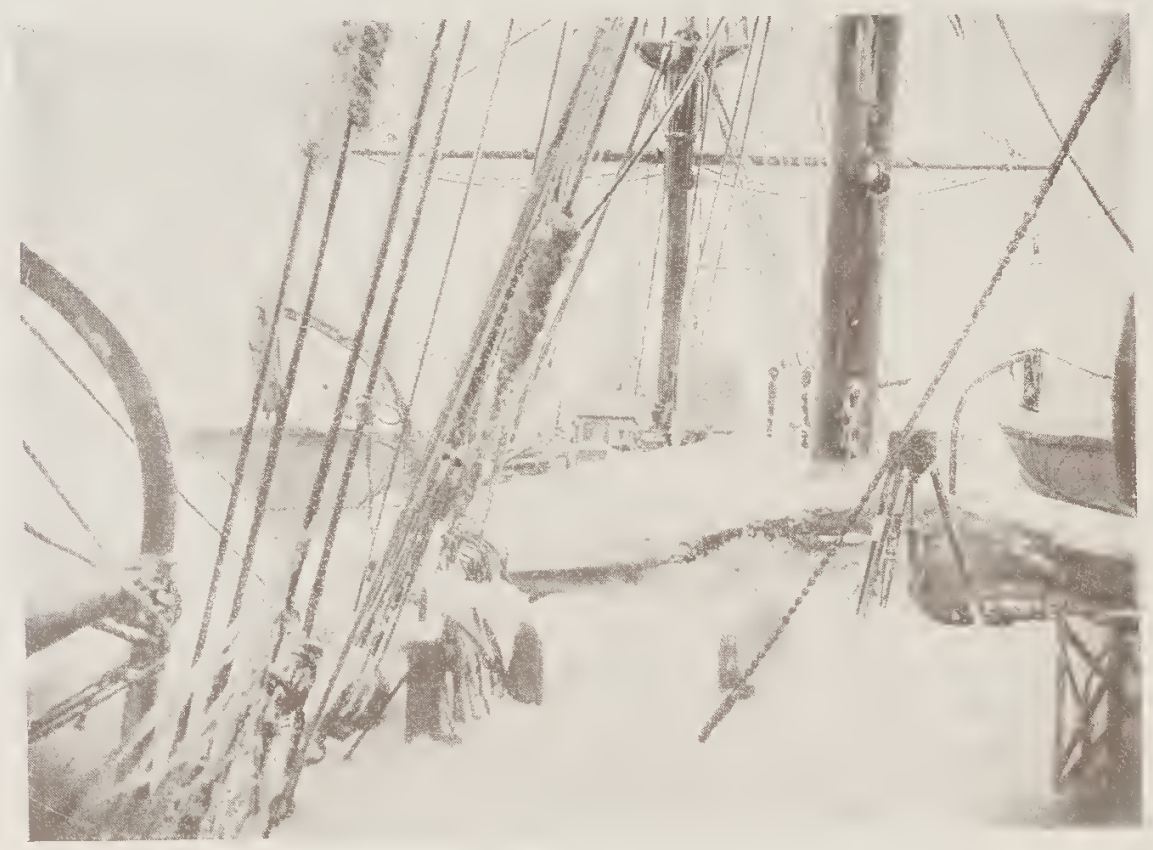

Thotographise du im Cook.

FIG. 68.

IE PONT RECOUYERT DE NEIGE.

Il est temps cffectivement de s'occuper dc celui-ci, car l'ancien local s'est transformé en un véritable réservoir. L'eau, qui s'ý est accumulét par la fonte des neiges, ne s'y recongèle plus, attendu que la toiture dc carton noir bitumé y maintient une chaleur relativement considérable.

En attendant, jobserve en plein air, ce qui n'est pas toujours agréable ni facile.

Pour éviter une seconde catastrophe de ce genre, le nouvel observatoire reposcra sur le sol de glace, sans y être encastré; de plus, il sera muni de dcux leviers qui lc rendront transportable. 
Le 23 novembre, en me levant, je ressentis dans les membres une faiblesse extrème, qui alla cn s’accentuant pendant toute la jounnór. 1,e soir, il me fut impossible de faire mes observations. Aux grants matx, les grands remides: j’ingurgitai en vingt-quatre lieures me telle quantité de beefsteaks de manchot et de phoque, que je ne tardai pas à me remettre

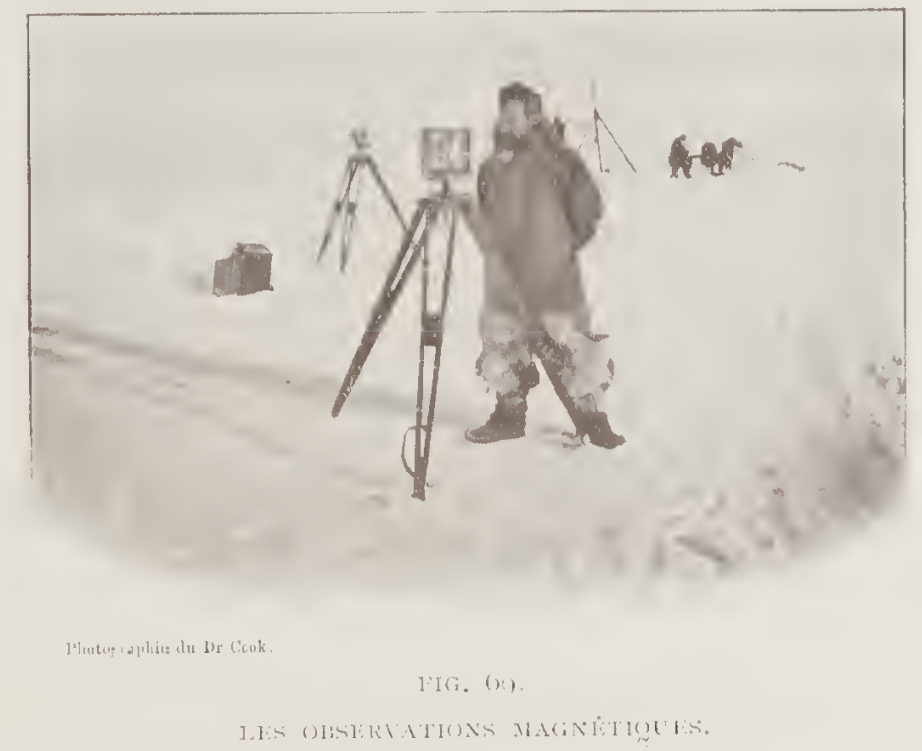

Aujourd'hui, j’ai aidé l'écuiphage à conlever les neiges. A mesure que le travail avance, le navire se redresse; on dirait memr qu'il flotte!

Le 28 notemlne. - La soiréc d'hier a été rakliense. Je travaillais trancuillement dans ma chambre, lorspue tout à coup jentendis venir du pont une stridente brabansomne. C"était Somers qui celchmit patrioti. quement la premicre appartion du soleil de minuit!

ion un instant, l'átat-major se joint à l'épuipage, sauf de (ierlache encore souffrant, mais qui a lá gracieuseté de nous cnvoyer des laftaichissements, - je devrais dire des réchaulfunents.

()uelle bonne saité! Nous oublions nos souffrances, mos redeve- 
nons jeunes: Johansen joue de l'aceordéon, Knudsen ehante, Van Rysselberghe lui-mềne fait entendre sa belle voix.

Et l'on parle du retour! MI. Somers, le seul de l'expédition qui soit marié, se sent tout ému en évoquant le sourenir de son enfant. Paurre petite qui, à l'heure présente, se eroit peut-être orpheline (I)!

Arec une joic très vive, nous pareourons la sileneieuse banquise et regardons voler les Thallassocca et les pétrels géants. Plus n’est besoin. pour lire les instruments, de s'embarrasser de lanternes que le vent éteint sans eesse, plus de lampe au earré, plus de bougie dans les ehambres : la lumic̀e, la perpétuelle lumière!

La banquise eommenee à se disloquer : les ieebergs, qui nous aecompagnaient l'hiver, se déplacent de façons très diverses ; le froid est moins piquant, le métal des instruments ne brûle plus les doigts. Oln! que rienne l'ivresse de voguer sur le libre océan! Olı ! la volupté l'aroir eneore le mal de mer !...

Le 29 novembre. - Le matelot X... continue à se montrer raisonnable. mais I... est de plus en plus troublé : hier soir, il est allé trouver le eommandant pour lui demander s'il est vrai qu'il se trouve à bord cle la Belgica. En entendant la réponse affirmative, il est devenu de plus en plus perplexe: il ne se rappelle absolument rien lu départ ni du voyage!

Le + décembre. - de Gerlaehe est plus mal depuis quelques jours; il se préoceupe de l'avenir de l'expédition et rédige un testament, en prérision du eas où lui et moi viendrions à mourir.

Cette question du droit à la sueeession du eommandant avait déjà été soulevée, mais d'une façon très inclireete, dans la séance du I 3 norembre.

Comme les fonds restants de l'expéclition cousistaient uniquement en une traite sur la Banque d'Anvers, payable en Australie, il convenait de laisser à notre suceesseur tous les renseignements nécessaires, afin de le soustraire, dans la limite dı possible, aux préoeeupations d'argent.

(1) l'endant ce temps, la petite fille de Somcrs mourait à Ostende. 
Tous avons donc signé le document suivant:

Testament. - Voulant prévoir le cas où nous viendrions à mouriv tous les deux, avant que l'expédition ait pu être menée à bonne fin, nous soussignés, commandant et commandant en second, prenons, pour ce qui concerne l'avenir de l'expélition, les dispositions testamentaires suivantes:

Nous désignons comme chef éventuel de l'expédition, N. A... et le prions de s'adjoindre comme second M. B... (I).

Le clief de l'expédition voudra bien payer, avec ces fonds, la solde du personnel et les frais d'escale.

De retour en Belgique, le chef de l'expédition ainsi que M. M... s'aboucheront arec le Comité de la Société royale belge de Géographie, i 16 , rue de la Limite, à Iruxelles, pour la destination du matériel et des collections.

Fait en simple expédition à bord de la Belgica.

$$
\begin{aligned}
& \text { Le } 4 \text { décembre i } 898 . \\
& \text { Signé }\left\{\begin{array}{l}
\text { A. De Gerlacie. } \\
\text { (i. Lecomete. }
\end{array}\right.
\end{aligned}
$$

Ce mêne jour, l'apris-midi, comme je faisais une promenade avec le matelot Yr..., il consent tout ì coup à déserrer les dents. Cook, mis au courant de ce fait, $y$ voit un heureux présage; il nous recommande, à Amundsen et à moi, de nous faire accompagner du malade, chaque fois que nous en aurons l'occasion.

Le iz récombre, après midi, Cooli et Amundsen partent à skis, pour aller examiner de pres un grand iceberg tabulaire, qui se trouve

(1) Je suplume ici un paragraphe se rapportant uniquement a la traite de la Batique d'Anvers. 
à quelques milles du navire. Comme ils comptent être rentrés pour minuit et que le temps est beau, ils sont vêtus légèrement et n'emportent pas de vivres. Chemin faisant, ils rencontrent le matelot I... errant comme une âme en peine. C'est une occasion de le distraire, ils l'emminent avec eux. Le temps est superbe, la neige très dure, les slis glissent avec rapidité.

Au bout de trois heures à peine, ayant atteint le colossal iceberg, ils découvrent une voie accessible et se hissent au sommet, d'où ils embrassent un vaste horizon. Ils s'oublient dans la contemplation du soleil, se prélassant sous ses chauds rayons: La faim les tenaillant tout à coup, ils se hâtent de redescendre.

Mais que se passe-t-il? Les champs de glace frémissent et se brisent, déterminant de longues crevasses d'eau libre. Ils s'empressent de les traverser et de contourner les chenaux.

Y..., terrorisé, suit sans mot dire ses deux compagnons, dont les craintes s'accentuent lorsqu'ils se roient isolés sur un petit champ) de glace, comme dans une île flottante. Rien à faire que d'attendre patiemment que la banquise se referme, car aucun signal, vu la distance, ne serait aperçu du navire.

Angoissé de plus en plus par la faim, Cook, qui s'est muni de son revolver, tue un phoque à bout portant. Amundsen, armé de son couteau, dépèce l'animal et se couche contre lui pour boire le sang encore chaud. Le froid devenait vif, il fallait se hater de souper, tant que l'animal n'était pas encore gelé.

Amundsen étant rassasié, Cook lui succcide; puis, après avoir élargi la plaie, offre sa place au matelot. Celui-ci, ternifié à la vue du sang, refuse catégoriquement d'en boire et déclare qu'il préfère mourir de faim.

Heureusement qu'au bout de quelques heures, les glaces se resserrant, nos amis peuvent se diriger vers le navire. I... file comme un trait; Amundsen et Cook ont peine à le suivre.

A 4 heures du matin, tous trois sont à bord, mais le matelot défaille et Cook cherche en vain un moyen rapide pour le ranimer. Se 
rappclant la thćorie que j'avais soutenue qu'un verre de liqucur est un rcmede énergique en eampagne, lorsqu'un lromme est sur le point de défaillir, le doctcur veut en essayer. Il donne au malade un demiverre à liqueur de Kirsch, que eelui-ci avale d'un seul trait. Mais à peine l'a-t-il absorbé, qu'il se précipite dans ma chambre, me dénonçant Cook et Amundsen comme des empoisonneurs.

Réveillé en sursaut, il me faut quelques minutes arant de me rendre compte de la situation.

Laissant $\mathrm{Y}$... dans ma chambre, affalé dans un coin, jc vais rejoindre Cook ct Amundsen, qui me mettent au eourant des événements.

Jorsque je rentre chez moi, le matelot se sent mieux : il eonsent à manger un petit pain beurré; puis il va se cacher dans son lit, où il espère ètre en séeurité.

Le 25 décembre. - L'état mental de I... cst de plus en plus inquiétant : il est atteint de la manie de la persécution ct craint surtout de Gerlaehe et Amundscn. Ce matin, il a fait comprendre à Johansen qu'il soupçonnait ce dernier de l'avoir entrainé dans leur dernic̀re excursion dans l'espoir qu'il y trouvcrait la mort.

Plus ardemment cncore, nous souhaitons la délivrance, qui mettrait un terme à tous ces maux!

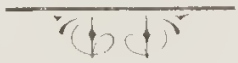




\section{CHAPITRE XXXVII.}

\section{Noël. - Nouvelle Année.}

Le 23 décembre. - Depuis plusieurs jours, la banquise est en mouvement à l'arrière du navire. L'aceumulation de détritus de toute espèce autour de la Belgica absorbe une quantité de ehaleur qui, peu à peu, amc̀ne le désagrégement des glaees. Le pont du navire vient d'être eomplètement dégagé; ee n'est que gràee à l'cau bouillante que la. jaumière a été débarrassée des glaees. La maehine est prête, les voiles sont enverguées; il ne nous manque plus que la rupture de la banquise et... un tout petit eanal de la largeur du navire, mais assez long pour nous conduire jusqu'à la mer libre!...

Lin réalité, nous sommes cruellement désappointés : le soleil est au tropique du Caprieorne et le vent reste si froid, quine eouche de jeune glaee se forme à nouveau sur les laes. Les optimistes se préoceupent peu de ces phénomènes; ils comptent, malgré tout, sur un heureux hasard. Les pessimistes, eux, n'entrevoient de salut qu'à l'issue d'une tempête et même Raeovitza déelare en plaisantant qu indépendamment de la tempète il faut un formidable tremblement de terre!

Le 27 décembre. - Toute la journée a été eonsacrée aux soins de propreté du navire, et ee soir nouss sommes réellement coquets pour eélébrer la veilléc de Noël. Pendant le souper, chacun s'efforce d'être gai, mais cette gaîté est factiee. C'est dans ees jours de fête surtout que l'on se sent étreint par la nostalgie. Et pourtant, quel décor féerique que eelui de la banquise! Noël, à minuit, aura pour lustre les mille feux du soleil, tandis que les eristaux du givre étineelant de toutes parts feront tristement pâlir les paillettes d'argent, dont on parsème, dans nos familles, le sapin traditionnel. Que font-ils, en ee moment, les ètres chéris que nous avons laissés là-bas? Peut-être versent-ils des larmes, en songeant à l'incertitude de notre sort!... 
Arctowslí s'est enfermé toute l'apres-midi dans son laboratoire, où il s'absorbe dans de mystérieuses préparations! De quoi s'agit-il? 11 ne confie son secret à personne!

linfin, vers 8 heures du soir, il nous invite, en grande pompe, à pénétrer clans le sanctuaire; puis, tenant en main un alambic, il nous explique gu'il va nous offrir des liqueurs de sa fabrieation : de l'orangeade et du cacao. Ce disant, il me présente le premier rerre. Ileureusement que j'y trempe à peine les lives, car c'est un véritable poison, - Arctowsli ayant employé de l'alcool à go".

En présence de na repugnance, il me traite de demoiselle; mais comme Somers, le plus fort gosier de l'expédition, est de mon avis, notre distillateur eonsent à réduire la teneur en alcool.

lit il entame devant nous une série de nouveaux mélanges, auxquels il goute conscieneieusement. Jiref, vers les g heures du soir, certain camarade vantait encore, mais avec unc légère agitation, les progres de la chimie moderne, qui permettent de fabriquer semblables nectars !

Le 2.5 aécembre. - Quel triste Nö̈l! Aucun de nous n'est cn gaité. Afin d'éveiller un peu d'animation dans le poste, nous envoyons quelques petits cadeaux aux hommes de l'équipage : de Gerlache, des cigares et les vitements; Racovitza, des cigarettes - hors prix dans l'Antarctique; Cook distribue à chacun d'eux un diapositif; moi, enfin, je leur remets un bon, qu'ils toucheront à notre premicie escale.

Le 3 r décembre. - Combien peu nous avons le coeur à la joie! Pourtant, nous voulons réveillonner avec l'équipage.

I to heures, un petit souper nous rassemble tous dans le poste, sauf de Gerlache, qui, souffrant, s'est retiré de bonne heure.

Vers Ir heures, arrivéc inattendue du... facteur! C'est Michotte qui remet, à chaque homme, une lettre du commandant. L'idée est ingrénieuse, et comme toutes ces épitres sont fort ćlogieuses, comme dles contiennent un "bon " à toucher à MIontevideo, elles raniment 
en un instant tous les hommes. A minuit, les toasts sont enthousiastes : la jeunesse et l'espoir nous ont ressaisis.

$I^{e r}$ janvier I89\%. - Notre rćveillon s'étant prolongé jusqu'au matin, nous nous sommes levés tarả aujourd'hui et sommes arrivés tous, à peu près au même moment, au carré. Alors, échange dc souhaits, mais sans chaleur, sans conviction! La journée se traînc très monne; nous l'employons à nous remémorer la passé, afin d'en déduire ce qu'il y a de mieux à faire pour l'avenir.

Si nous jetons un coup d'oeil sur la carte indiquant la route suivie par le navire pendant la dérive, nous remarquons que cette route est très tourmentée. Au début, nous restons sensiblcment à la même place, puis nous remontons vers le Nord; mais, dès le 15 mars, nous repartons dans la dircction du Sud-Ouest. Huit jours plus tard, nous remontons de nouveau vers le Nord, dépassant peu la latitude du i 5 mars, ct nous reprenons la route du Sud-Ouest, jusqu'au 2 I avril. Il semble alors que nous sommes arrivés à notre point extrême vers 1'Ouest, car notrc direction devient le Nord-Est. Dès le 4 mai, la dérive nous ramènc encore vers le Sud, à la mềnc position que le 23 mars. Du 4 mai au 20 août, nous dérivons, tantôt vers le SudOuest, tantôt vers le Nord-Est, et, à cette dernière date, nous nous trouvons à l'endroit où nous avons pénétré dans la banquise (cn février r 898). Peut-ètre la banquise ne s'étend-elle pas plus vers le Nord aujourd'hui qu'à cctte époque, mais peut-êtrc aussi le contraire se produit-il maintenant.

Jusqu'au 20 août, nous dérivons sensiblement sous l'influencc des vents et, chose assez curieuse, nos lignes génírales de dérive sont presque parallèles: lorsque nous sommes portés vers l'Oucst, notre route s'incline vcrs le Sud; au contraire, lorsquc nous sommes portés vers l'Est, nous rcmontons vers le Nord. Le voisinagc de l'ìle Pierre ler nc fournirait-il pas une explication à cette tendance d'allcr vers le Sud, tandis que la terro, que nos sondages renseignent d'une façon très sûre au Sud-Est, justi- 


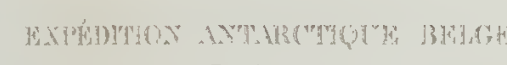

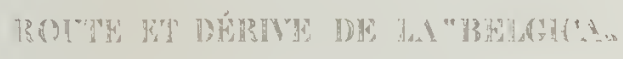

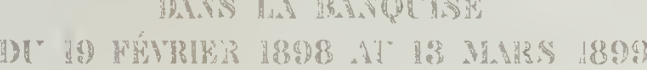

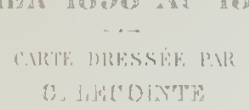

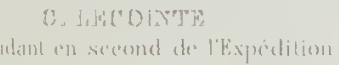

LEGENDE 

fierait la tendance qui nous refoule rers le Nord, lorsque nous dérivons à l'list.

Du 20 août au 20 décembre, date à laquelle nous revonons à notie position du 20 août, nous demeurons sur une mer peu profonde et dont la banquise est exeessivement dense, ce qui justifie, jusqu'à un certain point, la faiblesse de uos déplacements. Pendant eette période, plus encore que pendant la précédente, chaque fois que le vent nous chasse vers l'Est, nous sommes en même temps repoussés vers le Nord.

Enfin, du 20 au 3 I décembic, apris avoir été reportés vers l'Ouest, nous sommes ramenés sensiblement vers le Nord.

Aujourd'hui, I $^{\text {er }}$ janvier, nous nous trouvons ì un endroit oì la mer était libre le 27 février de l’année précédente; or, du nid de corbeau, on ne voit se prolonger au loin vers le Noril que l'éternelle banquise. Nous sommes done aussi fortement emprisonnés clu'il y a un an, et déjà le soleil redescend vers l'écfuateur. Serons-nous délivrés ectte année? Le serons-nous jamais?

Le 3 janvier. - Depuis huit jours, de grands mouvements semblent se produire dans la banquise... au loin, malheureusement! Nous nous en apereevons aux icebergs, qui, plusicurs fois, ont changé d'orientation. Souvent aussi, nous apercevons vers le Nord un watersky tris prononcé, mais nous n'y croyons plus: ces signes nous ont trop souvent décus. Journellement, nous sommes induits en erreur par des jeux d'optique. Ainsi, à maintes reprises, nous voyons entre le SudEst et le Sud-Ouest d'immenses falaises de glace aux murailles verticales surplombant des baies nombreuses. Or, tout cela est effet de mirage: les champs de glace n’énergent que d'un mètre en réalité, mais donnent des images réfractées multiples qui se superposent exactement.

Le + janvier. - Cook est fort soueieux : il parle avec une ecrtaine exaltation de la néeessité absolue de quitter la banquise et demancle cue, le travail seientificue cessant, toutes nos forces soient concentrées 
vers un seul but: la délivrance! Pcu à peu, sa parole nous cntraine; chacun se crcuse le cerveau pour trouver le moycn de vaincre la banquisc.

Le 7 janvier. - Le matclot Y... ne va pas mieux; ses terreurs sont continuelles et il s'ingćnie à se cacher dans tous les coins du navire; il a occasionnć, il y a dcux nuits, unc véritable panique à bord.

Vcrs I l heures du soir, je rentrais d'une reconnaissance faite sur la banquise, lorsque Johansen m'annonce que Y... a disparu. Ayant prévenu de Gerlache, nous montons enscmble clans la màture pour cxplorer l'horizon, tandis qu'on recommence, à bord, des rccherches minuticuses La clarté cst exceptionnclle, nous pourons scruter tout l'horizon. Ricn ! Plus de doute, un accident cst arrivé.

Théoriquement, le matelot n'aurait pas dù échapper un instant à une étroite surveillance, mais le tristc état de santé de l'équipage cxcusait cctte négligence momentanée.

En un instant, lcs rccherches sont organisées. de Gerlachc ct dcux hommes restent à bord, où il est convcnu que, si I... est retrouvé vivant, lc pavillon bclge scra hissé à la cornc d'artimon, tandis que, si le matclot cst mort, le pavillon sera immédiatement mis en berne.

Arctowsli ct moi, fort découlagés, nous cherchions cn vain une piste, lorsque mon camaradc aperçoit tout à coup le drapeau belge qui montc lcntement le long du màt, puis, soudain, s'arrêtc à midrisse. Totre cœur sc scrre à cc func̀bre signal et mous nous hàtons vers lc bord.

Les nouvclles y sont meilleures que nous nc le supposions : le matelot est vivant; la drisse du pavillon s'était coincée dans la poulie remplic de givre et c'est accidentellcment que lc drapeau a flottć en berne. I... a été dćcouvert caché derrière un hummock. Il ne parait pas remarquer l'inquiétude qu'il nous a causée; mais, asscz docilement, il se décide à regagncr sa couchette. 


\section{CHAPITRE XXXYII.}

\section{Efforts surlumains.}

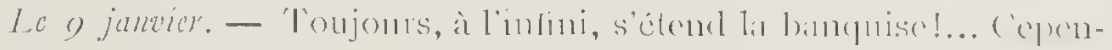

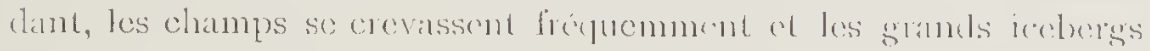

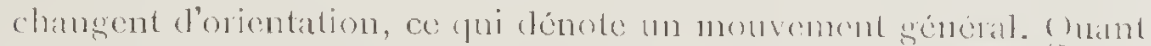
à nous, nous demenons immobiles, rives à moln champ de glace de

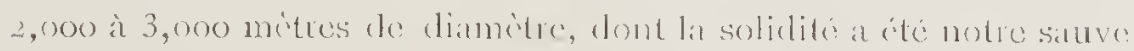

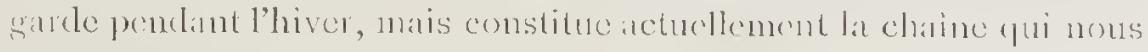
relient catplifs.

Bien fue nous soyens en plein be antanctipue, la neige fond it

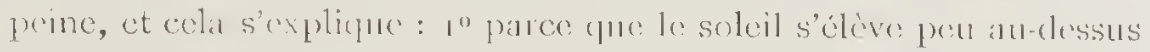

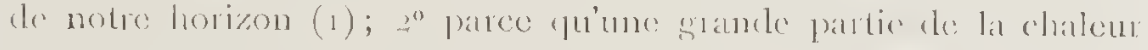

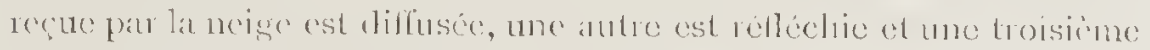
patrie: sculement, tris minime, ast alsombre.

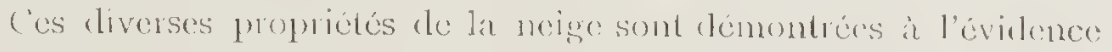
sur la bancuise, car, lit ou dle est eouverte de detritus, bouls de phanches, carton bitume, ete., lis glace fond aver raphdite, chant (tomné le pouvoir absorbant de cers comps.

Cook, estimant avec raison que nous devons, is tout prix, nous

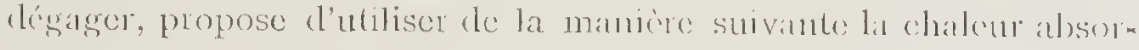
béc par ces colps.

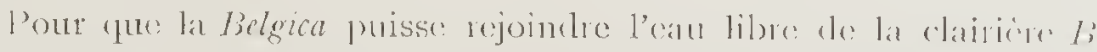
(voir fig. 70), il est d'avis de creuser dams lat ghatee, strivant a b et $b d$,

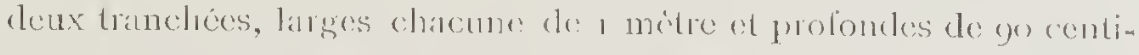

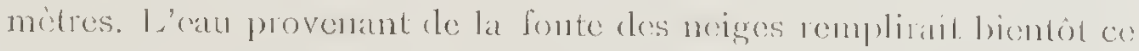
fosse et, comme le prouvoir alosorbant de l'oau cst plus gramel que

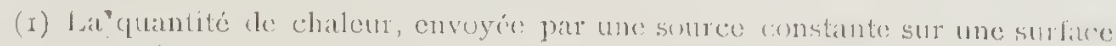

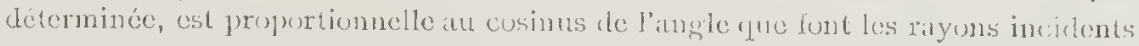
avec la mormale à cette surlike. 
celui de la neige, le soleil se chargerait d'approfondir constamment la tranchéc. L'action du soleil scrait plus efficace encore, si nous rcrsions des cscarbilles dans la tranchée. Ainsi, petit à petit, deux lignes de rupture se produiraient probablement.

de Gerlache et moi ne sommes guère partisans de cette tentative, attendu que, le pouvoir diathermane (I) de l'eau étant faible, la quantité de chaleur reçue par les escarbilles immergées sera très faible aussi (2). Cependant, ne fût-ce que pour faire diversion, nous entreprenons ce travail, dans lequel Cook et Arctorrski déploient une énergie extraordinaire.

En dehors des plénomènes naturels que nous venons d'indiquer et que quelques-uns d'entre nous cscomptent pour la délivrance, nous croyons devoir employer nos scies à glace pour découper un trait suivant les lignes $a b$ et $c d$. Nous commençons le travail en partant de la clairière $B$. Au début, cela va très bien, nous nous attaquons à de la glace peu forte; mais à peine avons-nous scié trente mètres, que nous pénétrons dans unc région aussi épaisse - même plus épaisse que la longuenr de nos scies. Alors, nous songeons à faire intervenir de nouveau la tonite.

Malgré le peu de résultats obtenus il y a trois scmaines, je construis une torpille formée d'un tube de grès de 30 centimètres de diamètre et de Im5o de longueur. Je charge le tube de I6o cartouches de tonite, puis j'en ferme avec soin les deux extrémités. La mise de feu s'opère à l'aide de trois mèches et de nombreuses capsules au fulminate de mercure. La torpille, retenue par un petit câble amarré à la banquisc, est introduite sous la glace par une ouverture pratiquée à la main (à l'endroit marqué $t$ sur la figure 7o). Le feu est mis aux trois mèches,

(I) Le pouvoir dithermane d'une substance est le rapport de la quantité de chaleur qu'elle laisse passer à celle qu'elle reçoit.

(2) Ce système ne pourrait réussir, me semble-t-il, que par une latitude moins élevée, ne fuit-ce que de 2 degrés, et dans des champs de glace moins épais que le nôtre. 


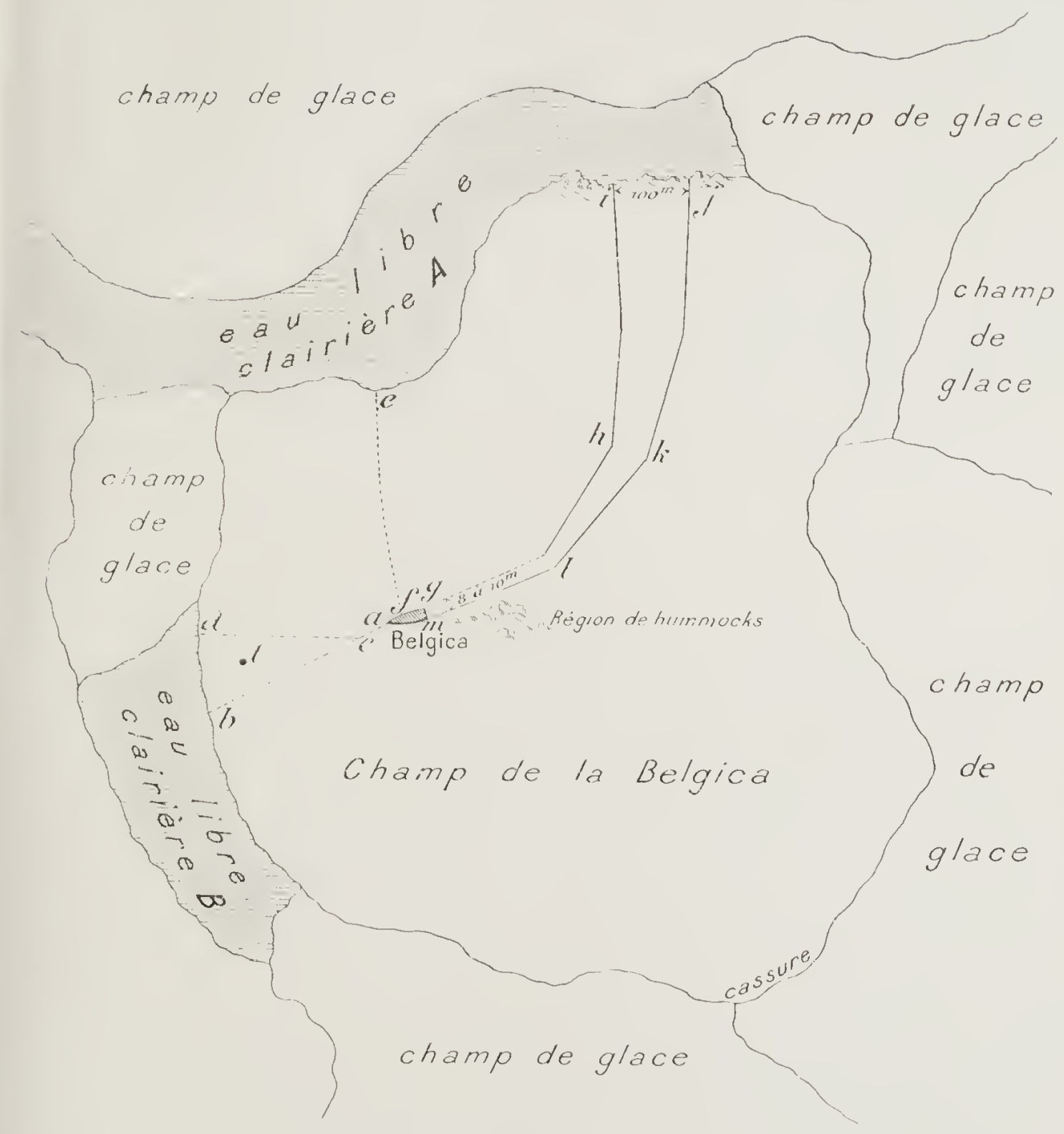

HIi, Ti. 
et nous fuyons pour nous mettre à l'abri. Au bout d'une demi-heure, rien encore! Nous retirons la torpille et nous constatons qu'en se mourant clle a enroulé les mèches autour du càble qui la retenait. Celles-ci s'étant brisées, une des extrémités s'est ouverte et l'eau a pénétré au milieu de la tonitc. Nous essayons deux ou trois cartouches ainsi mouillées, mais elles ne font plus explosion : les i6o cartouches sont arariées, nous devons les jeter à la mer.

Ce nouvel ćchec de la tonite achève de la déprćcier aux ycux de tout le personnel, excepté de de Gerlache, Racovitza et moi.

Mardi ro janvier. - Secondé par Amundsen, Mélacrts et Johansen, jc viens dc construire une machinc infernale. Nous avons mis 535 cartouches de tonitc dans un grand fût à pétrole qui a été fermé avcc un soin extrême. L'amorce consiste en 5 miches et 25 capsules au fulminate de mercure. Le fût, oricnté verticalement grâce au poids attaché à sa base, est introduit sous la glacc au même emplaccment que la torpille. Je mets le fcu aux cinq mèches ct, tout en invoquant la puissancc de sainte Barbe, patronne des artilleurs, je file à toutes jambes!

Rien d'abord : les mèches, avarićes par lc froid, ne conduisent pas la flamme. Cinq ou six fois, je reviens à la cliarge, je rallume même arec une certaine inquiétude, car les mèches deviennent courtes. Enfin, brusquement, une explosion formidable : de gros blocs de glace sont projetés à une grande hauteur, la banquisc frémit, le navire est ébranlé, et tous les blocs retombent du ciel comme une trombe. Nous nous précipitons. Oh! désillusion! les 535 cartouches de tonite ont fait une ouverture de ro mètres de rayon à pcine, et aucune crevasse, aucunc fissure ne s'est produite au delà. Pour comble de malchance, les blocs, projetés verticalement, sont retombés dans l'cxcavation, où ils ne tardent pas à former une nouvclle massc compacte. Cette dernière expérience est concluante : les adversaires de la tonite ne manquent pas de la ridiculiser et ses partisans reconnaissent que si jamais elle rend des services, ils ne seront guère importants.

Le I janvier. - Avec moins de conviction que jamais, nous continuons à creuser les fossés et à scier la glace. Ce travail se poursuit 
arec indifférence; Cooli et irctorslì seuls sont vétitablement enragés à la besogne.

Ce soir, de Gerlache, voyant avec certitude que nous n'a vons aucune chance de succès, vient de proposer de creuser un canal, à l'arrière du narire, suivant le tracé g hijklm (voir fig. 7o). In effet, l'hiver, il s'est

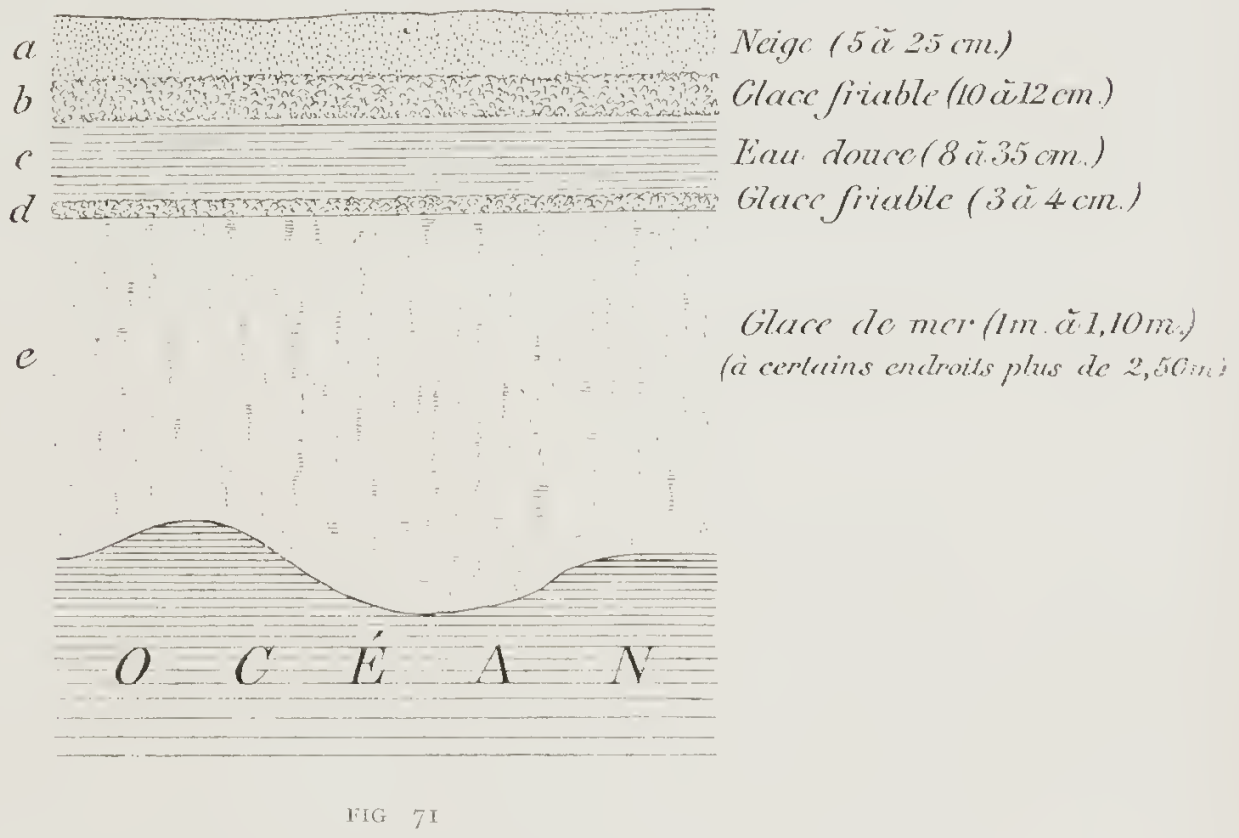

produit dans cette direction une crevasse qui, s'étant élargie, s'est recouverte d'une jeune glace, laquelle, actucllement, doit êtie moins épaisse que celle que nous scions. Cook ne veut pas entendre parler d"un projet autre que le sien; aussi fait-il une résistance acharnéc Pour lever les doutes, nous passons toute la nuit à faire des sondages dans la slace, afin de déterminer quel est le projet le plus avantageux.

Le I 2 janvier, à 8 heures du matin, les résultats des sondages, reportés șu: une carte spéciale, indiquent que le projet de Cook est à peu près irréalisable, mais que celui du commandant pourrait, si 
nous y consacrons toutes nos forces, aboutir, sauf l'imprévu, à une certaine réussite. 11 est donc arrêté que les travaux commenceront cet apres-midi et seront poursuivis mit et jour.

A 2 heures, nous voilà tous sur la banquise: les travaux scientifiques sont interrompus, hormis les observations météorologiques.

Le canal est jalonné avee un soin aussi minutieux que s'il s'agissait

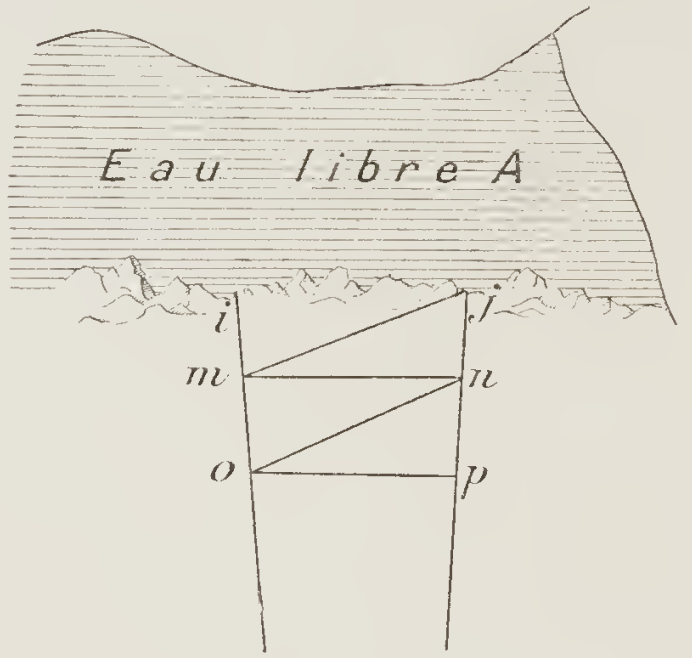

FIG. 72.

de creuser à nouveau le canal de Sucz! Pour en tracer les limites, nous nous basons sur les sondages qui nous donnent l'emplacement de l'ancienne crevasse.

La figure donnće ci-contre (fig. 7I) représente une coupe verticale de la trancliée.

A la partie $i j$ (voir fig. 7o, p. 309), le canal a une largeur de Ioo métres environ, puis il va cn se rétrécissant jusqu'au navire, où sa largeur n'est plus que de 8 à r o mètres. Cette forme permettra plus facilement l'évacuation des blocs vers la clairicie $A$.

A l'embouchure $i j$ se troure un amas le blocs de glace provenant d'anciennes pressions. Cette partic ne pourra être sciée, la glace y étant trop épaisse : elle sera encore attarquée à la tonite. 
Les outils dont nous disposons sont peu nombreur : 2 pioches, 6 pelles, 2 piolets, 2 larges ciseaux de menuisier pourvus d'un long manche; enfin, 4 scies à glace. Comme, à ccrtains endroits, la glace est plus épaisse que la longueur des scies, deux d'entre elles sont reliées bout à bout à l'aicle de deux plaques de fer. Nous ne disposons donc, en réalité, que de trois scies.

Pour ouviri la tranchée, nous commençons par creuser les couches superficielles (couches $a$ et $b$ de la fig. 7I), suivant les tracés $j m, m n, n o, o p$ (voir fig. 72). Ce premier travail est exécuté avec les pioches, piolets, etc. Puis nous don. nons un trait de scie dans les rainures ainsi formées.

La besogne avance très lentement; clle exige de réels efforts. Aussi les inventeurs ont-ils l'esprit en éveil. Van Mirlo propose d'adopter un système analogue à celui du scieur de marbre. A cet effet, il attache à un fil d'acicr de sondage un boulet qui est introduit dans la glace (fig. 74.) Le fil d'acier

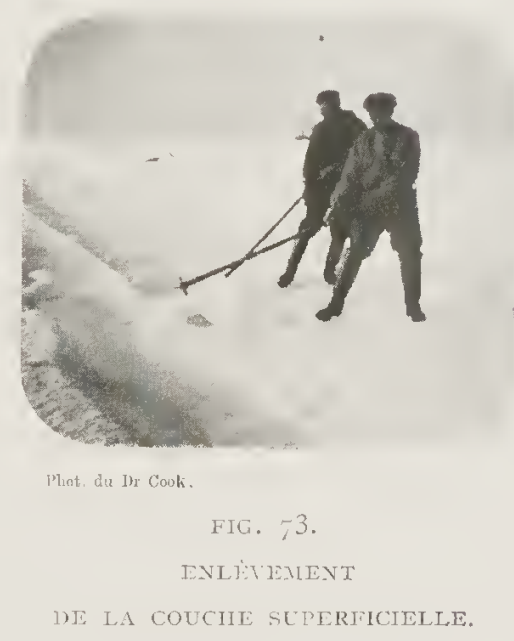
vient se fixer en a sur une tige munie d'une articulation en $b$, à son point de rencontre avec une planche que le scieur fixe dans la glace et maintient du pied. Enfin, le scieur saisit la poignée, puis fait monter et desccndre le boulet, dont le poids tend le fil d'acier. Ce fil coupe la glace, mais... si lcntement qu'on la fondrait plus vite en la suçant avec les lèvres.

De plus, le trait est si mince, que bientôt les deux partics quion a séparécs arce tant de peine se ressoulent à nouveau.

Le système Van Mirlo est mis au rancart avant même que d'avoir été essayé sérieusemcnt.

MI. Somers propose de modifier le systeme Van Mirlo en mettant plusieurs boulets au lieu d'un seul; en substituant une cordelette d"acier au fil et en se servant du treuil à vapeur et dc poulies de 
renvoi convenablement disposées, pour produire le mouvement d'ascension et de descente des boulcts. Ce système ne nous inspire pas plus de confiance que le précédent, car il a l'inconvénicnt d'exiger le mainticn sous pression de la chaudièrc et, par suitc, de diminuer notre combustible.

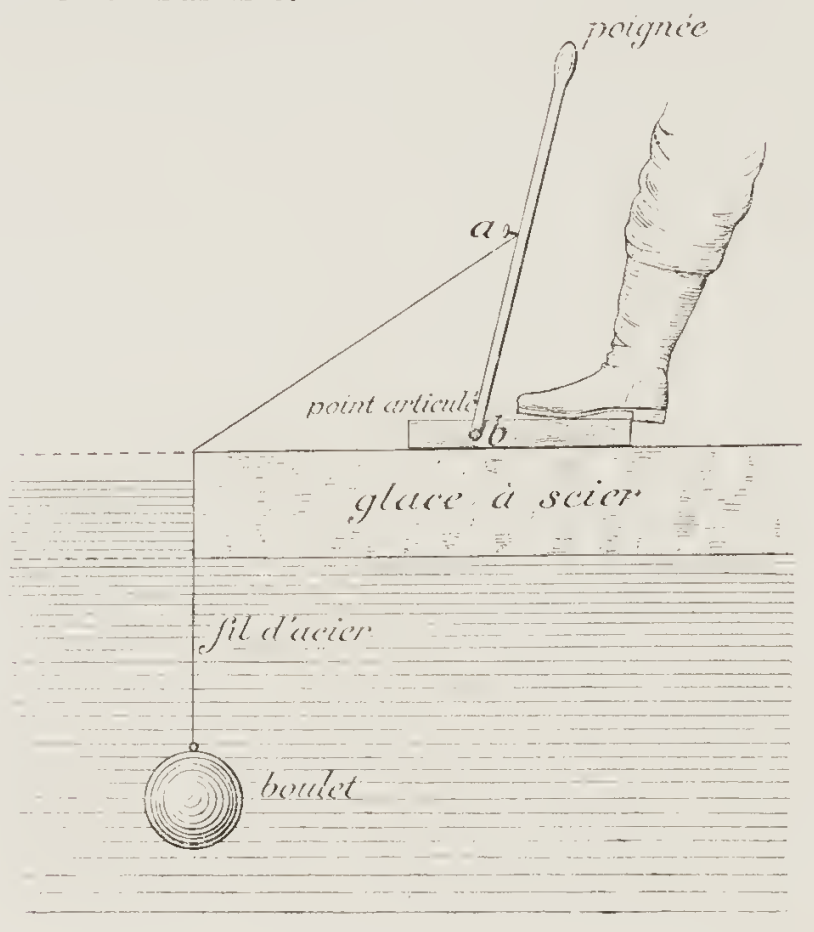

FIG. 7 .

Lc projet est donc rcfusé comme beaucoup d'autres. Ces inventions ont un excellent résultat ccpendant : elles occupent l'esprit des travailleurs, qui n'en scient pas moins activement pour cela.

Dimanche 15 janvier. - Ilier après-midi, nous arons préparé des charges de tonitc de IO, 20, 3o et 40 cartouches chacunc, et ce matin nous les avons fait exploser. Cette fois, cnfin, les résultats ont été brillants, - à part quelques échecs. Lcs charges ont été miscs à faible distance de l'eau libre et, comme les mouvements d'expansion étaient possibles dans cette direction, les triangles que nous avions découpés 
se fractionnèrent. En moins de deux heurcs, tous les hummocks roisins de l'eau libre étaient refoulés, ainsi que les deux promicrs triangles $i j m$ et $j m n$ (voir fig. 72). Mais pour le troisième triangle, des difficultés considérables se dressèrent : le triangle ayant légère-

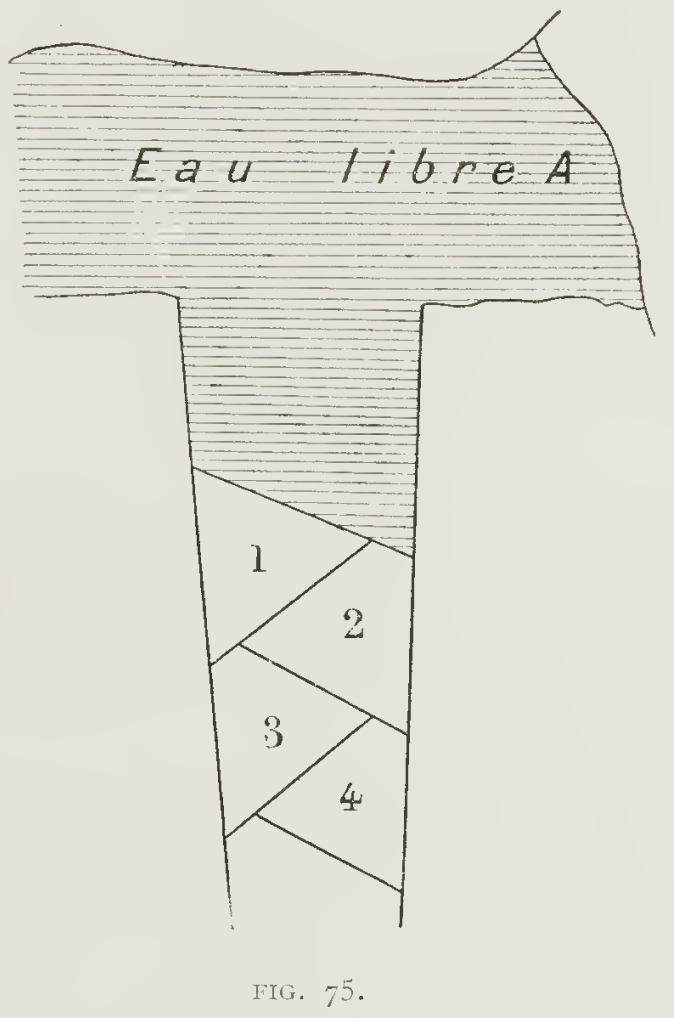

ment tourné autour d'un axe vertical, le coté no coinça tout le bloc et il fallut force tonite pour le dégager. Encore toute cette tonite produisit-elle une bouille de neige et de glace, qui encombra le canal.

Nous changeâmes alors le tracé des sections et adoptâmes cclui qui est indiqué sur la fig. 75. Les résultats furent excellents : une ou deux charges de tonite suffirent pour détacher les blocs.

Michotte seul étant nécessaire à bord pour préparer les repas, étatmajor et équipage sont répartis en deux équipes, pour la régularité du travail. La première équipe - comprenant de Gerlache, Mćlaerts, 
Racovitza, Van Mirlo, Tollefsen, Johansen, Koren et Tan Rysselberghe - travaille de 8 heures à midi, puis de I I/ 2 à 3 I $/ 2$ et de 4 à 6 heures du soir. La deuxième équipe-formée par Lecointe, Amundsen, Arctorvski, Cook, Somcrs et Dufour - travaillc la nuit de 7 à

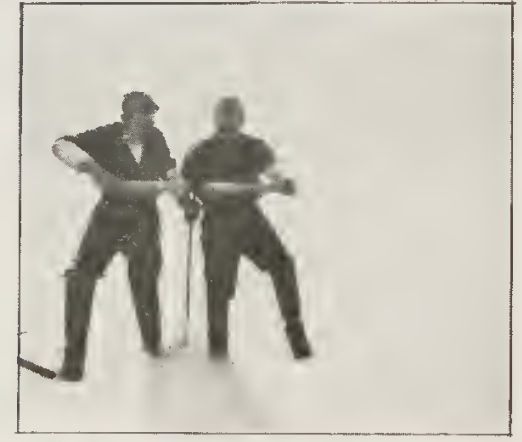

Phot du 7 hr Cook.

FIG. 76 .

TRAYAIL A UX SILL HOMAE

(LE RELEYEMENT DU TRATAII. I I heures, puis dè minuit à 4 heures du matin. Pendant les heures de rcpos, cette équipe prépare les charges de tonite et, je dois l'avoner, cette besogne se fait arec une imprudence vraiment téméraire. Les paquets de tonite sont apportés non loin $d u$ feu où les cartouches se dégèlent. Puis arec des couteaux de cuisine nous raclons tout ce qu'il $y$ a de mauvais. Souvent des morceaux de tonito tombent à terre et c'est à peine si nous $y$ prenons garde. On en trouve des déchets jusque dans les assiettes!

Ce n'est pas chose aisće que de creuser dans la glace un canal de près de 700 metres de long. Le sectionnement dos blocs exige qu'on scie des centaines et des centaines de mètres.

Il y a deux modes de travail. Ceur qui manient les petites scies sont au nombre de trois par outil; l'un scie pcndant 5 minutes consécutivcs sous la surveillance sévère de ses deux compagnons. Aussitòt le laps de temps écoulé, le second travailleur le remplace arec rapidité, sans intcrompre, pour ainsi dire, la marche de l'instrument.

Les trois hommes qui disposent de la scie double travaillent pendant cinquantecinq mimutes sans intermption, puis prennent 5 minutes de repos. L'un d'eux est placé à la barre horizontale et en a la direction, les deux autres tircnt sur le filin qui relève la scie; pour la descente, le propre poids de l'outil suffit.

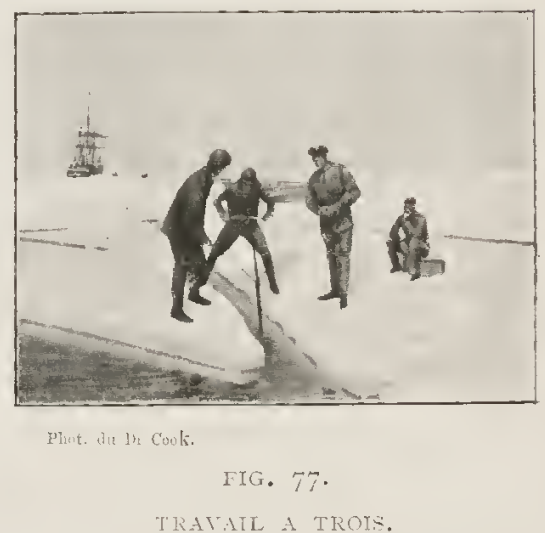


J)ans les endroits où l'épaisseur est considérable, on emploie la double seie, qui n'avance qu'avec peine.

Pendant ce travail monotone, on cherche à se distraire par la conrersation : Aretowski, amusant au possible avec une vicille pelisse et

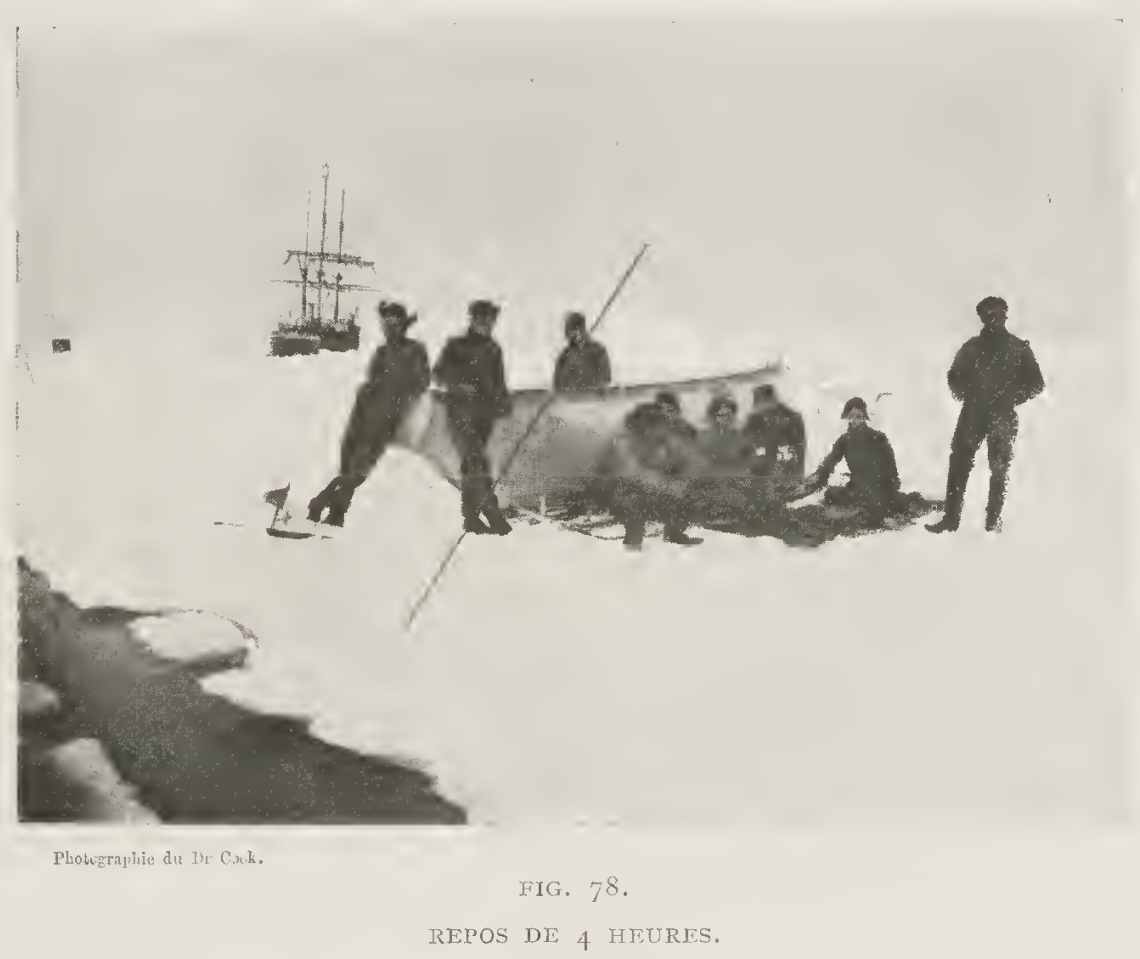

an chapeau haut de forme d'un modicle antique, raconte des histoires de Londres. Il s'engage dans des discussions sans fin, sur les usages mondains, sur les inconvénients des galoches, ctc., et met tant de feu dans ses assertions, qu'il scie pendant dix minutes au lieu de cinq. Amundsen et Cook le laissent aller, entretenant même la discussion... C'est autant de gagné pour eux.

Somers ne cesse pas de parler une minute. Il nous raconte ses aventures de régiment, celles qui sont arrivées à ses compagnons d'armes et beaucoup d'autres qui ne sont arrivées que dans son imagination féconde. 
Vienncnt ensuite ses aventurcs de marin, la description fantaisiste du service à bord des navires de la marine belge, etc., et tout cela est si drôle, si chargé, sans aucune méchanceté pour personne cependant, que nous faisons semblant de le croirc, afin de l'animer encore davantage.

De i l heures à minuit, notre équipe a rcpos; nous passons ce temps au laboratoire, afin de ne pas réveiller lcs autres. Nous y faisons un petit souper, trop pctit souvent, hélas! car nos estomacs se creusent plus rapidement que le canal. Puis quelqucs-uns somnolent pcudant dix minutes, tandis que Somers, intarissablc, continue ses histoircs...

Oui,pendant trentc-cinq jours, Somers a parlé chaque jour durant neuf heures consécutives, et cela avcc beaucoup d'humour, je dois lc déclarer, ct pour notrc plus grande distraction à tous.

La division de de Gerlache prend, à 4 heurcs de l'après-midi, un goûter de pain et de café servi sur la banquisc. Lc tableau en est pittoresque : les hommes s'étendent par groupes sur la neige, mangeant avec avidité leur " pain-plomb » (fig. 78).

Lorsqu'on a scié un certain nombrc de blocs de glace, on procède

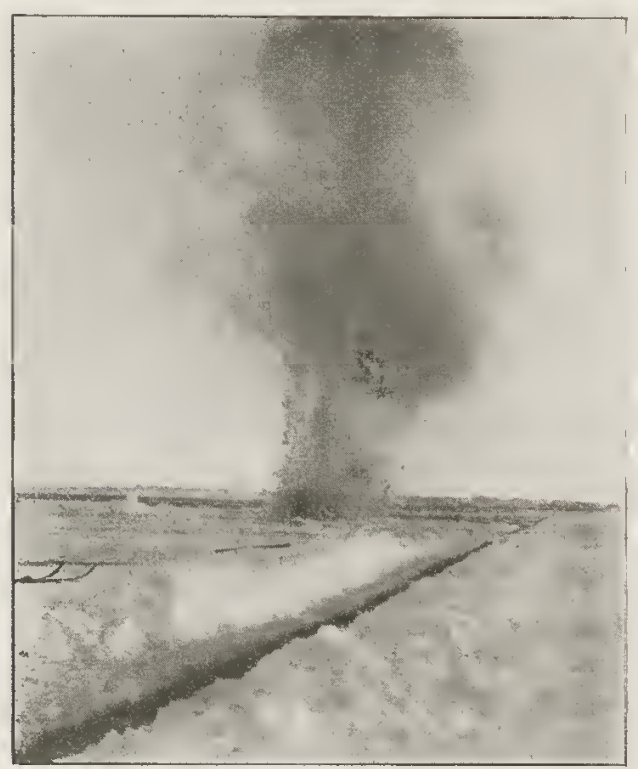

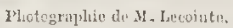

IIG. 79. à lcur évacuation dans la clairière : c'cst le moment lc plus agréable de la journéc. A l'aide de charges de tonite, on brise les blocs en leur centre. Puis, muni de longues perches, on pousse les fragments au large (fig. 8o). Dè qu'un fragment flottc, un homme y sautc avcc sa perche et navigue comme sur un radeau. Cook excellc dans ce genre de sport: il parodie les officiers de quart, se donne les commandcments à haute voix, court d'un bout à l'autrc de son fragile esquif, manque souvent 
de tomber à la mer, mais, avee une véritable souplesse de singe si je puis me servir de eette eomparaison! - parvient toujours à se rattraper à temps.

Les petits fragments de glaee sont entraînés autant que possible en mème temps que les grands, tandis que la bouillie de neige restante est poussée rers la elairière à l'aide d'un petit eanot.

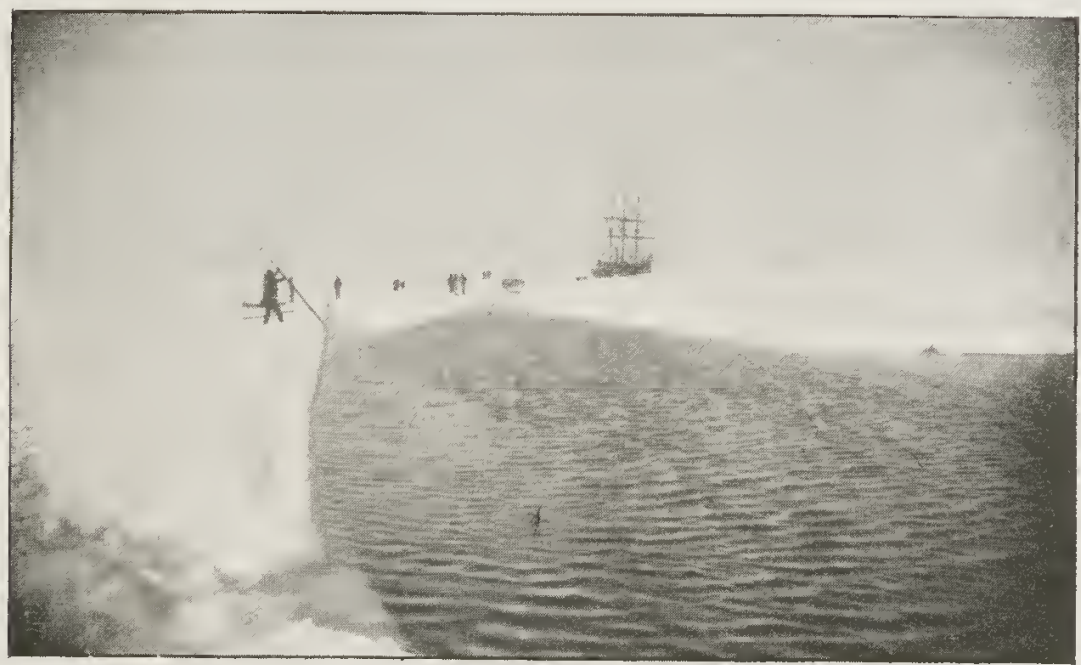

Plutugraphe in 1 ry rook.

IFIG. $8 \cap$.

MLNIS DE LONGUES PLRCIIES, NOUS POTSSONS IES BLOCS AU IARGE

Le 29 janvier. - Depuis dix-sept jours, nous scions, nous seions!... Quelques-uns d'entre nous sont exténués; d’autres ont mal aux yeux, paree qu'ils n'ont pas porté à temps les lunettes avee verres fumés. La lumière diffuse de la banquise est si éblouissante qu'on ne peut gucre la supporter. Le soleil ne se montre pourtant que rarement, trop rarement, hélas!

1)epuis deux jours, le travail est encore plus pénible. Nous avons traversé une région où, la eouehe aqueuse étant à la surfaee, nous avions de l'eau glacée jusqu'aux mollets. Maintenant nous sommes dans une région où la glace est très épaisse, l'aneienne région des pres- 
sions, où les hummocks, cn se comprimant, ont formé unc glace d'eau douce rebelle à la scie. De plus, nos instruments sont fort émoussés.

Bien que nous soyons presque tous courbaturés, les repas sont cmpreints encore d'une certaine gaité ; mais, dès qu'ils sont tcrminés

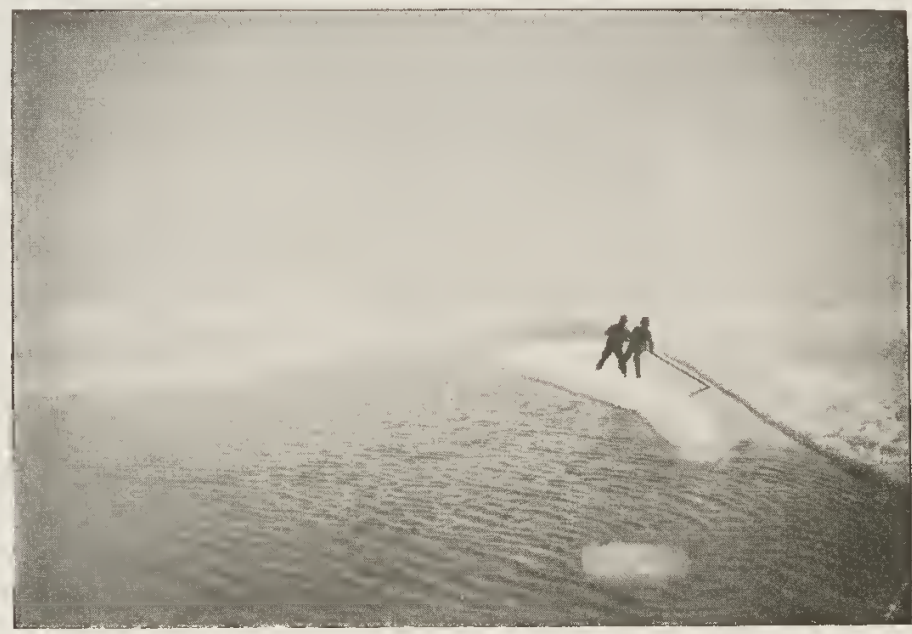

Photograplic dil I) Cusk.

FIG. $8 I$.

MAVIGATION SLR UN BLOC DE GLACE.

et qu'on n'est pas de corvéc, on plongc dans sa couchette... à moins qu'on ne doive s'occuper de la tonite!

Le 30 janvier. - Quelle catastrophe! L'embouchurc du canal vient d'être obstruée par des glaces flottantes qui se trouvaient dans la clairicre.

Une crevasse s'est formée suivant la ligne ef (voir fig. 70). Le canal était à peu près terminé; dans deux jours, nous aurions été délivrés.

La nuit du 30 au $3 \mathrm{~s}$, nous travaillons avec acharnement; mais, comme nous sommes à quclques mètres du navire et qu'en cet endroit l'épaisseur de la glace est augmentée d'une couchc de détritus de toute espèce, la grande scie n'avance qu'arcc peine, arrêtée à chaque 
instant par des boîtes de fer-blanc, des os, des cadavres de phoques ou de manchots.

Le $3 r$ janvier. - Catastrophe plus grande encore que celle de la veillc : la nappc de glace ef $g h i$ s'est déplacée (voir fig. 70), la crevasse ef s'cst élargie, mais en resserrant le canal, qui devient infranchissable pour la Belgica. Bien plus, ce canal présente un danger terrible : la nappe ef $g h i$, étant libre, peut tourner autour de la partic $f g$ du navire, qui consti. tue une véritable charnic̀re. La nappe, par moment, tressaille et elle est de si grandes dimensions, qu'elle menace de nous écraser.

Le 3 février. - L'anéantissement de notrc rude labeur a produit un choc moral très

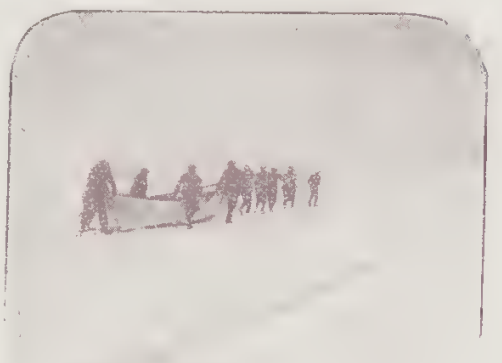

FIG, 8_. ESSAIS DE TRACTION. sérieux parmi nous. De plus, le voisinage dangereux de la nappe mobile qui se presse à tribord nous force à envisager encore une fois la terrible éventualité où le navire serait écrasé.

Les deux canots ct les deux baleinières sont amenés sur la glaco pour être soumis à différents essais de charge et de traction. Nous

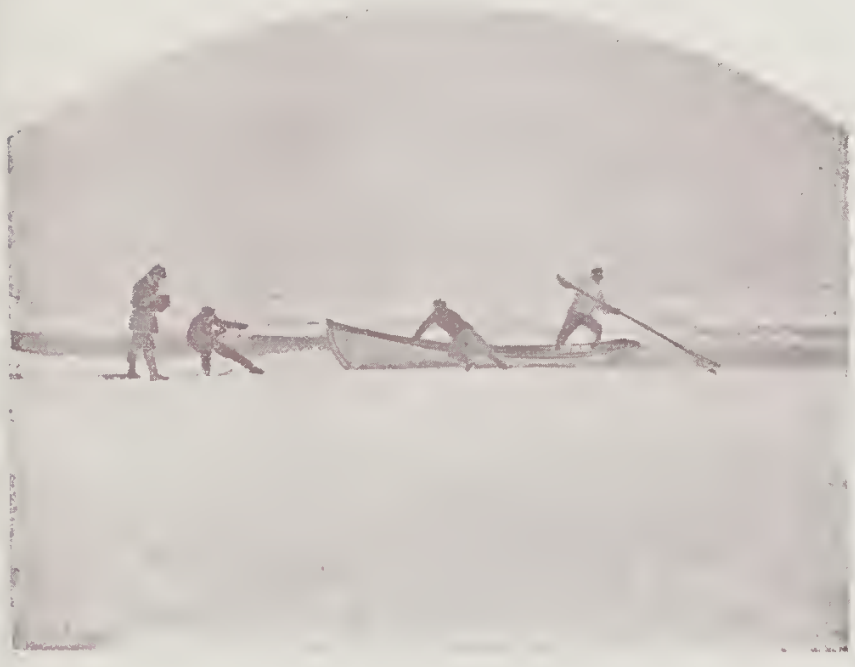

ho' ographis de M. Ic sinto. constatons une fois de plus que deux embarcations, la baleinicre moyenne et le you. you, sont dangereusement instables. Quant aux essais do traction, ils établissent que nos embarcations sont tellement lourdes, qu'il est douteux que nous puissions en trầ. ner deux. Une seule 
est assez maniable, et c'est précisément celle qui n’est pas stable. İn tous eas, il est évident qu'on ne pourra les transporter sur la neige sans les placer sur un traîneau.

L'après-midi, l'état-major se réunit pour discuter l'importante question de la route à suivre, si le navirc est écrasé. Deux hypothèses se présentent : la premicre soutient que, vu la lourdeur excessire des embarcations et l'état d'affaiblissement des hommes, il faut faire route rers le Nord, gagner la lisière de la banquise, puis la longer en canot. Si une tempête nous menace, nous aurons peut-être la faculté de nous mettre à l'abri sur un champ de glacc. Après une longue discussion, ce plan est rejeté, vu l'instabilité des cmbarcations et la houle riolente qui sévit constamment à la lisière de la banquise.

L'autre plan nous conduit, comme le premier d'ailleurs, à essayer d'atteindre le détroit de Gerlache, mais en nous tenant à une distance telle de la lisière, que la houle ne puisse nous atteindre, et en choisissant les champs de glace assez vastes pour que nous ne nous trouvions pas constamment obligés de franchir les chaînes de hummoclis, qui bordent généralement les champs. L'obstacle le plus sérieux qui nous arrête est la lourdeur des canots et le degré d'affaiblissement des hommes.

C'est cependant à ce dernier parti, faute d'un meilleur, que se rallie la majorité. Nous arrêtons donc, en commun, la liste du matériel à emporter, en cas de sinistre, et nous décidons de nous occuper inmédiatement de la construction des tentes, des sacs de couchage et des vêtements en peau de plioque.

de Gerlache, Ainundsen et Cook, les trois spécialistes dans ces travaux, se mettent aetivement à la besogne.

Le soir même, de Gerlache, ayant fini le recensement des virres, nous réunit encore pour nous annoncer que les provisions diminuent et qu’à partir du lundi suivant, état-major ct équipage seront réduits à la même ration. Chacun de nous recevra, par jour, un petit pain et un biscuit, et, par semaine, 150 grammes de margarine et I 50 grammes de sucre. Les autres provisions, vins, desserts, etc., seront partagées 
également cntre tous et dans de certaines proportions, par semaine.

Cette nouvelle, loin de produire une mauvaise impression, nous met en gaîté. Nous commençons aussitôt un petit trafic : l'un cède son sucre pour du pain, l'autre ćchange sa ration de vin pour un peu de beurre, un troisième mange immédiatement toute sa ration de

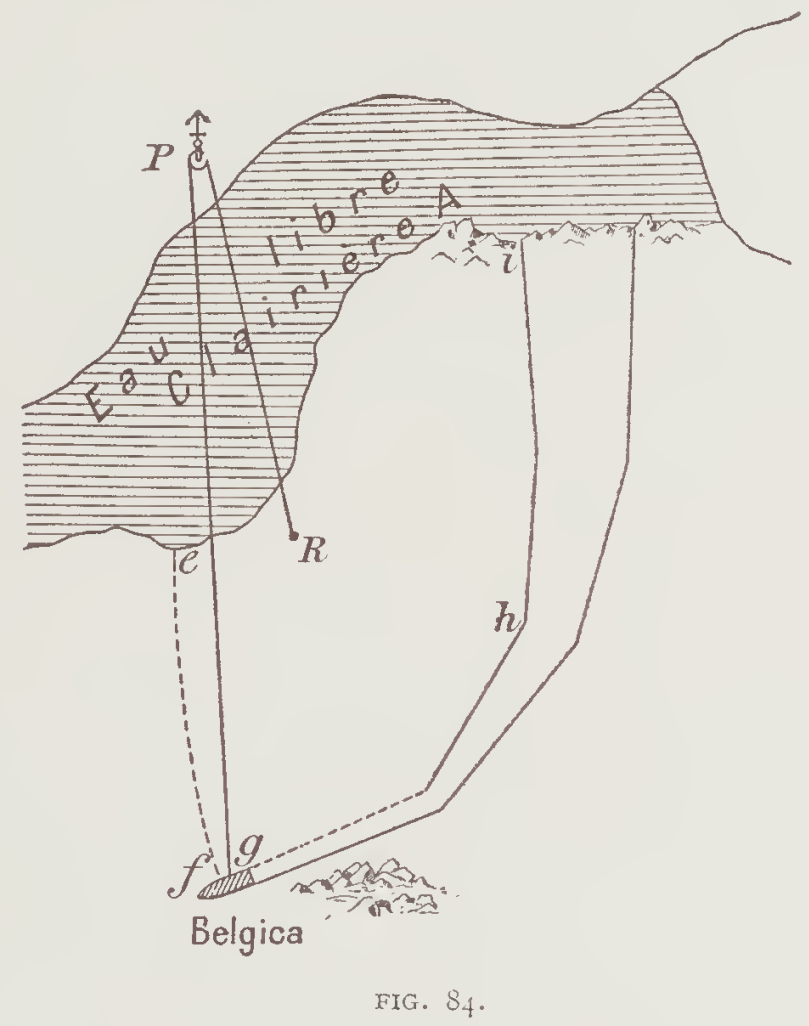

desserts. Somme toute, la chose est plaisante pour ceux qui mangent du phoque sans dégoût; mais pour les autres, ce sera la faminc peut-ĉtre.

Le \& février. - Le canal reste dans le même état; il nous semble, par moments, que les champs de glacc ont un mouvement d'ascension et de descente, comme s'ils subissaicnt l'influence de la houle. Ce fait nous paraît d'abord invraisemblable, attendu que nous occupons à peu près la même position qu'il y a neuf mois. Toutefois, 
les dernières observations astronomiques tendent à démontrer que nous nous déplaçons assez rapidement vers l'Ouest. Notre inaction ne peut se prolonger: il est convenu que, si dans deux jours une détente n'a pas rouvert le canal, nous l'élargirons nous-mêmes. Dans l'entre-temps, les observations reprennent leur cours.

Lo 7 fioricr. - Le grand traîneau destiné à supporter éventuelle-

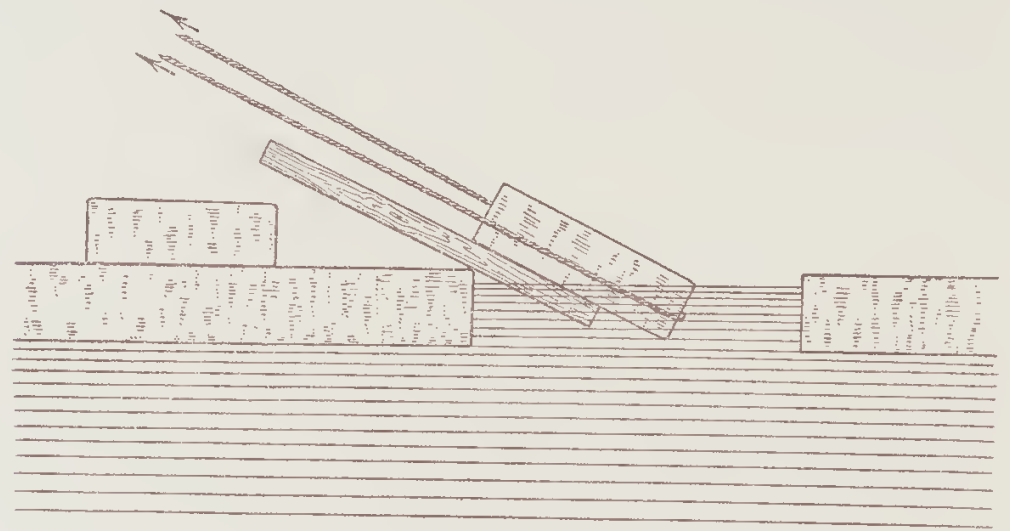

IIG. $8 \overrightarrow{5}$

ment le canot a été terminé et expérimenté hier. Les résultats sont satisfaisants, mais rien de plus. Aujourd'hui, nous avons repris les travaux d'élargissement du canal: de Gerlache a proposé un moyen qui semblait plus expéditif que les précédents.

Le gros filin d'acier, destiné aux dragages, aurait été amarré par une de ses extrémités au point $R$ (fig. 84) sur la nappe e f $g h i$, puis passé sur une poulie $P$ - fixée de l'autre côté de la clairière $A$ - enfin enroulé, à bord, sur le treuil. Alors, s'aidant de la vapeur et d'un palan supplémentaire, on aurait cherché à détacher la nappe $\bullet f g h i$ et à faire route vers la clairière, soit par la crevasse $e f$, soit par le canal $g h i$.

Ce projet ne fut pas adopté, parce que nous avions déjà constaté que des nappes analogues se coincent très facilement et que l'effort nécessaire pour les dégager était supérieur aux forces dont nous pouvions disposer. 
L'élargissement du canal ne fut pas chose facile, surtout que l'embouchure en était fermée. Il fallut done recouper des blocs et plaecr, en-dessous, des espars formant plan incliné (fig. 85), les hisser sur ee plan pour les déposer finalement sur la rive. Ces bloes devaient être de petites dimensions, car, hors de l'eau, ils ne subissaient plus la poussée de la mer et devenaient, à cause de leur poids, très diffieiles à manier.

Ce labeur de forçat se continuait jour et nuit sans interruption.

Le I4 février. - Au bout de sept jouss, il ne nous restait plus à dégager que l'aricire du navire, où la glace était trop dure et trop épaisse pour se laisser entamer par les seies. Nous recourons une fois cneore à la tonite. Nous en faisons éclater des charges placées à 3 et 4 mètres du navire. Tout eela est fort dangereux: nous risquons de faire sauter " par induction " toute la tonite qui se clégèle, pris du feu, à bord. Mais il n'y a pas une minute à perdre, le moindre retard peut nous bloquer à nouveau pour tout un hiver.

Chaeune des explosions est marquée, à bord, par une forte dépression du baromètre; de plus, résultat moins scientifique, des détritus de toute espèce sont projetés violemment en l'air, puis retombent rlans toutes les directions en une ignoble pluie !...

Enfin, le navire étant à peu près dégagé, il est mis cn marehe vers l'arricre, au risque de rompre le gouvernail et l'hélice.

Un moment, ò joie! nous nous croyons sans cntraves, mais bientòt les coups de bélier, donnés avec le gouvernail, deviennent impuissants. Il faudrait, surtout pour franehir l'embouehure eneombrée de glace, faire agir l'avant clu navire.

Ifin de virer de bord, nous découpons, en $l$ no (fig. 86), un port de 600 mètres carrés, dans une glace relativement friable, que nous faisons sauter avee de nombreuses eharges de tonite.

Tout à coup, la nappe ef $g$ h $i$ s'éearte doucement et le canal s'élargit.

Vite, nous faisons machine arrière, nous gagnons le port d'évitage, nous virons, en nous aidant d'aussicres et d'aneres, mais voilà qu'au 
moment où le navire est en travers du canal dans la position $B^{\prime}$, ce dernier se resserre. La Belgica est donc eomprimée longitudinalement, de telle sorte que l'hélice et le gouvernail courent grand risque d'être brisés.

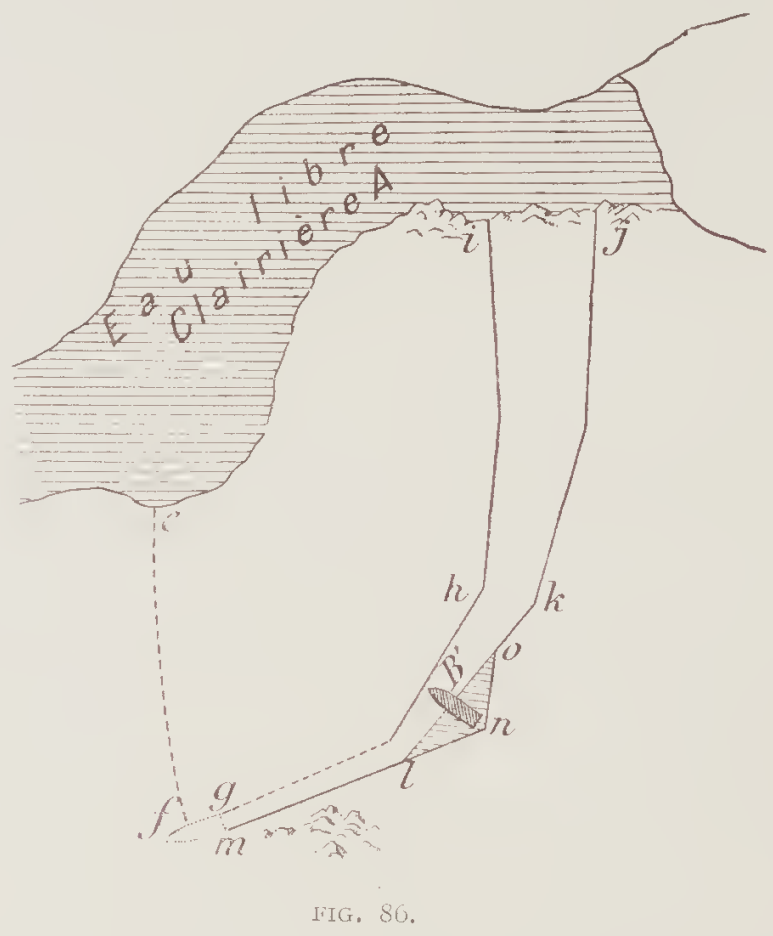

Anxieux, nous travaillons, nous regardons! Toutes nos pensées, toute notre âme appellent la détente.

Elle se produit. La Belgica à l'affùt se lance à pleine vapeur vers le barrage de glaces accumulées à l'emboutehure, le fait voler cn éclats et. sans plus d'obstacle, vogue triomphantc dans la grande clairic̀re.

Aucun mot ne pourrait rendre le sentiment de délivrance, de joie, d'allégresse qui gonfle nos ecurs.

Je jette un dernier regard vers le champ de glaee qui nous a retenus si longtemps prisonniers, vers le canal qui nous a coùté tant d'efforts, puis mes yeux ravis se tournent vers le Nord! 


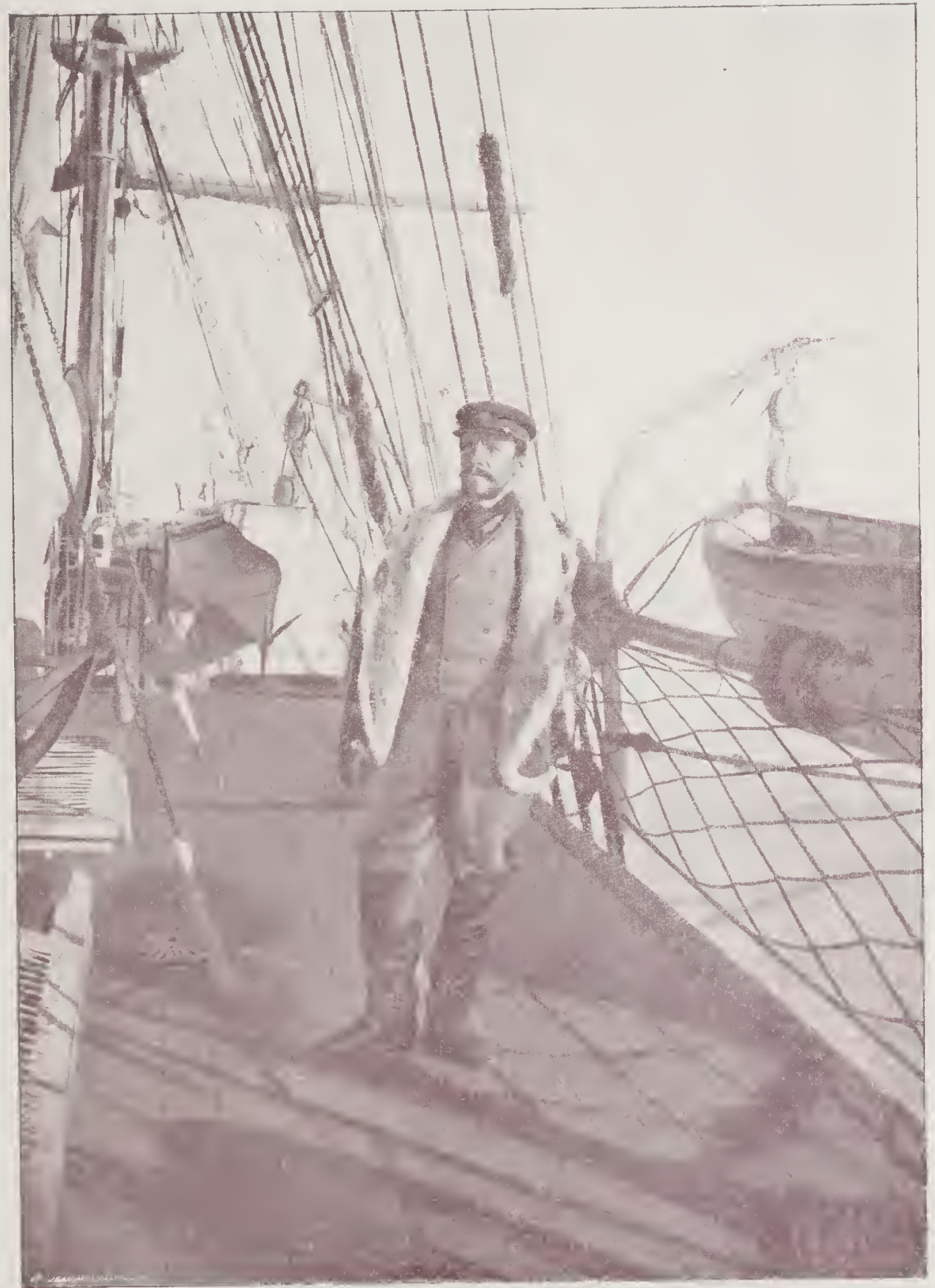

Photorraphite in 1): Cuok

FIG. 87 .

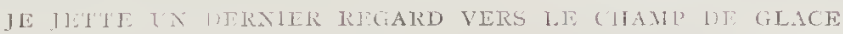

QUI NOT' A RIITALS SI LONGTLMLS PRISONNILRS. 



\section{CHAPTTRE XIXIX.}

\section{Bloqués à la lisière.}

Les jours qui suivirent notie délivranee furent utilement employés à l'aménagement de la Belgica, en vue de lá navigation ordinaire et surtout en prévision des tempêtes que nous aurions valisemblablenent ¿ affronter, dis que nous nous trouverions en plein océan. Ifin de conner au navire la stabilité nécessaire - car, en un an, nous avions consommé pas mal de charbon et de vivres - les seizo grancls réservoirs de la cale furent remplis d'eau de mer.

Lc quart se faisait constamment du nicl de conteau : il était indispensable de scruter un vaste horizon, pendiant ce long trajet qui nous sćparait de la mer libre et que nous devions pareourir en nous faufilant avec adresse entre les eliamps de glace.

I.c I 6 février, au soir, nous constatons que, depuis deux jours, nous avons gagné I 8 à 20 milles vers le Nord. In réalité, nous avous parconru un chenin bien plus considérable, étant donnés nos nombrenx circuits entre les nappes. P'al contre, nous avions souvent la surprise de maviguer sur d’immenses laes, au milieu diesquels la Belgica bondissait éperdue, ivic de liberté! A la lisière de ceux-ci, la lutte reommençait. Le navire se précipitait entre deux champs, essalyant de les séparer, puis se trourait artèté. Alors nous faisions macline arricre el, brsque nous arions assez (le place pour rendre à la proue son ćlan, nous renversions brusquement la mardie. ('es comps de bélier répétés finissaient par aroir raison de la glace, qui. d'aillents,

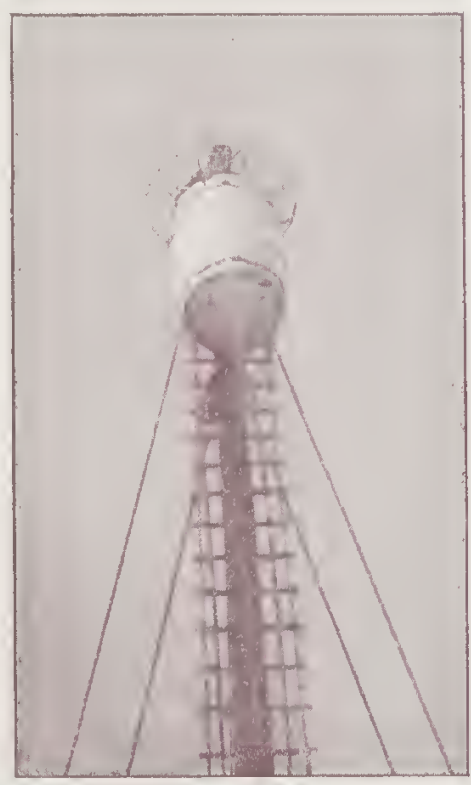

I'wit. flu I)r cook, FIC, I. I: UCAKT SE I. II DU NII) 1)]: ("OKEIAU. 
paraissait beaucoup plus friable et était composée le plus souvcnt de nappes peu étendues. Parfois encore, nous longions de vastes champs. Une chose nous était surtout défavorable, c'était la direction longitudinale des clairières, qui, étant presque toujours perpendiculaires aux vents des derniers jours, étaient orientées de l'Est vers l'Ouest. Nous devions donc traverser ces clairières dans leur largeur seulement.

Ce soir, nous sommes arrêtés non loin d'un superbe iceberg tabulaire et, comme nous avons aperçu des manchots, nous mettons un canot à la mer pour une partie de chassc. Nous sommes cinq : Racovitza, Amundsen, Mélaerts, Van Mirlo et moi. Nous rentrons avec du butin, tous très satisfaits à l'idée de cette chair fraìche qui nous reposera des conserves.

A peine sommes-nous à bord, que la brise se live et le ciel s'obscurcit. Nous sommes sccoués par une violente tempête, analogue à celle qui a favorisé, il y a un an, notre entrée dans la banquise.

Bien que les glaces nous enlacent à nouvcau, nous ne voyons là aucun mauvais présage. De plus, comme j’ai une faim de loup et que je ne vois plus la nécessité đle l'abstinence, je consomme, en une fois, non seulement les provisions économisées sur mes précédentes rations, en prévision des jours de miscrre noire, mais encore les rations de toute une semaine qui viennent d'c̀tre distribuées. Je suis tellement certain de la délivrance, que je fais mème des générosités à mes compagnons de quart.

Le 3 mars. - Nous sommes toujours immobilisés au même endroit; la banquise demeure compacte, mais les nappes s'agitent dans tous les sens contre les flancs du navire, ce qui constitue pour nous un danger réel. Certaines plaques étant particulièrement inquiétantes, nous les avons morcelées avec des explosions de tonite et leurs fragments, ainsi groupés, nous fournissent un matelas, contre lequel s'amortit la pression.

Nous sommes toujours à la ration, car il se pourrait fort bien que nous ne fussions pas dégagés cette année. Combien je regrette d'avoir- 
consommé si rapidement mes vivres de réserve! C"est une amère leçon pour mon imprévoyance.

D’un autre côté, comme le pétrole va faire défaut el que déjà les jours deviennent courts, il est temps de soccuper de la guestion " éclairage ». La recherche d’un procédé brillant et ćconounique est mise atl eoneours.

Cook fait valoir le système des Escpuimaux : un réservoir rempli de morceaux de graisse de plioque dans lesquels on pique plusicurs mèches. Ce luminaire donne peu de clarté, empoisonne l'air par une odeur nauséabonde et oceasionne une véritable pluie te noir do fuméc. Hais, a part cela, c’est très bon!... Cook, très frer de sá nourelle lampe, la tient allumée, mème le jour!

Lés deux mécaniciens ont enfanté, chácun, des procédés assez compliqués. Lá lanteme de Van Rysselberghe est grossc comme une maison et loge une flamme microscopieque et vacillante.

Déeidément Ráeovitza a le pompon! Inncoulágé pár le sucese il fonde avec Aretowslí une véritable huilerie, ou l'aneienne maeline hache-viande (prise à l'insu de Michotte) est utiliséc pour découper lá graisse de phoque. Son laboratoire fournit les étamines, celui cl'Aretorrski les filtres. En deux ou trois jours, ils ont une usine morlile.

Mlais l’ingénieux Van Mirlo parvient à leur dancr le pion en falrriquant, dans de vicilles boîtes à conserves et sáns grand'peine, une huile très peu inférieure à celle du laboratoire.

Cook, moins préoceupé par les malades, cherche un nouvel aliment pour son activité : il déclare qu’il est nécessaire de construire un canot en peatu de ploque. Comme il ne parvient pas à nous émouvoir en fareur de son projet, il annonce solennellement que son canot a un but scientifique : fátoriser les lointaines exeursions, de manicie à ćludier sur une plus vaste échelle les différentes formations des grlátces.

Cet argument ne lui fournit pas plus d'adeptes, mais comme il a rrononeé le mot "scientifique ", il devient impossible (le ne pas lapprouvei. Cook est done mis en possession de peaux de ploque et de ricilles planches, et, ce matéricl ne lui sulfisant pas, il rôde dauns 
tous les coins, dans toutcs les chambres même, à l'affùt d'un morceau de bois. Si on le laissait faire, il scierait, pour son tameux canot, la table, la bibliothèque et les armoircs du carré.

Le 6 mars. - Depuis quelques jours, nous ne sommes plus seuls. Des manchots de la Terre Adélic ont élu domicile auprès de nous. Au

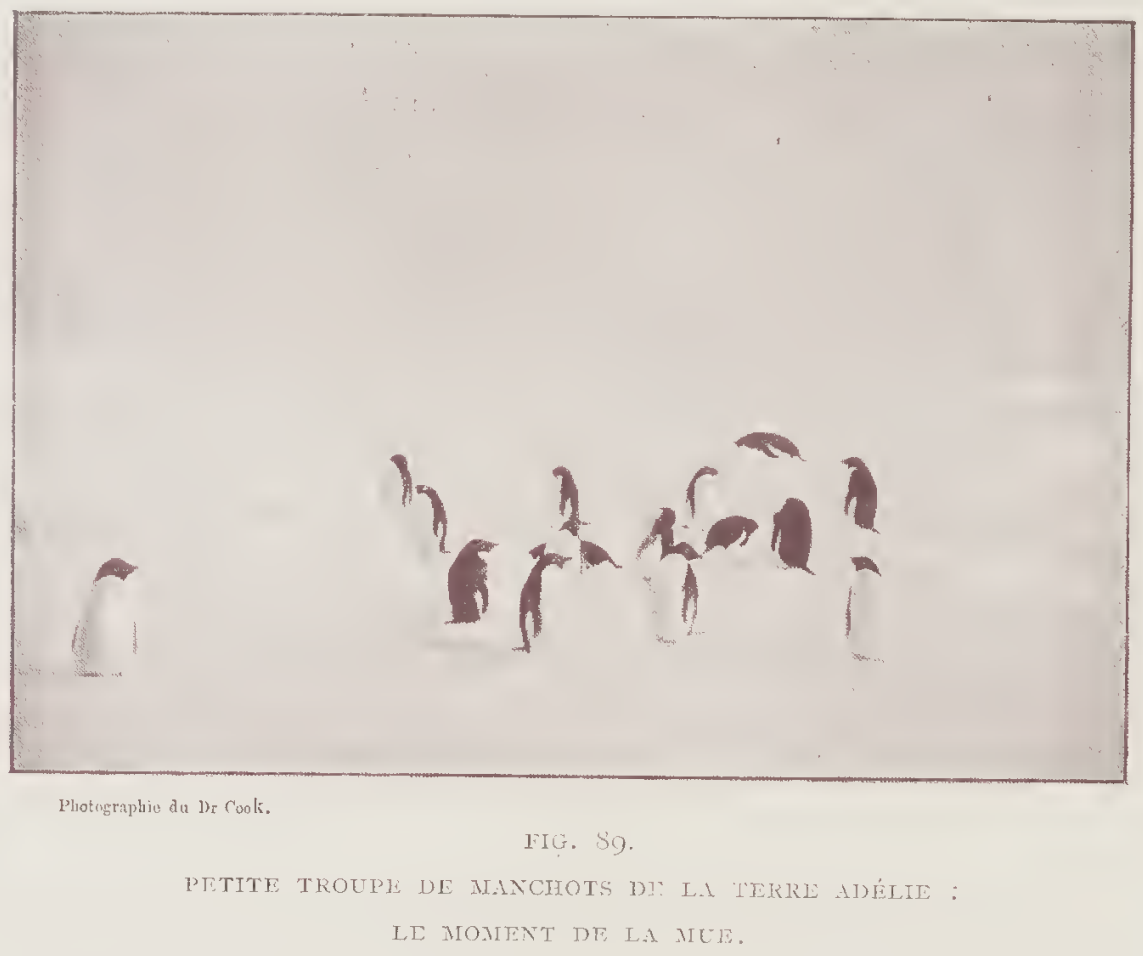

début, on en a tué un certain nombre, mais Racovitza, le seul qui sache les dépecer convenablement, a fini par se lasser de ce travail. Il a déclarć que les deux petits bcefsteaks fournis par chaque manchot ne valent pas la peine qu'il se donne pour lc dépeçage; il estime donc que les phoques seuls doivent être cxécutés. Et, pour achever de nous rallier à son idće, il déclarc qu'il faut, au contraire, épargner les manchots qui se trouvent dans nos parages, car ils sont, à cette époque de 'année, particulièrement intéressants à étudier.

C'est, en effet, le moment de la mue. Les manchots se réunissent 
par groupes de 8 à Io; puis, cherchant un abri derricre les hummoclss, ils demeurent à peu près immobiles, en proie à la fièvre. Insensiblement, la petite troupe grossit, mais mon sans difficulté, car chaque fois qu'un nouveau venu se présente, ce sont des explosions de colère chez ceux qui sont déjà installés. Ils ouvrent le bec démesurément, en tendant le cou et agitent leurs petites ailes. Peu à peu, le calme renaît, on fait place aux nouveaux arrivés et ils demeurent tous là, tristes, enfiévrés, sans prendre de nourriture. Puis, leurs beaux pardessus tombent en micttes, comme mangés par les mites, tandis que, honteux, ils se cachent ou ils peuvent.

Le 8 mars. - Notre position devient chaque jour plus eritique. Depuis le 27 février déjà, Michotte, du nid de corbeau, a constaté à l'horizon une étroite ligne noire, en deçà de laquelle des points blanes montent et descendent. Nul doute ne subsiste donc à cet égard : c'est bien la lisière de la banquise et la houle de l'océan. Cette houle nous arrive maintenant en grandes ondes qui chassent les nappes de glace contre nos flancs et y accumulent une véritable "enceinte ", tandis qüà quelques milles de nombreux icebergs forment les "points d'appui " le notre "ligne avancée ".

Impossible d'exécuter encore des mesures de précision sur cette banquise instable et morcelée.

Les observations astronomiques assignent aetuellement une dérive assez rapide qui nous porte vers l'Ouest-Sud-Ouest. Notre premic̀re hypothèse va-t-elle se réaliser et serons-nous entraînés dans la mer de Ross?

Un fait semble déjà certain : l'apparence de terro que signale Walker par 102 degrés de longitude Oucst et par 71 degrés de latitude australe est un mythe, car notre dérive nous fait passer à l'endroit même où cette terre était censée se trouver.

Le ro mars. - J'ai eu un long entretien avec de Gerlache. J'avais terminé le tracé préliminaire du nouveau détroit, et il convenait de baptiser les parties de terre et de mer, afin d'en donner la deseription dans nos rapports scientifiques. 
Avee un taet tout partieulier, de Gerlaehe désirait que nous fissions cnsemble ee baptême, qu'il avait le droit de régler à sa fantaisie.

Je eollaborai done eomme conseil, ne désirant intervenir personnellement que le moins possible.

Ce travail a été repris ensuitc en présenee de Raeovitza, Cook, Arctorski et Amundsen. C'était très intéressant. Il fallait éviter les oublis et s'efforeer de distribuer les noms des proteeteurs de 1'Expé-

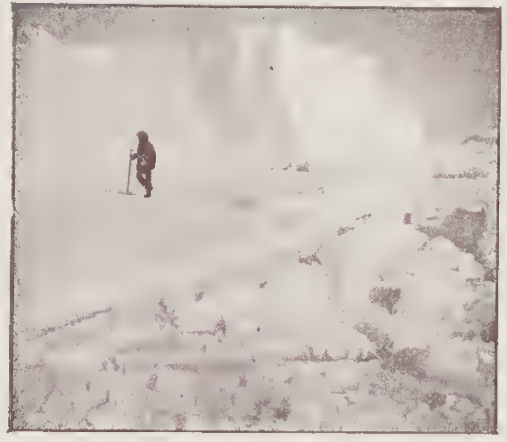

Pho* du tor Cuok

11G. 90. - A LA LISITERE. dition de manière à proportionner l'importance des parties de terre ou de mer repré sentées à l’importanee des services rendus avant notre départ d'Europe.

Certains noms subirent de tcls déplaeements, qu'en eet après-midi seulement ils voyagèrent;'îile en eap, de eap en détroit, de détroit en baie, de baie en montagne, etc.

C'est eette question de répartition proportionnelle qui nous avait empêehés de baptiser les déeouvertes, au fur et à mesure qu'elles se présentaient.

Le I3 mars. - Il y aura demain un long mois que nous avons quitté notre champ d'hivernage et que nous sommes prisonniers à lá lisière de la banquise, sans ecsse roulés et agités par le tangage.

Du nid de eorbeau, nous apereevons l'oećan libre de glace et, suppliee de Tantale, nous ne parrenons pas à l'attcindre.

Ce soir, les mouvements de la banquise sont extraordinaires; la houle et le vent poussent les ieebergs dans tous les sens. Non loin de nous, un groupe serré semble vouloir nous aborder. Rien à faire devant cette menaee de eollision qui nous éeraserait, que d'attendre ct d'espérer. Le mereure du baromètre marin monte et deseend ineessamment : e'est eomme si le navire était brusquement enlevé, puis replongeait dans la mer. Les lames, sous la glace, atteignent-elles donc une telle hauteur?

Le If mars, 2 herres du matin. - Depuis hier à I I heures du soir, 
notre marche vers les icebergs s'est ralentie et la houle a diminué. A minuit, les glaces se sont disjointes, la détente a commencé. Mais lobscurité nous a empêchés d'en profiter.

Voici enfin le crépuscule. On hisse les voiles, on cale les soupapes de sûreté, afin de faire monter la pression à son maximum, et, de nouveau, le cylindre de basse pression est employé comme cylindre de haute pression; nos efforts sont surhumains. Peu à peu, nous nous dégageons de l'étreinte, nous avançons, la détente nous aide, les champs de glace se font de plus en plus mignons. Voici, enfin, le dernier, plus d'obstacles! Cette fois, c'est l'Ocćan sans entraves, c'est la liberté!...

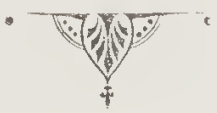




\section{CHAPITRE XL.}

\section{Vers Punta $=$ Arenas.}

Quelles sensations multiples se suecèdent en nous, pendant ees premiers instants de la délivrance! Quelque ehose d'infiniment heureux, et pourtant mêlé de tristesse, de regret, s'agitait au fond de nos ecurs: Adieu à la banquise avee son eortège de souffranees et de deuils, mais qui nous a donné, dans l'âpre joie de la déeouverte, un sentiment de fierté et d'orgueil que plus jamais nous ne revivrons! Adieu à nos pauvres eompagnons, Danco et Wieneke, qui ont été la rançon de notre salut à tous! Hourrah pour l'Oeéan sans limites, qui nous emporte au loin, vers le pays, vers tous ceux que nous aimons! Ah! puissions-nous les retrouver tous?...

Le ciel, au-dessus de nous, étend de sombres nuages; la mer est d'un beau bleu foneé, sur lequel nos regards errent délieieusement après avoir été éblouis si longtemps par la lumière diffuse de la banquise; la Belgica glisse et bondit tour à tour, toutes voiles dehors sous un vent favorable. La nuit, des animaux phosphorescents illuminent les vagues et avec l'embrun sont projetés jusque sur la passerelle.

Quelle voie allons-nous suivre pour amiver à. Punta-Arenas? Car la saison est bien trop avaneée pour que nous puissions exécuter notre projet d'expédition au cap Gauss .

Trois routes s'ouvrent devant nous : eelle du eap des Vierges, peu avantageuse à eause des vents dominants de l'Ouest, qui entraveront notre marche dans le détroit de Magellan; celle du cap Pilar, qui nous fait entrer, par l'Ouest, dans le détroit, et nous permet de gagner Punta-Arenas avec le vent arrière; eelle du canal de Coekburn, enfin, qui nous fait pénétrer dans le détroit, par le Sud, en mous faufilant entre les Furies de l'Est et les Furies de l'Ouest. Cette 


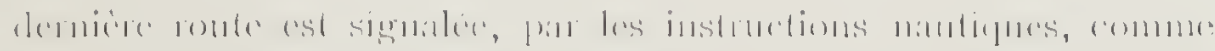

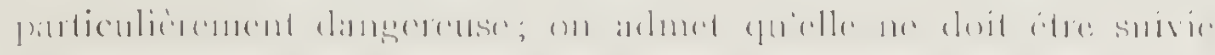

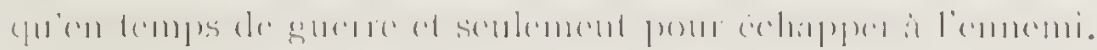

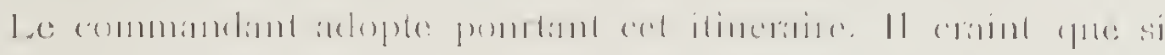

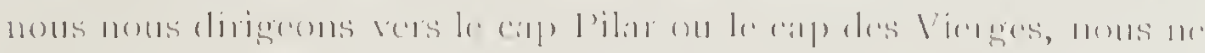

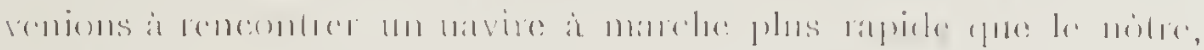

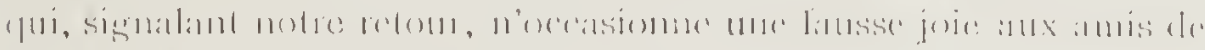

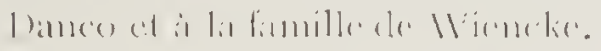

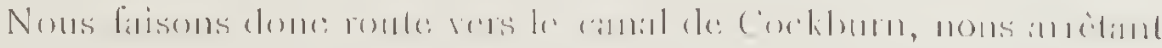

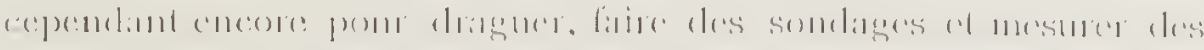

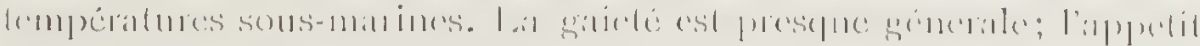

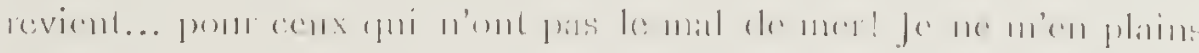

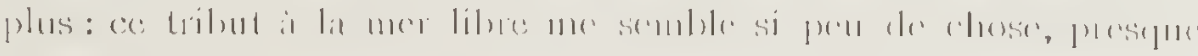
:sicillu!

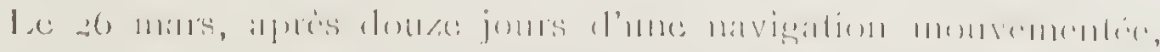

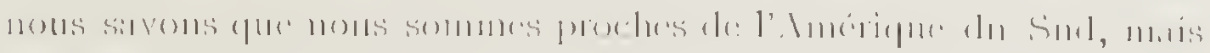

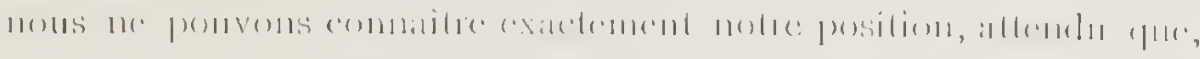

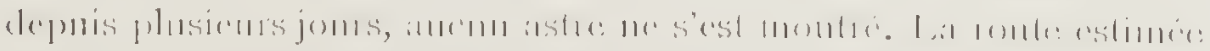

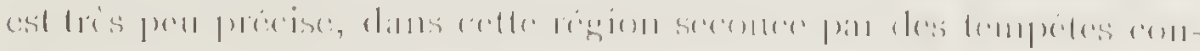

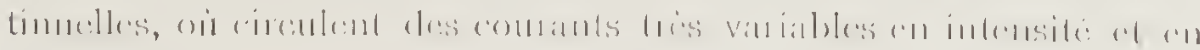
lifeceli(u).

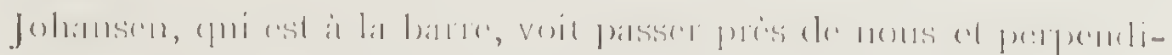

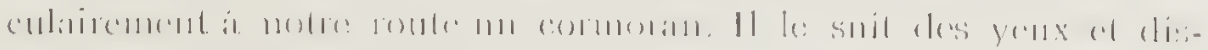

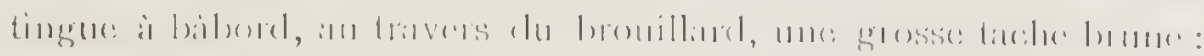

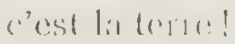

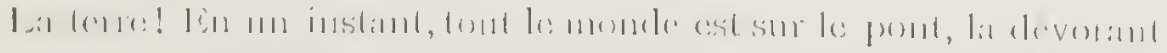

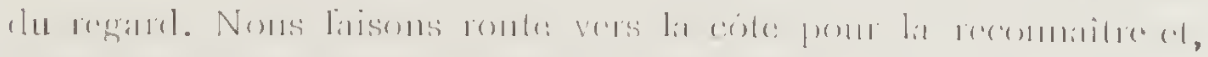

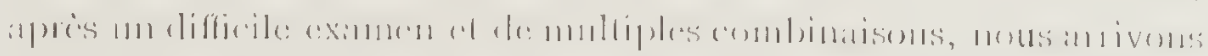

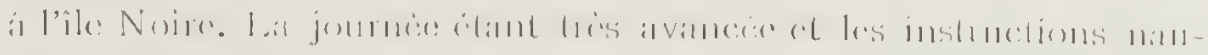

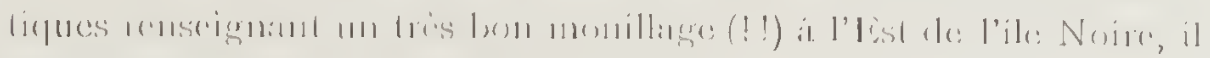

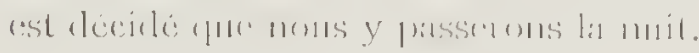

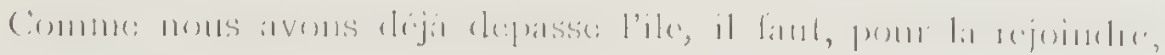


facilement distinguer les roches à fleur d'eau (I). Luri-même prend lo quart sur la passerclle, car nous sommes dans une région où les récifs forment un si long chapelet, qu'on leur a donné le nom de voie lactée.

Mon ascension dans la mâture par cc temps épouvantable, sur ce navire qui roule de $40^{\circ}$ sur chaque bord, me dégoûte profondément!

En bas, sur le pont, je vois Racovitza, Cooli et Arctorvslí se maintenir tant bien que mal sur la dunette arrièe : ils devinent le mal qui mc ronge et me jettent des rogards de commisération!

Ouf! me voilà dans le nid dc corbeau. J'y puis être malade, sans crainte de dégringoler dans la mer. Je m'installe dans le tonneau et fais gaiement mon quart.

Lorsque je redesccnds, une heurc plus tard, de mon poste d'observation, nous doublons les Furies. La tempête souffle cncore au large, mais nous sommes à l'abri dans lc canal de Cockburn, où la mer s'ondule simplement sous lcs rafales qui descendent des hauteurs.

Toute la journéc et la nuit, nous naviguons dans le détroit ct le lcndemain, 28 mars 1897 , nous mouillons, à 6 heures du matin, à Punta-Arenas.

Notre entrée dans la rade y occasionne quelque étonnement : on nous croyait morts depuis longtemps!

Des gens peu scrupulcux avaicnt profité de notre silence pour l'interpiéter comme un désastre, et vendre à la presse des renseigncments à sensation.

Un capitaine de navire déclarait même avoir aperçu notre éparc non loin des Shetland du Sud.

Un autre affirmait nous aroir rencontrés près du cap Adare, au moment où nous allions nous cngager dans la mer de Ross. Mais ce qui est un comble, c'cst que, dćclarant être montć à bord de la Belgica,

(1) Du haut du màt, on reconnaît les roches sous-marines à la teinte rerdâtre que l'cau prend au-dessus. 
prendre le rent presque debout. Mais qu'à cela ne tienne : Somers fait exécuter un tour de force à sa machinc en la poussant à donner cent ringt-cinq tours à la minute. Tout le personnel scientifique est requis pour la manceuve des voiles; l'animation est si grande, qu'on clirait que nous allons monter à l'abordage.

$\Lambda 6$ heures du soir, à la brune, l’ancre tombe et la Belgica mouille devant wne terre.

L'ile Noire porte bien son nom : c'est un énorme massif sombre, coloré à de rares endroits par une maigre végétation. Telle quelle, cette premiire terre que nous revoyions nous paraissait un éden. Malgré l'obscurité, la pluie et le brouillard, plusieurs d'entre nous auraicnt vivement désiré aller à terre, mais la mer était trop mauvaise pour qu’il fùt possible d’amener un canot. Il fut donc décidé ‘ue, le lendemain matin à 6 heures, si l'océan s'était un peu calmé, nous cxécuterions un débarquement.

La nuit fut mauraise. I a mer, en fureur, cherchait à nous arracher à notre abri; nous dûmes filer de la chaîne.

I,c 27 mars, à I heure du matin, l'ancre dérape. Tite, nous filons cncore de la chaîne, mais inutilement : le rent nous pousse vers un récif dangereux. Il faut à tout prix relerer l'ancre. 'Tout le personnel se met à la manœuvie! C'est cn rain : voilà le récif, nous y courons droit. Il n'y a qu'une issue : abandonner ancre et chaîne et fuir à toutc vapeul...

Le navire, brusquement dégagé de ses liens, hésite un moment, ¿́tourdi, puis file droit vers les I'uries, excité par la machine, aiguillonné par l'ouragan qui nous chasse de l'aric̀re et gonfle nos voiles à les crever.

Le spectacle de la mer démontée est superbe, terrifiant; il contraste puissamment avec les déplacements lents et continus de la banquise.

Entraînés avec une vitesse vertigineuse, nous atteindrons bientòt les Iruries. de Gerlache me prie d'aller faire le quart dans le nid dc corbeau, d'où je reconnaitrai mieux les îles et d'où je pourrai plus 
il donnait le compte, rendu de son interview avec de Gerlache et moimême !...

Un troisieme capitaine, aussi ignorant que menteur, avait assuré que nous lui avions montré les cales de la Belgica remplies d'or ramassé, par blocs, presque à fleur de sol. Il déplorait notre sinistre, ne fût-ce que pour les milliards qui avaient sombré arec nous.

Enfin un quatrième personnage avait fait la déclaration suivante: " J'avais mis à bord de la Belgica une couple de mes meilleurs pigeons voyageurs. Les oiseaux me sont revenus avec d'importantes dépêches. "Suivaient toute une série de découvertes plus extravagantes les unes quc les autres.

Comme Punta-Arcnas n'est pas relié au réseau transocéanique, nos dépêchcs ne furent portées à Montevideo que quelques jours plus tard; de sorte qu'elles ne parvinrent à nos familles, en Belgique, que le I4 avril. Or, l'anxiété était grande, car les lettres, qui nous avaient été envoyées en Australie venaient de rentrer en Europe.

Aussi, peu de nouvelles missives nous attendaient à Punta-Arenas. Pour ma part, je n'en trouvai qu'une seule et avec cette adresse sommaire :

\author{
Monsicur Lecointe \\ à bord de la BEigICA \\ Dans un port de l'Amérique du Sud.
}

Dès que notre mouillage cst signalé, nous recevons des visites assez intéressées : des consuls " marchands " qui viennent solliciter l'avantage de nous ravitailler. Ayant reçu nos commandes, ces messieurs veulent bien nous mettrc au courant des principaux événements qui se sont passés depuis nos quinze mois d'absence :

I. Les "pacifiques " Etats-Unis d'Amérique - Cook cn fait une tête! — ont écrasé militairement l'Espagne, puis se sont montrés très larges pour le ríglement défnnitif des affaircs;

II. Les Européens ont décidé de ne plus faire la guerre et de 
constituer un tribunal international darbitrage. Voilà une nouvelle stupéfiante à laquelle nous ne pouvons ajouter foi ;

III. En France, on a fait beaueoup de bruit autour d'une affaire d'espionnage;

IV. On est parvenu à liquéfier l'air. Voilà une déeouverte seientifique qui nous fait à tous dresser l'oreille;

V. La télégraphie sans fil a fait son apparition. Ces mots redoulblent notre attention.

Des tas de journaux et de revues s'amoncellent sur nos tables, envoyés de toutes les parties du monde. Nous ne les lisons pas. Quel intérêt peut éveiller en nous les menus faits journaliers dont la presse a alimenté ses lecteurs pendant ees quinze derniers mois? Tout eela, vu de loin, est si mesquin, si futile.

Attendons pour nous réinitier que la civilisation nous ait ressaisis.

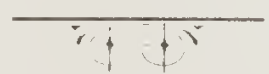




\section{$-342-$ \\ CHAPITRE XLI.}

\section{Retour.}

Retenu à bord par les nécessités du service, je ne descendis à tcrre, à Punta-Arenas, que le lendemain de notre arrivée. En entrant à l'Hôtel de France, j'y trouvai tout notre monde absolument méconnaissable; les chereux coupés, le teint frais, du linge neuf : la civilisation, quoi!

Je fus tout heureux d'en faire autant et, surtout, de prendre un vrai repas, bien préparé et substanticl. Cc fut d'aillcurs une de nos impor* tantes occupations, à Punta-Arenas, de manger copieusement, par besoin, et abstraction faite de toute espèce de gourmandise!

Le 29 mars, nous eûmes une conférence à l'Hôtel de l'rance, dans le but d'arrêter le programme d'une cxploration scientifique dans les canaux de la Terre de Feu.

Ouelques jours plus tard, cc projet fut abandonné, très heureusement, je pense.

Le jour même oì nous avions jeté l'ancre à Punta-Arenas, le matelot I... s'était enfui dans les bois. Tous les deux ou trois jours, il revenait en ville, achetait des vivres, puis regagnait sa retraite Lorsque son argent était épuisé, il guettait, à la porte de l'hôtel, la sortie du commandant, demandait quelques francs, puis disparaissait de noureau. Afin de ne pas l'exciter davantage, on le laissait faire.

Comme il était nécessaire de séjourner quelque temps à PuntaArenas pour réparer le navire et refairc la santé chancelante de plusieurs hommes d'équipage, le personnel scientifique put reprcndre sa liberté : en conséquenee, Racovitza, Arctowski et Dobrorrolsli regagnèrent l'Europe par paquebot.

Lc lieutenant Amundsen reçut l'autorisation de rentrer cn Norvège, afin d'y ramener l'infortuné Y...

Ce dernier ne voulut jamais consentir à retourner à bord de la 
Lidgica, même pour y prendre ses rêtencnts ol ses papiers : on dul les lui enroyer le jour du départ. Il est tris regrettable pue ses calmatratles de poste se soient cru autorisés à lutiker ses papiers et son journal de bord. Cess documents antrient présenté un certain intérèt. Je tiens, pour nua part, à léclarer que je suis étranger à cet acte ot que je blame ceux qui, directement ou indirectement, y out contribuc.

Cook nous quitant également pour aller continure, a lat Torre de loru, ses études sul les () mas, l'état-major se trouva reduit il lorsis nembres : le Cicrlache, Mélaterts et moi.

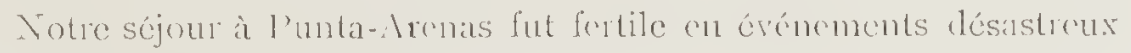
all point de: vue nautiejue.

de Ciedáche et moi descendions, charpue jour, alternativenent i terre. O), un soir pue le temps et la mer élaient calmes, le commandiunt se rendit che\% des Ijelges, à un petil souper aupuel était convié prespue tout notre monde. Comme il s'anissatit de compatriotes, de compatriotes malheureux dins leurs entreprises, de Gerlache avait accepté afun de leur fáre plaisir. Je restai (lone seul a bonel arere Nichotte et quatre hommes d'épuip)age.

lout ì ooup, ringt minutes à peine apris leur départ, le décor change : le vent se déchâne, la mer se lémonte. Let tandis fue je ne hate pour parer ce maurais conp, deux navires, nou loin du notue, brisent leurs chaines et se jettent à la côte! \u uneme instant, clarpuement formidable : notie clânes subit le mene soll! le's hommos nont que le comps de: bondir sur les drisses pour hisser les voiles;

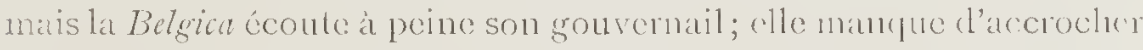
tun navie de guere chilien, puis court, affolece, vers deux goflettes.

()ue: faire? Si je tomme bride, nous comons sur des recifs; si je: m'ábstiens, nous coupons les goćlettos et leur épuipage. Cruclle alternative! lin un instant, j'entrevois la perte de tous les matériatux acepuis par l'expédition el... je garde ma roule! Máis jáa compté sans

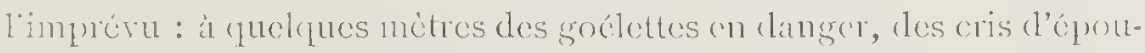
vante me.serrent le corur ; vite, je fais mottre la barre a la coite! Jo frile les goélettes, puis veux regragner le large pour éviler l'écueil. 
Oln! bonheur! le vent, dans un brusque éeart, nous ehasse loin du danger. Alors je prends le large, ct, voyant la mer libre devant nous, jenvoie Dufour et Van Mirlo dans la machine pour allumer les feux, tandis quc le troisième homme restc à la barre ct le quatrième à la manœuvre des voiles! Michotte a l'ordre de nous faire du café assez fort pour ćveiller un mort.

Cinquante minutes plus tard, mes mécaniciens improrisés avaient de la pression : nous pouvions rejoindre Punta-Arenas. La nuit était noire et la rade eneombrée de navircs, dont plusicurs avaient leurs feux éteints par le vent; néanmoins, comme je connaissais parfaitemont le mouillage de chacun d'eux, je risquai l'aventure.

A 2 heures du matin, je laissai tomber l'ancre. Le 1endemain, à l'aube, grand fut mon étonnement: impossible de relcver l'ancre! Le navire ćtant en sécurité, je remis le quart à de Gerlachc, qui renait de rentrer, et je descendis à terre m'informer de ce qui pourait offrir une telle résistance dans ce fond.

J'appris alors qu'à l'emplaeement même où la Belgica était mouillée un crirassé anglais avait sombré jadis.

Les Chilicns insouciants ne pensent même pas à mettre une bouée cu permanenee à ec maurais emplacement.

Pour dégager notre anere, tombée dans la euisinc du cuirassé, au milicu de la vaisselle, il fallu lintervention d'un plongeur - ee qui se paye très cher dans le détroit de Magellan; de plus, l'anere avait une patte cassée. Quelques jours plus tard, pendant que j'étais à terre, un ouragan se leva de nouveau ct fit déraper la Belgica. Heureusement que cettc fois le vent venait de terre et chassait le navire rers le large, ear, tandis que les hommes faisaient des efforts pour relever la chaînc, elle se coinça.

Pendant deux jours, de Gerlache navigua aux hasards des rents, arec un navire lège qui ne gouvernait pas, et dont une ancre pendait à 30 mètres sur le flanc, sans qu'on parvint à la relever.

Lorsque de Gerlache revint à Punta-Arenas, cette demière ancre s'ćtant casscée, il dut s'amarrer à la bouée réservéc aux narires de 
guterre chiliens et dont aucun ne faisait heureusement usage a ce moment. Pendant ces quelques jours, nous avions eu plus d'avaries que pendant toute notre campagne dans l'A ntarctiquc; non seulement nos trois ancres et une chaîne faisaient défaut, mais nos écubicrs euxmêmes étaient brisés. Impossible de prendre la mer dans ces eonditions.

Le temps nécessaire pour ces réparations fut long dans ce pays où il n'existe guère d'hommes du métier et où ces rares ouvriers ne travaillent que " quand et comme il leur plaît et sous promesse de prix exorbitants ". Nous pûmes donc faire à loisir une ćtude approfondie des us et coutumes des habitants dc la Patagonic et même de leurs débouchés commerciaux.

A la fin de mai, le navire était prêt. Afin de payer l'addition, de Gerlache revendit, à un dépôt de conserves du Noureau Mondc, le stock de Kjoedbollers, Kjoedpolsers, etc., que nous avions économisés avec tant de soin dans l'Antarctique!...

Depuis quclque temps, de Gerlache m'avait fait une proposition que j'arais acceptée avec plaisir : il s'agissait de faire, aree deux Français, MM. Gcx et Poirre, un voyage de reconnaissance dans la Cordillère des Andes. Cet aller et retour de l'Est à l'Ouest de l'Amériqute du Sud, à la hauteur environ du $5 v^{e}$ parallèle, me permettrait non seulcment d'examiner les terrains en litige que se disputaicnt le Chili et l'Argentine, mais encore de tracer une ligne d'observations magnétiques. Il fut donc convenu que la Belgica me conduirait à SantaCruz ct que de Gerlacho m'attendrait à Buenos-Ayres, pendant un mois.

Comme l'hiver austral s'arançait et pouvait nous retenir prisonnicrs dans la Cordillère, de Gerlache dexait faire voile pour l'Europe si, après ce laps de temps, je n'étais pas de retour.

Au commencement de juin, nous entrions dans le Rio de santa- 
Cruz où, très gracicusement, nous allàmes échouer sur un banc de sable, placé en arant de l'île Lion. Cet échouage n'avait rien d'étonnant, puisque nous n'arions pas la carte du fleuvc.

Comme l'amplitude de la maréc, à cet endroit, attcint jusque I 8 mètres, le navire, au moment du reflux, se trouva complìtement à sec; il fallait mème parcourir plusieurs containes de mètres pour arriver à l'eau. Cet accident nous fournit l'occasion d'inspecter avec soin la carine. Nous ne courrions aucun danger: nous étions couchés sur un moelleux banc de sable, qu'on dit tris riche en pépites d'or!

Le ıo juin, au matin, le narire étant remis à flot, je quittai la Belgica et partis pour la Cordilière des Andes avec les deux ingénieurs français, MMI. Poivrc et Gex (I); deux marins de la Belgica, Johansen et Koren, et deux domestiques, dont un nègre.

Commc matériel, je disposais du grand canot de la Bclgica, de deux tcntes et de virres pour trente jours. Deux troupilles de chevaux, dont une sur chaque rive du Santa-Cruz, pouvaient remorquer le canot et nous servir de montures.

Alors, tandis que de Gerlache allait m'attendre à Bucnos-Ayres, nous parcourùmes en plein hiver, pendant soixante jours, les pampas de la Patagonie et la Cordillère des. Indes près des lacs Argentin ct de Viełma. L'hirer étant terminé, je parvins à rejoindre Santa-Cruz, où la Belgica avait levé l'ancre, comme c'était convenu, depuis un mois. M. Poivre, Koren ct lc nìgrc avaicnt dù me quittcr dès le début de la campagne, afin de ramener à la côte Johansen, atteint d'unc grave maladie.

De Santa-Cruz à Buenos-Ayres, je nariguai sur un navire dc guerre argentin et là, je m'embarquai, pour l'Europa, à bord d'un rapide des Messageries Maritimes, ce qui me permit d'arriver, avant de Gerlache, à Boulogne-sur-Mer, ou nous nous étions donné rendezvous arec Arctorrsli et Racovitza.

(I) II. Georges Gex est mort depuis, accidentellement, en Argentine. 


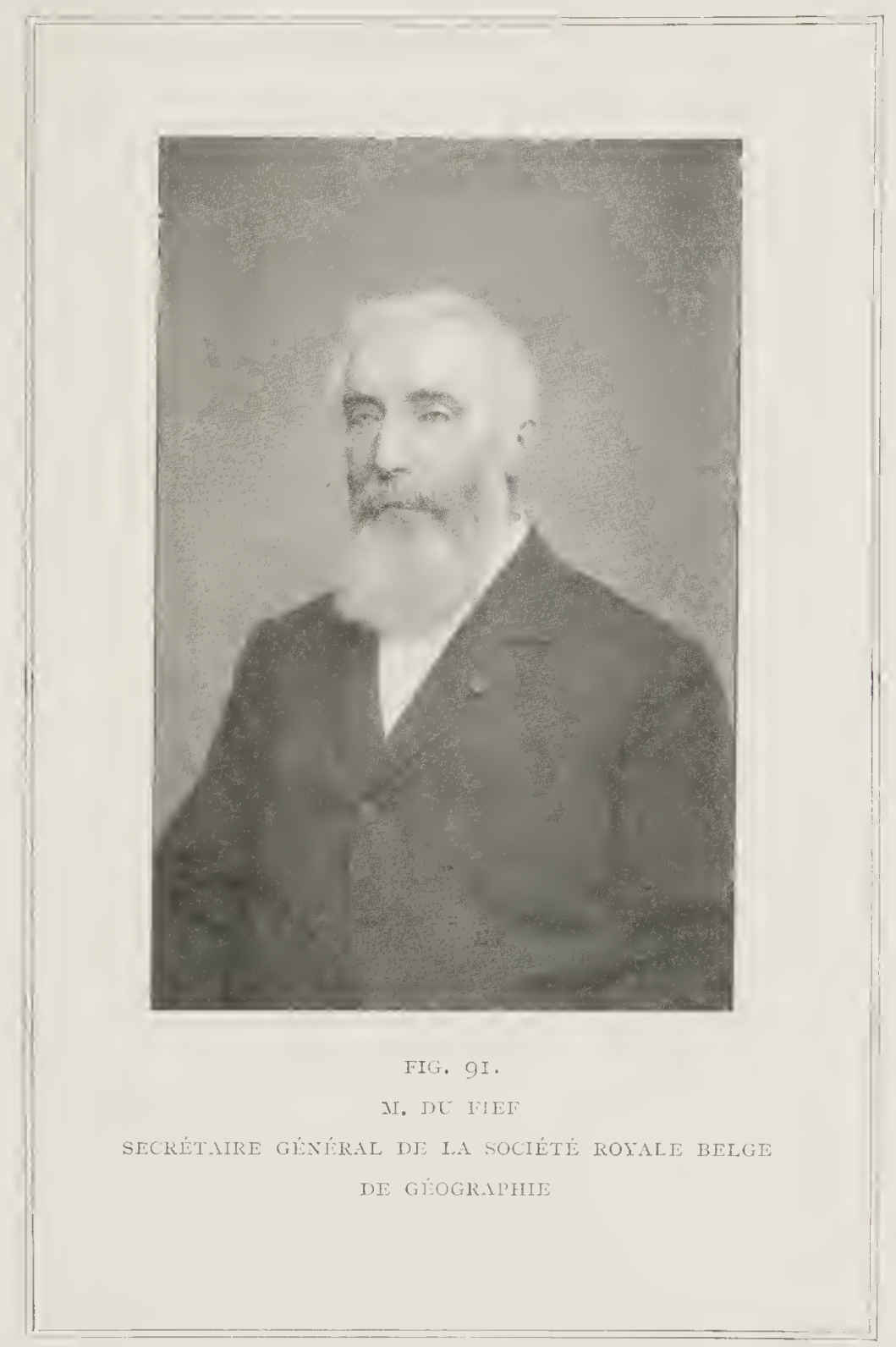



A la fin du mois d'oetobre I899, nous étions tous réunis à Boulogne-sur-Micr, d'où, le 29, nous nous dirigeâmes vers Anvers, par petites étapes.

Le 5 novembre, la malle-poste Princesse Clémentine, envoyée par le Gouvernement à notre reneontre, nous rejoignait à la frontière et nous eseortait jusqu'à Anvers avee toute une flottille de yaehts et de bateaux de plaisance.

Sur le navire officiel se trouvaient M. de Trooz, sueeesseur de M. Sehollaert eomme ministre de l'Intérieur et de l'Instruetion publique, puis le délégué du ministre de la Guerre, de nombreux offciers, des membres de l'Académie royale de Belgique et des Soeiétés savantes du pays.

Le grand eanot de parade du Roi nous eonduisit à bord de la malleposte, où M. Dejardin, le sympathique président de la Soeićté royale de géographie d'Anvers, ouvrit la séance de réception par un trís éloquent discours. Alors, le Ministre de l'Intérieur et de l'Instruetion publique, après nous avoir, de sa voix elaire et chaude, souhaité en termes élevés la bienvenue, fit lonner leeture des arrêtés royaux eréant chevaliers de l'Ordre de Léopold les membres de l'état-major et du personnel seientifique et déeernant la déeoration civique à l’équipage.

A 1'hôtel de rille d'Anvers, la réecption fut enthousiaste.

Quelques jours plus tard, lc Roi nous recevait en audience spéeiale.

Puis ee fut Ja Société royale belge de géographie qui organisa une fête superbe, présidée par S.A. R. le Prince Albert de Belgique et suivie d'une soirée à l'hôtel de ville de Bruxelles.

Puis encore l'Aendémie royale de Belgique, qui remit une médailie d'or aux membres de l'état-major.

De toutes parts, les réeompenses affluèrent: médailles d'or, d'argent, de bronze, diplômes, nominations eomme membre d'honneur de nombreuses soeiétés seientifiques.

Ainsi, ayant " tous été à la peine, nous fûmes tous admis à l'honneur s et à la joie. 


\section{CHAPITRE NLII.}

\section{Conclusions.}

L'expédition de la Belgica n'avait pas pour objectif d'atteindre une haute latitude; clle s'était donné pour mission de seruter, aree le plus de soin possible, un coin de la raste région de l'Antarctique, région dont l'étude préliminaire et hardie avait été l'neuvre des Cook, des Bcllingshausen, des Biscoë, des I)umont d'Urrille, des Balleny, des ITilkes et des Ross.

Au point de rue géographique, l'expédition a étudié la région située au nord de la Terre de Graham. Elle y a décourert un vaste détroit - le détroit de Gerlache - dont les còtes ont été relevées arec soin et sur lesquelles vingt débarquements ont été opérés.

L'existcnce de ce détroit ne constitue pas sculcment une découverte gćographique sans utilité; dans la suite, il offrira des abris sûrs aux navires chassés par la tempête jusqu'au Shetland du Sud. Là, naîtra peut-être aussi une pêche rémunératrice, car les balénoptères ct les mégaptères y sont très abondants.

Rappelons cncore que, si les missions internationales de 1882 avaient connu l'île de Cavelier de Cuverville, que nous avons releréc, il est probable que l'une d'elles s'y serait installéc avantageusement.

Pendant notre dérive, nous arons été entraînés au Sud de l'île Pierre Ier. Cette île est done isolée ou fait partie d'un très petit archipel.

Le navire a navigué à l'endroit où Walker eroyait avoir aperçu une terre et à l'cndroit où Bellingshausen croyait aroir aperçu la muraille de glace.

Alu point de vue océanographique, l'expédition a rapporté des tracés batlyymétriques et des données importantes sur le fond de la mer, les températures sous-marines et de nombreuses mesures de la densité de l'eau de mer. 


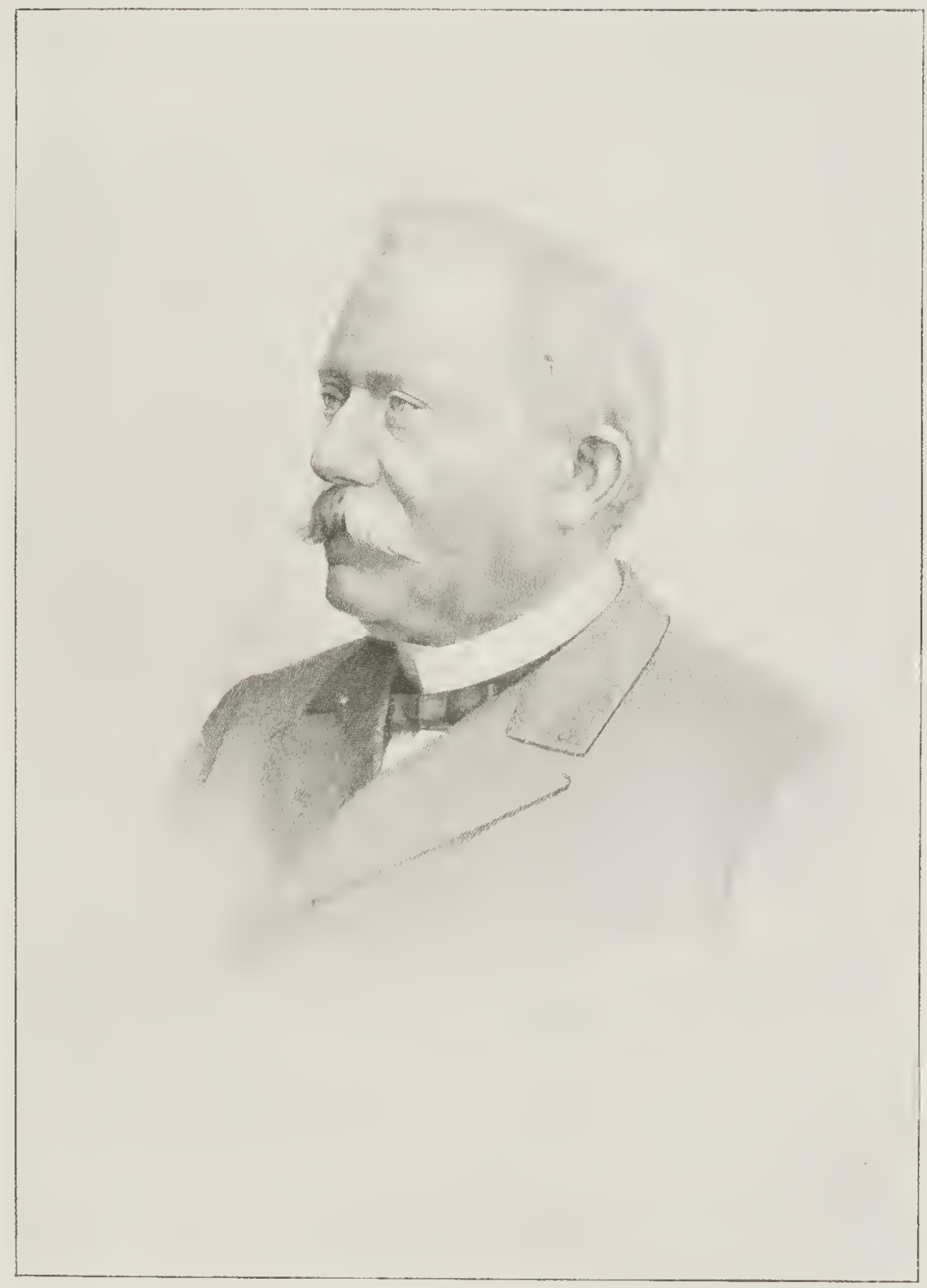

IIG. 92.

I.E IIEUTEAANT-GIENTAL WTIAIAONT

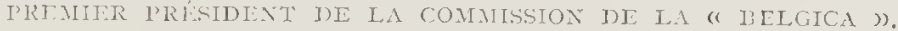



La géologie a recueilli une riche collection d'échantillons et des renseignements importants sur les glacicrs.

L'astronomic et la plyysique du globe ont été l'objet de notre attention; nous arons notamment tracé avec exactitude les courbes relatives au magnćtisme tcrrestrc, courbcs qui, pour cet endroit, étaient dessinćes d'un façon hypothétique.

La météorologic s'est cnrichie des observations qui furent faites, pour la première fois dans ces régions, d'hcurc en heure ct durant une annće entic̀re. I_es aurores australes, les phénomìnes optiques de l'atmosphèrc, les nuages, la ncige et le givre ont été étudiés d'une façon suivic.

Arant l'crpćdition belge, on ne connaissait que très imparfaitement la flore et la faune terrestre antaretiques, et nous sommes les premiers qui ayons rapporté des échantillons de la faunc marine qui vit au delà du cercle polaire austral. Les collections comprennent I, 200 numéros de zoologic et 400 de botaniquc, - encorc ces numéros ne représentent.ils cue des catégories, le nombre des individus ćtant bien plus considérable.

La physiologie humaine a pu s'enrichir d'études, sur nature, des phénomènes qui résultent pour l'homme d'un séjour prolongé dans ce climat rigoureux.

On ne peut non plus passer sous silence les travaux effectués en Patagonic ct à la Tcrrc de Fcu. L'expédition rapporte des documents sur les misérables tribus Onas et Yahgans, dont la race bicntét disparaitra de la terre ; elle a contribué à fairc connaître la faune ct la flore de ces régions ct a rccucilli plusieurs donnécs relatives aux éléments magnétiques sur les rives du Rio Santa-Cruz.

Infin, que ceux qui voicnt des questions sportives dans de scmblables expéditions soient satisfaits d'apprendre que la Belgica est 1c premier navire qui ait hiverné dans la région antarctique. Et cet hivernage a été d'autant plus hcurcux, qu'il s'est effectué à un endroit très intércssant à étudier, à l'cndroit même oủ les Anglais avaient résolu de faire hiverner l'expédition, commandéc par Scott, yui 
s'est dirigée vers l'Antarcticue une année apres notre retour.

Mais si nous faisons abstraction de ccs résultats scientifiques, nous pouvons dirc que l’expédition belge a été pour le pays d’une heurcuse influence morale. Elle a étcndu notrc chanp d'inrestigation qui, jusqu'alors, s'était borné à l'ourre - gigantesque, il est rrai, mais isolée - de la colonisation du Congo. Les Belges ont prouvé que si leurs usines regorgent de commandes qui les enrichissent, s'ils sarent organiser des royages d'exploration commerciale dont ils retirent des monceaux d'or, ils sont capables aussi de travailler avec désintéressement pour payer largement leur tribut à la science.

Oni, le pavillon belge a flotté dignement à la corne de notre navire; il a réreillé les sentiments patriotiques de nos nationaux cu leur montrant mos coulcurs à la conquête de terres lointaines.

L'expédition antarctique enfin a fait justice du préjugć suirant lequel la B̉elerique n'aurait pas les éléments nécessaires pour crécr le bons marins, ni pour fonder une marine nationale florissante.

Mais il ne suffisait pas d'aroir rccucilli de nombrcux documents et de riches collections scientifiques : il fallait mettre ces matériaux èn valeur.

Avec une ampleur de vue qu'on ne peut qu'admiser, N. de Trooz, ministre de l'Intéricur et de l'Instruction publique, adressa au Roi un rapport spécial montrant l'utilité de la mise en raleur de nos natériaux scientifiques et présentant à la sanction roỹale un arrèté qui instituait la Commission de la "Belgza ".

Cette commission était composée des membres de l'état-major scientifique de la Belgica et des nembres de l'Académic royale de !’elgrique qui s'étaicnt specialement voués à la réussite de l'expédition; clle était présidée par le lieutenant-génúral Brialmont.

Quatre-vingts sarants belges et étrangers furent alors choisis par la Comnission pour étudier les collections, les rapports scientifiques et en détcrminer loyalenncnt la valcur. 


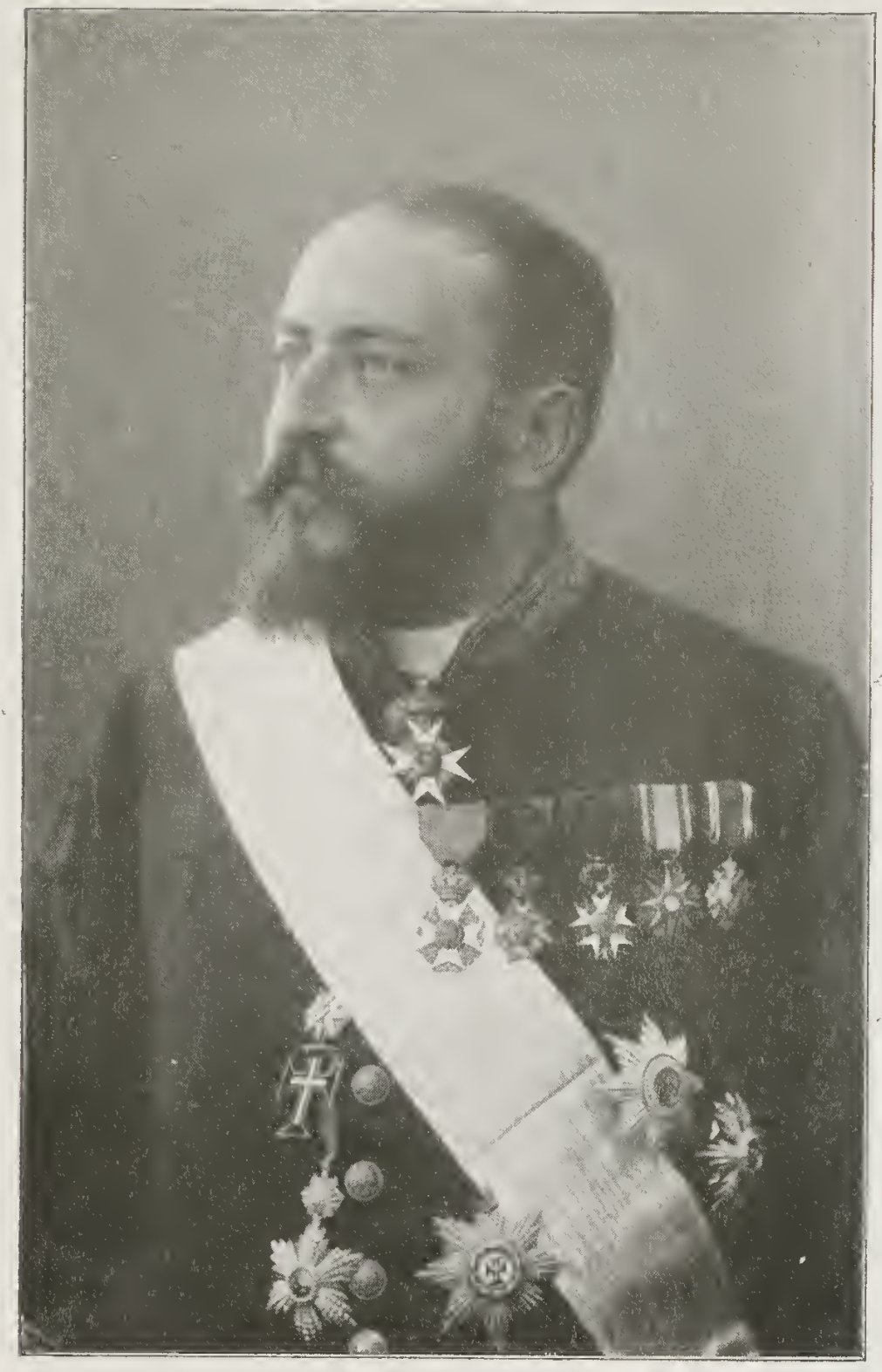

FIG. 93.

AI. J. DE TROOZ

MINISTRE DE L'INTTLRIEUR LT DE L'INSTRUCTION PUBLIOUE 



\section{$-357-$}

Dans un premier devis estimatif, la somme nécessaire aux frais'de publieation des rapports avait été évaluée à I 3o,00o franes; mais, à mesure que l'importanee du travail s'aeeentuait, eette somme fut jugée insuffisante. Alors M. de 'Trooz, ne voulant pas que l'œuvre de ses eompatriotes supporte des réduetions mesquines, sollicita et obtint des Chambres législatives les erédits nécessaires à l'aehìvement complet et dans d'exeellentes eonditions de tous les mémoires seientifiques publiés sous la direetion de la Commission de la Belgica.

Cette mesure arrêtée par le ministre de l'Intérieur et de l'Instruetion publique fut accueillie avec la plus grande satisfaetion par le monde savant. Elle donne à M. de Trooz un nouveau titre à la reconnaissanee des membres de l'expédition antaretique belge.

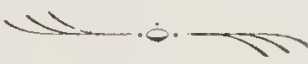





\title{
APPENDICE
}

\section{Composition de la Commission de lat " Belgical "}

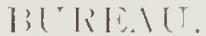

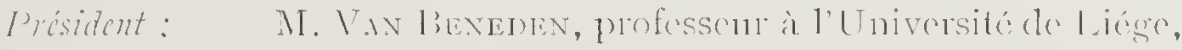

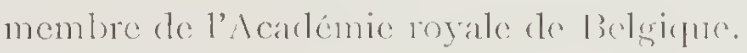

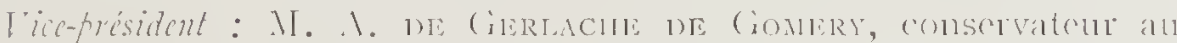
Musée d’I listoire naturelle de l'itat, promotem ef commandant de l'expextition antaretipue belere.

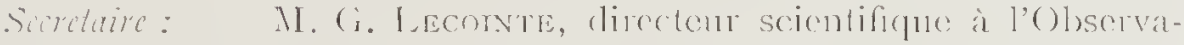
boine royal de lielsique, commantant an secombl re l'experlition antaretiepe bolege.

Mlinglistis.

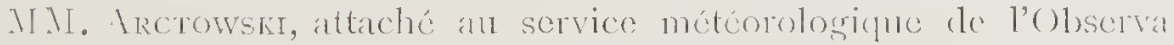
toive royal de lielsique, mombre da personnel scientifiepue (1) la Belgica.

Le [) (Ook, médecin rle l'expédilion antaretirpue belge.

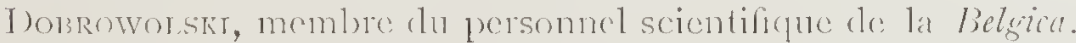

RACovtTz, sous-directerur du Labotatoire Araso de Lanynls-

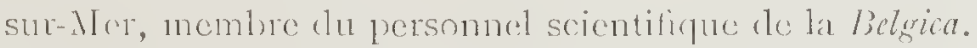

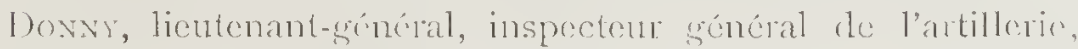
airle rle cánplu rlu Roi.

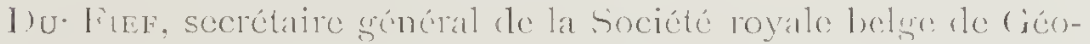
(araphic. 
Duront, directeur du Musée royal d'Histoire naturelle de l'État, membre de l'Académie royale de Belgique.

Durand, dirceteur du Jardin Botanique de l'Etat.

Errera I éo, professeur à l'Univcrsité de Bruxelles, membre de l'Académie royale de Belgique.

Lagrange Citarles, professeur à l'ícole militaire, directeur honoraire à l'Observatoire royal de Belgique, membre de l'Académie royale de Bclgique.

Lancaster, directeur scientifique à l'Observatoire royal de Jelgique, membre de l'Académie royale de Belgique.

Peiseneer, professeur à l'Ecole normale de Gand, membre de l'Académie royale de Belgique.

Sprtag, professeur à l'Université de Liége, membre de l'Aeadémic royale de Belgique.

StatNier, professeur à l'Université de (iand.

Lorsque la Commission de la Belgica fut instituée, elle comprenait:

MA. le lieutenant-général BBriLAiont, membre de l'Académie royale de Belgique (décédé en juillet Igo3).

Créprex, directeur du Jardin Botanique de l'État, membre de l'Académic royale de Belgique (décédé en mai rgo3).

DE LA Tadríe-Poussin, professeur à l'Université de Louvain, membre de l'Académic royale de Belgique (đécédé en avril igo3).

Rerard, professeur à l'Université de Gand, membre de l'Áteadémic royale de Belgique (décédé en juillet Igo3). 


\title{
L.ISTE
}

\section{DES RAPPORTS SCIENTIFIQUES}

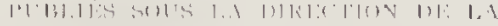 \\ COMMISSION I)I IA “ BIIIGCAICA,
}

V()I.1 MI: 1 .

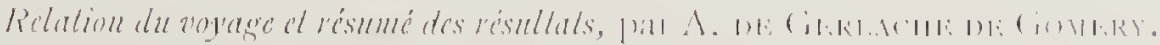

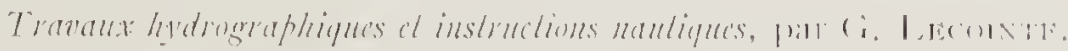

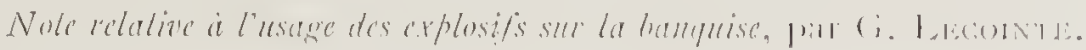

V()1,1 MI: 11 .

\section{Astronomic et pliysigue du globe.}

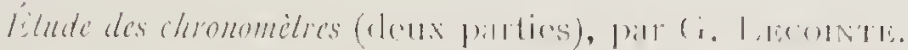

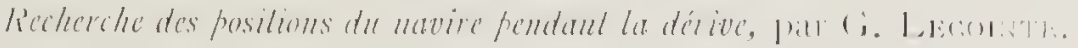

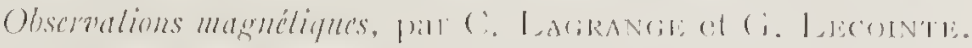

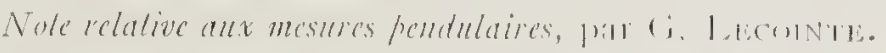

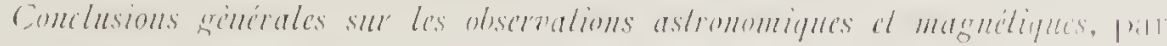
rivion.

$$
\text { V()I,I:MES III I:T IV. }
$$

\section{Météorologrie.}

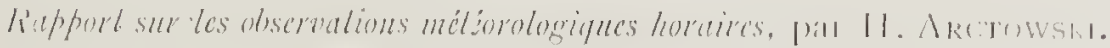

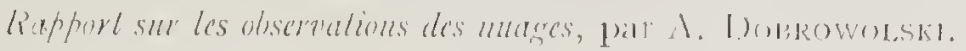


La neige et te give, par A. Donkowolsis.

Phénomènes optiques de l'atmosphiere, par II. A RCTowsis.

Aureres australes, paĩ H. Arctowsin.

Discussion des résultats nétéorologiques, par i. LANCASTER.

VOLUME V.

\section{Océanographie et géologie.}

Rapport sur les sondages et les fonds marins recueillis, par H. ARCTowsti et $\mathrm{A}-\mathrm{T}$. RENARD.

Rapport sur les relations thermiques de l'océan, par II. IrCTowsin ct II. R. Mill.

Détermination de la densité de l'eau de mer, par J. Triour.eT.

riapport sur la densité de l'eau de mer, par II. Arctowszi et J. Trouler.

Note sur la couleur des eaux océaniques, par IT. ArCTowsis.

Les glaces antarctiques (Fournal d'observations relatives aux glaciers, aux iccbergs et à la banquise), par I[. ArCrowsrit.

Note relative à la grographie physipue des terres antarctiques, par II. ARCTOIVSEI.

La géologie des terres antarctiques, par \.-F. REvird.

Note sur quelques plantes fossiles des terres magellaniques, par MI. (irr.trxe'r.

VOLUII: VI.

\section{Botanique.}

Diatomées (moins Chactocérés), par II. VAN IIEURCI.

Póridiniens et Chactocérés, par Fr. ScriitTr.

Algues, par E. De Wildenax.

Champignons, par MIMmes Boxmer et Rousseau.

Lichens, par li.-1. IVAño.

Hépatiques, par F. Stephaxi. 


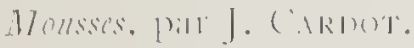

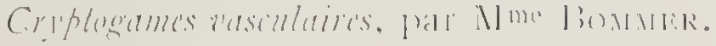

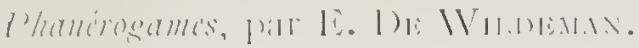

V()tumbs VIl, VIII li, M.

\section{Zoologic.}

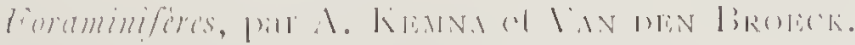

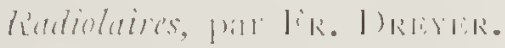

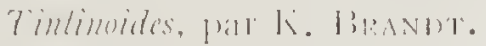

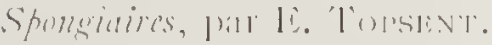

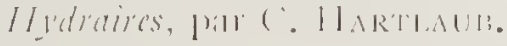

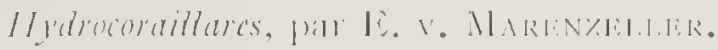

Siphomophores, pard ('. C'muv.

Merduss, pare 1. Scomulays.

Alymares, par 'la. Sinum:

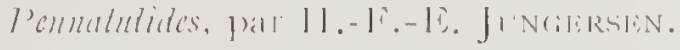

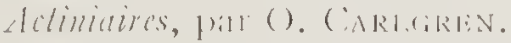

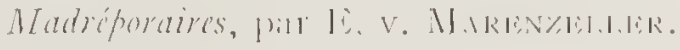

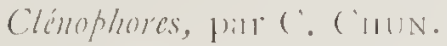

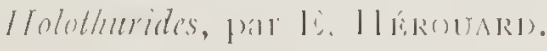

Astrides, pia 11. I. Unwali.

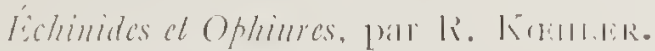

Crimoides, pall J.-ג. BA⿵⺆lik.

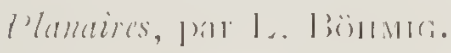

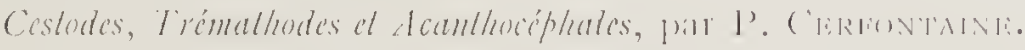

Vimerles, patr lïircilik.

Vémulhodes titures, pal J.-1). B]: N1 AN.

Sémalhodes parasites, par J. Ciurake.

(Kaclogmalhes, par (). STrinuaus.

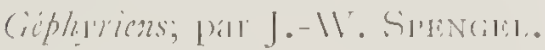

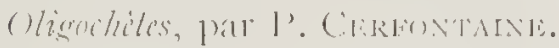


Polychites, par G. Pruvot et E.-G. Racoritza.

Rryozocires, par A.-W. Waters.

Brachiopodes, par L. Joubin.

Rotijeres et Tardigrades, par C. Zílinisa.

Phyllopodes, par Hérouard.

Ostracodes, par G.-IV. Müiller.

Copépodes, par Wr. Giesbrecht.

Cirripides, par P.-P.-C. Howk.

Crustacés édryophthalmes, par J. Boxiner.

Schizopodes et Cunacés, par H.-J. Haxsex.

Crustacés décapodes, par H. Coutrère.

Pycnogonides, par G. Pferfer.

Acariens libres, par A.-D). Michael et I) Trocessart.

Acariens parasites, par G. Neunaxis.

Arancídes, par E. Sinox.

Myriapodes, par C. v. Attenis.

Collemboles, par V. Wit.IEMI

Orthopteres, par Brunner von WatTENWYL.

Hémiptères, par E. Bergroth.

Pédiculides, par V. WilLex

Diptères, par J.-C. Jacons.

Coléoptères, par Schouteden, E. Rousseau, - 1. Grouverle, E. Olivier,

1. Lameere, Bollead, E. Brengke, Bourgeois et Fatruitre.

Iyménoptères, par C. Emery, Tosouninet, E. André et J. I'achai..

Solénoconques, par L. Plate.

Gastropodes et Lamellibranches, par P. Peisexiezr.

Céphalopodes, par L. Joubin.

Tuniciers, par L. VAn Beneden.

Poissons et reptiles, par L. Dollo.

Bile des oiseaux antarctiqnes, par P. Portier.

Oiseaux (Biologie), par E.-G. RacovitzA.

Oiseaux (Systématique), par Howard SaUaders.

Cétacés, par E.-G. Racovitza. 


\section{$-365-$}

Embryogénie des pinnipédes, par E. VAN I3ENEDEN.

Organogénie des pimipides, par Brachet et LeboucQ.

Encéplaale des pimipièdes, par Brachet.

Pimnipides (Biologie), par E.-G. Racorrtza.

Pimipèdes (Systématique), par E. BarretT-Hanutox.

Bactéries de l'intestin des animaux antarctiques, par J. CAYTACuż̀NE.

La biogéographic de l'Antarctide, par E.-G. Racovitza.

VOIUME X.

\section{Anthropologie.}

Médical report, par F.-A. Cook.

Report upon the Onas, par F.-A. Cook.

A Yahgan grammar and dictionary, par I'.-A. Cook.

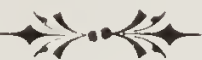





\section{TABLE DES MATIERES}

Pinges.

Introduction historique très succinte . . . . . . . . . . . . . . . . . . . . 9

Cinapırre I. - Organisation generale de l'expédition antarctique belge . . I7

CinArire Il - Dans le port d'invers . . . . . . . . . . . 38

Chantre III. - Iaux clépart . . . . . . . . . . . . . . 44

CHAP'TER IV. - A Ostende . . . . . . . . . . . . . . 53

CinATRE V. - Ennuis domestiques . . . . . . . . . . . . . 56

CIInTRE VI. - Dans l'Atlantique . . . . . . . . . . . . . 58

CinaptTre VII. - Dans l'Atlantique (suite). . . . . . . . . . . . 75

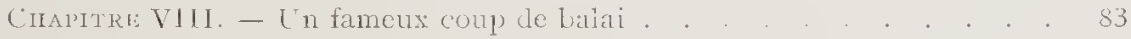

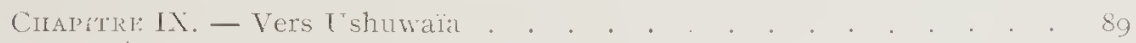

Cinarire .. - Noel à bord de la Belsica . . . . . . . . . . . 99

Chairure NI. - En détresse. . . . . . . . . . . . . . . . . Iot

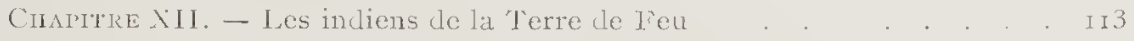

CinAlTRE XIH. - C'est rous le nègre? . . . . . . . . . . . . 122

CimprTte IIV. - La mort de Wiencke. . . . . . . . . . . . . 132

Cinptrke XV. - Tos premicrs débarquements dans l'Antarcticlue. . . . I43

Cinfirte IVI. - En reconnaissance dans le détruit de Gerlache . . . . I53

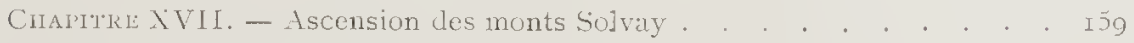

CHAlTRE XVIII. - Derniers travaux dans le détruit de Gerlache. . . I63

CiALTIRE XIX. - Juelques particularités du détroit de Gerlache . . . 168

Chap'TRE XX. - Les glaces. . . . . . . . . . . . . . . . . Ij8

Cirnplike XXI. - Cin ouragan dans la banquise. - Hloqués. . . . . . Is8

Cimartere XX1. -- Debuts de l'hivernage . . . . . . . . . . . . 195

Ciraritre NXII. - Tout le moncle grincheux . . . . . . . . . . 205

CHAITRL XXIV. - « Alea jactil est » . . . . . . . . . . . 2 II

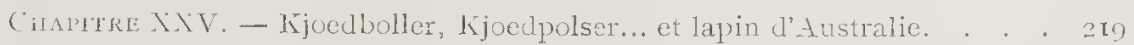

CHAITRE XIVL. - Concours le beanté. . . . . . . . . . . . . 224

- Cifarte MIVII. - Travaux scientifiques. . . . . . . . . . . . 230

Ciname liVIII. - Derniers jours de suleil . . . . . . . . . . . 235

Cinpreris XXl. - La mort de Danco . . . . . . . . . . . . . 242

Ciñtre $\mathrm{X}$. - Interminable nuit. . . . . . . . . . . . . 25 I 
Chamtre TXXI. - I'n royage d'agrément sur la banquise . . . . . . 257

Chapitre XXXil. - Tristesse et sourire . . . . . . . . . . . 27 I

Chapitre XXXili. - Projets . . . . . . . . . . . . . . 278

Chapttre MXXIV. - Égarés sur la banquise. - Les rats. - La tonite . . $28_{+}$

ChaptTRe XXXV. - Le scorbut. - La folie . . . . . . . . . . 29 I

Chapitre TAXvi. - Le soleil de minuit . . . . . . . . . . . 295

Cinatri XXXvil. - Noel et Nouvelle Annéc . . . . . . . . . . 302

Ciapitre XXXVili. - Efforts surhumains . . . . . . . . . . 307

Chapitre XXXix. - Bloqués à la lisière . . . . . . . . . . . . 329

ChaptTre XL. - Vers Punta-Arenas. . . . . . . . . . . . . 336

ChaptTRe Xli. - Retour. . . . . . . . . . . . . . . . . . 342

ChaptTre XIII. - Conclusions . . . . . . . . . . . . . 350

Appendice : Composition de la Commission de la Bdgica . . . . . . . 359

Liste des raplorts scientifiques . . . . . . . . . . . . . 36 I

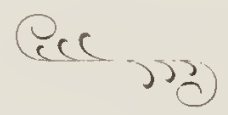







$$
\frac{420}{e m /}
$$


ANTARetic

502.989

L. 464 
